\title{
ESTUDOS ESTRUTURAIS EM COMPOSTOS DE INTERESSE \\ FARMACOLÓGICO CONTENDO ÁTOMOS PESADOS
}

Sauli dos Santos Júnior

Tese apresentada ao Instituto de Física de São Carlos, da Universidade de São Paulo, para obtenção do título de doutor em Ciências: Física Aplicada.

Orientador: Prof. Dr. Javier Ellena

\section{São Carlos}




\section{UNIVERSIDADE DE SÃO PAULO}

INSTITUTO DE FÍSICA DE SÃO CARLOS

\section{ESTUDOS ESTRUTURAIS EM COMPOSTOS DE INTERESSE FARMACOLÓGICO CONTENDO ÁTOMOS PESADOS}

Sauli dos Santos Júnior

Tese apresentada ao Instituto de Física de São Carlos, da Universidade de São Paulo, para obtenção do título de doutor em Ciências: Física Aplicada.

Orientador: Prof. Dr. Javier Ellena

\section{São Carlos}


DEDICATORIA

À minha esposa, meus pais, meus irmãos e amigos que muito me incentivaram.

\section{CARPEDIEM}




\section{AGRADECIMENTOS}

Ao Prof. Dr. Javier Ellena, por esse trabalho em conjunto, amizade, dedicação e principalmente o grande incentivo.

Ao Prof. Dr. Eduardo Ernesto Castellano pelos proveitosos esclarecimentos.

Aos grandes amigos (Alexandre e José Ricardo) que fiz aqui, os quais a convivência foi sempre muito agradável, divertida e com proveitosos aprendizados.

Aos técnicos que de uma forma ou de outra ajudaram, em especial ao Augusto que sempre que pôde ajudou e tornou-se um bom amigo.

Ao Bernardo que apesar do pouco convívio me ajudou com muitas dúvidas de química.

As secretarias do grupo de Cristalografia e ao Fernando pelo profissionalismo e presteza sempre que necessário.

As secretarias da Pós-graduação do IFSC, em especial a Wla, Cris e a Bete.

Ao pessoal da Biblioteca, que muito me ajudou com bastante afinco, presteza e dedicação em todos os momentos necessários.

Aos colegas de grupo, que em muitas vezes permitiu conversas agradáveis e profícuas.

A todos os grupos de onde provieram os cristais que foram medidos neste trabalho.

A todos que, direta ou indiretamente ajudaram no produto final.

As agências financiadoras, CNPq e FAPESP. 


\section{SUMÁRIO}

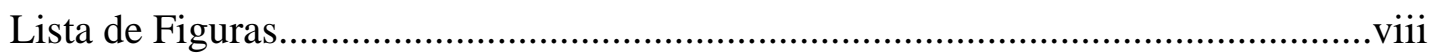

Lista de Tabelas...............................................................................................

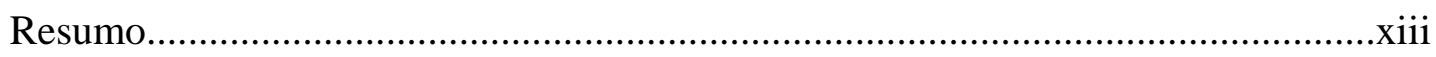

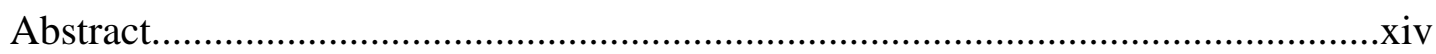

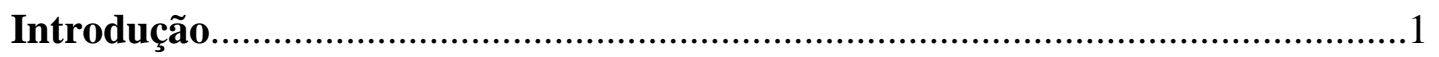

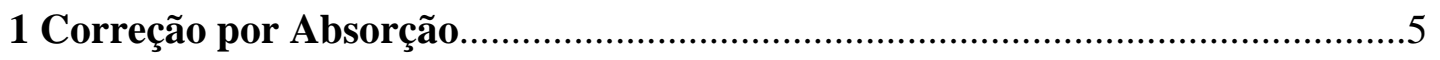

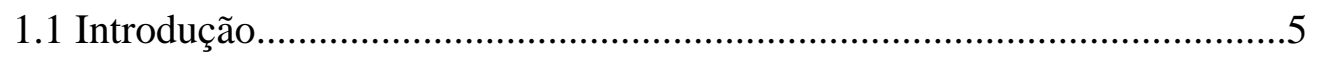

1.2 Métodos de Correção por Absorção........................................................7

1.2.1 Correções Analíticas e Numéricas.............................................7

1.2.1.1 Correção por absorção analítica....................................8

1.2.1.2. Correção por absorção numérica................................11

1.2.2 Correções Semi - Empíricas...................................................13

1.2.2.1 Correção Psi - Scan...................................................13

1.2.2.2 Correção Multiscan...................................................20

1.2.3 Correções Empíricas............................................................23

1.2.3.1 Correção DIFABS..................................................23

1.2.3.2 Correção XABS2 .....................................................25

2 Interações Intra e Intermoleculares e Supramoléculas.....................................30 
2.1 Introdução..........................................................................................

2.2 Ligações Químicas......................................................................................31

2.2.1 Ligação Iônica............................................................................31

2.2.2 Ligação Covalente........................................................................34

2.2.3 Ligação Metálica.........................................................................36

2.3 Interações Intermoleculares.......................................................................38

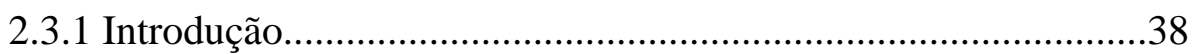

2.3.2 Interações Intermoleculares Secundárias....................................38

2.3.3 Ligação de Hidrogênio................................................................39

2.3.4 Interações de van der Waals..........................................................40

2.4 Organização Supramolecular....................................................................42

2.4.1 Self - Assembly (Construção Espontânea)..................................43

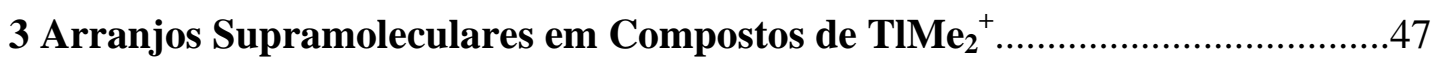

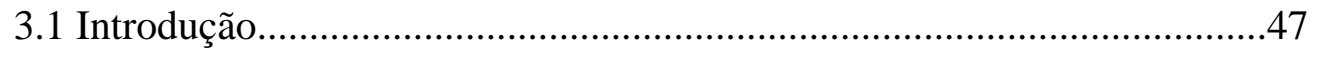

3.2 Base de dados CSD..............................................................................50

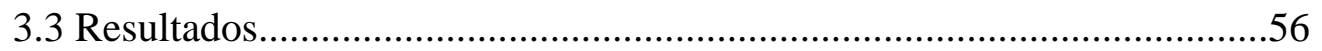

3.3.1 DimetilTálio 2-mercapto-3-piridina-ácido carboxílico ( I ).......56

3.3.2 DimetilTálio 6-mercapto-3-piridina-metoxicarboxilato ( II )....63

3.3.3 DimetilTálio 2-mercapto-3-piridina-metoxicarboxilato ( III )...67

3.3.4 DimetilTálio 6-mercapto-3-piridina-ethoxicarboxilato (IV)......72

3.3.5 DimetilTálio 2-mercapto-3-piridina-ethoxicarboxilato (V).......79

3.4 Discussão dos Resultados........................................................................83

4 Compostos Corrigidos por Absorção.................................................................. 


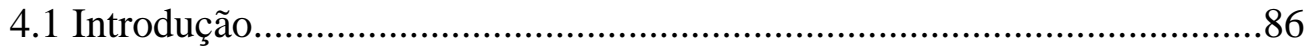

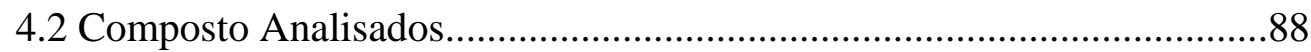

4.3 Figuras de Mérito ou Parâmetros de Concordância.................................91

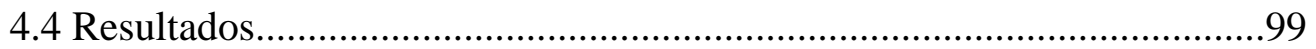

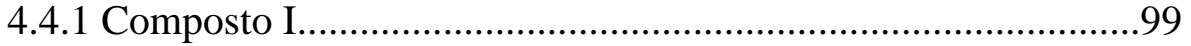

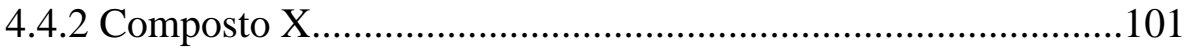

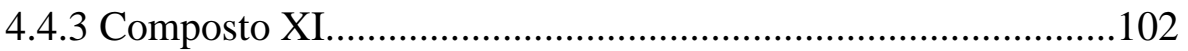

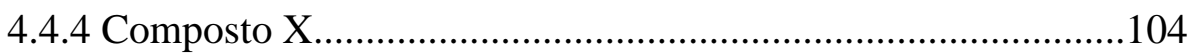

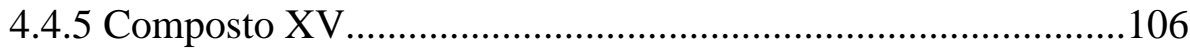

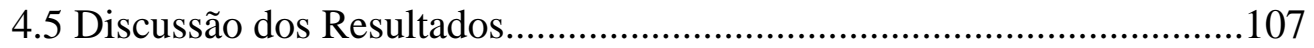

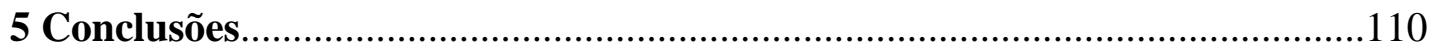

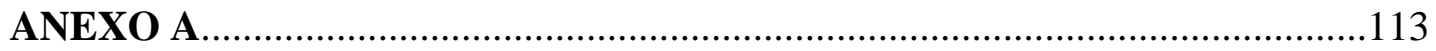

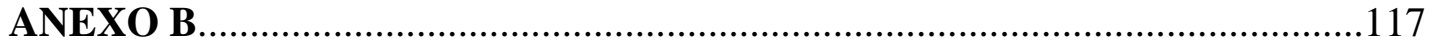

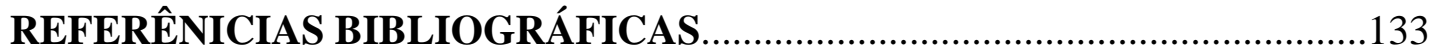




\section{Lista de Figuras}

Figura 1.1: Direções dos feixes incidente e difratado para a correção do fator de transmissão pelo o método de North-Philips-Mathews (Aslanov et al, 1998).

Figura 1.2: Um cristal assimétrico colado dentro de um capilar (a parte tracejada é cola) (Aslanov et al, 1998).

Figura 1.3: Variação do fator de transmissão para valores diferentes de $\mu R$ (Dunitz, 1979).

Figura 1.4: Direções dos feixes incidente e difratado em ângulos polares.

Figura 2.1: Contribuições Coulombiana e repulsiva para potenciais interatômicos em sólidos iônicos.

Figura 2.2: Overlapping de funções de ondas no cristal de lítio.

Figura 2.3: a) Composto DimetilTálio 2-mercapto-3-piridina-ácido carboxílico formando uma cadeia zerodimensional. b) Calixareno em arranjo zerodimensional, também chamado de supermolécula.

Figura 2.4: Quinolinas formando um arranjo unidimensional.

Figura 2.5: Quinolinas formando um arranjo bidimensional.

Figura 2.6: Quinolinas formando um arranjo tridimensional.

Figura 3.1: Histograma com a distribuição de ocorrências das interações Tl - S.

Figura 3.2: Histograma com a distribuição de ocorrências das interações $\mathrm{Tl}$ - O.

Figura 3.3: Histograma com a distribuição de ocorrências das interações Tl - N.

Figura 3.4: Histograma com a distribuição de ocorrências das interações $S$ - C.

Figura 3.5: Histograma com a distribuição de ocorrências das interações $\mathrm{O}=\mathrm{C}$.

Figura 3.6: Histograma com a distribuição de ocorrências das interações $\mathrm{N}$ - C.

Figura 3.7: Diagrama tipo ORTEP da unidade assimétrica do composto I, incluindo os nomes dos átomos, sem a molécula de água. 
Figura 3.8: Dímero formado pela interação $\mathrm{Tl}$ - O e $\mathrm{Tl}$ - S.

Figura 3.9: Arranjo ao longo da direção [010], promovido pelas interações Tl - S (em preto

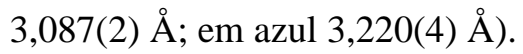

Figura 3.10: Arranjo na direção [010] com a presença das ligações de hidrogênio, O1WH11W...O2 e N-H1N...O1W (azul ciano).

Figura 3.11: Arranjo tridimensional do composto I.

Figura 3.12: Diagrama tipo ORTEP da unidade assimétrica do composto II, incluindo os nomes dos átomos.

Figura 3.13: Arranjo ao longo da direção [010], sendo que as interações Tl - O estão em azul e $\mathrm{Tl}-\mathrm{S}$ em vermelho.

Figura 3.14: Arranjo bidimensional no plano (101), sendo que as ligações de hidrogênio (C7 - H7B ... O2) estão em amarelo.

Figura 3.15: Diagrama tipo ORTEP da unidade assimétrica do composto III, incluindo os nomes dos átomos.

Figura 3.16: Arranjo ao longo da direção [001] com duas vistas diferentes, apresentando uma cavidade quadrada (foram omitidos os átomos de hidrogênio para a melhor visualização).

Figura 3.17: Arranjo zero-dimensional apresentando uma cavidade quadrada, com a interação $\mathrm{Tl}$ - O em azul e a ligação de hidrogênio (C8 - H8B ... O2) em vermelho.

Figura 3.18: Arranjo tridimensional do composto III, foram omitidas as interações $\mathrm{Tl}-\mathrm{S}$ e Tl - O e ligações de hidrogênio para melhor visualização.

Figura 3.19: Diagrama tipo ORTEP da unidade assimétrica do composto IV, incluindo os nomes dos átomos.

Figura 3.20: Arranjo na direção [001], formada pela interação $\mathrm{Tl}-\mathrm{S}^{i}$ (verde).

Figura 3.21: Arranjo na direção [010] com interações $\mathrm{Tl}-\mathrm{S}^{i}$ (verde) e $\mathrm{Tl}$ - S ${ }^{i i}$ (vermelho).

Figura 3.22: Arranjo com duas moléculas, gerado pela ligação de hidrogênio C8 - H8A ... O2 (amarelo). 
Figura 3.23: Arranjo na direção [010] com a presença da ligação de hidrogênio, C8 - H8B ... O1(azul).

Figura 3.24: Arranjo na direção [001] gerado pela forte ligação de hidrogênio, C3 - H3 ... O1(azul).

Figura 3.25: Arranjo na direção [010] gerado pela ligação de hidrogênio, C7 - H7A ... O1(azul).

Figura 3.26: Diagrama tipo ORTEP da unidade assimétrica do composto V, incluindo os nomes dos átomos.

Figura 3.27: Arranjo unidimensional na direção [100], com as interações Tl - S (vermelho) e $\mathrm{Tl}-\mathrm{O}$ (azul).

Figura 3.28: Arranjo bidimensional do composto V, onde a ligação de hidrogênio (C4 - H4 ... S) está em verde, com o hidrogênio da ligação em preto.

Figura 4.1: Mapas residuais de densidade carga, $F_{\text {obs }}-F_{\text {calc }}$ para o composto I, em azul é o maior vale de densidade de carga residual, os rótulos representam as posições atômicas no mapa: (a) antes da correção por absorção; (b) depois da correção por absorção analítica.

Figura 4.2: Mapas residuais de densidade carga, $F_{\text {obs }}-F_{\text {calc }}$ para o composto $X$, em vermelho é o maior pico de densidade de carga residual, os rótulos representam as posições atômicas no mapa: (a) antes da correção por absorção; (b) depois da correção por absorção analítica.

Figura 4.3: Mapas residuais de densidade carga, $F_{\text {obs }}-F_{\text {calc }}$ para o composto $X$, em azul é o maior vale de densidade de carga residual, os rótulos representam as posições atômicas no mapa: (a) antes da correção por absorção; (b) depois da correção por absorção analítica.

Figura 4.4: Mapas residuais de densidade carga, $F_{\text {obs }}-F_{\text {calc }}$ para o composto XI, em vermelho é o maior pico de densidade de carga e em azul é o maior vale de densidade de carga residual, os rótulos representam as posições atômicas no mapa: (a) antes da correção por absorção; (b) depois da correção por absorção analítica.

Figura 4.5: Mapas residuais de densidade carga, $F_{\text {obs }}-F_{\text {calc }}$ para o composto XIV, em vermelho é o maior pico de densidade de carga residual, os rótulos representam as posições atômicas no mapa: (a) antes da correção por absorção; (b) depois da correção por absorção analítica.

Figura 4.6: Mapas residuais de densidade carga, $\mathrm{F}_{\mathrm{obs}}-\mathrm{F}_{\text {calc }}$ para o composto XIV, em azul é o maior vale de densidade de carga residual, os rótulos representam as posições atômicas no mapa: (a) antes da correção por absorção; (b) depois da correção por absorção analítica. 
Figura 4.7: Mapas residuais de densidade carga, $\mathrm{F}_{\text {obs }}-\mathrm{F}_{\text {calc }}$ para o composto $\mathrm{I}$, em vermelho é o maior pico de densidade de carga e em azul é o maior vale de densidade de carga residual, os rótulos representam as posições atômicas no mapa: (a) antes da correção por absorção; (b) depois da correção por absorção analítica. 


\section{Listas de Tabelas}

Tabela 3.1: Compostos estudados e seus respectivos diagramas.

Tabela 3.2: Distâncias e ângulos de ligação para o composto I.

Tabela 3.3: Distâncias e ângulos para as ligações de hidrogênio do composto I.

Tabela 3.4: Distâncias e ângulos de ligação para o composto II.

Tabela 3.5: Distâncias e ângulos para a ligação de hidrogênio do composto II.

Tabela 3.6: Distâncias e ângulos de ligação para o composto III.

Tabela 3.7: Distâncias e ângulos para as ligações de hidrogênio do composto III.

Tabela 3.8: Distâncias e ângulos de ligação para o composto IV.

Tabela 3.9: Distâncias e ângulos para as ligações de hidrogênio do composto IV.

Tabela 3.10: Distâncias e ângulos de ligação para o composto V.

Tabela 3.11: Distâncias e ângulos para a ligação de hidrogênio do composto V.

Tabela 4.2: Parâmetros cristalinos selecionados dos compostos analisados.

Tabela 4.3: Valores das figuras de mérito e outros dados sem correção por absorção.

Tabela 4.4: Valores das figuras de mérito e outros dados com correção por absorção do tipo semi-empírico.

Tabela 4.5: Valores das figuras de mérito e outros dados com correção por absorção do tipo analítica.

Tabela 4.6: Valores das figuras de mérito e outros dados com correção por absorção do tipo DFABS.

Tabela 4.7: Valores das figuras de mérito e outros dados com correção por absorção do tipo SHELXA. 


\section{RESUMO}

A determinação de estruturas tridimensionais de quelatos com metais pesados e de alguns potencialmente úteis agentes quelantes, é uma ferramenta muito importante no estudo de complexos que poderão agir como antídotos na intoxicação por ingestão de metais pesados. Um conhecimento detalhado destes complexos é exigido para auxiliar na modelagem de estruturas moleculares e na determinação de procedimentos que sejam mais efetivos na neutralização dos processos, desenvolvidos por indivíduos com intoxicação crônica por metais pesados. Aqui serão reportados os resultados de um estudo sistemático de complexos [ $\mathrm{TlMe}_{2} \mathrm{~L}$, onde $\mathrm{L}=$ 2-mercapto-3-piridina ácido carboxílico (I), 6-mercapto-3-piridinametoxicarboxilato (II), 2-mercapto-3-piridina-metoxicarboxilato (III), 6-mercapto-3piridina-etoxicarboxilato (IV) e 2-mercapto-3-piridina-etoxicarboxilato (V). O estudo dos arranjos supramoleculares destes complexos mostra que, devido às diferenças na simetria dos grupos espaciais e os substituintes nos ligantes, o empacotamento no cristal são similares. Os complexos formam polímeros infinitos em uma, duas e três dimensões, baseadas em interações $\mathrm{Tl}-\mathrm{S}, \mathrm{Tl}-\mathrm{N}$ e $\mathrm{Tl}-\mathrm{O}$ e ligações de hidrogênio. Existem várias formas de correções dos dados de difração de raios $\mathrm{X}$ em monocristais. Durante o processamento das intensidades coletadas realizam-se várias correções, tais como de Lorentz, polarização, absorção e eventualmente correção por deterioração da amostra. A correção por absorção é fortemente recomendada para cristais que possuem fortes absorvedores em sua forma estrutural. Foram estudados os efeitos da absorção dos raios X em amostras cristalinas e uma comparação dos resultados obtidos ao aplicar os diferentes métodos de correções por absorção disponíveis. Constatou-se que após serem realizados diferentes formas de correção por absorção, houve diferenças significativas nas figuras de mérito, picos e vales de densidade de carga residual e parâmetros de deslocamentos anisotrópicos. Já nos ângulos e distâncias de ligações não foram observados mudanças significativas. 


\begin{abstract}
The determination of the three-dimensional structures of heavy-metal chelates and of some potentially useful chelating agents is a very important tool in the study of complexes that may act as antidotes against poisoning by ingestion of heavy metals. A detailed knowledge of these complexes is expected to assist in the design of molecular structures and procedures that are more effective in counteracting the life threatening processes inevitably developed by individuals with chronic heavy-metal intoxication. Within this framework a series of dimethylthallium(III) complexes were studied. Here we present complexes of the type [TIMe $2 \mathrm{~L}$ ], where $\mathrm{L}=2$-mercapto-3pyridine carboxylic acid(I), 6-mercapto-3-pyridine-methoxycarboxylate(II), 2mercapto-3-pyridine-methoxycarboxylate(III), 6-mercapto-3-pyridineethoxycarboxylate(IV) and 2-mercapto-3-pyridine-ethoxycarboxylate(V). The study of the supramolecular arrangement of these complexes shows that, in spite of the differences in space group symmetry and substituents in the ligand, the crystals packing are remarkably similar. The complexes form infinite polymers in one, two and three dimensions, based upon Tl-S, Tl-O e Tl-N covalent bonds and intermolecular secondary interactions. The complexes also present strong hydrogen bond intermolecular interactions.

There are many forms of corrections to the data collected in a single crystal X-ray diffration experiment. During the data reduction many corrections take place, such as: Lorentz, polarization, absorption and eventualy corrections for the deterioration of the sample. The absorption correction is strongly recommended for crystals with strong absorbers in its structural form. The effect of the absorption of the X rays has been studied in crystalline samples, as well as a comparison between the result obtained from the different available methods of absorption corrections. This work that showed different forms of absorption correction, made significant differences in the merit figures, peak and hole of residual charge density, as well as the anisotropic displacements parameters. Bonds distances and angles, on the other hand, did not change significantly.
\end{abstract}




\section{Introdução}

Nas últimas décadas as pesquisas relacionadas às áreas de farmacologia vêm crescendo substancialmente, uma vez que a humanidade perece de várias mazelas, provocadas por uma gama muito grande de fatores, como: patógenos, contaminações provocadas pelo homem e mutações genéticas. Estes problemas geram grandes desafios e a ciência acaba sendo movida por essa busca incessante do êxito, sendo a curiosidade e a busca pelo bem estar os combustíveis principais que fomentam o desenvolvimento científico.

A pesquisa de fármacos é muito extensa, tendo várias linhas distintas a serem seguidas. Hoje a pesquisa em fármacos é baseada em estudos da funcionalidade de proteínas, buscando seus inibidores, utiliza-se do conhecimento popular para isolarem compostos que tenham princípios ativos contra algum mal, extraindo estes princípios ativos de plantas e animais e ainda explora toda a potencialidade na sintetização de compostos com interesse farmacológicos.

Os compostos de interesse farmacológico são largamente utilizados e a grande parte dos fármacos existentes hoje no mercado são sintetizados em laboratório. Dentro deste universo quase infinito de fármacos e potenciais fármacos, existem os compostos de coordenação com metais pesados. Estes compostos são largamente utilizados e estudados para fins terapêuticos. Durante todo o processo de 
“construção" de um fármaco, várias etapas são necessárias, e a caracterização de um composto é uma das etapas mais relevantes nesta "engenharia".

No processo de caracterização estrutural dos compostos, a técnica mais utilizada é a difração de raios X e também a que melhor resultados apresentam do ponto vista estrutural.

O grupo de cristalografia do Instituto de Física de São Carlos vem trabalhando na área de difração de raios $\mathrm{X}$ em monocristais de pequenas moléculas a algumas décadas, sendo o pioneiro no Brasil nesta técnica. $O$ interesse em compostos de coordenação com átomos pesados já remonta desde sua origem, sendo que hoje, grande parte das estruturas cristalográficas estudadas aqui é destes compostos.

A presença de átomos pesados muitas vezes está associada à localização de regiões agrícolas e industriais; prejudicando a produção de alimentos em solos contaminados com estes metais. Todas as formas de vida são afetadas pela presença de metais dependendo da dose e da forma química. Muitos metais são essenciais para o crescimento de todos os tipos de organismos, desde as bactérias até mesmo o ser humano, mas eles são requeridos em concentrações ideais e para altas concentrações podem causar prejuízos aos sistemas biológicos. Os compostos de coordenação com átomos pesados são importantes em um grande leque de aplicações, utilizando de ligantes orgânicos para fazer uma "limpeza" seletiva, desintoxicação e também na produção de fármacos.

Este trabalho concentrou-se em estudar algumas características destes compostos do ponto de vista cristalográfico, como a formação de arranjos supramoleculares a partir de complexo de $\left[\mathrm{TlMe}_{2}\right]^{+}$. O estudo dos compostos 
baseados em $\left[\mathrm{TlMe}_{2}\right]^{+}$têm interesse no combate a intoxicação crônica por metais pesados

Parte deste trabalho é avaliar a importância das interações $\mathrm{Tl}-\mathrm{S}$, Tl - O e Tl - N em conjunto com ligações de hidrogênio na formação de arranjos supramoleculares em complexos de dimetil-tálio. Este trabalho é baseado estritamente em resultados obtidos a partir de medidas cristalográficas de compostos de $\left[\mathrm{TlMe}_{2}\right]^{+}$.

Como cristais que contém átomos pesados são fortes absorvedores, a idéia da outra parte deste trabalho é estudar os efeitos da absorção sobre a estrutura cristalina dos compostos por meio das diferentes figuras de mérito, picos e vales de densidade de carga residual, parâmetros de deslocamentos anisotrópicos e distâncias e ângulos de ligação, analisando quais as influências da metodologia adotada após serem realizadas as correções necessárias. A partir daí, sugerir a utilização do melhor método de correção por absorção baseado nas informações da morfologia cristalina, condições experimentais e coeficiente de absorção do composto.

Para a exposição do trabalho realizado, estruturou-se a tese em cinco capítulos.

O primeiro capítulo apresenta às descrições teóricas dos principais aspectos dos diferentes métodos de correção por absorção, com principal destaque nos aspectos relacionados ao cálculo matemático utilizado por cada um deles e a utilização destes para a resolução de estruturas cristalográficas. O segundo capítulo traz uma breve exposição sobre ligações químicas e interações intermoleculares em suas diferentes formas, abrangendo ligações de hidrogênio e interações de van der Waals. Levando a uma explanação sobre arranjos supramoleculares e algumas de suas formas. 
O terceiro capítulo trata dos resultados obtidos para os compostos de coordenação contendo $\left[\mathrm{TlMe}_{2}\right]^{+}$, onde são apresentados e discutidos as diferentes formas de arranjo e as interações responsáveis pelas arquiteturas supramoleculares.

No quarto capítulo são apresentados e discutidos os resultados obtidos com a aplicação dos diferentes métodos de correção por absorção.

No quinto e último capítulo, são descritas as conclusões geradas por este trabalho. Posteriormente, são apresentados anexos, com informações relevantes e essenciais à compreensão deste trabalho. 


\section{Correção por Absorção}

\subsection{Introdução}

Devido ao fato que os valores do módulo do fator de estrutura ao quadrado $|\mathbf{F}|^{2}$ calculado da teoria cinemática da difração de raios X para um cristal ideal, não corresponderem exatamente aos valores determinados das intensidades integradas das reflexões de Bragg medidas no difratometro, surgem discrepâncias entre as medidas. A concordância entre os valores pode ser alcançada por vários métodos determinados empiricamente que levam em conta as diferenças entre o modelo de difração real e o cinemático idealizado. Passos importantes na redução de dados das intensidades medidas são; correção por absorção de raios X pela amostra, efeitos de espalhamento múltiplo, extinção relacionada a efeitos de difração dinâmica, subtração de 'background' contínuo e outros efeitos que não são levados em conta pela teoria de difração cinemática, mas interfere no experimento de difração.

Algumas correções podem ser calculadas prontamente das condições do experimento, enquanto muitas outras são mais complicadas e algumas delas não são calculadas diretamente. A única correção que pode ser calculada 'a priori' é a correção por absorção, portanto esta correção é feita antes de todas as outras. 
A presença de efeitos de absorção é a mais séria fonte de erros sistemáticos na determinação dos fatores de estrutura nas medidas de difração de raios X. A absorção da radiação pelo cristal é estritamente dependente da composição química da amostra e do comprimento de onda da radiação incidente. Muitos fatores influenciam na escolha do comprimento de onda no experimento de difração de raios $\mathrm{X}$, mas quanto menor o comprimento de onda da radiação incidente, menor será a absorção da radiação pelo cristal. Esta é uma das razões do uso da radiação de comprimento de onda da linha $K_{\alpha}$ do Mo para a difração de raios X. Para casos onde o cristal é transparente para a radiação, a correção por absorção é negligenciável. Geralmente cristais que apresentam $\mu R \leq 0,1$, onde $R$ é a metade da maior dimensão do cristal, são considerados transparentes. O fator de correção para absorção também depende fortemente do ângulo de difração e da forma do cristal. À medida que aumenta o ângulo de difração, a absorção de raios X pelo cristal sofre um acréscimo. Negligenciar a correção por absorção leva a erros significativos, nas distâncias interatômicas, nos ângulos entre átomos da estrutura, no posicionamento e dimensionamento dos elipsóides térmicos e distorções na distribuição de densidade eletrônica calculada, influenciando nas figuras de mérito.

Para obter a correção por absorção real para uma reflexão é necessário conhecer o caminho que o feixe incidente e difratado percorreu dentro do cristal. Mas este problema não é simples, devido às várias diferentes formas topológicas que um cristal pode adquirir durante seu processo de formação. Para solucionar este problema o passo mais relevante seria descrever precisamente a forma do cristal de acordo com a indexação ${ }^{1}$ das suas faces

\footnotetext{
${ }^{1}$ Para cristais que apresentam morfologias esféricas ou cilíndricas, basta apresentar o raio (esférico) ou raio e altura (cilíndrico).
} 


\subsection{Métodos de Correção por Absorção}

\subsubsection{Correções Analítica e Numérica}

A correção por absorção para muitas reflexões é calculada baseada em informações sobre o fator de absorção linear $\mu$, específico ao composto em questão, e a forma morfológica do cristal. A difração por um cristal é descrita como uma soma de difrações por seus elementos de volumes, $d V$. Portanto, a correção por absorção poderá ser calculada separadamente para muitas reflexões, desde que o comprimento do caminho do feixe seja dependente na orientação do cristal e ângulo de difração. A transmissão acaba sendo uma função de quatro ângulos polares, dois que descrevem a direção do feixe incidente e outros dois que descrevem o feixe difratado. Se o feixe incidente de raios $\mathrm{X}$ tem seu caminho dado por $p(\vec{r})$, dentro do volume espalhador, onde a posição do volume é determinada pelo vetor $\vec{r}$ e o caminho do feixe difratado é $q(\vec{r})$, então o fator de transmissão $A$ para o cristal é expresso como uma integral sobre todo o volume $V$ do cristal,

$$
A=\frac{1}{V} \int_{V} \exp \{-\mu[p(r)+q(r)]\} d r
$$

Fica visível que $p(\vec{r})$ e $q(\vec{r})$ são calculados individualmente para as reflexões em cristais de forma anisotrópica. Pode ser visto que a integral pode ser calculada tanto numericamente, quanto analiticamente. Para cálculos analíticos da integral, a forma e as dimensões do cristal deverão ser conhecidas com muita precisão. A forma tem 
sido descrita analiticamente em termos de superfícies; planas, esféricas ou cilíndricas. Métodos de integração analítica foram desenvolvidos por; Meulenaer \& Tompa (1965), Evans \& Ekstein (1952) e Alcock (1970). Cálculos numéricos da integral podem ser resolvidos por muitos métodos propostos, por exemplo; Busing \& Levy (1957), Coppens et al. (1965), Coppens (1970), Flack (1984), usando grades Gaussianas, mas os mais difundidos dentre estes, são os que utilizam a formula da quadratura e o método de Monte Carlo.

\subsubsection{Correção por absorção analítica}

A correção por absorção leva em conta o fato que a intensidade dos feixes de raios $\mathrm{X}$, incidente e difratado sofrem uma redução em sua intensidade quando passam pelo cristal, devido à absorção. A magnitude desta absorção para um dado cristal é dependente do caminho que os feixes percorrem dentro do cristal, e desta forma é uma função da forma do cristal e orientação de suas faces, em termos de $\mathbf{h}, \mathbf{k}$ el.

A proposta de Meulenaer e Tompa (1965) foi desenvolver um método para casos tridimensionais, porque até então, as propostas concretizadas de programas, só levavam em conta casos bidimensionais, Zalkin \& Sands (1958) e Ferrari et al. (1961).

Sendo $I_{\mu}$ a intensidade do feixe difratado por um cristal com coeficiente de absorção $\mu$ e $I_{0}$ a intensidade correspondente a $\mu=0$. Então o fator de transmissão $T\left(=I_{\mu} / I_{0}\right)$ é dado por $T=A / V$, onde; 


$$
A=\int \exp (-\mu L) d V
$$

O caminho total $L$ é igual a $l_{i n c}+l_{d i f}$, onde $l_{i n c}$ é comprimento do caminho do feixe incidente e $l_{d i f}$ do feixe difratado em $d V$. A integração é feita sobre todo volume, $V$, do cristal, assumindo ser um poliedro de Howells limitado por faces planas. A base do método para calcular a integral é dividir o cristal conforme proposto por Howells (1950) em seu trabalho.

Subdividindo os poliedros em tetraedros, a expressão ana lítica de $A$ é a soma sobre todas as contribuições individuais de cada tetraedro, $A_{T}$. A partir daí, é deduzida a expressão para $A_{T}$, que estabelece que um dos vértices do tetraedro é a origem das coordenadas e os três eixos que saem deste vértice são $x, y$ e $z$. O tetraedro é, deste modo, limitado por três planos coordenados e um quarto plano, cuja equação pode ser escrita na forma;

$$
\frac{x}{u}+\frac{y}{v}+\frac{z}{w}=1
$$

Os quatros vértices são $(0,0,0),(u, 0,0),(0, v, 0)$ e $(0,0, w)$. Desde que $L$ seja uma função linear das coordenadas, pode-se escrever:

$$
\mu L=g=p x+q y+r z+s
$$

e $d V=K d x d y d z$. O $g=$ const. para cada tetraedro e não são necessariamente relacionados aos lados ou faces do tetraedro. Logo, 


$$
\begin{aligned}
& A_{T}=\int \exp (-\mu L) d V=\iiint \exp [-(p x+q y+r z+s)] K d x d y d z \\
& =K \exp (-s) \int_{0}^{u} \int_{0}^{v(1-x / u)} \int_{0}^{w\left(1-x / u^{-} y / v\right)} \exp (-r z) d z \exp (-q y) d y \exp (-p x) d x
\end{aligned}
$$

O resultado da integral é direto e se dá em termos de $u, v, w, p, q$, $r$ e $s$. Substituindo estes parâmetros em termos de $g$ nos quatros vértices, temos;

$$
g_{1}=s, g_{2}=p u+s, g_{3}=q v+s, g_{4}=r w+s
$$

e $K u v w=6 V_{T}$. Depois de alguns cálculos matemáticos,

$$
A_{T}=6 V_{T}\left[\begin{array}{l}
\frac{\exp \left(-g_{1}\right)}{\left(g_{2}-g_{1}\right)\left(g_{3}-g_{1}\right)\left(g_{4}-g_{1}\right)}+\frac{\exp \left(-g_{2}\right)}{\left(g_{1}-g_{2}\right)\left(g_{3}-g_{2}\right)\left(g_{4}-g_{2}\right)}+ \\
\frac{\exp \left(-g_{3}\right)}{\left(g_{1}-g_{3}\right)\left(g_{2}-g_{3}\right)\left(g_{4}-g_{3}\right)}+\frac{\exp \left(-g_{4}\right)}{\left(g_{1}-g_{4}\right)\left(g_{2}-g_{4}\right)\left(g_{3}-g_{4}\right)}
\end{array}\right]
$$

Esta expressão também pode ser escrita como uma razão de dois determinantes,

$$
A_{T}=-6 V_{T}\left|\begin{array}{llll}
\exp \left(-g_{1}\right) & g_{1}^{2} & g_{1} & 1 \\
\exp \left(-g_{2}\right) & g_{2}^{2} & g_{2} & 1 \\
\exp \left(-g_{3}\right) & g_{3}^{2} & g_{3} & 1 \\
\exp \left(-g_{4}\right) & g_{4}^{2} & g_{4} & 1
\end{array}\right| /\left|\begin{array}{llll}
g_{1}^{3} & g_{1}^{2} & g_{1} & 1 \\
g_{2}^{3} & g_{2}^{2} & g_{2} & 1 \\
g_{3}^{3} & g_{3}^{2} & g_{3} & 1 \\
g_{4}^{3} & g_{4}^{2} & g_{4} & 1
\end{array}\right|
$$

Esta é uma forma para contornar o problema quando $\left(g_{i}-g_{j}\right)$ for igual a zero. Para cada tetraedro, $A_{T}$ e $V_{T}$ são calculados e depois somados, resultando em; 


$$
T=\sum A_{T} / \sum V_{T}
$$

\subsubsection{Correção por absorção numérica}

Busing e Levy (1957) sugeriram este método baseado nas idéias usadas por Albrecht (1939). O cálculo da integral (equação 1.1) pelo método de Gauss é iniciado a partir da descrição da forma do cristal, um sistema ortogonal é usado para cristais de qualquer simetria.

Assume-se que o cristal esteja limitado por $n$ planos superficiais e deste modo é descrito por um sistema de expressões,

$$
a_{s} x+b_{s} y+c_{s} z-d \geq 0
$$

onde $s=0,1,2, \ldots, n ; a_{s}, b_{s}, c_{s}$ são os cossenos diretores das normais as faces com número $s$. Os coeficientes para todas direções de todas faces são selecionados de modo que a origem do sistema de coordenadas ortogona is esteja dentro do cristal ou em sua superfície.

A idéia da integração numérica é que o volume do cristal seja dividido em volumes $V_{i}$. O comprimento do caminho $\left(l_{i n c}+l_{d i f}\right)_{i}=l_{i}$ é calculado para feixes de raios X passando direto por esses pontos e sofrendo difração.

No método de Gauss a integral é aproximada por uma soma de $m$ termos, que pode ser escrita para o caso unidimensional, como; 


$$
\int_{a}^{b} g(x) d x \approx(b-a) \sum_{i=1}^{m} R_{i} g\left(x_{i}\right)
$$

onde $x_{i}=a+(b-a) u_{i} ; u_{i}$ e $R_{i}$ são constantes fracionárias, cujos valores dependem em $m$. Os $u_{i}$ determinam as posições dos pontos $x_{i}$, enquanto $R_{i}$ são os pesos relativos dos termos da soma

Para o caso tridimensional a equação 1.11 toma a forma;

$$
\begin{aligned}
& \int_{a}^{b} d x \int_{c(x)}^{d(x)} d y \int_{e\left(x_{i}, y_{i}\right)}^{f\left(x_{i}, y_{i}\right)} g(x, y, z) \approx \\
& \sum_{i=1}^{m} \sum_{j=1}^{m} \sum_{k=1}^{m}(b-a)\left[d\left(x_{i}\right)-c\left(x_{i}\right)\right]\left[f\left(x_{i}, y_{i}\right)-e\left(x_{i}, y_{i}\right)\right] \times R_{i} R_{j} R_{k} g\left(x_{i}, y_{j}, z_{k}\right)
\end{aligned}
$$

onde,

$$
\begin{aligned}
& x_{i}=a+(b-a) u_{i}, \\
& y_{j}=c\left(x_{i}\right)+\left[d\left(x_{i}\right)-c\left(x_{i}\right)\right] u_{j}, \\
& z_{k}=e\left(x_{i}, y_{j}\right)+\left[f\left(x_{i}, y_{j}\right)-e\left(x_{i}, y_{j}\right)\right] u_{k} .
\end{aligned}
$$

O problema da determinação de $A$ fica reduzido a encontrar os limites de integração, $a, b, c\left(x_{i}\right), d\left(x_{i}\right), e\left(x_{i}, y_{j}\right)$ e $f\left(x_{i}, y_{j}\right)$ e desenvolver $g\left(x_{i}, y_{j}, z_{k}\right)$, onde;

$$
g\left(x_{i}, y_{j}, z_{k}\right)=\frac{1}{V} \exp \left[-\mu l_{i j k}\right]
$$


onde $\left(l_{i n c}+l_{d i f}\right)$ é o comprimento do caminho do feixe incidente da superfície do cristal ao ponto $i, j, k$ e deste ponto à saída do feixe difratado do cristal. A escolha do número $m$ depende do valor de $\mu$ e das dimensões do cristal.

\subsubsection{Correções Semi-empíricas}

A idéia dos métodos semi-empíricos é simples, fundamenta-se na dependência das intensidades das reflexões observadas e no caminho que os feixes incidentes e difratados percorrem dentro do cristal. Para correções semi-empíricas é necessário que existam várias reflexões equivalentes por simetria ou que seja feita uma varredura angular em reflexões escolhidas previamente. Estes métodos geram os coeficientes de absorção a partir de dados já coletados, não requerendo um conhecimento sobre a forma do cristal. São métodos úteis quando; a forma exata do cristal é desconhecida ou apresenta formas irregulares ou está dentro de tubos capilares.

A diferença entre os métodos semi-empíricos existentes é somente na abordagem dada à obtenção do valor do fator de transmissão, $A$, para algumas reflexões, pela observação na variação da intensidade. A desvantagem dos métodos semi-empíricos está no fato que a intensidade da reflexão pode variar também por muitas outras razões junto com a absorção do cristal. Portanto, para a correção semiempírica deve assegurar-se que as reflexões não sofram outros efeitos como extinção, reflexão simultânea ou espalhamento térmico difuso, que são graves fontes de erros sistemáticos. 


\subsubsection{Correção Psi-scan}

O idealizador de todos os métodos semi-empíricos foi Furnas (1957). A priori o método foi proposto para um difratometro que usava câmeras de 'equi-inclination' ou Weissenberg. Baseando-se no fato que a variação da absorção pelo cristal pode ser obtida da variação nas intensidades das reflexões quando o cristal é rotacionado sobre a normal ao plano responsável pela reflexão.

Supõe-se que o cristal tenha eixos ortogonais e está montado de forma que rotacione sobre o eixo a. Então, a inclinação apropriada é dada por;

$$
\sin \mu=\frac{h a^{*}}{2}
$$

uma reflexão h00 é obtida, podendo ser observada para grandes quantidades de valores de $\varphi$, desde que a variação deste ângulo sirva somente para rotacionar o cristal sobre a normal aos planos que estão refletindo. De modo que a intensidade da reflexão pode ser estudada como uma função de $\varphi$. Portanto, uma variação na intensidade provê uma medida da absorção relativa sofrida pelos raios X passando pelo cristal, de acordo com Furnas, correções de absorção relativa para o caso geral das reflexões hkl são dadas por;

$$
A(h k l)=\frac{I_{\max }(\varphi)}{I\left(\varphi_{h k l}\right)}=\frac{1}{T(h k l)}
$$


onde $I_{\max }$ é a máxima intensidade para a reflexão h00 quando está sendo rotacionado em torno de $\varphi, \operatorname{com} \varphi$ variando de 0 a $2 \pi$, e $\varphi_{h k l}$ é o ângulo para que o plano hkl seja paralelo ao feixe incidente. $T(h k l)$ é o fator de transmissão correspondente a reflexão estudada.

Quando a rede recíproca é descrita em coordenadas polares com o eixo polar paralelo ao eixo de rotação do cristal, o ângulo $\varphi$ é simplesmente o ângulo azimutal medido com referência a alguma origem conveniente.

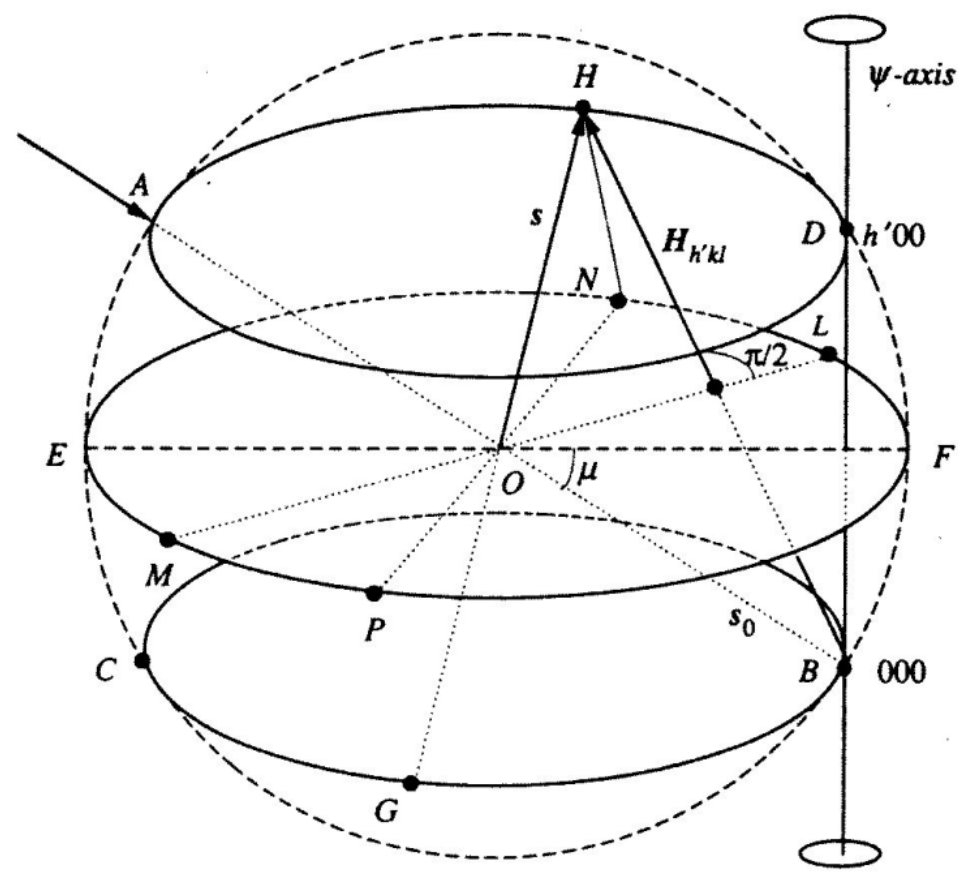

Figura 1.1: Direções dos feixes incidente e difratado para a correção do fator de transmissão pelo o método de North-Philips-Mathews (Aslanov et al., 1998).

North et al. (1968) modificou o método de Furnas melhorando-o, levando em conta a média das transmissões relativas, medidas em uma reflexão de referência, para dois ângulos azimutais arranjados de modo que suas direções ao feixe incidente 
são paralelas, respectivamente as direções dos feixes incidente e difratado da reflexão que está sendo corrigida. Na aproximação, o feixe incidente AOB (figura 1.1) é substituído por sua projeção EOF dentro do plano equatorial EPFN, o feixe refletido GOH é substituído por sua projeção PON no mesmo plano equatorial. Daí assume-se que a diferença entre a absorção de raios $\mathrm{X}$ entre EON e AOH é negligenciada. Os fatores de transmissão ao longo das direções EOF e PON podem ser determinados a partir do método descrito acima, isto é quando a intensidade relativa da reflexão $h^{\prime} 00$ está no zero da posição azimutal. O valor médio destes fatores é dado por,

$$
A^{\prime}\left(\Psi_{h^{\prime} k l}\right)=\frac{1}{2}\left[A^{\prime}(0)+A^{\prime}\left(2 \Psi_{h^{\prime} k l}\right)\right]
$$

e é aceito como um fator de transmissão para a reflexão $h^{\prime} k l$.

O método desenvolvido por North et al. é aplicável a amostras cuja forma externa tem um eixo de ordem 2 orientado ao longo do eixo de rotação. Se esta condição é violada a equação (1.17) torna-se incorreta, como pode ser visto na figura 1.2. Neste caso, o fator de transmissão para as reflexões $h k l$ e $\bar{h} \bar{k} \bar{l}$ são diferentes, porque o cristal é assimétrico e há cola nas paredes do tubo capilar. Portanto, os caminhos dos feixes I- $d V$-II e III- $d V$-IV são bastante diferentes.

A correção por absorção baseada nas curvas de transmissão especifica para cada reflexão de uma rede recíproca, leva a um resultado que é equivalente ao calculado para o cristal, cuja forma é aproximadamente um cilindro com um valor desconhecido de $\mu R$ para cada reflexão. Isto significa que as intensidades corrigidas por absorção não estão em uma mesma escala e os fatores de escala (que são 
individuais para alguma reflexão) estão sendo refinados no estágio de refinamento da estrutura do cristal pelo método de mínimos quadrados.

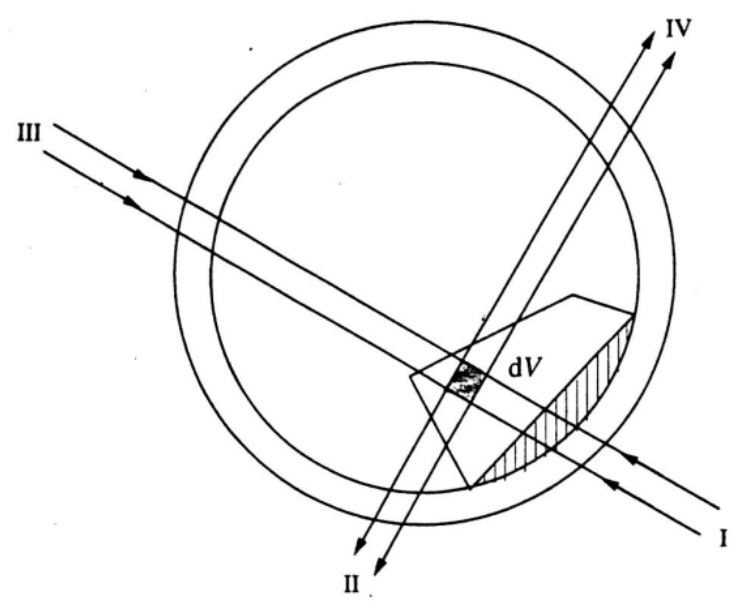

Figura 1.2: Um cristal assimétrico colado dentro de um capilar (a parte tracejada é cola) (Aslanov et al., 1998).

Kopfmann e Huber (1968) generalizaram o método North et al. à aplicação em cristais com formas arbitrárias. No método de Kopfmann e Huber o fator de absorção da reflexão é dividido em dois termos, que são os fatores de absorção parciais $a_{p}\left(V_{i}\right)$ e $a_{s}\left(V_{i}\right)$ correspondendo as direções de feixes primários e secundários, respectivamente. A correção por absorção para todas as reflexões pode ser obtida na mesma escala, pela forma discreta a transmissão pode ser calculada como;

$$
A_{p, s}=\frac{1}{V} \sum_{i} \exp \left\{-\mu\left[a_{p}\left(V_{i}\right)+a_{s}\left(V_{i}\right)\right]\right\} V_{i}
$$


onde $\mu$ é o coeficiente de absorção; $a_{p}\left(V_{i}\right)$ é o comprimento do caminho do feixe primário no elemento de volume $V_{i} ; a_{s}\left(V_{i}\right)$ é o comprimento do caminho do feixe secundário no elemento de volume $V_{i}$.

A relação entre a intensidade medida $I_{p, s}^{H}$ e a intensidade corrigida $I^{H}$ é dada por:

$$
I_{p, s}^{H}=I^{H} A_{p, s}
$$

Kopfmann e Huber mostram que a determinação experimental da transmissão requer uma separação da expressão da transmissão em um produto de transmissões parciais, primária e secundária.

$$
A_{p, s} \cong A_{p}^{\prime} \cdot A_{s}^{\prime}
$$

onde

$$
A_{p}^{\prime}=\frac{1}{V} \sum_{i} \exp \left\{-\mu\left[a_{p}\left(V_{i}\right)\right]\right\} \Delta V_{i}
$$

$\mathrm{e}$

$$
A_{s}^{\prime}=\frac{1}{V} \sum_{i} \exp \left\{-\mu\left[a_{s}\left(V_{i}\right)\right]\right\} \Delta V_{i}
$$

Se for escrito $\exp \left[-\mu a_{p}\left(V_{i}\right)\right]=b_{i}^{p}$ e $\exp \left[-\mu a_{s}\left(V_{i}\right)\right]=b_{i}^{s}$, então; 


$$
A_{p}^{\prime} \cdot A_{s}^{\prime}=\frac{1}{V^{2}} \sum_{i} b_{i}^{p} b_{i}^{s} \Delta V_{i}^{2}+\frac{1}{V^{2}} \sum_{i}^{i \neq j} b_{i}^{p} b_{j}^{s} \Delta V_{i} \Delta V_{j}
$$

$\mathrm{e}$

$$
A_{p, s}=\frac{1}{V^{2}} \sum_{i} b_{i}^{p} b_{i}^{s} \Delta V_{i}^{2}+\frac{1}{V^{2}} \sum_{i}^{i \neq j} \sum_{j}^{j \neq i} b_{i}^{p} b_{i}^{s} \Delta V_{i} \Delta V_{j}
$$

As duas equações anteriores serão iguais, se;

$$
\sum_{j}^{j \neq i} b_{j}^{s} \Delta V_{j}=b_{i}^{s} \sum_{j}^{j \neq i} \Delta V_{j}
$$

A aproximação é boa para pequenos cristais e baixos coeficientes de absorção e bastante aplicável para cristais de hábitos irregulares com dimensões até $1 \mathrm{~mm}$. A discrepância principal entre a aproximação e a transmissão real negligencia a dependência em $\theta$ da transmissão.

Se forem desenhados todos $A^{\prime}$ como vetores em coordenadas polares, centrado a partir do sistema goniométrico do difratômetro, será gerada uma superfície que pode ser chamada de superfície de transmissão. A transmissão para uma reflexão poderá ser obtida pela multiplicação dos módulos dos vetores nas direções dos feixes primários e secundários, daí fica claro que a superfície é centrossimétrica.

Para a determinação de $A^{\prime}$, uma reflexão é medida em vários pontos em torno do vetor de rede recíproco $\mathbf{H}$, esse processo é realizado para muitas outras reflexões independentes com o objetivo de construir a superfície de transmissão. 
Para cada medida pode ser escrita uma equação na forma:

$$
I_{p, s}^{H}=I^{H} A_{p}^{\prime} \cdot A_{s}^{\prime}
$$

onde todos termos do lado direito são desconhecidos. Aplicando logaritmo na equação anterior, em um sistema de equação linear, temos;

$$
\log I_{p, s}^{H}=\log I^{H}+\log A_{p}^{\prime}+\log A_{s}^{\prime}
$$

Estas equações são reduzidas às equações normais e podem ser resolvidas pelo método de mínimos quadrados, para um número suficiente de intensidades medidas em diferentes pontos em torno do vetor de rede recíproca.

Huber e Kopfmann (1969) concluíram que para obter uma superfície de transmissão aceitável, a distância angular entre as intensidades observadas deveria ser entre $12^{\circ}-15^{\circ}$, podendo ser menor também.

\subsubsection{Correção Multiscan}

Conforme pode ser visto, no método psi-scan a correção por absorção fica sujeita aos dados experimentais e um refinamento por mínimos quadrados das intensidades das reflexões utilizadas para calcular os fatores de transmissão. O método de multiscan, desenvolvido por Blessing (1995), utiliza a mesma metodologia, mas tem uma grande vantagem, que é utilizar as reflexões equivalentes por simetria na construção da superfície de transmissão. O método foi implementado 
para difratometro que faz uso de detector de área. Por meio deste sistema é otimizado o tempo de coleta, podendo coletar muito mais reflexões em menos tempo e com uma grande redundância. Este modelo de construção da superfície de transmissão usa uma série de harmônicos esféricos baseada na diferença entre as reflexões equivalentes.

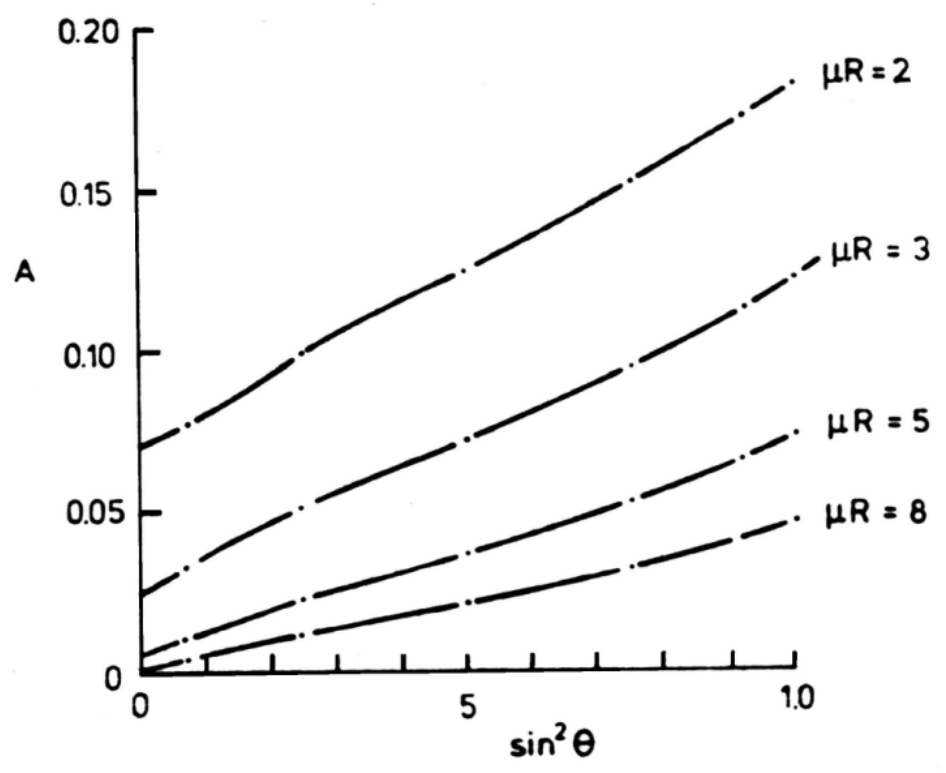

Figura 1.3: Variação do fator de transmissão para valores diferentes de $\mu R$ (Dunitz, 1979).

Para cristais com hábitos irregulares, a necessidade de fazer a correção por absorção se resume em utilizar outros métodos que não sejam os analíticos ou numéricos. O mais recomendado é que seja feita uma correção semi-empírica, daí é necessário que se calcule o caminho do feixe dentro do cristal, onde o fator de transmissão é expresso, como;

$$
A=A_{\text {esf }} / A_{\text {anis }}
$$


onde $A_{e s f}=A_{e s f}(\mu, R, 2 \theta)$ é um fator de transmissão para um cristal equivalentemente esférico e $A_{\text {anis }}$ é um fator de correção. Toda dependência angular do fator de transmissão total está contida em $A_{\text {esf }}$, que aumenta quase que linearmente com a dependência em $\sin ^{2} \theta$, como mostra a figura 1.3 (Dunitz, 1979).

Um raio esférico equivalente pode ser estimado da média das dimensões medidas do cristal ou como um raio de uma esfera ou ainda como a metade da dimensão de um cubo de volume igual ao estimado para o cristal. Se o cristal é da forma de paralelepípedo, lâminas ou placas, um raio equivalente pode ser estimado da menor espessura do cristal e o mínimo fator de correção anisotrópico,

$$
\exp \left(-\mu t_{\text {min }}\right) \cong A_{\text {esf }} / A_{\text {anis, } \min }
$$

A correção para a anisotropia fica na forma;

$$
A_{\text {anis }}=1+\sum_{l=1}^{l_{\max }} \sum_{m=-l}^{l} a_{l m} f_{l m}
$$

onde

$$
f_{l m}=\left[y_{l m}\left(\vec{u}_{0}\right)+y_{l m}\left(\vec{u}_{1}\right)\right]
$$

e $y_{l m}$ são funções harmônicas esféricas reais, cujos os argumentos são vetores unitários das direções dos feixes incidente e espalhado, respectivamente. Os vetores relativos as direções dos feixes são calculados da orientação do cristal e da geometria 
de difração para cada intensidade medida, e os coeficientes $a_{l m}$ são obtidos pela a análise do refinamento em mínimos quadrados das diferenças entre as intensidades medidas que são equivalentes por simetria e/ou pelas intensidades iguais medidas em posições azimutais diferentes.

\subsubsection{Correções Empíricas}

Geralmente são os últimos métodos usados para correção por absorção, por serem métodos desacreditados. Essa desconfiança gerada pelos métodos é porque sua metodologia está fundamentada basicamente na construção da superfície de absorção do cristal por meio da minimização nas diferenças algébricas entre os fatores de estrutura calculado e observado.

\subsubsection{Corre ção DIFABS}

O método desenvolvido por Walker \& Stuart (1983), trabalha com a premissa que o surgimento dos erros sistemáticos devido à absorção não estão distribuídos igualmente por todo cristal, mas sim, localizados. Uma série de Fourrier em ângulos polares definindo as direções dos caminhos do feixe incidente e difratado (figura 1.4) é usada para definir o modelo da superfície de absorção, considerando a diferença entre os fatores de estrutura calculado e observado. Quando as amplitudes reais (corresponde as amplitudes que não sofreram absorção) são conhecidas, então a superfície de absorção pode ser construída da diferença entre as amplitudes reais e observadas. Normalmente estas amplitudes não são conhecidas, uma boa 
aproximação é calcular os fatores de estrutura a partir das posições atômicas e parâmetros de deslocamento anisotrópicos usando os dados que sofreram absorção.

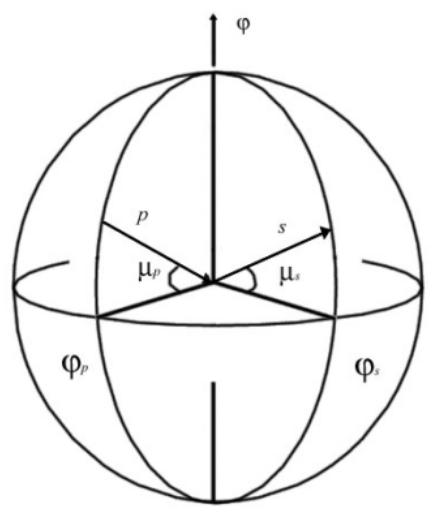

Figura 1.4: Direções dos feixes incidente e difratado em ângulos polares.

Se $F_{j}^{o}$ são as amplitudes observadas dos fatores de estrutura e $F_{j}^{c}$ são as amplitudes dos fatores de estrutura calculados, modificando os valores de $F_{j}^{o}$ pela correção empírica, temos:

$$
F_{j}^{m}=k F_{j}^{o} A_{p, s}
$$

onde $k$ é o fator de escala obtido do refinamento por mínimos quadrados. O coeficiente de absorção, $A_{p, s}$ está representado por uma série de Fourrier:

$$
\begin{aligned}
A_{p, s} & =\sum_{n} \sum_{m} P_{n, m}\left[\sin \left(n \varphi_{p}+m \mu_{p}\right)+\sin \left(n \varphi_{s}+m \mu_{s}\right)\right] \\
& +Q_{n, m}\left[\cos \left(n \varphi_{p}+m \mu_{p}\right)+\cos \left(n \varphi_{s}+m \mu_{s}\right)\right]
\end{aligned}
$$


onde $\varphi_{p}, \mu_{p}, \varphi_{s}$ e $\mu_{s}$ são os ângulos polares definindo as direções dos feixes incidente e difratado, respectivamente. $P_{n, m}$ e $Q_{n, m}$ são coeficientes de Fourrier, cujo os valores são obtidos minimizando a soma quadrática de $R_{j}$, onde $R_{j}$ é dado por:

$$
R_{j}=\left(\left\|F_{j}^{c}|-| F_{j}^{m}\right\|\right) \omega_{j}
$$

e $\omega_{j}$ é uma função peso, $\omega_{j}=1 /\left(k \sigma_{j}\right)^{1 / 2}$, onde o valor de $\sigma_{j}$ para cada reflexão é dado do desvio padrão da contagem estatística, $\sigma_{j}^{I}$, onde

$\sigma_{j}=\frac{\sigma_{j}^{I}}{2 F_{j}^{o} L_{p}}$, onde $L_{p}$ é o fator de Lorentz e polarização.

Todas as reflexões são corrigidas por absorção, mas somente as que preenchem os critérios abaixo são utilizadas para gerar a superfície de absorção:

$$
\begin{aligned}
& (i) F_{j}^{o} \geq 3 \sigma_{j} \\
& \left(\text { ii) } F_{j}^{c} \geq 3 k \sigma_{j}\right. \\
& (i i i) F_{j}^{c} \leq 2 k F_{j}^{o}
\end{aligned}
$$

O terceiro critério é para prevenir o uso de alguma reflexão que esteja provavelmente sofrendo fortes efeitos de extinção. 


\subsubsection{Correção XABS2}

A base da construção do método usado em XABS2 desenvolvido por Parkin et al. (1995), é similar à usada no DIFABS. Ambos dependem da observação que os erros causam nas leves delocalizações atômicas e nas suposições que os erros são distribuídos igualmente por todo espaço recíproco, uma vez que os efeitos de absorção são mais localizados. Os algoritmos, portanto são bastante diferentes.

O XABS2 depende fortemente da qualidade dos dados calculados. Visto que os parâmetros térmicos anisotrópicos são influenciados negativamente por efeitos de absorção, a correção poderá ser normalmente executada com os dados de um modelo com parâmetros térmicos isotrópicos. O usuário é livre para especificar vários parâmetros. $\sin \theta_{\min }$ poderá ser ajustado para omitir reflexões de baixo ângulo que são sombreadas pelo 'beamstop' ou também pode aumenta-lo como uma forma de assegurar que nenhuma reflexão que sofra sérios efeitos de extinção seja usada no cálculo. Se as extinções são tratadas apropriadamente, seus efeitos podem ser analisados independentemente. Mas, se todos os dados forem bem avaliados, deverá ser necessário incorporar uma correção de extinção nos refinamentos posteriores. Senão houver uma avaliação dos dados, o fator de correção do XABS2 para todas reflexões poderá ser influenciado pelas reflexões que sofreram extinção.

Em todo caso, se os parâmetros térmicos dos átomos pesados são fixados razoavelmente bem para uma aplicação do XABS2, os efeitos de absorção podem ser minimizados nos refinamentos subseqüentes, quando todos os parâmetros são refinados juntos. O ponto de partida do XABS2 foi estabelecer uma relação de aproximação entre o fator de correção por absorção, $A^{*}$ e o ângulo de difração $\theta$, que poderá ser substituído na equação, 


$$
F_{c}^{2}=A^{*} F_{o}^{2}
$$

sendo $A^{*}=1 / A$ e $A$ é dado por;

$$
A=a_{1} \sin ^{6} \theta+a_{2} \sin ^{4} \theta+a_{3} \sin ^{2} \theta+a_{4}
$$

os coeficientes $a_{n}$ poderão ser obtidos de um refinamento de mínimos quadrados que minimiza $\omega_{2}\left(F_{o}^{2}-k A F_{c}^{2}\right)^{2}$, onde $\omega_{2}=1 / \sigma\left(F_{o}^{2}\right)^{2}$ e $k$ é um fator de escala sobre todas as reflexões.

O algoritmo usado em XABS2 faz uma aproximação, como será mostrado a seguir. No caso de um cristal esférico, a função minimizada é,

$$
R_{2}=\sum_{\text {data }} \omega_{2}\left[F_{o}^{2}-\left(\sum_{n=1}^{4} a_{n} \sin ^{2(4-n} \theta\right) k F_{c}^{2}\right]^{2}
$$

A função é mínima quando a derivada da função em relação a cada coeficiente $a_{1}, a_{2}$, $a_{3}$ e $a_{4}$ é zero;

$$
\frac{\partial R_{2}}{\partial a_{n}^{\prime}}=\sum_{\text {data }} \omega_{2}\left[F_{o}^{2}-\left(\sum_{n=1}^{4} a_{n} \sin ^{2(4-n)} \theta\right) k F_{c}^{2}\right] \times k F_{c}^{2} \sin ^{2\left(4-n^{\prime}\right)} \theta=0
$$

onde $n^{\prime}=1,2,3,4$. Equação 1.39 pode ser rearranjada na forma 


$$
\sum_{\text {data }} \omega_{2}\left(\sum_{n=1}^{4} a_{n} \sin ^{2\left(4-n^{\prime}\right)} \theta\right) k F_{c}^{2} \sin ^{2\left(4-n^{\prime}\right)} \theta=\sum_{\text {data }} \omega_{2} F_{o}^{2} F_{c}^{2} \sin ^{2\left(4-n^{\prime}\right.} \theta
$$

para $n^{\prime}=1,2,3,4$. E da equação 1.40 pode-se tirar os 4 coeficientes $a_{n}$ e obter a correção, conforme equação 1.37, para cada reflexão. Para generalizar o algoritmo para cristais não-esféricos, a superfície de absorção é aproximadamente a de um elipsóide e cada coeficiente $a_{n}$ é expandido em seis termos,

$$
a_{n}\left(h_{1} h_{2} h_{3}\right)=\left(\frac{\lambda^{2}}{4 \sin ^{2} \theta}\right) \sum_{i=1}^{3} \sum_{j=1}^{3}\left(a_{n i j} h_{i} h_{j} a_{i}^{*} a_{j}^{*}\right)
$$

onde $h_{1}, h_{2}, h_{3}, a_{1}^{*}, a_{2}^{*}$ e $a_{3}^{*}$ representa $h, k, l, a^{*}, b^{*}$ e $c^{*}$, respectivamente, e $a_{n i j}=a_{n j i}$. Substituindo a equação 1.41 na equação 1.38 , temos;

$$
R_{2}=\sum_{h k l} \omega_{2}\left\{F_{o}^{2}-\left[\sum_{n=1}^{4}\left(\frac{\lambda^{2}}{4 \sin ^{2} \theta}\right) \sum_{i=1}^{3} \sum_{j=1}^{3}\left(a_{n i j} h_{i} h_{j} a_{i}^{*} a_{j}^{*}\right) \sin ^{2(4-n)} \theta\right] k F_{c}^{2}\right\}^{2}
$$

que é mínimo quando a derivada em relação a todos os $24 a_{n i j}$ é zero, isto é;

$$
\frac{\partial R^{2}}{\partial a_{n i j}}=\sum_{\text {data }} \omega_{2}\left[\left(F_{o}^{2}-A k F_{c}^{2}\right)\left(k F_{c}^{2} \frac{\partial A}{\partial a_{n i j}}\right)\right]=0
$$

A equação 1.43 pode ser rearranjada para o caso não-esférico, da forma; 


$$
\begin{gathered}
\sum_{\text {data }} \omega_{2}\left(\frac{\lambda^{2}}{4 \sin ^{2} \theta}\left[\sum_{n=1}^{4} \sum_{i=1}^{3} \sum_{j=1}^{3}\left(a_{n i j} h_{i} h_{j} a_{i}^{*} a_{j}^{*}\right) \sin ^{2(4-n} \theta\right] k F_{c}^{4}\left(h_{i} h_{j} a^{*} a^{*} a_{j}^{*}\right) \sin ^{2(4-n)} \theta=\right. \\
\sum_{\text {data }} \omega_{2} F_{o}^{2} F_{c}^{2}\left(h_{i} h_{j^{\prime}} a_{i}^{*} a_{j^{\prime}}^{*}\right) \sin ^{2(4-n)} \theta
\end{gathered}
$$

para $n^{\prime}=1,2,3,4 ; i^{\prime}=1,2,3 ; j^{\prime}=1,2,3$. Estas equações são resolvidas e daí encontrase os 24 coeficientes $a_{n i j}$ necessários para calcular o fator de transmissão de cada reflexão,

$$
A=\sum_{n=1}^{4}\left\{\frac{\lambda^{2} \sin ^{2(3-n)} \theta}{4}\right\} \sum_{i=1}^{3} \sum_{j=1}^{3} a_{n i j} h_{i} h_{j} a_{i}^{*} a_{j}^{*} .
$$




\section{Interações Intra e Intermoleculares e Supramoléculas}

\subsection{Introdução}

Gilbert Newton Lewis estudou em sua teoria eletrônica de valência, publicado em 1916, o mecanismo de ligação dos átomos que leva a formação de agregados moleculares. Os íons e as moléculas de uma substância formam-se pelas interações dos elétrons dos átomos que participam da combinação. As ligações ocorrem porque os átomos tendem a se estabilizar, buscando completar sua camada eletrônica externa, assumindo na maioria das vezes uma estrutura semelhante à dos gases nobres, que têm a camada externa completa. As moléculas de uma substância sólida ou líquida se mantêm unidas através da atração existente entre elas. Quanto maior for a força de atração, maior será a coesão entre as moléculas.

Do mesmo modo que moléculas são construídas conectando-se átomos, através de ligações covalentes, compostos supramoleculares são construídos ligandose moléculas através de interações intermoleculares. Um grande número de interações intermoleculares é possível em qualquer estrutura supramolecular. Contudo, só umas poucas são de fato observadas (Desiraju, 2001). 
As forças intermoleculares que levam à formação de estruturas supramoleculares podem ser ligações secundárias, ligações de hidrogênio, interações doador-aceptor (tipo ácido-base de Lewis) ou interações iônicas. Estas forças são importantes na formação de complexos "host-guest", no controle de estados de agregação e são fundamentais para o que é hoje conhecido como "crystal engineering". A formação de estruturas supramoleculares é um processo espontâneo (self-assembly) e não um processo em etapas, sendo um mecanismo conhecido como "reconhecimento molecular". As estruturas supramoleculares são resultados não somente de interações aditivas, mas também de interações cooperativas, e suas propriedades são, em geral, conseqüência do caráter supramolecular.

\subsection{Ligações Químicas}

\subsubsection{Ligação Iônica}

Um exemplo clássico de um cristal iônico é o $\mathrm{NaCl}$ (sal de cozinha). Ele é chamado iônico porque é constituído de íons positivos $\left(\mathrm{Na}^{+}\right)$e negativos $\left(\mathrm{Cl}^{-}\right)$. A ligação iônica é resultante de uma interação eletrostática de ânions $\left(\mathrm{Cl}^{-}\right)$e cátions $\left(\mathrm{Na}^{+}\right)$na estrutura do cloreto de sódio. A energia de ligação é da ordem de $10 \mathrm{eV}$ por átomo. A configuração eletrônica dos íons é essencialmente uma configuração de gás inerte, a distribuição de cargas mais próximas do núcleo (“core”) de cada íon é simetricamente esférica. Conseqüentemente os sólidos iônicos cristalizam em uma 
estrutura "close-packed", $\mathrm{NaCl}$ e $\mathrm{CsCl}$ são encontrados, por exemplo, em sistemas cristalinos cúbicos.

Porém, os ânions e cátions não se comportam como esferas maciças sem sobreposição (sem-'overlap’) no estado sólido como sugere a teoria clássica. Se assim fosse, as distâncias interatômicas no cristal deveriam ser maiores do que a soma dos raios iônicos. Experimentalmente, observa-se que as distâncias interatômicas são menores do que a soma dos raios iônicos.

Isto leva a um considerável overlap entre as camadas eletrônicas. A configuração final é atingida com o balanço de dois termos, o primeiro é a energia potencial interatômica de Coulomb, dada na forma $\pm e^{2} / R$, e sendo $R$ a distância entre os íons (com sinal positivo para íons de cargas iguais e negativos para íons de cargas diferentes). O potencial líquido de Coulomb entre os átomos vizinhos é atrativo e tende a fazer a rede colapsar. O segundo termo é a interação devido ao overlap de camadas eletrônicas de átomos vizinhos e tem a forma $A \exp (-R / b)$, onde $A$ e $b$ são constantes empíricas. A função energia potencial interatômica total é a soma das duas contribuições, como mostra a figura 2.1. 


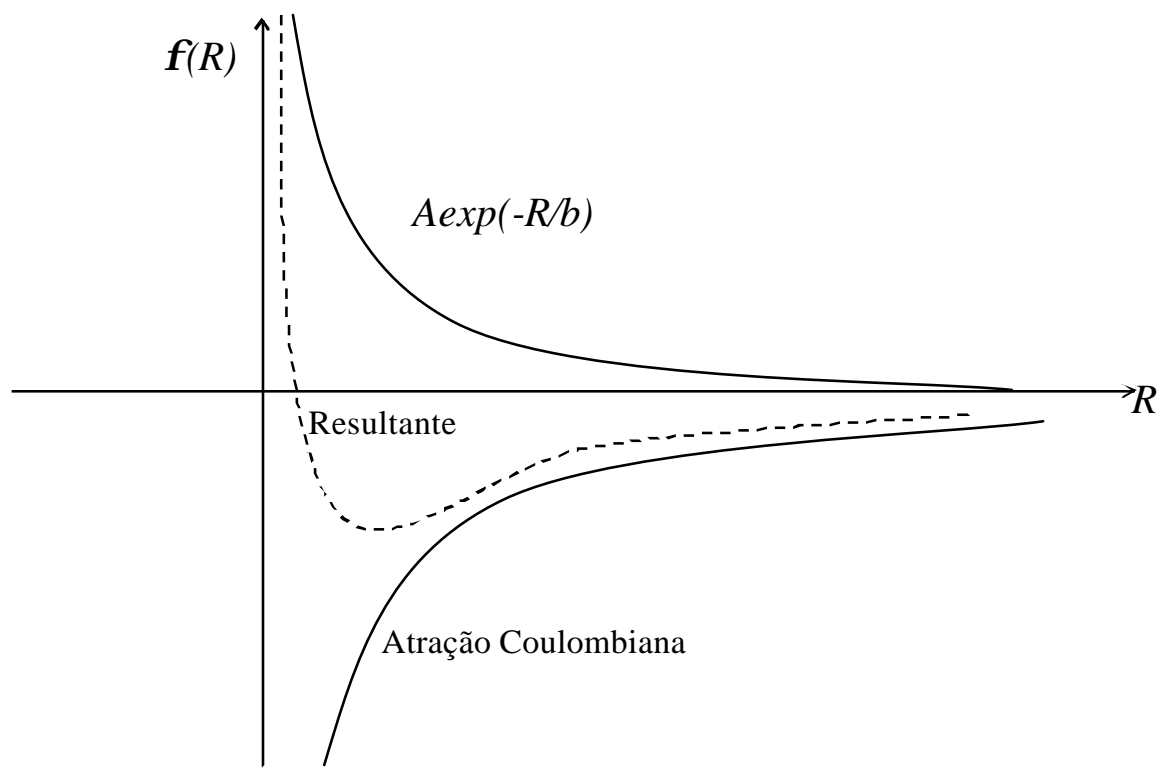

Figura 2.1: Contribuições Coulombiana e repulsiva para potenciais interatômicos em sólidos iônicos.

O potencial interatômico tem uma parte repulsiva, um mínimo de função bem definido e uma parte atrativa (devido ao caráter Coulombiano). A contribuição à energia total de todos os íons devido a seus potenciais Coulombianos é,

$$
\phi_{M}(R)=-N \sum( \pm) \frac{e^{2}}{R_{i j}}=-\frac{N \alpha e^{2}}{R}
$$

$R_{i j}$ é a separação entre o $i^{\text {th }}$ e o $j^{\text {th }}$ átomo no cristal iônico, e $R$ é à distância entre os vizinhos mais próximos. A soma $\phi_{M}(R)$ é chamada energia de Madelung e $a$ a constante de Madelung. 


\subsubsection{Ligação Covalente}

A energia das ligações covalentes é da mesma ordem das ligações iônicas, 10 $\mathrm{eV}$ por átomo (Animalu, 1977). Elas prevalecem em cristais da forma $A^{N} B^{8-N}$, composto de elementos $A$ e $B, \operatorname{com} N$ e $8-N$ sendo os elétrons de valência por átomo, como oito elétrons de valência $s-p$ (camadas de valência) por par de átomos.

"Dois átomos A e B são chamados quimicamente ligados quando as forças atuando entre eles são suficientemente fortes para formar um agregado estável na temperatura de interesse. A ligação covalente envolve o compartilhamento entre os átomos de pares ou par de elétrons, dois por cada ligação simples. Uma ligação múltipla envolve o compartilhamento de $2 N$ elétrons, onde $N$ é a ordem da ligação e $N$-1 é comumente chamado de ordem da ligação $\pi$. Geralmente, em uma ligação A-B alguma densidade eletrônica é transferida de A (o cátion) para B (o ânion). A ligação é então dita sendo parcialmente iônica $\left(\mathrm{A}^{+}-\mathrm{B}^{-}\right)$e parcialmente covalente (A:B). Esta separação é muitas vezes descrita quanticamente como uma superposição das amplitudes das funções de onda covalentes e iônicas. Os elétrons de valência poderão, probabilisticamente falando, gastar parte do tempo no estado iônico e parte do tempo no estado covalente." (Phillips, 1970).

A característica mais impressionante da ligação covalente é o compartilhamento de densidade eletrônica. Isto leva a um forte caráter direcional da ligação. Deste modo, o carbono tem uma conformação para a estrutura do diamante em que cada átomo de carbono está conectado a quatro átomos de carbonos vizinhos em uma forma tetraédrica. A configuração eletrônica do átomo de carbono neutro é $1 s^{2} 2 s^{2} 2 p^{2}$; a configuração do átomo de carbono no estado de valência que tem 
ângulos de ligações tetraédricos é $1 \mathrm{~s}^{2} 2\left(\mathrm{sp}^{3}\right)^{4}$. Os quatro orbitais que determinam a configuração $1 \mathrm{~s}^{2} 2 \mathrm{~s}^{2} 2 \mathrm{p}^{2}$ são $|s\rangle,\left|p_{x}\right\rangle,\left|p_{y}\right\rangle,\left|p_{z}\right\rangle$, onde;

$$
\begin{gathered}
|s\rangle=(4 \pi)^{-1} \\
\left|p_{x}\right\rangle=\sqrt{1 / 2}\left(Y_{11}+Y_{1-1}\right)=\left(\frac{3}{4} \pi\right)^{1 / 2} \operatorname{sen} \theta \cos \phi \\
\left|p_{y}\right\rangle=-\sqrt{1 / 2} i\left(Y_{11}-Y_{1-1}\right)=\left(\frac{3}{4} \pi\right)^{1 / 2} \operatorname{sen} \theta \operatorname{sen} \phi \\
\left|p_{z}\right\rangle=Y_{10}=\left(\frac{3}{4} \pi\right)^{1 / 2} \cos \theta .
\end{gathered}
$$

São as funções angulares normalizadas, em coordenadas esféricas. As quatro funções que determinam a configuração $1 \mathrm{~s}^{2} 2\left(\mathrm{sp}^{3}\right)^{4}$ são combinações lineares (chamadas de orbitais tetraédricos):

$$
\Psi_{1}=\frac{1}{2}\left(|s\rangle+\left|p_{x}\right\rangle+\left|p_{y}\right\rangle+\left|p_{z}\right\rangle\right), \quad \Psi_{2}=\frac{1}{2}\left(|s\rangle+\left|p_{x}\right\rangle-\left|p_{y}\right\rangle-\left|p_{z}\right\rangle\right)
$$

e duas outras funções ortogonais, $?_{3}$ e $?_{4}$.

O quadrado do módulo da função ? ${ }_{1}$, que representa a distribuição angular dos elétrons neste estado, tem um valor máximo na direção da diagonal do octante formado pelos eixos x, y e z. Esta é também a direção da ligação de valência produzida pelos elétrons neste estado, para os átomos ligados $\mathrm{B}$ e $\mathrm{A}(\mathrm{A}=\mathrm{B}=$ carbono). Similarmente, $\left|\Psi_{2}\right|^{2}$ tem um máximo na direção da diagonal do octante formado 
pelos eixos x, -y e -z; $\left|\Psi_{3}\right|^{2}$ ao longo da diagonal do octante formado pelos eixos -x, +y e $-\mathrm{z}$ e $\left|\Psi_{4}\right|^{2}$ ao longo da diagonal do octante -x, -y e z. Os estados ligados têm menor energia e estão centrados predominantemente no átomo mais eletronegativo (para átomos não idênticos) e apontando na direção dos primeiros vizinhos.

\subsubsection{Ligação Metálica}

O overlap das funções de ondas ocorre não somente quando dois átomos se aproximam, mas também quando um grande número de átomos estão próximos. A figura 2.2 mostra o overlapping de duas funções de onda $2 \mathrm{~s}$ dos átomos de lítio separados por distâncias iguais as distâncias interatômicas em um cristal de lítio. A energia ganha depois do aumento no número de overlap leva a uma tendência na formação do maior número de ligações possíveis. A maioria dos metais cristaliza em estruturas altamente simétricas com grande número de coordenações.

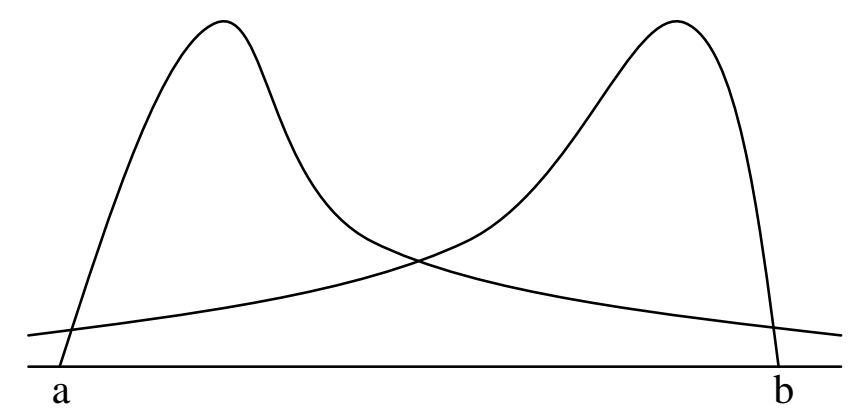

Figura 2.2: Overlapping de funções de ondas no cristal de lítio.

Átomos metálicos formam estruturas em que o número de ligações, determinado pelo número de vizinhos mais próximos, excede o número de elétrons 
de valência. Deste modo, em cristais de metais alcalinos os átomos que são monovalentes formam 14 ligações, 8 ligações com átomos da primeira esfera de coordenação e 6 com a segunda esfera, onde as 8 menores são mais fortes que as 6 ligações da segunda esfera de coordenação. O raio da segunda esfera é somente $14 \%$ maior que o da primeira esfera de coordenação. O número médio de ligação pode ser $\approx 12$ (que corresponde ao número de coordenação em um empacotamento de esferas). Na média um átomo fornece 1/12 de elétron para cada ligação e dois átomos vizinhos fornecem 1/6 elétron, em vez dos dois elétrons que são compartilhados em uma ligação covalente normal. Nas estruturas de metais rabalha-se com ligações fracionárias, com multiplicidade menor que um.

A energia de cada ligação no cristal metálico é menor que em uma molécula. Em um cristal de lítio a energia de uma ligação simples na média é de $0,14 \mathrm{eV}$ enquanto que na molécula de $\mathrm{Li}_{2}$ é $1,14 \mathrm{eV}$. O enfraquecimento das ligações no cristal metálico é confirmado pelo aumento da distância interatômica, que é de 1015\% maior que nas moléculas diatômicas. $\mathrm{O}$ enfraquecimento de cada ligação nos metais, quando comparado a ligações simples, é mais do que compensado pelo aumento no número de ligações, de modo que a formação de um cristal metálico é energeticamente mais favorável do que a formação de sistemas moleculares com baixos números de coordenação. 


\subsection{Interações Intermoleculares}

\subsubsection{Introdução}

As interações fracas são basicamente as ligações de hidrogênio fortes e fracas, ligações $\pi-\pi$ e interações de van der Waals, sendo estas últimas interações de longa distância. Hoje há uma nova perspectiva no que diz respeito ao estudo de interações intermoleculares e intramoleculares da ordem da soma dos raios de van der Waals, (Alcock, 1972). Estas interações são comumente referenciadas na literatura (Landrum e Hoffmann, 1998) como weak interactions' ou 'secondary bonding', mas apesar do nome este tipo de interação tem uma energia maior que as interações convencionais de van der Waals.

\subsubsection{Interações Intermoleculares Secundárias}

Interações intermoleculares acontecem entre uma molécula e uma vizinha próxima que podem ter a mesma conformação estrutural ou não. Estas interações são diferentes das interações intramoleculares, que na maioria das vezes são mais fortes energeticamente. No entanto, as interações intermoleculares em arranjos supramoleculares têm grande importância não só na estabilização energética de moléculas e agregados moleculares, mas também no direcionamento dos arranjos, mantendo a coesão entre as partes (Dance, 2003). Devido a estas interações podemse conseguir agregados estáveis com finalidades diversas, tais como: desintoxicante, 
retirando metais pesados do corpo humano e da natureza, peneiras moleculares e outros (Casas et al., 1998, 1999, 2000 e 2002 ).

Ligações secundárias são bastante comuns em compostos de coordenação no estado cristalino. Desta forma, a identificação deste tipo de ligação é alcançada somente após a determinação da estrutura do cristal por métodos de difração. Estas ligações não são fortes o suficiente para coexistir em solução, (Haiduc, 1997).

Estas Igações ocorrem basicamente com uma conformação Inear X-A...Y em que A-X é uma ligação covalente normal e A...Y é uma ligação secundária. Onde A é um metal pesado e X é tipicamente um halogênio, N, O ou S, (Starbuck, 1999). De acordo com Alcock, a ligação secundária é formada pela 'doação' de um 'lone pair' X para um orbital $s$ na ligação A-Y, ou na forma de um sistema assimétrico de três centros, com três orbitais atômicos $s$ em A, X e Y, combinados na forma de três orbitais moleculares; um orbital molecular completo localizado entre A e X, um orbital completo não ligado ou fracamente ligado entre A e Y e um orbital vazio antiligante, (Alcock, 1972; Alcock e Countryman, 1977 e Alcock e Sawyer, 1977).

\subsubsection{Ligação de Hidrogênio}

Este tema é e foi extensivamente discutido, sendo objeto de incontáveis estudos. Devido à importância do assunto neste trabalho vamos descrever as formulações básicas, mas não há interesse em prolongar-se.

A ligação de hidrogênio (chamada também de 'ponte de hidrogênio', uma nomenclatura em desuso) é a ligação entre um hidrogênio deficiente eletronicamente e uma região de alta densidade eletrônica. Um déficit de elétrons é formado em um átomo de hidrogênio se o hidrogênio estiver quimicamente ligado a um átomo mais 
eletronegativo. Uma observação na tabela periódica dos elementos revela que os átomos mais eletronegativos são; C, N, O, F, P, S, Cl, Se, Br e I. A existência de ligações de hidrogênio com estes átomos tem sido observada. Regiões com uma alta densidade eletrônica estão em átomos com 'pares de elétrons livre', mais comumente chamado 'lone pairs'. Em suma, a ligação de hidrogênio é mais freqüentemente compreendida sendo uma ligação do tipo A-H...B, onde A é um átomo eletronegativo e B é um átomo com lone pairs.

Ligações de hidrogênio afetam fortemente a geometria estrutural de biomoléculas, DNA, proteínas e supramoléculas; a importância destas ligações é bem conhecida e continuamente estudada. O interesse na ligação de hidrogênio é pelo fato que esta ligação é muito comum na natureza. A ligação de hidrogênio é considerada sendo a transição entre as interações fortes e interações fracas.

A formação da ligação de hidrogênio A-H...B causa o alargamento da ligação A-H e uma mudança na densidade eletrônica dos átomos envolvidos. Estes efeitos permitem serem observados experimentalmente, juntamente com a própria ligação de hidrogênio, utilizando técnicas já bem conhecidas, como: Infravermelho, Ultravioleta, Ressonância Magnética, Raman, Difração de nêutrons e de raios X.

\subsubsection{Interações de van der Waals}

As forças (ou interações) de van der Waals estão presentes em todos compostos, o que atrai a atenção sempre que se estuda agregados moleculares. Estas forças também são conhecidas como forças de London, dipolos induzidos, forças de flutuação de cargas, forças de dispersão, dipolo-dipolo, íon-íon, íon-dipolo e forças eletrodinâmicas. São forças que aparecem entre todos os átomos e moléculas. 
Estas forças são produzidas por dipolos induzidos temporariamente, devido ao constante movimento dos elétrons em torno dos núcleos em um curto período. Embora constantemente variando, estes dipolos independentes produzem momentaneamente distribuições assimétricas dos elétrons ligados resultando em forças de van der Waals.

Existem dois tipos diferentes de parâmetro atômico para se referir ao raio de van der Waals. Em cristalografia, o termo raio significa a descrição do contato intermolecular na estrutura do cristal. Em mecânica molecular, o raio de van der Waals é o "raio de equilíbrio", correspondente à distância de equilíbrio entre dois átomos não ligados, isto é a energia mínima da interação de van der Waals.

Os raios de van der Waals em cristalografia são bem conhecidos para átomos não-metálicos, mas não para átomos metálicos, que são raramente expostos o bastante para participar em contatos intermoleculares. Por outro lado, o raio de equilíbrio é avaliado de medidas físicas diretas somente em casos excepcionais (carbono e gases). Para muitos elementos, os raios de van der Waals são obtidos por extrapolação, interpolação e otimização, de modo a alcançar a melhor concordância com os cálculos de mecânica molecular. Portanto, recentemente tornou-se possível determinar o raio de van der Waals diretamente das distâncias interatômicas em complexos de gás de fase (Batsanov, 1999). Os valores obtidos deste modo para alguns metais e não-metais são similares aos estabelecidos em mecânica molecular (Allinger, 1976). 


\subsection{Organização Supramolecular}

“O estudo de arranjos supramoleculares é o estudo de ligações intermoleculares e a analise da relação entre a estrutura e função das entidades formadas pela associação de duas ou mais espécies químicas”. (Lehn, 1995)

Estruturas supramoleculares são estruturas unidas por interações não covalentes. As estruturas deste tipo estão presentes na natureza. Macromoléculas biológicas, como proteínas e DNA podem unir-se seletivamente a outras espécies moleculares para formar complexos maiores, supramoléculas. Estes processos de união despertam um grande interesse na comunidade científica para a compreensão dos mecanismos de interação na formação das supramoléculas por uniões espontâneas, 'self-assembly'. A partir do self-assembly podem se formar sistemas de milhares de moléculas unidas por interações intermoleculares, que apresentam novas propriedades químicas.

Estes arranjos supramoleculares se mantêm unidos por interações, tais como: interações secundárias, ligações de hidrogênio e as interações de van der Waals. Toda esta organização gera grandes perspectivas industriais. As aplicações industriais incluem o design de drogas, a síntese de polímeros, peneiras químicas, compostos sintéticos para a desintoxicação ambiental e filmes finos.

Devido à baixa energia das interações intermoleculares, a organização supramolecular esta sujeita ao estado termodinâmico do sistema. Sendo esta uma ótima qualidade para muitos compostos supramoleculares, que permitem serem "corrigidos" durante a "construção", o que não é possível para compostos 
construídos totalmente por ligações covalentes. Permitindo a construção de grandes sistemas sintéticos com alta complexidade estrutural.

\subsubsection{Self-Assembly (Construção Espontânea)}

Self-assembly é definido como o processo em que um composto supramolecular se forma espontaneamente a partir de seus compostos primários. A informação necessária para a estrutura supramolecular se formar deverá estar nos receptores moleculares dos compostos primários. Esta complementaridade molecular deverá atrair cada uma das partes sob condições propicias para formar espontaneamente uma bem definida arquitetura supramolecular. Para um grande número de compostos sintéticos isto é admiravelmente simples em processos convergentes, levando a composto desejado diretamente (Amabilino e Stoddart, 1994). O self-assembly não é uma característica única de compostos supramoleculares, mas também de supermoleculares.

Sistemas supramoleculares podem ser constituídos sem um controle termodinâmico. Especialmente quando componentes moderadamente rígidos estão envolvidos, esta situação tende a formar grandes construções supramoleculares com muitos contatos intermoleculares. Isto também pode ocorrer quando íons metálicos, e especialmente íons metálicos cineticamente inertes, são incorporados na construção do composto supramolecular ou quando um produto intermediário no processo de construção precipita por causa de sua baixa solubilidade.

Os sistemas supramoleculares podem ser definidos como redes ordenadas de várias dimensões. Estas redes são geralmente chamadas de arranjos e podem ser 
encontrados com diferentes dimensões: adimensional (dimensão zero), unidimensional, bidimensional e tridimensional.

Arranjos com dimensão zero são aqueles que depois das interações intermoleculares não se estendem em nenhuma direção, sendo a menor ordem dimensional de simetria supramolecular. Alguns exemplos são; dímeros e calixarenos, figura 2.3 .
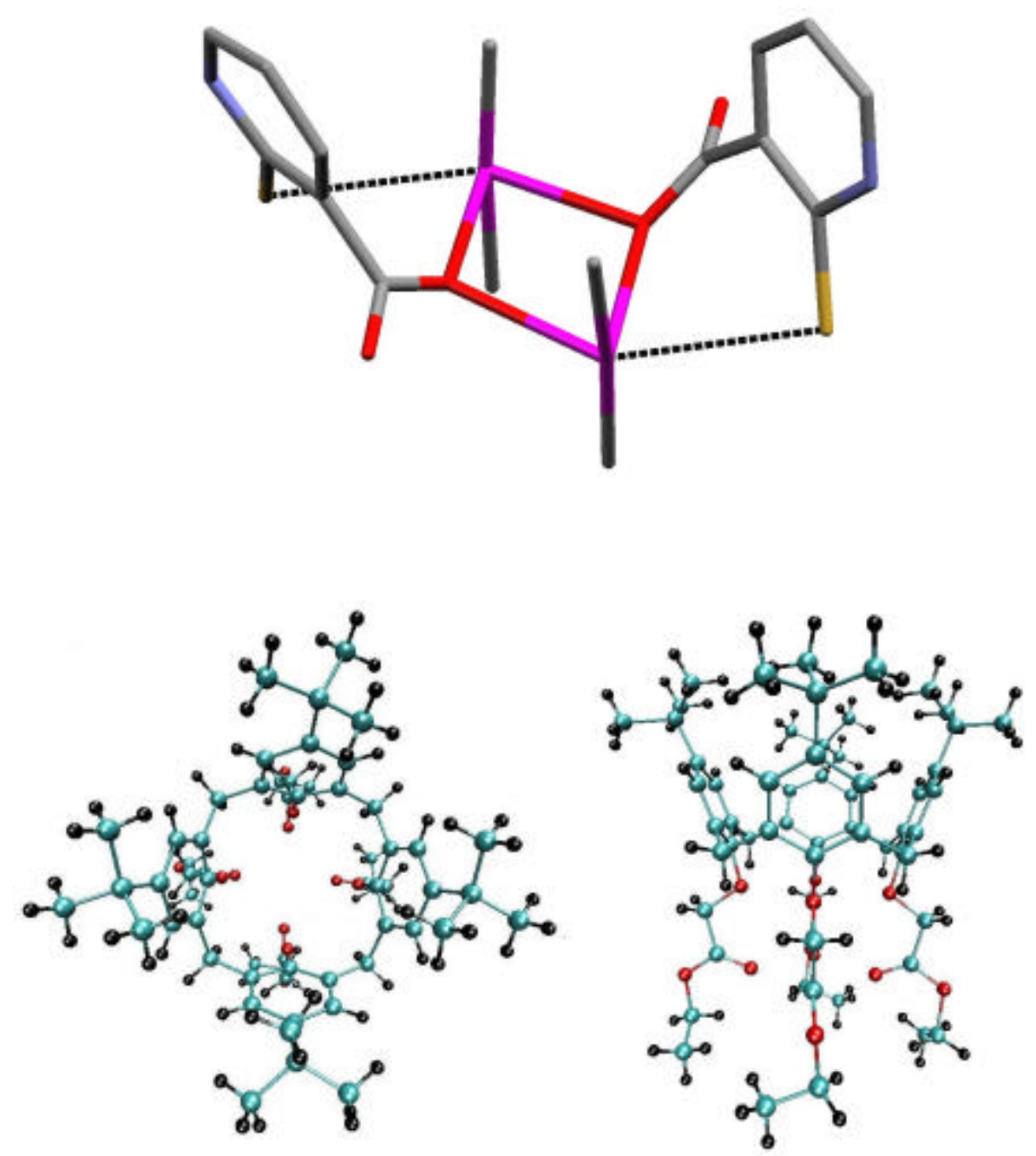

Figura 2.3: a) Composto DimetilTálio 2-mercapto-3-piridina-ácido carboxílico formando uma cadeia zerodimensional. b) Calixareno em arranjo zerodimensional, também chamado de supermolécula. 
Em uma dimensão, os arranjos comportam-se com um padrão linear estendendo por todo cristal, apresentando cadeias "infinitas". Estas estruturas são usualmente descritas como fitas, fios ou hélices, figura 2.4.

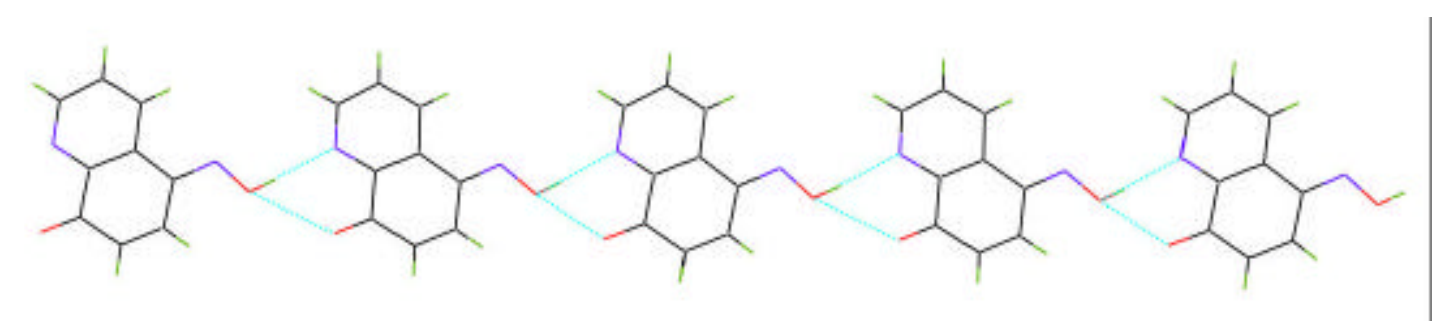

Figura 2.4: Quinolinas formando um arranjo unidimensional.

Bidimensional, esta conformação supramolecular é uma das mais encontradas e demonstra um grande interesse em diversas áreas, como: filmes poliméricos e peneiras atômicas. Geralmente são descritas como planos ou tecidos moleculares, (Batten e Robson, 1998), figura 2.5.

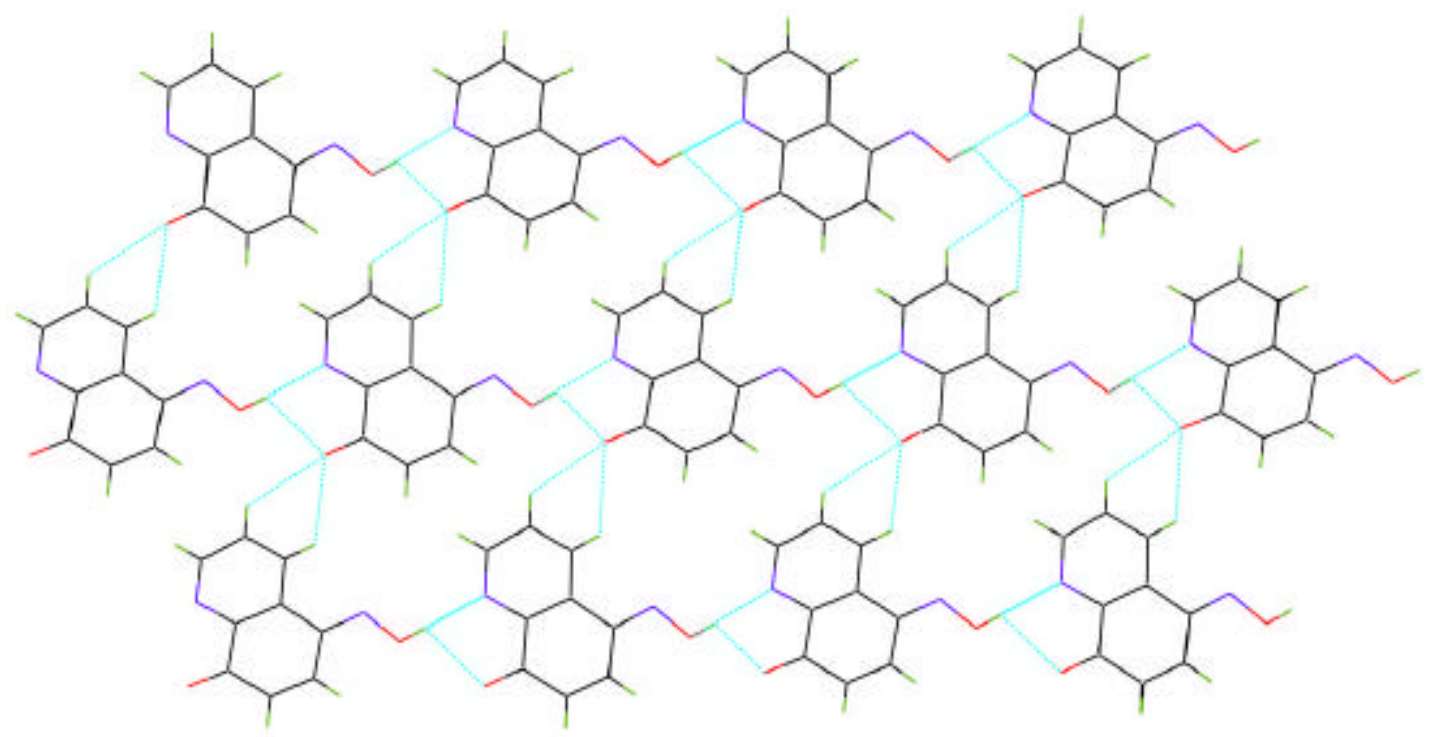

Figura 2.5: Quinolinas formando um arranjo bidimensional. 
Arranjos tridimensionais também são encontrados com enorme freqüência em arranjos supramoleculares. Estes arranjos apresentam uma grande ocorrência de redes interpenetrantes, com propriedades magnéticas, óticas e catalíticas, (Batten e Robson, 1998), figura 2.6.

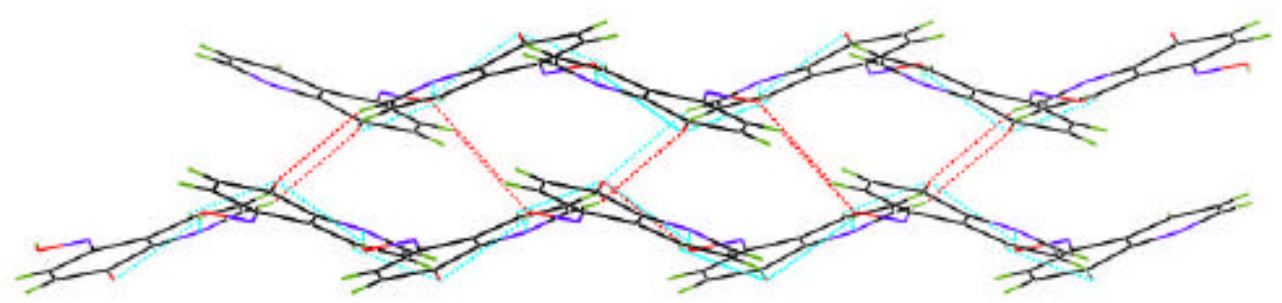

Figura 2.6: Quinolinas formando um arranjo tridimensional. 


\section{Arranjos Supramoleculares em Compostos de $\mathrm{TIMe}_{2}^{+}$}

\subsection{Introdução}

A determinação de estruturas tridimensionais de quelatos com metais pesados e de alguns potencialmente úteis agentes quelantes é uma ferramenta muito importante no estudo de complexos que poderão agir como antídotos na intoxicação por ingestão de metais pesados. Um conhecimento detalhado destes complexos é exigido para auxiliar na modelagem de estruturas moleculares e na determinação de procedimentos que sejam mais efetivos na neutralização dos processos desenvolvidos por indivíduos com intoxicação crônica por metais pesados. Este trabalho é resultado do interesse deste grupo e outros laboratórios, no estudo dos arranjos supramoleculares de complexos que possuem, entre outros, tálio como metal pesado (Casas et al., 1994; Haiduc et al., 1995; Haiduc, 1997; Haiduc \& Edelmann, 1999; Casas et al., 2002).

Recentemente, tem havido uma reativação do interesse no Tálio na forma aquosa e geoquímica marina. Este interesse é baseado na descoberta de variações significantes na composição de isótopos estáveis de Tálio na água do mar, sedimentos oceânicos e na elevada concentração de Tálio em muitos rios, lagos e 
lençóis freáticos. Em muitos casos, entradas antropogênicas (mineração de carvão ou combustão de carvão) aparecem sendo responsável por uma alta concentração de Tálio, mas outras têm sido atribuídas a fontes naturais (mineração de sulfito, sendo o sulfito rico em Tálio) ou uma combinação de fatores. A alta toxicidade do Tálio levou à investigação de suas emissões, particularmente porque o Tálio pode ser acumulado por algumas plantas e animais (gado bovino, suíno e outros). A toxicidade aguda e crônica do Tálio aparece sendo similar a do Mercúrio, Cádmio e Chumbo. Intoxicação está associada com desordens do sistema digestivo e nervoso assim como no metabolismo de $\mathrm{Na} / \mathrm{K}$. Sintomas comuns na ingestão do Tálio, incluem: alterações gastrintestinais, poli neuropatias, perda de cabelo e perda parcial da visão, (Rehkamper \& Nielsen, 2000).

$\mathrm{TlMe}_{2}{ }^{+}$é um dos cátions organometalicos mais estáveis conhecidos (Casas et al., 2002). Métodos analíticos sensitivos têm recentemente mostrado que esta espécie é gerada por biometilação (Schedlbauer \& Heumann, 2000). Portanto, é necessário um estudo detalhado de sua coordenação para propor estratégias de descontaminação e análise do comportamento no meio-ambiente. As estruturas tridimensionais dos compostos a serem estudados são caracterizadas (a) por várias interações secundárias intermoleculares $\mathrm{Tl}-\mathrm{S}, \mathrm{Tl}-\mathrm{N}$ e $\mathrm{Tl}-\mathrm{O}$ e (b) por uma grande quantidade de ligações de hidrogênio. Uma interpretação das relações entre as interações secundárias intramoleculares e intermoleculares e das várias ligações de hidrogênio foi proposta com base na análise dos dados obtidos cristalograficamente e dos obtidos da base de dados CSD (Allen, 1991; Kenard \& Allen, 1993a \& 1993b). Aqui serão reportados os resultados de um estudo sistemático de complexos [TIMe $2 \mathrm{~L}$, onde $\mathrm{L}=2$ mercapto-3-piridina-ácido carboxílico (I), 6 mercapto-3-piridina-metoxicarboxilato (II), 2-mercapto-3-piridina-metoxicarboxilato (III), 6-mercapto-3-piridina- 
etoxicarboxilato (IV) e 2-mercapto-3-piridina-etoxicarboxilato (V), tabela 3.1. Os ligantes (L) têm sido selecionados por manifestar diferentes modos de arranjos supramoleculares, incluindo interações secundárias intermoleculares e ligações de hidrogênio, na formação de polímeros de coordenação (Braga et al., 1995).

Tabela 3.1: Compostos estudados e seus respectivos diagramas.

\begin{tabular}{|l|l|}
\hline \multicolumn{1}{|c|}{ Composto } \\
Dimetil - tálio - 2-mercapto-3-piridina- \\
ácido carboxilico
\end{tabular}




\subsection{Base de dados CSD (Cambridge Structural Database)}

Houve uma grande discrepância nos valores encontrados na literatura no que diz respeito aos comprimentos das ligações classificadas como: interações primárias e secundárias. Devido a esse fato, resolveu-se utilizar a base de dados $C S D$ e alguns trabalhos publicados como um instrumento norteador para a definição do intervalo de comprimentos de ligações a serem utilizados neste trabalho. Estes valores são informativos e extremamente dependentes do número de ocorrências encontrados na base de dados $C S D$. Em muitas das consultas feitas à base de dados, ilustradas no decorrer do trabalho, podem ser observado com boa nitidez a ocorrência de dois picos, o que leva concluir a existência de dois intervalos para as interações. A base de dados CSD (Cambridge Structural Database) foi utilizada neste trabalho por meio do programa CONQUEST, incluído no pacote de softwares distribuído pela CCDC (Cambridge Crystallographic Data Centre). O CONQUEST foi utilizado na geração dos dados estatísticos a partir das ocorrências fornecidas pela base de dados.

Para as interações $\mathrm{Tl}-\mathrm{S}$ foram encontradas 313 ocorrências na base de dados. A partir daí, foi elaborado um histograma com a distribuição das entradas. O histograma apresentou uma distribuição que pode ser aproximada por duas curvas no formato de gaussianas, sendo que a média encontrada das interações foi de 2,928(12) ^̊ com desvio padrão de 0,218 ̊. O histograma com a distribuição está mostrado na figura 3.1. 


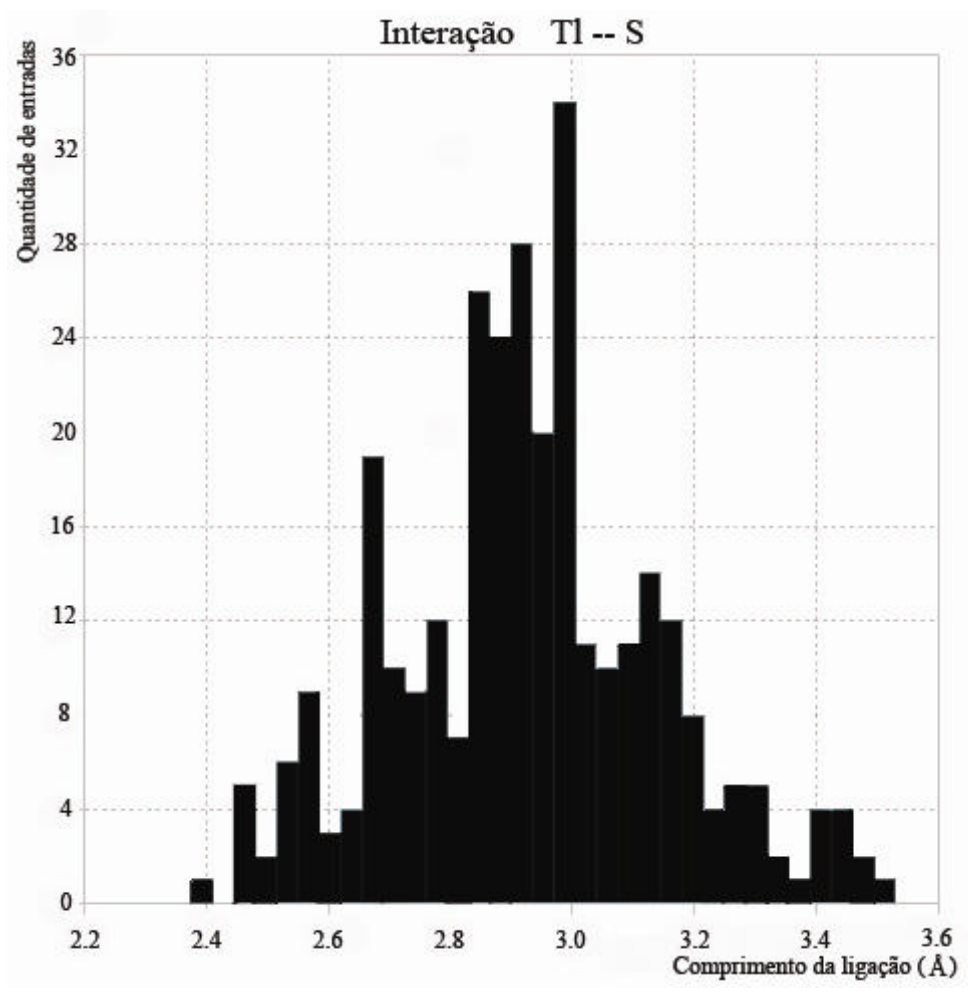

Figura 3.1: Histograma com a distribuição de ocorrências das interações $\mathrm{Tl}$ - S.

Enquanto que para interações do tipo $\mathrm{Tl}-\mathrm{O}$ com o oxigênio ligado ao carbono, foram obtidas 747 ocorrências distribuídas sobre um histograma dentro de um intervalo de 1,182 A. Este histograma apresentou um pico muito bem definido, com a média das interações sendo de 2,747(8) $\AA$ e desvio padrão de $0,225 \AA$. O histograma está mostrado na figura 3.2. 


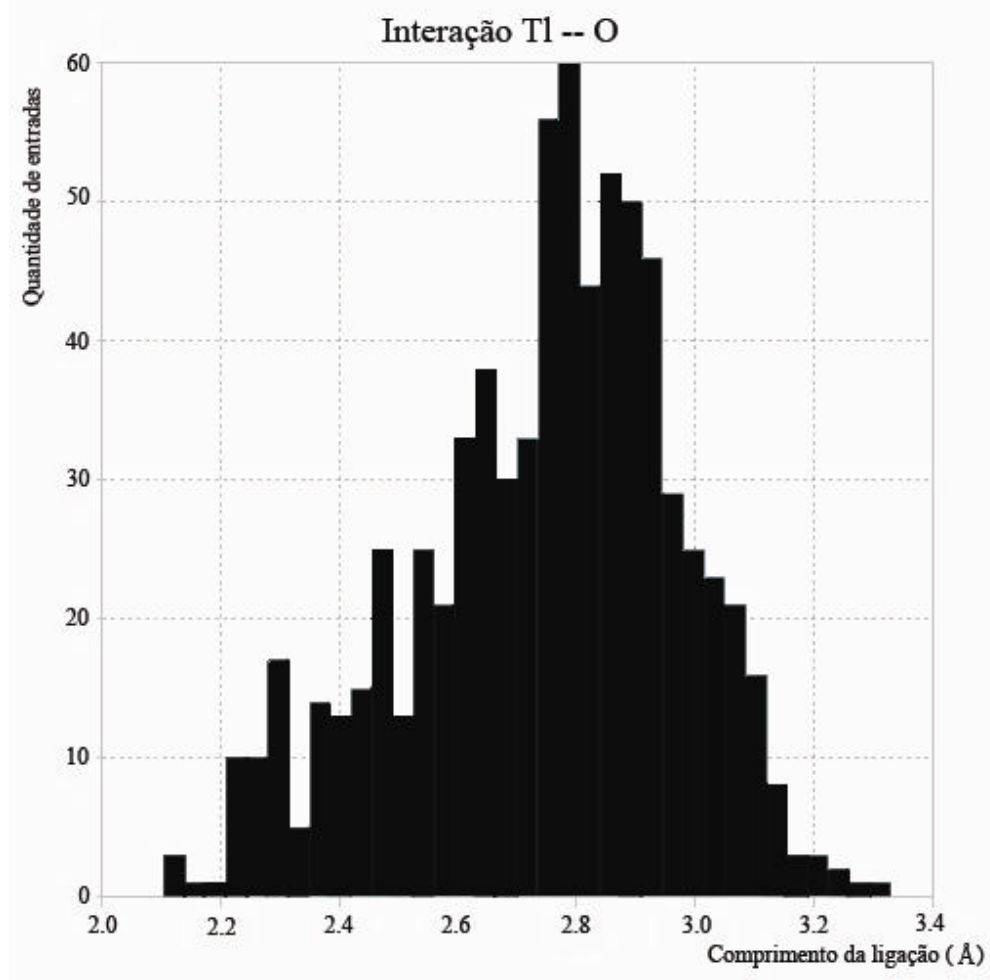

Figura 3.2: Histograma com a distribuição de ocorrências das interações $\mathrm{Tl}$ - O.

Já para a interação $\mathrm{Tl}-\mathrm{N}$ com o nitrogênio da piridina foram obtidas da base de dados $C S D$, 94 ocorrências distribuídas no histograma dentro de um intervalo de 1,003 Å. Como esta interação não apresentou muitas ocorrências à aproximação deste histograma a uma gaussiana ficou um pouco prejudicada, mas é ressaltada a região de maior incidência de interações. A média das interações encontradas é de 2,590 (19) Å e um desvio padrão de 0,182 Å. O histograma está mostrado na figura 3.3 . 


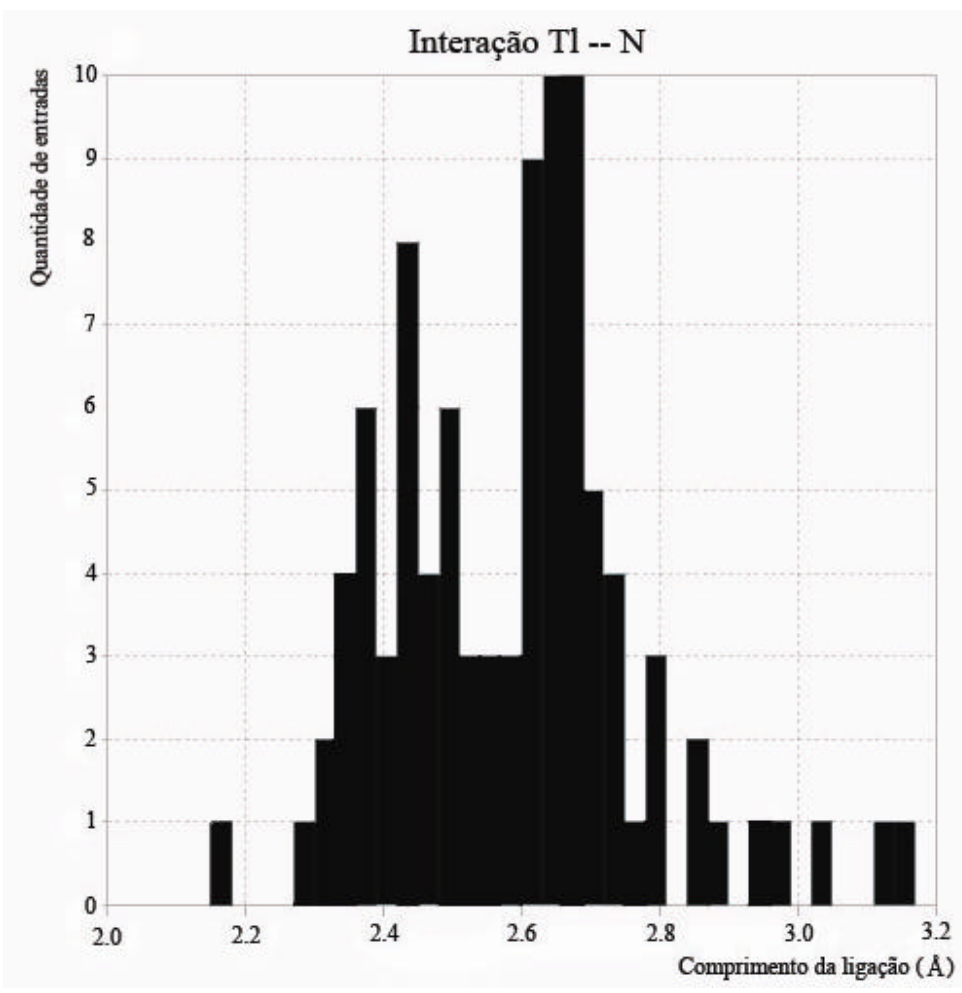

Figura 3.3: Histograma com a distribuição de ocorrências das interações $\mathrm{Tl}-\mathrm{N}$.

A ligação $S$ - C com o carbono da piridina apresentou 1674 ocorrências na base de dados $C S D$, distribuídas no histograma dentro de um intervalo 0,255 Å. Este histograma apresentou uma distribuição muito próxima de uma gaussiana, com uma média de 1,746(1) Å com um desvio padrão de 0,038 Å. O histograma está mostrado na figura 3.4. 


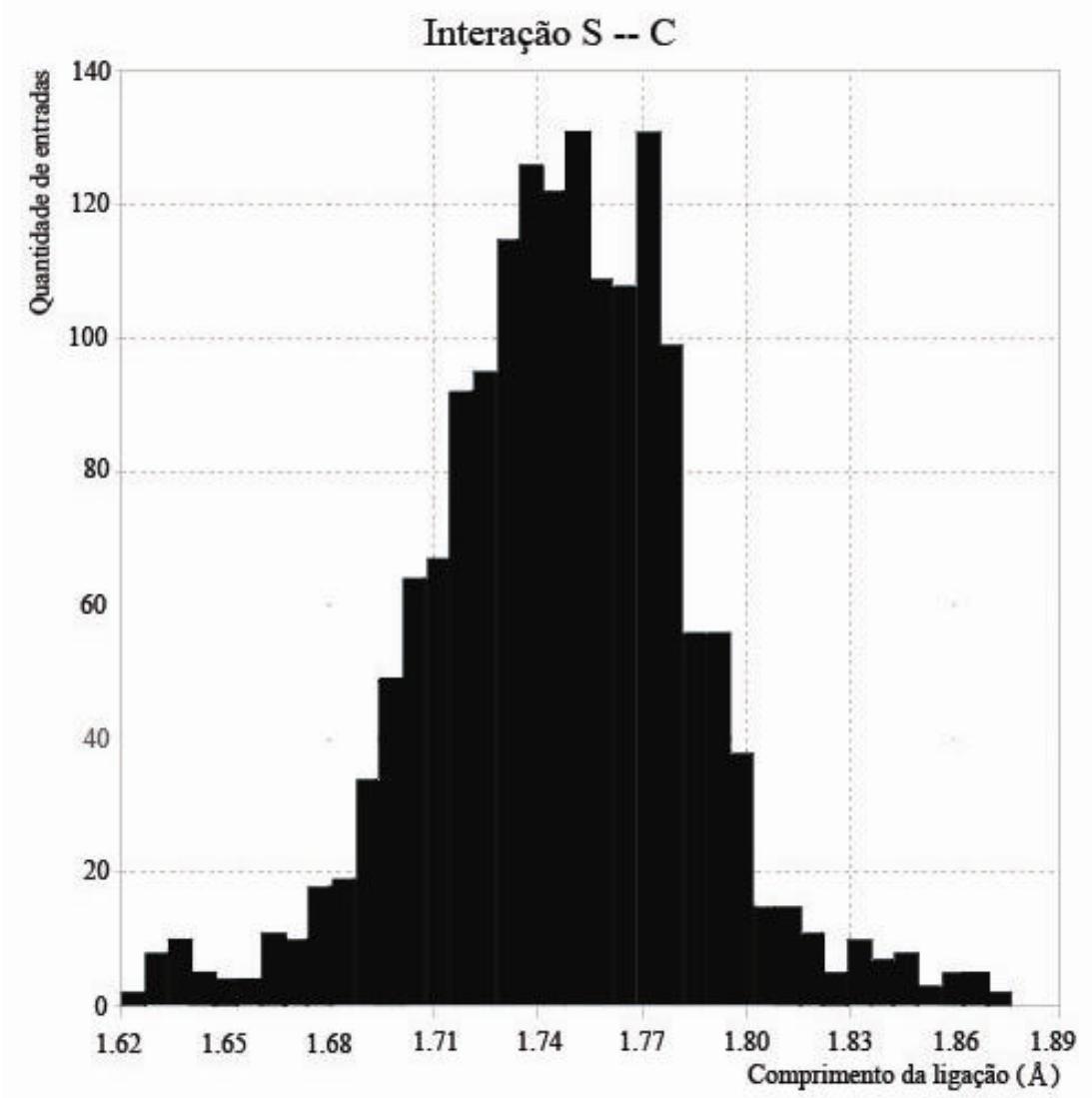

Figura 3.4: Histograma com a distribuição de ocorrências das interações $S$ - C.

Para a ligação $\mathrm{O}=\mathrm{C}$ foram encontradas 5637 ocorrências na base de dados, a partir daí, foi elaborado um histograma com a distribuição das entradas. O histograma apresentou uma distribuição que pode ser aproximada por uma curva no formato de gaussiana, sendo que a média encontrada das interações foi de 1,223(1) com desvio padrão de $0,030 \AA$ A. O histograma com a distribuição está mostrado na figura 3.5 . 


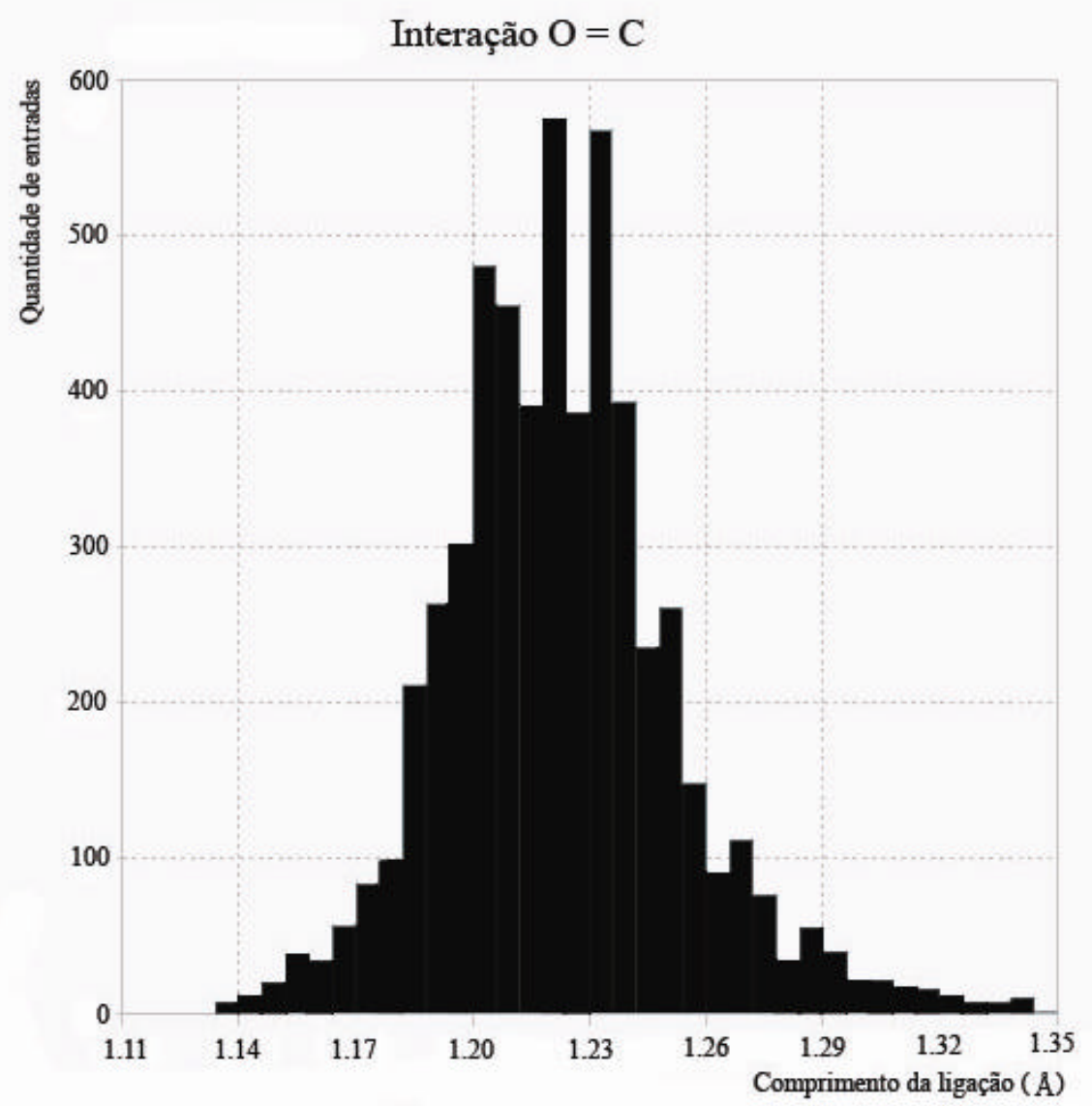

Figura 3.5: Histograma com a distribuição de ocorrências das interações $\mathrm{O}=\mathrm{C}$.

Enquanto que para a interação do tipo $\mathrm{N}-\mathrm{C}$ delocalizada na piridina, foram obtidas 1674 ocorrências distribuídas sobre um histograma dentro de um intervalo de 0,237 Å. Este histograma apresentou um pico muito bem definido, com a média das interações sendo de 1,352(1) $\AA$ e desvio padrão de 0,029 A. O histograma está mostrado na figura 3.6. 


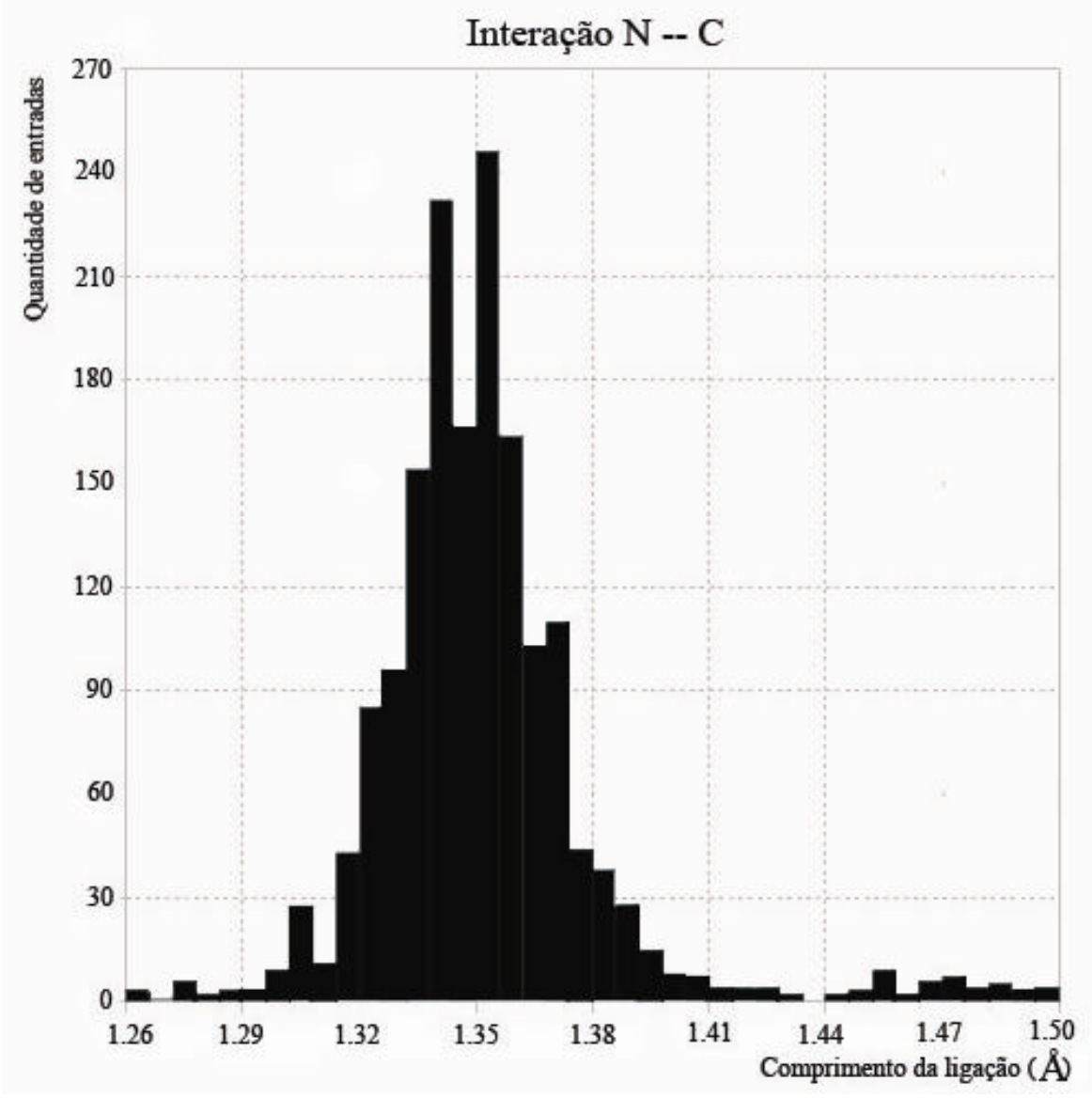

Figura 3.6: Histograma com a distribuição de ocorrências das interações $\mathrm{N}-\mathrm{C}$.

\subsection{Resultados}

\subsubsection{DimetilTálio 2-mercapto-3-piridina -ácido carboxílico ( I )}

A figura 3.7 mostra um diagrama tipo ORTEP (Farrugia, 1997) da estrutura cristalográfica do composto I, com os nomes dos átomos. O complexo forma um dímero em que cada átomo metálico está coordenado ao carbono de cada um dos dois grupos metil em trans, dois enxofres $[\mathrm{S}(\mathrm{x}, \mathrm{y}, \mathrm{z})$ e $\mathrm{S}(-\mathrm{x},-\mathrm{y},-\mathrm{z})]$ do mercapto e dois 
oxigênios $[\mathrm{O} 1(\mathrm{x}, \mathrm{y}, \mathrm{z})$ e $\mathrm{O} 1(\mathrm{x}, 1 / 2-\mathrm{y}, 1-\mathrm{z})]$ do ácido carboxílico. $\mathrm{O}$ átomo de tálio está com uma coordenação hexaédrica do tipo bipiramidal de base quadrada distorcida $\left[\mathrm{TlC}_{2} \mathrm{O}_{2} \mathrm{~S}_{2}\right.$ ]. Portanto, cada ligante age como uma ponte bidentada entre os dois átomos de tálio adjacentes de lados opostos do arranjo supramolecular, sendo que o oxigênio interage com o átomo de tálio na posição $(x, 1 / 2-y, 1-z)$ e o enxofre com o tálio em $(-\mathrm{x},-\mathrm{y},-\mathrm{z})$.

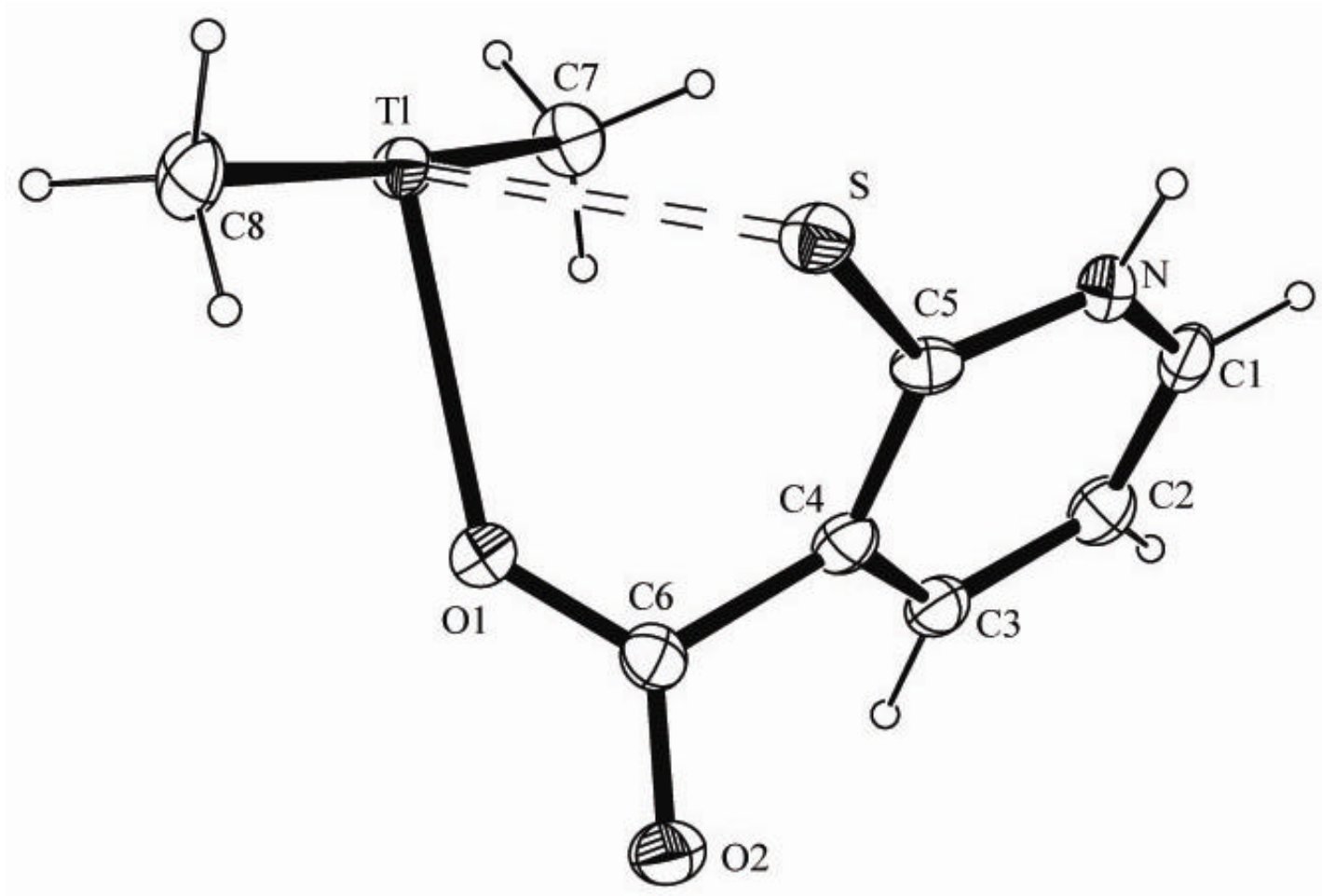

Figura 3.7: Diagrama tipo ORTEP da unidade assimétrica do composto I, incluindo os nomes dos átomos, sem a molécula de água.

As pontes de enxofre são assimétricas, com uma interação $\mathrm{Tl}$ - S maior que a outra $\left[\mathrm{Tl}-\mathrm{S}=3,087(2) \AA\right.$; $\left.\mathrm{Tl}-\mathrm{S}^{i}=3,220(4) \AA\right]$ mas ambos dentro da distribuição estatística encontrada na base de dados CSD, figura 3.1. A distância mais curta está dentro do intervalo $(2,832 \AA-3,141 \AA$ ) encontrado em outros complexos de tálio 
tendo enxofre como ponte (Kimblin et al., 2000 ${ }^{\mathrm{a}, \mathrm{b}}$ e Bosch et al., 1996). Já as distâncias $\mathrm{Tl}$ - O [2,522(3) ̊ e 2,589(3) $\left.\AA^{i i}\right]$ são significantemente menores que a média encontrada na base de dados CSD, figura 3.2. Presumivelmente o alargamento da ligação O1 - C6 [1,269(5) Å] é compensado por este fortalecimento da interação Tl - O, figura 3.5. As ligações e ângulos de ligação de interesse estão relacionados na tabela 3.2 .

O composto I apresenta uma arquitetura supramolecular baseada em interações secundárias $\mathrm{Tl}-\mathrm{S}$ e fortes interações $\mathrm{Tl}-\mathrm{S}$ e Tl - O. Ainda há ligações de hidrogênio do tipo $\mathrm{O}-\mathrm{H} \ldots \mathrm{O}$ e $\mathrm{N}-\mathrm{H} \ldots \mathrm{O}$ que são também responsáveis pelo arranjo tridimensional. Desta forma, as combinações destas interações moleculares constroem um rígido arranjo supramolecular.

As moléculas estão conectadas em arranjos unidimensionais, via interações secundárias do tipo "double chain”, na direção do eixo $b$, [010]. Com a forte presença de ligações de hidrogênio a arquitetura supramolecular toma a forma tridimensional.

As interações $\mathrm{Tl}$ - S são responsáveis por um arranjo paralelo ao longo da direção [010], gerado pelo eixo de rotação $2 \mathrm{em}(\mathrm{x}, 1 / 4,0)$. O centro de inversão na origem gera um dímero, que através do elemento de simetria citado anteriormente, prolonga-se em uma cadeia unidimensional por todo cristal. O íon metálico em (x, y, $\mathrm{z}$ ) interage com o átomo de $\mathrm{O}$ em $(-\mathrm{x},-\mathrm{y},-\mathrm{z})$ formando um dímero junto com o átomo de S em (x, 1/2-y, - z), figura 3.8. Os íons metálicos de Tl em (-x, -y, -z) e (x, 1/2-y, -z) interagem com os átomos de $\mathrm{S}$ em $(\mathrm{x},-1 / 2+\mathrm{y}, \mathrm{z})$ e com o átomo de $\mathrm{O}$ em (x, $1 / 2+y, z)$, deste modo formando uma cadeia infinita de dímeros unidos por interações secundárias, $\mathrm{Tl}-\mathrm{S}$, ao longo da direção do eixo $b$, figura 3.9. 


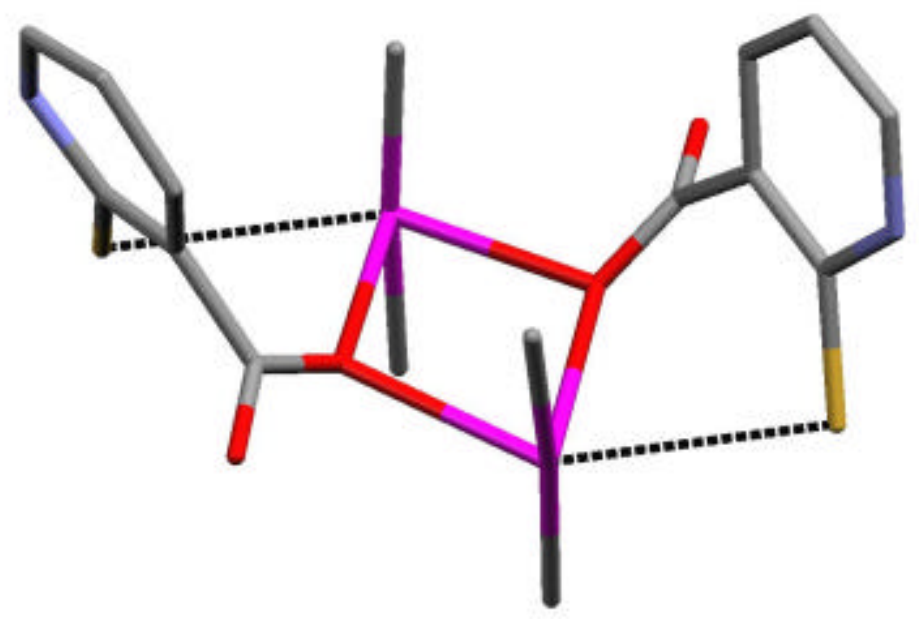

Figura 3.8: Dímero formado pela interação $\mathrm{Tl}-\mathrm{O}$ e $\mathrm{Tl}-\mathrm{S}$.

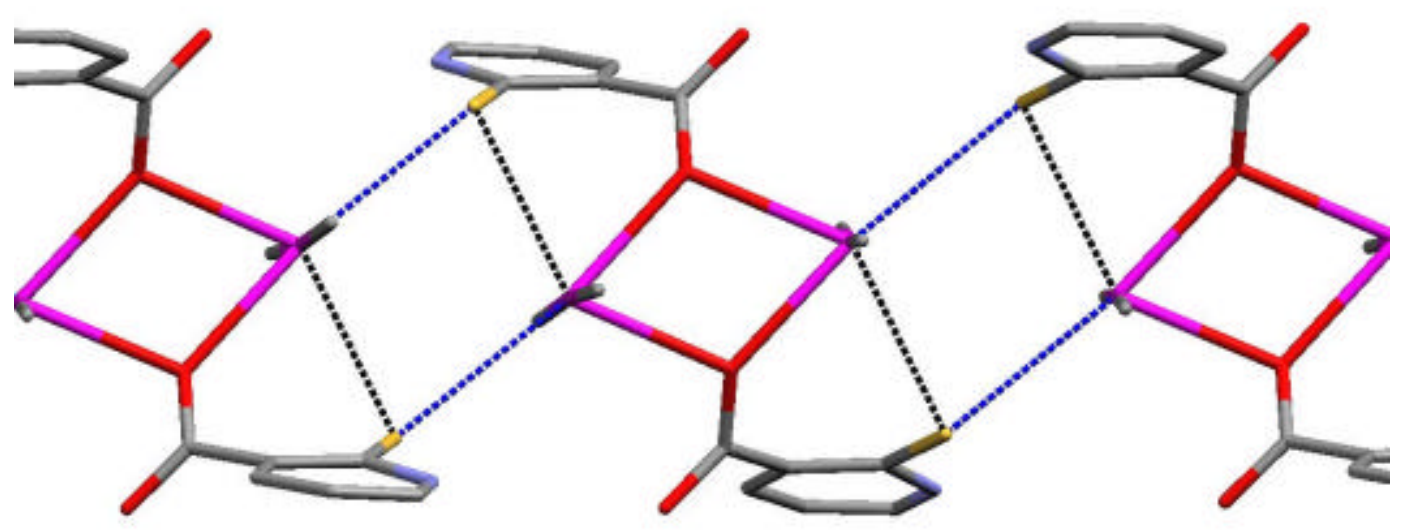

Figura 3.9: Arranjo ao longo da direção [010], promovido pelas interações $\mathrm{Tl}$ - S (em preto

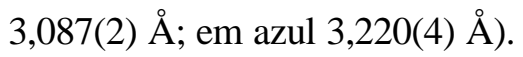


Tabela 3.2: Distâncias e ângulos de ligação para o composto I.

\begin{tabular}{|c|c|c|c|c|}
\hline & Distâncias $(\AA)$ & Ângulos $\left(^{\circ}\right)$ & $\begin{array}{l}\text { Soma dos raios } \\
\text { de van der } \\
\text { Waals }(\AA) . \\
\text { (Bondi, 1964 e } \\
\text { Batsanov, 1999.) }\end{array}$ & $\begin{array}{l}\text { Soma dos raios } \\
\text { covalentes }(\AA) \text {. } \\
\text { (Glidewell 1976.) }\end{array}$ \\
\hline $\mathrm{Tl}-\mathrm{S}$ & $3,087(2)$ & $102,2(3)\left(\mathrm{S}-\mathrm{Tl}-\mathrm{S}^{i}\right)$ & 4,15 & 2,47 \\
\hline $\mathrm{Tl}-\mathrm{S}^{i}$ & $3,220(4)$ & $117,9(4)\left(\mathrm{O} 1^{i i}-\mathrm{Tl}^{\prime} \mathrm{S}^{i}\right)$ & 4,15 & 2,47 \\
\hline $\mathrm{Tl}-\mathrm{O}$ & $2,522(3)$ & $69,55(7)(\mathrm{O} 1-\mathrm{Tl}-\mathrm{S})$ & 3,87 & 2,195 \\
\hline $\mathrm{Tl}-\mathrm{O}^{i i}$ & $2,589(3)$ & $69,72(12)\left(\mathrm{O} 1^{i}-\mathrm{Tl}-\mathrm{O} 1\right)$ & 3,87 & 2,176 \\
\hline $\mathrm{S}-\mathrm{C} 5$ & $1,714(5)$ & 91,87(14) (Tl-S-C5) & 3,50 & 1,787 \\
\hline $\mathrm{C} 5-\mathrm{N}$ & $1,369(5)$ & $118,2(3)(\mathrm{S}-\mathrm{C} 5-\mathrm{N})$ & 3,25 & 1,493 \\
\hline $\mathrm{C} 4-\mathrm{C} 5$ & $1,425(6)$ & $\begin{array}{c}125,9(3)(\mathrm{S}-\mathrm{C} 5-\mathrm{C} 4) \\
121,1(3)(\mathrm{C} 5-\mathrm{C} 4-\mathrm{C} 6)\end{array}$ & 3,25 & 1,493 \\
\hline $\mathrm{O} 1-\mathrm{C} 6$ & $1,269(5)$ & $\begin{array}{ll}132,7(3) & (\mathrm{Tl}-\mathrm{O} 1-\mathrm{C} 6) \\
118,7(4) & (\mathrm{O} 1-\mathrm{C} 6-\mathrm{C} 4)\end{array}$ & 3,22 & 1,512 \\
\hline
\end{tabular}

$i(-\mathrm{x},-\mathrm{y},-\mathrm{z}) ; i i(\mathrm{x}, 1 / 2-\mathrm{y}, 1-\mathrm{z})$

Além das interações secundárias existe a presença de fortes ligações de hidrogênio (Bilton et al., 2000) do tipo O-H...O e N-H...O. As ligações de hidrogênio existentes neste composto funcionam como um forte agente estabilizador e direcional do arranjo. 


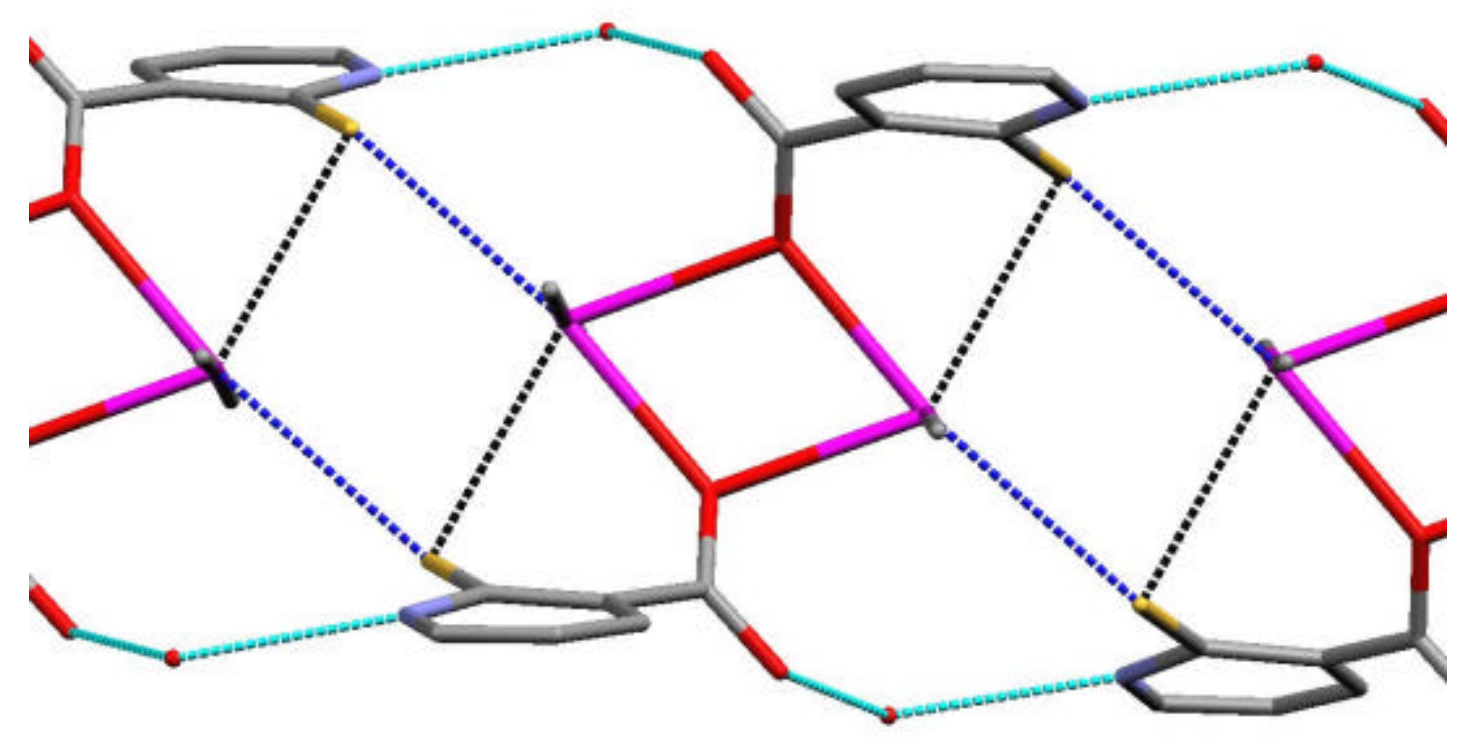

Figura 3.10: Arranjo na direção [010] com a presença das ligações de hidrogênio, O1WH11W...O2 e N-H1N...O1W (azul ciano).

As ligações de hidrogênio neste composto fazem a conexão entre os arranjos nas direções [001] e [010] com os vizinhos mais próximos na mesma direção. Esta interação é promovida por uma molécula de água que se encontra entres as espécies, por via de O1W-H12W...O2, O1W-H11W...O2 e N-H1N...O1W, tabela 3.3. O átomo $\mathrm{O} 1 \mathrm{~W}$ em $(\mathrm{x}, \mathrm{y}, \mathrm{z})$ age como um doador da ligação de hidrogênio ao átomo $\mathrm{O} 2$ nas posições $(\mathrm{x}, \mathrm{y}, \mathrm{z})$ e $(1 / 2+\mathrm{x}, \mathrm{y}, 1 / 2-\mathrm{z})$. Enquanto que o átomo $\mathrm{N}$ em $(1 / 2-\mathrm{x}, 1 / 2+\mathrm{y}$, 1/2-z) age como doador ao $\mathrm{O} 1 \mathrm{~W}(\mathrm{x}, \mathrm{y}, \mathrm{z})$ e assim sucessivamente. A combinação das ligações de hidrogênio O1W-H12W...O2 e O1W-H11W...O2 produz um arranjo ao longo do eixo $c$, gerado pelo plano de deslizamento $a$ em (x, y, 1/4). Já a combinação das ligações $\mathrm{O} 1 \mathrm{~W}-\mathrm{H} 12 \mathrm{~W} . . . \mathrm{O} 2$ e N-H1N...O1W produz um arranjo paralelo ao plano $b c$, gerado pelo eixo de roto-translação $2{ }_{1}$ em $(1 / 4, \mathrm{y}, 1 / 4)$. A combinação das ligações $\mathrm{N}-\mathrm{H} 1 \mathrm{~N} . . . \mathrm{O} 1 \mathrm{~W}$ e $\mathrm{O} 1 \mathrm{~W}-\mathrm{H} 11 \mathrm{~W} . . . \mathrm{O} 2$ produz um arranjo ao longo do eixo $b$, 
figura 3.10, gerado pelo eixo de roto-translação $2_{1}$ em $(1 / 4, y, 1 / 4)$ e pelo plano de deslizamento $a$ em (x, y, 1/4). Estas últimas ligações de hidrogênio em conjunto com as interações secundárias, ajudam a estabilizar o arranjo gerando o arranjo tridimens ional, figura 3.11.

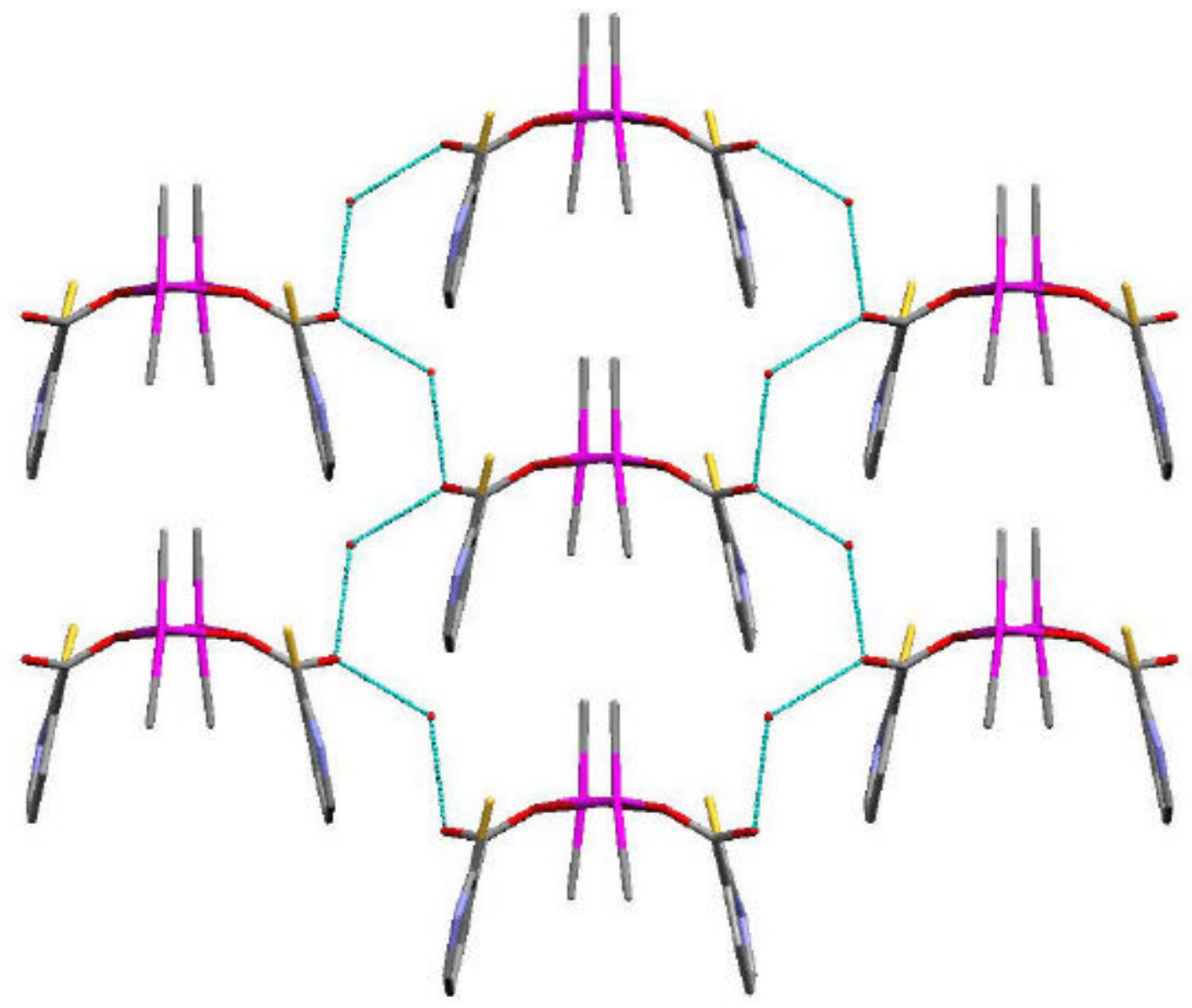

Figura 3.11: Arranjo tridimensional do composto I.

Tabela 3.3: Distâncias e ângulos para as ligações de hidrogênio do composto I.

\begin{tabular}{cccc}
\hline $\mathrm{D}-\mathrm{H} \ldots \mathrm{A}$ & $\mathrm{H} \ldots \mathrm{A}$ & $\mathrm{D} \ldots \mathrm{A}$ & $\mathrm{D}-\mathrm{H} \ldots \mathrm{A}$ \\
\hline $\mathrm{O} 1 \mathrm{~W}-\mathrm{H} 12 \mathrm{~W} \ldots \mathrm{O} 2$ & $1,848 \AA$ & $2,726(4) \AA$ & $156^{\mathrm{o}}$ \\
\hline $\mathrm{O} 1 \mathrm{~W}-\mathrm{H} 11 \mathrm{~W} \ldots \mathrm{O} 2$ & $2,152 \AA$ & $2,805(5) \AA$ & $171^{\mathrm{o}}$ \\
\hline $\mathrm{N}-\mathrm{H} 1 \mathrm{~N} \ldots \mathrm{O} 1 \mathrm{~W}$ & $1,855 \AA$ & $2,720(4) \AA$ & $168^{\circ}$ \\
\hline
\end{tabular}




\subsubsection{DimetilTálio 6-mercapto-3-piridina-metoxicarboxilato ( II )}

A figura 3.12 mostra um diagrama tipo ORTEP da estrutura do composto II, com os nomes dos átomos. O composto é um monômero em que cada íon metálico está coordenado com os carbonos dos grupos metil em trans, com dois enxofres nas posições $(\mathrm{x}, \mathrm{y}, \mathrm{z})$ e $(1 / 2-\mathrm{x}, 1 / 2+\mathrm{y}, 1 / 2-\mathrm{z})$ do grupo mercapto, com o oxigênio do ácido carboxílico $[\mathrm{O} 1(\mathrm{x}, \mathrm{y}, \mathrm{z})]$ e um nitrogênio da piridina $[\mathrm{N}(1 / 2-\mathrm{x}, 1 / 2+\mathrm{y}, 1 / 2-\mathrm{z})] . \mathrm{O}$ átomo de tálio está com uma coordenação hexaédrica do tipo bipiramidal de base quadrada distorcida $\left[\mathrm{TlC}_{2} \mathrm{~S}_{2} \mathrm{ON}\right]$. Portanto, cada ligante age como uma ponte tridentada entre os dois átomos de tálio adjacentes do arranjo supramolecular.

As distâncias $\mathrm{Tl}-\mathrm{S}$ apresentam valores bem diferentes $[\mathrm{Tl}-\mathrm{S}=2,782(2) \AA$; $\mathrm{Tl}-\mathrm{S}^{i}=3,336(6) \AA$ com uma ligação bem mais curta do que a outra. Esta primeira ligação é menor que a média encontrada no CSD, 2,928 Å, sendo que as duas estão dentro da distribuição estatística, figura 3.1. Já a distância Tl - O [2,972(4) Å] é mais longa do que a média encontrada, $2,747 \AA$, na base de dados $C S D$, figura 3.2 , o que possivelmente gerou o encurtamento da ligação $\mathrm{O}=\mathrm{C}[1,215(10) \AA$ A $]$. A interação Tl

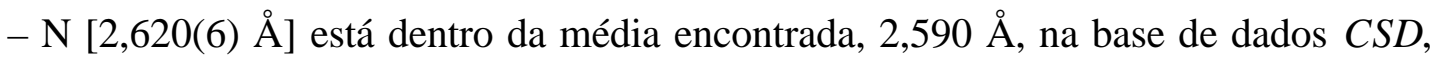
figura 3.3. Os comprimentos das ligações e ângulos de principal interesse estão na tabela 3.4. 


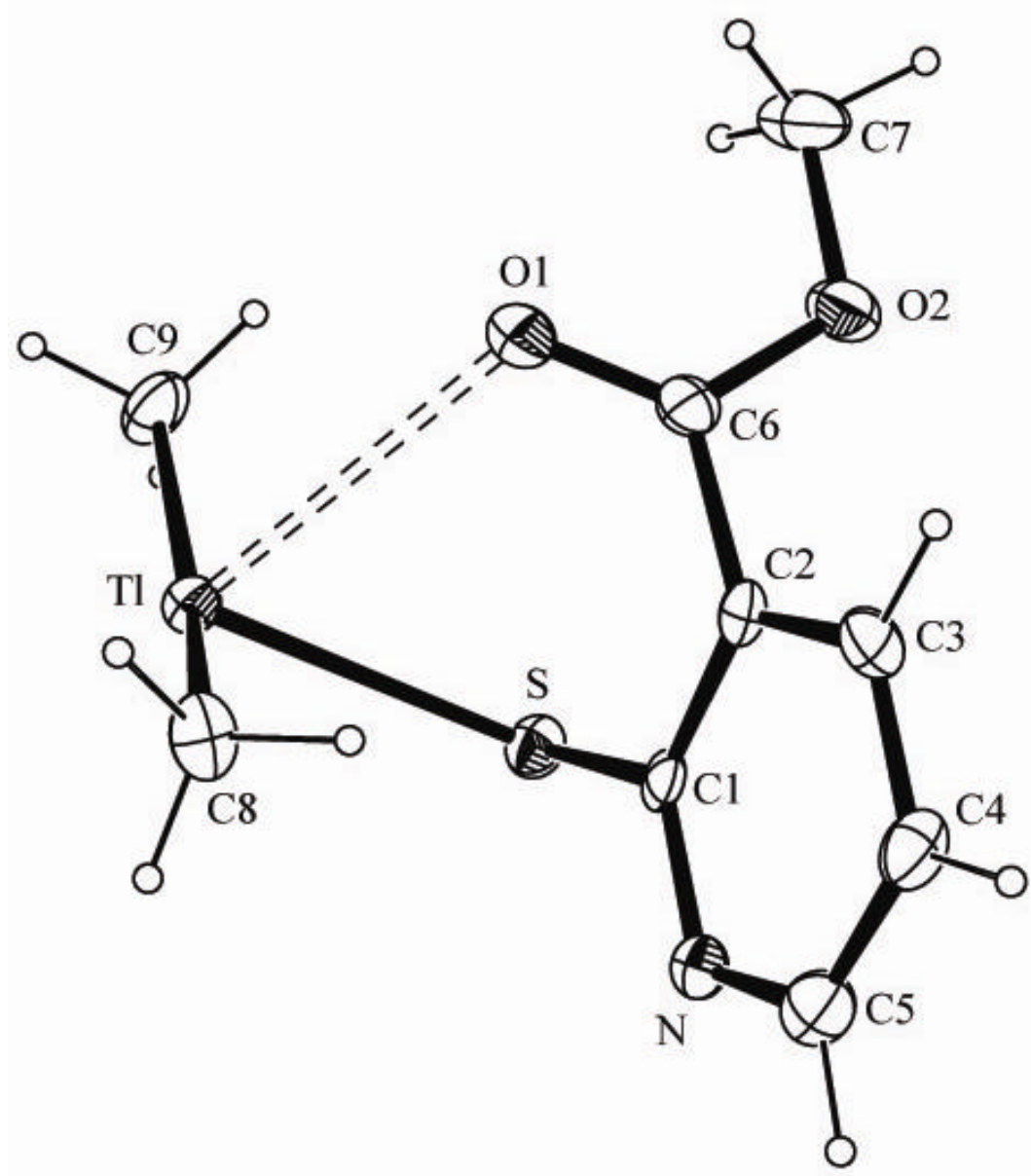

Figura 3.12: Diagrama tipo ORTEP da unidade assimétrica do composto II, incluindo os nomes dos átomos.

O arranjo supramolecular do complexo (II), figura 3.13, é dominado por interações secundárias intermoleculares do tipo $\mathrm{Tl}-\mathrm{S}$ e $\mathrm{Tl}-\mathrm{O}$ que orienta a formação das cadeias. $\mathrm{O}$ íon $\mathrm{Tl}$ da molécula na posição $(\mathrm{x}, \mathrm{y}, \mathrm{z})$ interage com o átomo $\mathrm{O}$ na mesma molécula e ao átomo de $\mathrm{S}$ da molécula na posição $(1 / 2-\mathrm{x}, 1 / 2+\mathrm{y}$, 1/2-z), tabela 3.4. Portanto o íon $\mathrm{Tl}$ da molécula em $(1 / 2-\mathrm{x}, 1 / 2+\mathrm{y}, 1 / 2-\mathrm{z})$ está interagindo similarmente com os átomos de $\mathrm{O}$ e $\mathrm{S}$ em $(1 / 2-\mathrm{x}, 1 / 2+\mathrm{y}, 1 / 2-\mathrm{z})$ e $(\mathrm{x}, \mathrm{y}+1$, z), respectivamente. 


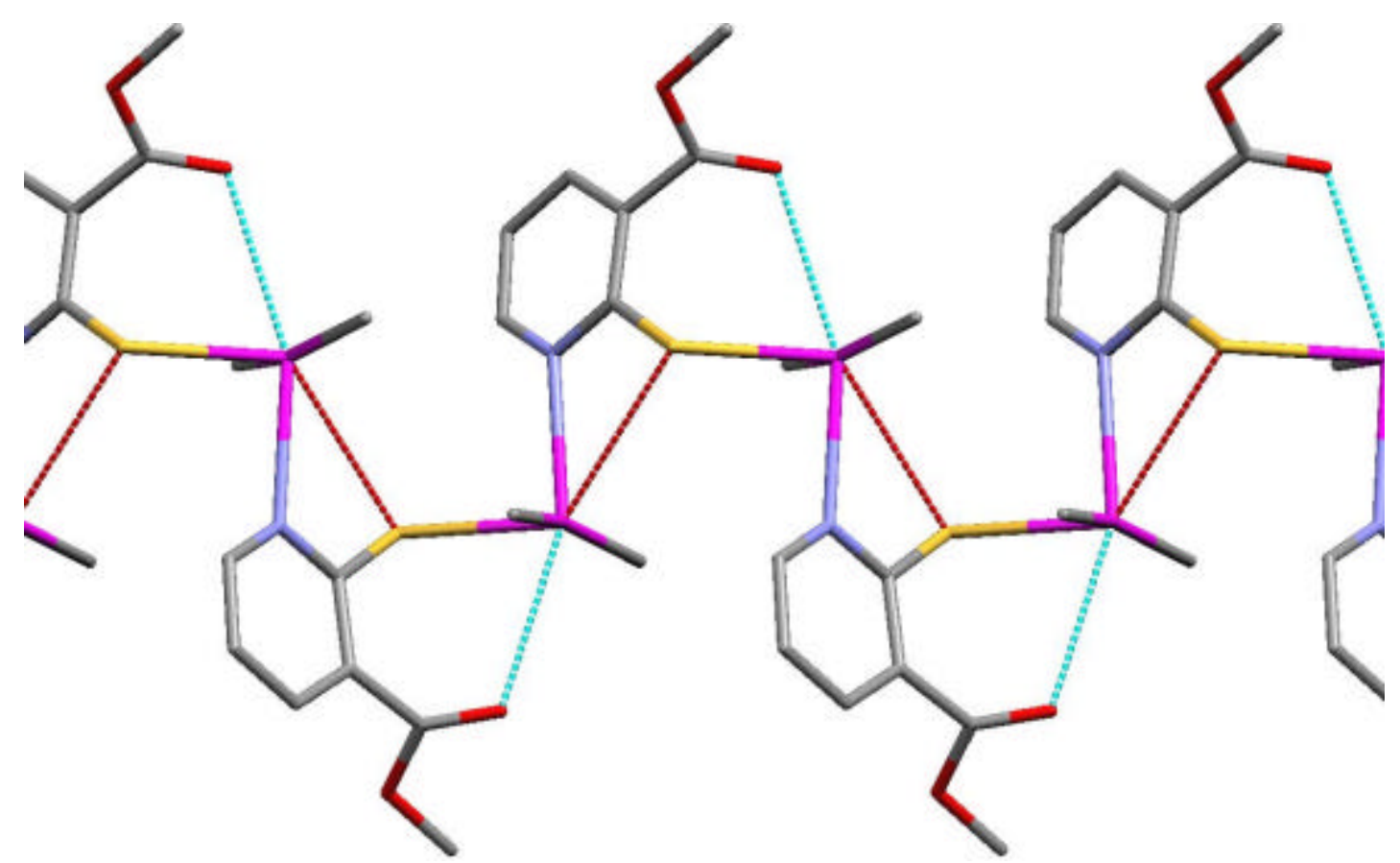

Figura 3.13: Arranjo ao longo da direção [010], sendo que as interações $\mathrm{Tl}$ - O estão em azul e $\mathrm{Tl}-\mathrm{S}$ em vermelho.

O arranjo supramolecular gerado pelas interações secundárias no composto II apresenta uma arquitetura tipo 'double-chain', na direção do eixo $b$.

As interações secundárias neste composto comportam-se como um agente estabilizador dos arranjos supramoleculares, onde existem fortes ligações $\mathrm{Tl}-\mathrm{S}$ e Tl - N que são predominantes na construção da 'double-chain' ao longo da direção [010], figura 3.13. O arranjo paralelo ao eixo $b$ é gerado pela operação de simetria do eixo de roto-translação $2{ }_{1}$ na posição $(1 / 4, y, 1 / 4)$. O íon $\mathrm{Tl}$ em $(\mathrm{x}, \mathrm{y}, \mathrm{z})$ liga-se ao átomo $\mathrm{N}$ em $(1 / 2-\mathrm{x}, 1 / 2+\mathrm{y}, 1 / 2-\mathrm{z})$ e interage com o átomo $\mathrm{S}$ da mesma molécula $(1 / 2-$ $\mathrm{x}, 1 / 2+\mathrm{y}, 1 / 2-\mathrm{z})$, enquanto liga-se ao átomo $\mathrm{S}$ em $(\mathrm{x}, \mathrm{y}, \mathrm{z})$ e interage com o oxigênio em $(\mathrm{x}, \mathrm{y}, \mathrm{z})$. Desta forma as interações subseqüentes vão acontecendo até a formação da cadeia na estrutura cristalina. 
Tabela 3.4: Distâncias e ângulos de ligação para o composto II.

\begin{tabular}{|c|c|c|c|c|}
\hline & Distâncias $(\AA)$ & Ângulos $\left(^{\circ}\right)$ & $\begin{array}{l}\text { Soma } \text { dos raios } \\
\text { de van der } \\
\text { Waals } \\
\text { (Bondi } 1964 \quad \text { e } \\
\text { Batsanov } 1999 \text { ) }\end{array}$ & $\begin{array}{l}\text { Soma dos raios } \\
\text { covalentes }(\AA) \text {. } \\
\text { (Glidewell 1976) }\end{array}$ \\
\hline $\mathrm{Tl}-\mathrm{S}$ & $2,782(2)$ & $83,20(1) \mathrm{S}-\mathrm{Tl}-\mathrm{N}^{i}$ & 4,15 & 2,47 \\
\hline $\mathrm{Tl}-\mathrm{S}^{i}$ & $3,336(6)$ & & 4,15 & 2,47 \\
\hline $\mathrm{Tl}-\mathrm{O}$ & $2,972(4)$ & $70,55(2) \mathrm{S}-\mathrm{Tl}-\mathrm{O}$ & 3,87 & 2,195 \\
\hline $\mathrm{Tl}-\mathrm{N}^{i}$ & $2,620(6)$ & $51,40(1) S^{i}-\mathrm{Tl}-\mathrm{N}^{i}$ & 3,90 & 2,176 \\
\hline $\mathrm{S}-\mathrm{C} 1$ & $1,743(7)$ & $97,02(20) \mathrm{Tl}-\mathrm{S}-\mathrm{C} 1$ & 3,50 & 1,787 \\
\hline $\mathrm{N}-\mathrm{C} 1$ & $1,335(9)$ & $112,8(4) \mathrm{Tl}-\mathrm{N}^{i}-\mathrm{C}^{i}$ & 3,25 & 1,493 \\
\hline $\mathrm{N}-\mathrm{C} 5$ & $1,355(10)$ & $126,3(5) \mathrm{Tl}-\mathrm{N}^{i}-\mathrm{C}^{i}$ & 3,25 & 1,493 \\
\hline $\mathrm{O} 1-\mathrm{C} 6$ & $1,215(10)$ & $117,6(3) \mathrm{Tl}-\mathrm{O} 1-\mathrm{C} 6$ & 3,22 & 1,512 \\
\hline
\end{tabular}

A ligação de hidrogênio deste composto funciona como o elo de ligação de dois arranjos vizinhos e paralelos ao eixo [010], sendo uma ligação fraca do tipo $\mathrm{C}-\mathrm{H}$...O, tabela 3.5. O átomo $\mathrm{C} 7$ da metila no fim da molécula em $(\mathrm{x}, \mathrm{y}, \mathrm{z})$ age como doador da ligação de hidrogênio para o átomo $\mathrm{O} 2$ em $(-\mathrm{x},-\mathrm{y},-\mathrm{z})$ por meio do centro de inversão em $(0,0,0)$, de modo que gera um arranjo bidimensional em conjunto com as interações secundárias no plano (101), figura 3.14. 


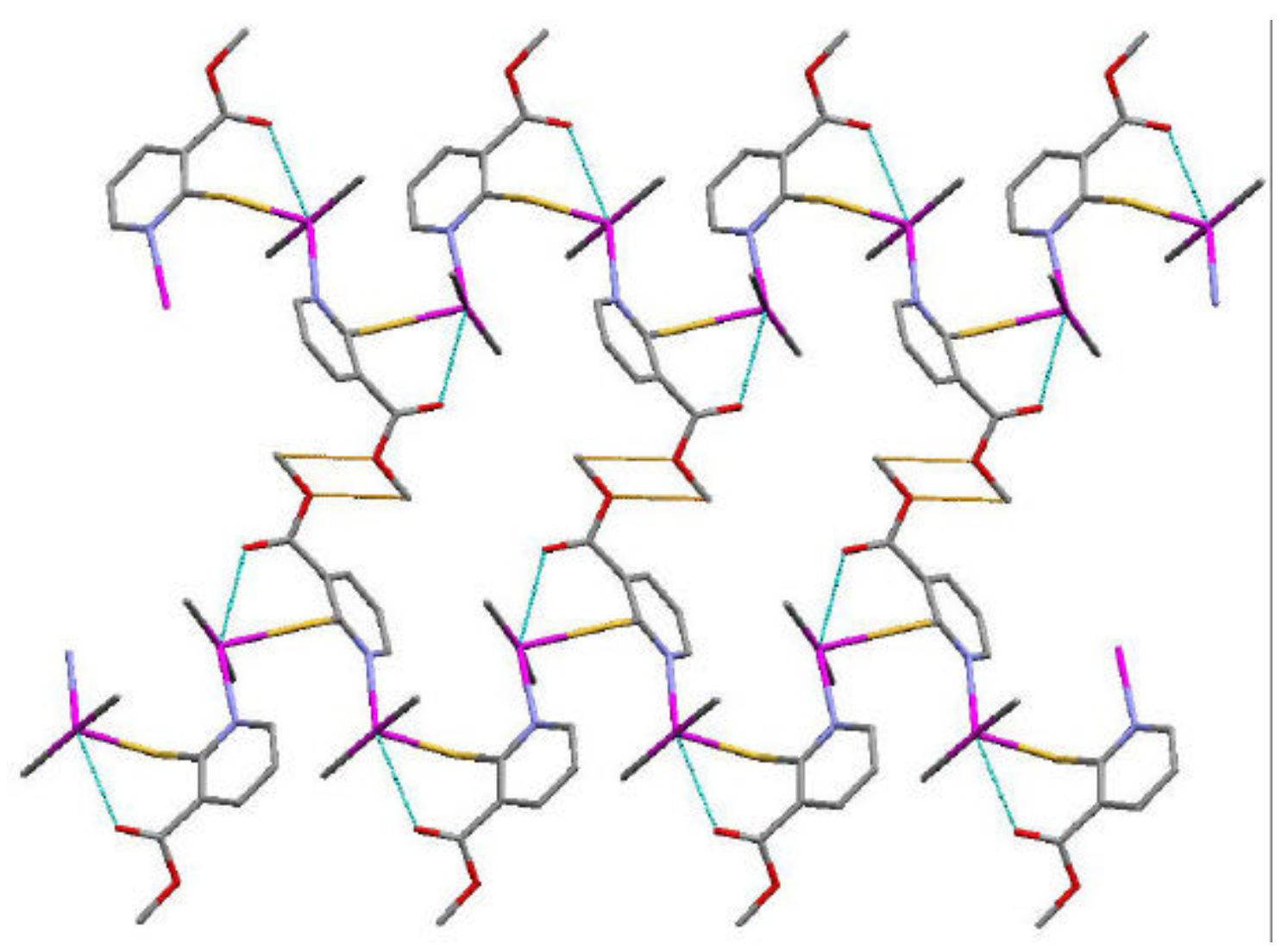

Figura 3.14: Arranjo bidimensional no plano (101), sendo que as ligações de hidrogênio (C7 - H7B ... O2) estão em amarelo.

Tabela 3.5: Distâncias e ângulos para a ligação de hidrogênio do composto II.

\begin{tabular}{cccc}
\hline $\mathrm{D}-\mathrm{H} \ldots \mathrm{A}$ & $\mathrm{H} \ldots \mathrm{A}$ & $\mathrm{D} \ldots \mathrm{A}$ & $\mathrm{D}-\mathrm{H} \ldots \mathrm{A}$ \\
\hline $\mathrm{C} 7-\mathrm{H} 7 \mathrm{~B} \ldots \mathrm{O} 2$ & $2,290(6) \AA$ & $3,194(9) \AA$ & $153^{\circ}$
\end{tabular}

\subsubsection{DimetilTálio 2-mercapto-3-piridina -metoxicarboxilato ( III )}

A figura 3.15 mostra um diagrama tipo ORTEP da estrutura cristalográfica do composto III, com os nomes dos átomos. O composto é um monômero em que cada íon metálico está coordenado com os carbonos dos grupos metil em trans, dois enxofres $[S(x, y, z)$ e $S(3 / 4+y, 3 / 4-x,-1 / 4+z)]$ do grupo mercapto, um oxigênio 
[O2(1/4-y, 1/4+x, 5/4-z)] do ácido carboxílico e um nitrogênio $[\mathrm{N}(\mathrm{x}, \mathrm{y}, \mathrm{z})] \mathrm{da}$ piridina. O íon tálio possui uma coordenação hexaédrica do tipo bipiramidal de base quadrada distorcida $\left[\mathrm{TlC}_{2} \mathrm{~S}_{2} \mathrm{ON}\right]$. Portanto, cada ligante age como uma ponte tridentada entre os dois átomos de tálio adjacentes do arranjo supramolecular.

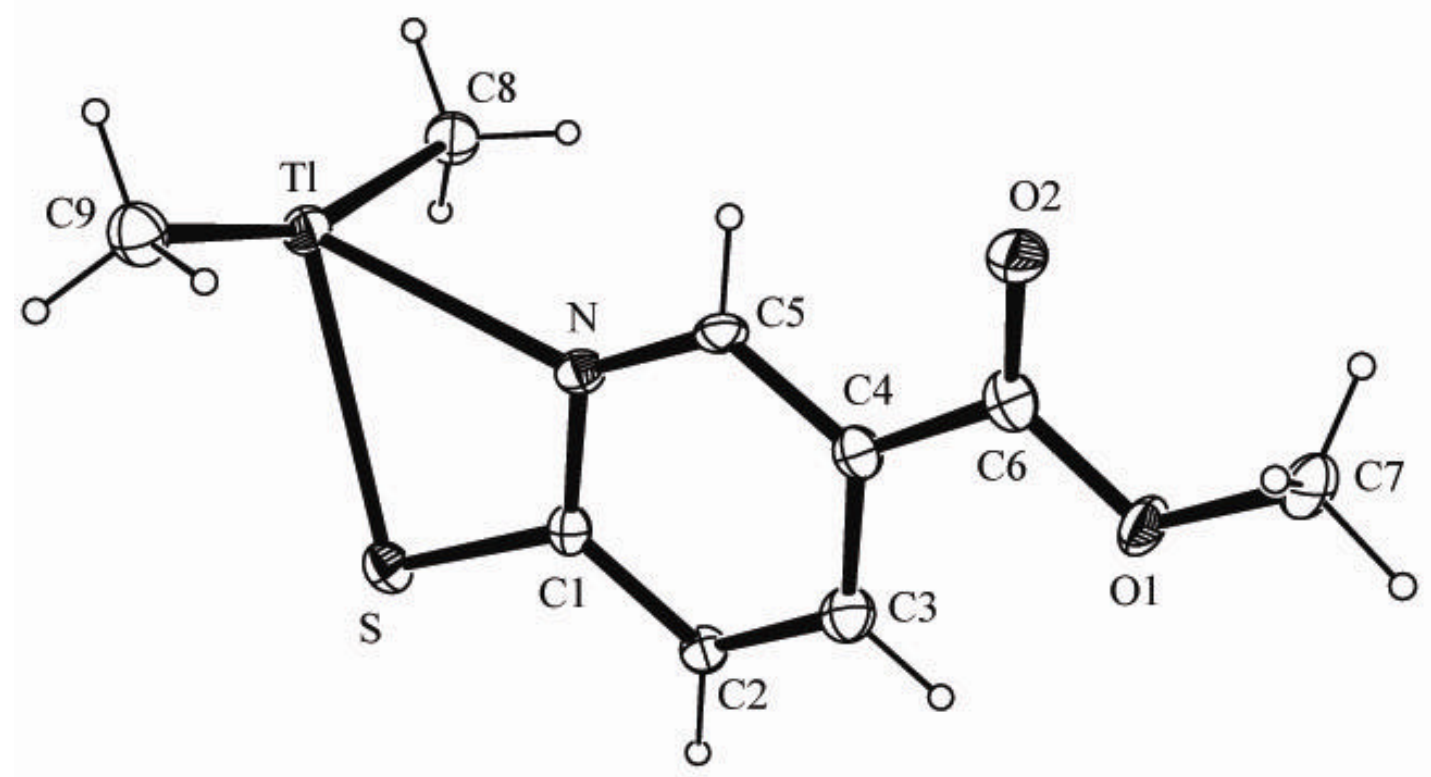

Figura 3.15: Diagrama tipo ORTEP da unidade assimétrica do composto III, incluindo os nomes dos átomos.

As distâncias $\mathrm{Tl}-\mathrm{S}$ apresentam valores $\left[2,813(2) \AA ̊\right.$ e 3,083(2) $\left.\AA^{i}\right]$ com uma ligação mais curta do que a outra, sendo que as duas estão dentro da distribuição estatística encontrada na base de dados CSD, figura 3.1. Já a distância $\mathrm{Tl}-\mathrm{O}$ $\left[3,212(2) \AA^{i i}\right]$ é significativamente mais longa do que a média encontrada na base de dados $C S D$, figura 3.2, e a ligação $\mathrm{O}=\mathrm{C}[1,209(7) \AA$ é mais curta que a média encontrada na base de dados $C S D$, figura 3.5. A interação $\mathrm{Tl}-\mathrm{N}[2,573(4) \AA ̊$ é menor que a média encontrada na base de dados CSD, presumivelmente o 
alargamento da ligação $\mathrm{N}-\mathrm{C}[\mathrm{N}-\mathrm{C} 1=1,368(7) \AA ̊]$, figura 3.6, é compensado pelo fortalecimento da interação $\mathrm{Tl}-\mathrm{N}$. Os comprimentos das ligações e ângulos de principal interesse estão na tabela 3.6.

O arranjo supramolecular é dominado por interações secundárias, Tl - S e $\mathrm{Tl}$ - O que funcionam como o elo na formação da cadeia. O átomo de Tl da molécula na posição $(\mathrm{x}, \mathrm{y}, \mathrm{z})$ liga covalentemente aos átomos de $\mathrm{N}$ e $\mathrm{S}$ na mesma molécula. Ao mesmo tempo interage com o átomo de $\mathrm{O}$ da molécula na posição $5 / 4-\mathrm{y},-3 / 4+\mathrm{x}$, 5/4-z) e ao átomo $S$ da molécula na posição (3/4+y, 3/4-x, -1/4+z). Portanto o íon Tl da molécula em $(3 / 4+y, 3 / 4-x,-1 / 4+z)$ está interagindo similarmente com os átomos de $\mathrm{O}$ e $\mathrm{S}$ de suas moléculas vizinhas.

As unidades assimétricas estão ligadas em camadas, cuja formação é mais facilmente descrita em termos de três motivos unidimensionais, formando cadeias paralelas ao longo das três direções [100], [010] e [001].

As interações $\mathrm{Tl}-\mathrm{S}$ são responsáveis por um arranjo unidimensional ao longo da direção [001], gerada pelo eixo de roto-translação $4_{3}^{-}$em $(3 / 4,0, z)$. O íon Tl em (x, y, z) interage com o átomo de $\mathrm{S}$ em (3/4+y, 3/4-x, 3/4+z), o íon Tl desta molécula interage com o próximo átomo de $\mathrm{S}$ da molécula em $(1 / 2-\mathrm{x},-\mathrm{y}, 1 / 2+\mathrm{z})$, desta maneira formando uma cadeia em espiral gerada em torno da direção [001] e apresentando uma cavidade quadrada, figura 3.16. As interações $\mathrm{Tl}-\mathrm{O}$ geram um arranjo zerodimensional, gerado pelo eixo de roto-inversão $\overline{4}$ em $(0,1 / 4, \mathrm{z})$. O íon Tl em $(\mathrm{x}, \mathrm{y}, \mathrm{z})$ interage com o átomo de $\mathrm{O}$ em $(1 / 4-\mathrm{y}, 1 / 4+\mathrm{x}, 1 / 4-\mathrm{z})$. O átomo de Tl desta molécula interage com o próximo átomo de $\mathrm{O}$ da molécula em $(-\mathrm{x}, 1 / 2-\mathrm{y}, \mathrm{z})$, desta maneira formando uma cadeia fechada ao longo da direção [001], apresentando também uma cavidade quadrada, figura 3.17. As combinações dos dois arranjos formam um arranjo tridimensional, figura 3.18. 

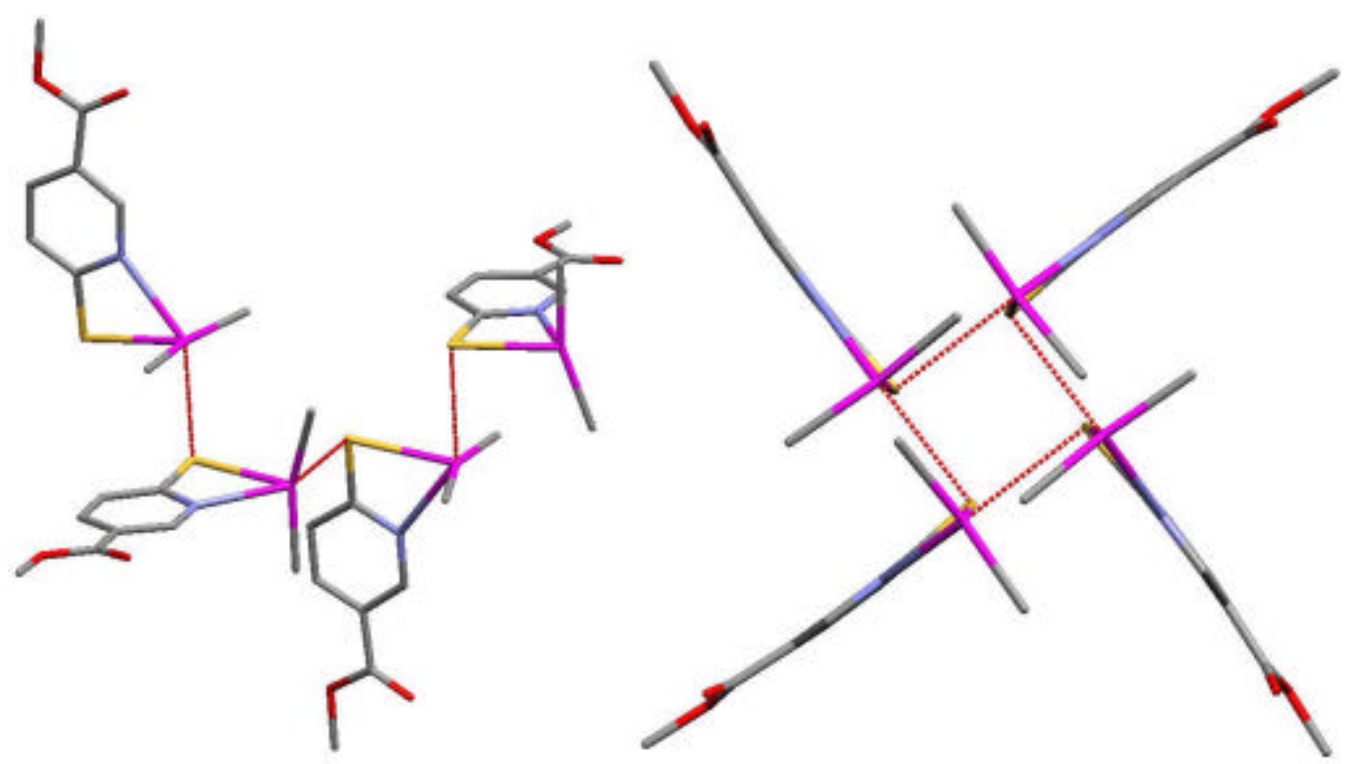

Figura 3.16: Arranjo ao longo da direção [001] com duas vistas diferentes, apresentando uma cavidade quadrada (foram omitidos os átomos de hidrogênio para a melhor visualização).
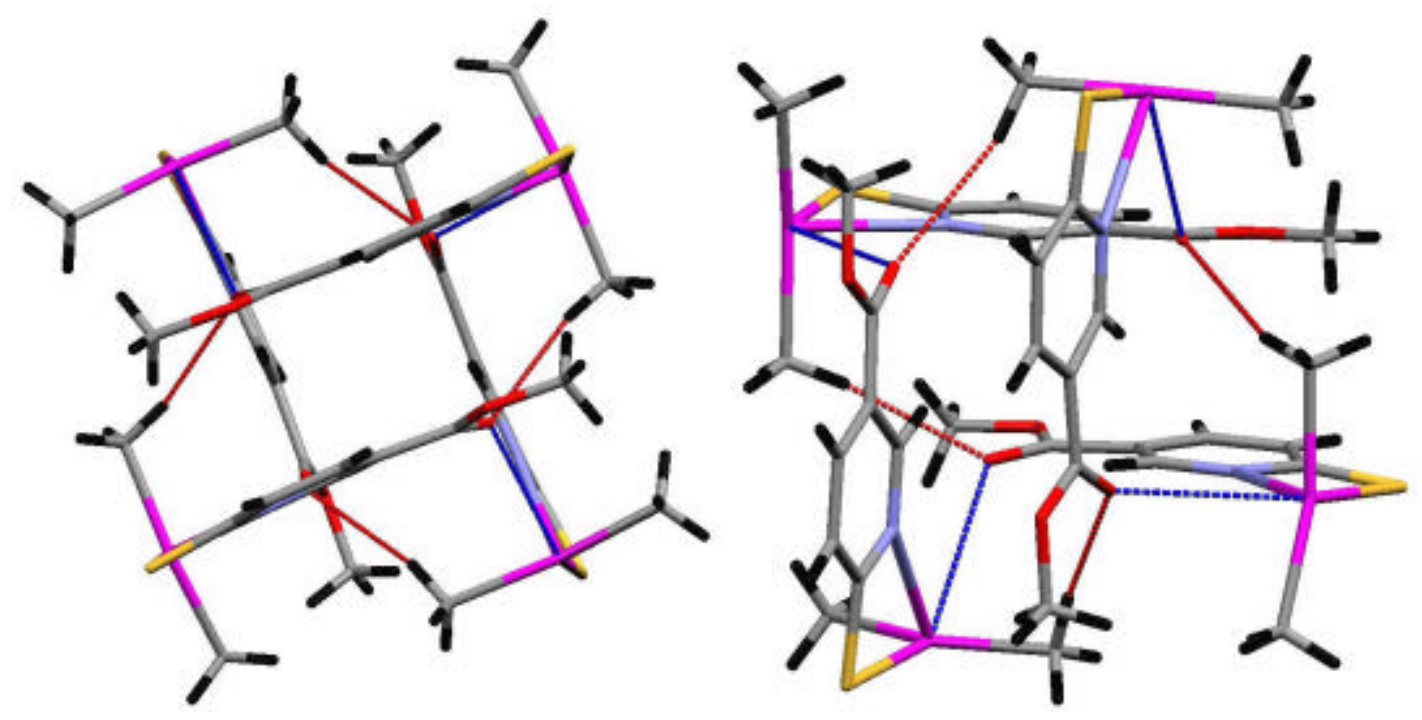

Figura 3.17: Arranjo zero-dimensional apresentando uma cavidade quadrada, com a interação $\mathrm{Tl}$ - $\mathrm{O}$ em azul e a ligação de hidrogênio $(\mathrm{C} 8$ - H8B ... O2) em vermelho. 
O composto III contém ligações de hidrogênio fortes e fracas Desiraju e Steiner, 1999), tabela 3.7. Estas ligações formam arranjos zero dimensional com os vizinhos mais próximos. Na ligação C8 - H8B ... O2, o átomo $\mathrm{C} 8 \mathrm{em}(\mathrm{x}, \mathrm{y}, \mathrm{z})$ age como um doador da ligação de hidrogênio ao átomo $\mathrm{O} 2$ em (-x, 1/2-y, z), formando um arranjo com duas moléculas, gerado por meio do eixo de rotação 2 em $(0,1 / 4, z)$. Já na ligação $\mathrm{C} 2-\mathrm{H} 2 \ldots \mathrm{O} 1$, o átomo $\mathrm{C} 2$ em $(\mathrm{x}, \mathrm{y}, \mathrm{z})$ age como um doador da ligação de hidrogênio ao átomo $\mathrm{O} 1$ em $(1 / 4-\mathrm{y}, 1 / 4+\mathrm{x}, 1 / 4-\mathrm{z})$ e o átomo C2 desta molécula, age como doador ao átomo $\mathrm{O} 1 \mathrm{em}(-\mathrm{x}, 1 / 2-\mathrm{y}, \mathrm{z})$ e o átomo C2 em (-x, 1/2$\mathrm{y}, \mathrm{z})$ age como doador ao átomo $\mathrm{O} 1 \mathrm{em}(3 / 4+\mathrm{y}, 1 / 4-\mathrm{x}, 1 / 4-\mathrm{z})$ e assim por diante, formando um arranjo fechado com 4 moléculas, por meio do eixo de roto-inversão $\overline{4}^{-}(0,1 / 4, \mathrm{z})$. A combinação dos arranjos formados pelas ligações de hidrogênio com os arranjos formados pelas interações secundárias consolida o arranjo tridimensional do composto III, figura 3.18 .

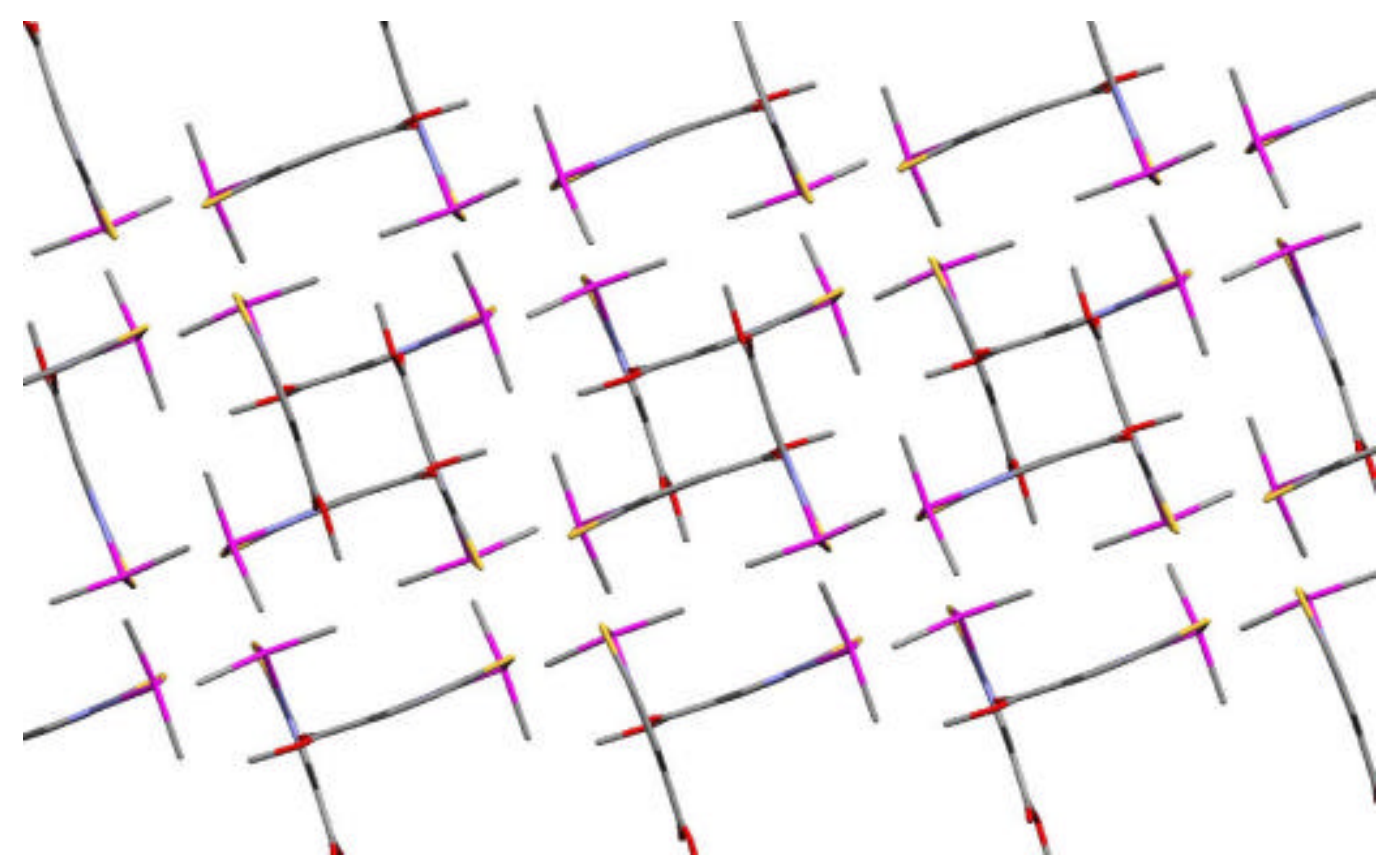

Figura 3.18: Arranjo tridimensional do composto III, foram omitidas as interações $\mathrm{Tl}-\mathrm{S}$ e $\mathrm{Tl}$ - O e ligações de hidrogênio para melhor visualização. 
Tabela 3.6: Distâncias e ângulos de ligação para o composto III.

\begin{tabular}{|c|c|c|c|c|}
\hline & Distâncias $(\AA)$ & Ângulos $\left(^{\circ}\right)$ & $\begin{array}{l}\text { Soma dos raios } \\
\text { de van der } \\
\text { Waals (A). } \\
\text { (Bondi 1964 e } \\
\text { Batsanov 1999) }\end{array}$ & $\begin{array}{l}\text { Soma dos raios } \\
\text { covalentes }(\AA) \text {. } \\
\text { (Glidewell 1976) }\end{array}$ \\
\hline $\mathrm{Tl}-\mathrm{S}$ & $2,8135(15)$ & 94,04(4) (S-Tl-S) & 4,15 & 2,47 \\
\hline $\mathrm{Tl}-\mathrm{S}^{i}$ & $3,083(2)$ & 94,04(4) (S-Tl-S) & 4,15 & 2,47 \\
\hline $\mathrm{Tl}-\mathrm{O}^{i ̈}$ & $3,212(2)$ & $131,44(3) \quad(\mathrm{S}-\mathrm{Tl}-\mathrm{O} 2)$ & 3,87 & 2,195 \\
\hline $\mathrm{Tl}-\mathrm{N}$ & $2,573(4)$ & $\begin{array}{cc}58,36(10) & (\mathrm{S}-\mathrm{Tl}-\mathrm{N}) \\
73,14(14) & \left(\mathrm{O}^{i i}-\mathrm{Tl}-\mathrm{N}\right)\end{array}$ & 3,90 & 2,176 \\
\hline $\mathrm{S}-\mathrm{C} 1$ & $1,731(5)$ & $\begin{array}{cc}83,99(19) & (\mathrm{Tl}-\mathrm{S}-\mathrm{C} 1) \\
93,64(18) & \left(\mathrm{Tl}^{i i i}-\mathrm{S}-\mathrm{C} 1\right)\end{array}$ & 3,50 & 1,787 \\
\hline $\mathrm{N}-\mathrm{C} 1$ & $1,368(7)$ & $\begin{array}{ll}101,5(3) & (\mathrm{C} 1-\mathrm{N}-\mathrm{Tl}) \\
115,9(4) & (\mathrm{S}-\mathrm{C} 1-\mathrm{N})\end{array}$ & 3,25 & 1,493 \\
\hline $\mathrm{N}-\mathrm{C} 5$ & $1,348(7)$ & 139,3(4) (Tl-N-C5) & 3,25 & 1,493 \\
\hline $\mathrm{O} 2-\mathrm{C}^{i i}$ & $1,209(7)$ & 127,4(2) (Tl-O2-C6) & 3,22 & 1,512 \\
\hline
\end{tabular}

Tabela 3.7: Distâncias e ângulos para as ligações de hidrogênio do composto III.

\begin{tabular}{cccc}
\hline $\mathrm{D}-\mathrm{H} \ldots \mathrm{A}$ & $\mathrm{H} \ldots \mathrm{A}$ & $\mathrm{D} \ldots \mathrm{A}$ & $\mathrm{D}-\mathrm{H} \ldots \mathrm{A}$ \\
\hline $\mathrm{C} 2-\mathrm{H} 2 \ldots \mathrm{O} 1$ & $2,633(4) \AA$ & $3,300(6) \AA$ & $127,7^{\circ}$ \\
\hline $\mathrm{C} 8-\mathrm{H} 8 \mathrm{~B} \ldots \mathrm{O} 2$ & $2,637(2) \AA$ & $3,587(3) \AA$ & $163,2^{\circ}$ \\
\hline
\end{tabular}

\subsubsection{DimetilTálio 6-mercapto-3-piridina -ethoxicarboxilato (IV)}

A figura 3.19 mostra um diagrama tipo ORTEP da estrutura cristalográfica do composto IV, com os nomes dos átomos. O composto é um monômero em que cada íon metálico está coordenado com os carbonos dos grupos metil em trans, três átomos de enxofre $[(\mathrm{x}, \mathrm{y}, \mathrm{z}),(\mathrm{x}, 1 / 2-\mathrm{y}, 1 / 2+\mathrm{z})$ e $(-\mathrm{x}, 1 / 2+\mathrm{y}, 1 / 2-\mathrm{z})]$ dos grupos mercapto e um nitrogênio $[\mathrm{N}(\mathrm{x}, \mathrm{y}, \mathrm{z})]$ da piridina. $\mathrm{O}$ íon tálio possui uma coordenação 
hexaédrica do tipo bipiramidal de base quadrada distorcida $\left[\mathrm{TlC}_{2} \mathrm{~S}_{3} \mathrm{~N}\right]$. Cada ligante age como uma ponte bidentada entre os dois átomos de tálio adjacentes de lados opostos do arranjo supramolecular.

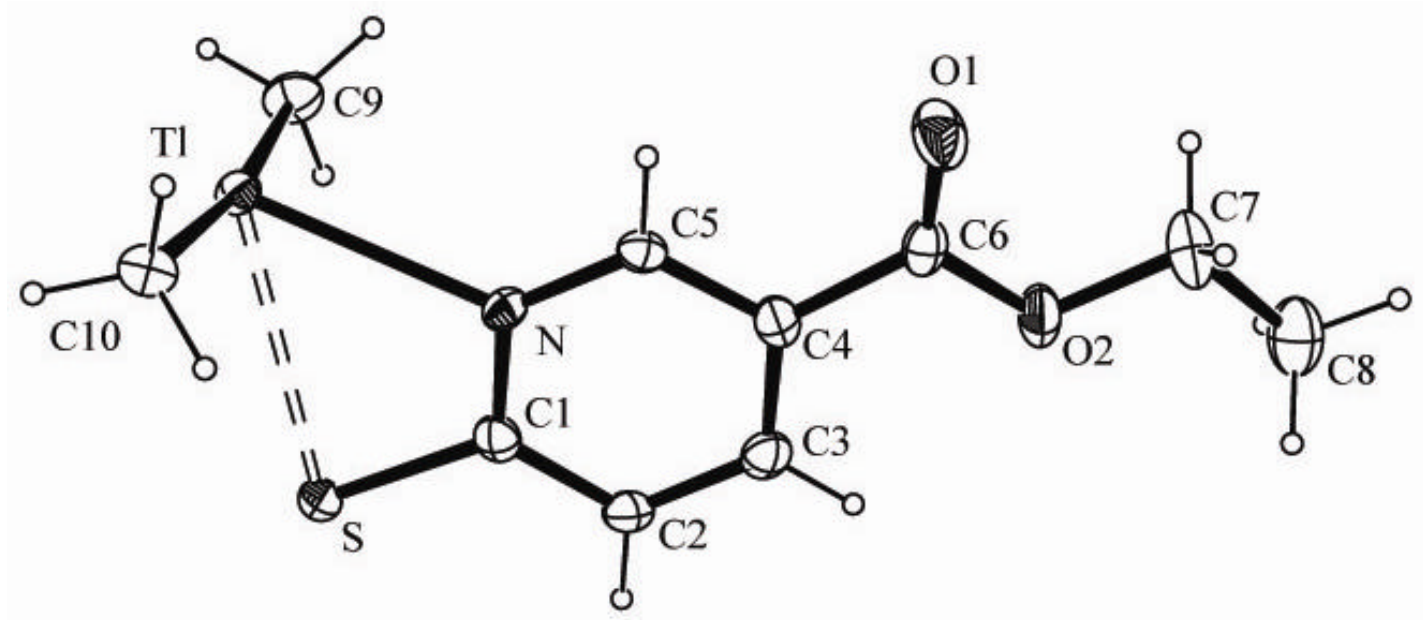

Figura 3.19: Diagrama tipo ORTEP da unidade assimétrica do composto IV, incluindo os nomes dos átomos.

As pontes de enxofre fazem a ligação entre as moleculas com interações de comprimentos diferentes $\left[\mathrm{Tl}-\mathrm{S}=3,008(1) \AA ̊ \mathrm{~T}\right.$; $-\mathrm{S}^{i}=3,193(2) \AA ; \mathrm{Tl}-\mathrm{S}^{i i}=$ 3,379(2) ̊]. A distância mais curta está dentro do intervalo $(2,832 \AA-3,141 \AA$ A e a intermediária coincide com os valores encontrados em outros complexos de tálio tendo enxofre como ponte (Kimblin et al., 2000 ${ }^{\mathrm{a}, \mathrm{b}}$; Bosch et al., 1996). Os comprimentos das ligações e ângulos de principal interesse estão na tabela 3.8. 
Tabela 3.8: Distâncias e ângulos de ligação para o composto IV.

\begin{tabular}{|c|c|c|c|c|}
\hline & Distâncias $(\AA)$ & Ângulos $\left(^{\circ}\right)$ & $\begin{array}{l}\text { Soma dos raios } \\
\text { de van der } \\
\text { Waals }(\AA) \text {, Bondi } \\
1964 \text { e Batsanov } \\
1999 .\end{array}$ & $\begin{array}{l}\text { Soma dos raios } \\
\text { covalentes }(\AA) \text {, } \\
\text { Glidewell } 1976 .\end{array}$ \\
\hline $\mathrm{Tl}-\mathrm{S}$ & $3,008(1)$ & $75,50(13) \mathrm{S}-\mathrm{Tl}-\mathrm{S}^{i i}$ & 4,15 & 2,47 \\
\hline $\mathrm{Tl}-\mathrm{S}^{i}$ & $3,193(2)$ & $104,0(3) S^{i}-T l-S^{i i}$ & 4,15 & 2,47 \\
\hline $\mathrm{Tl}-\mathrm{S}^{i i}$ & $3,379(2)$ & $109,0(5) \mathrm{Tl}-\mathrm{S}^{i i}-\mathrm{Tl}^{i i i}$ & 4,15 & 2,47 \\
\hline $\mathrm{Tl}-\mathrm{N}$ & $2,553(5)$ & $55,93(10) \mathrm{S}-\mathrm{Tl}-\mathrm{N}$ & 3,90 & 2,147 \\
\hline $\mathrm{S}-\mathrm{C} 1$ & $1,744(5)$ & $\begin{array}{c}80,19(18) \mathrm{S}-\mathrm{C} 1-\mathrm{Tl} \\
116,3(4) \mathrm{S}-\mathrm{C} 1-\mathrm{N}\end{array}$ & 3,50 & 1,787 \\
\hline $\mathrm{N}-\mathrm{C} 1$ & $1,352(7)$ & $106,4(6) \mathrm{C} 1-\mathrm{N}-\mathrm{Tl}$ & 3,25 & 1,493 \\
\hline $\mathrm{N}-\mathrm{C} 5$ & $1,344(7)$ & $132,3(3) \mathrm{C} 5-\mathrm{N}-\mathrm{Tl}$ & 3,25 & 1,493 \\
\hline
\end{tabular}

Este composto apresenta uma arquitetura supramolecular baseada em interações secundárias $\mathrm{Tl}-\mathrm{S}$, que tem a propriedade de construir a cadeia ao longo da estrutura cristalina. $\mathrm{O}$ íon $\mathrm{Tl}$ da molécula na posição $(\mathrm{x}, \mathrm{y}, \mathrm{z})$ liga covalentemente aos átomos de $\mathrm{N}$ e $\mathrm{S}$ da mesma molécula e interage por via de interações secundárias com os átomos de $\mathrm{S}$ de outras moléculas, em posições $(-\mathrm{x}, 1 / 2+\mathrm{y}, 1 / 2-\mathrm{z})$ e (x, 1/2-y, 1/2+z) (tabela 3.8). Todavia íons Tl nestas posições interagem similarmente com os átomos de S e N das moléculas vizinhas, ao longo das direções [001] e [010].

As moléculas estão conectadas em forma de fitas unidimensionais, que se interconectam formando arranjos supramoleculares bidimensionais. 


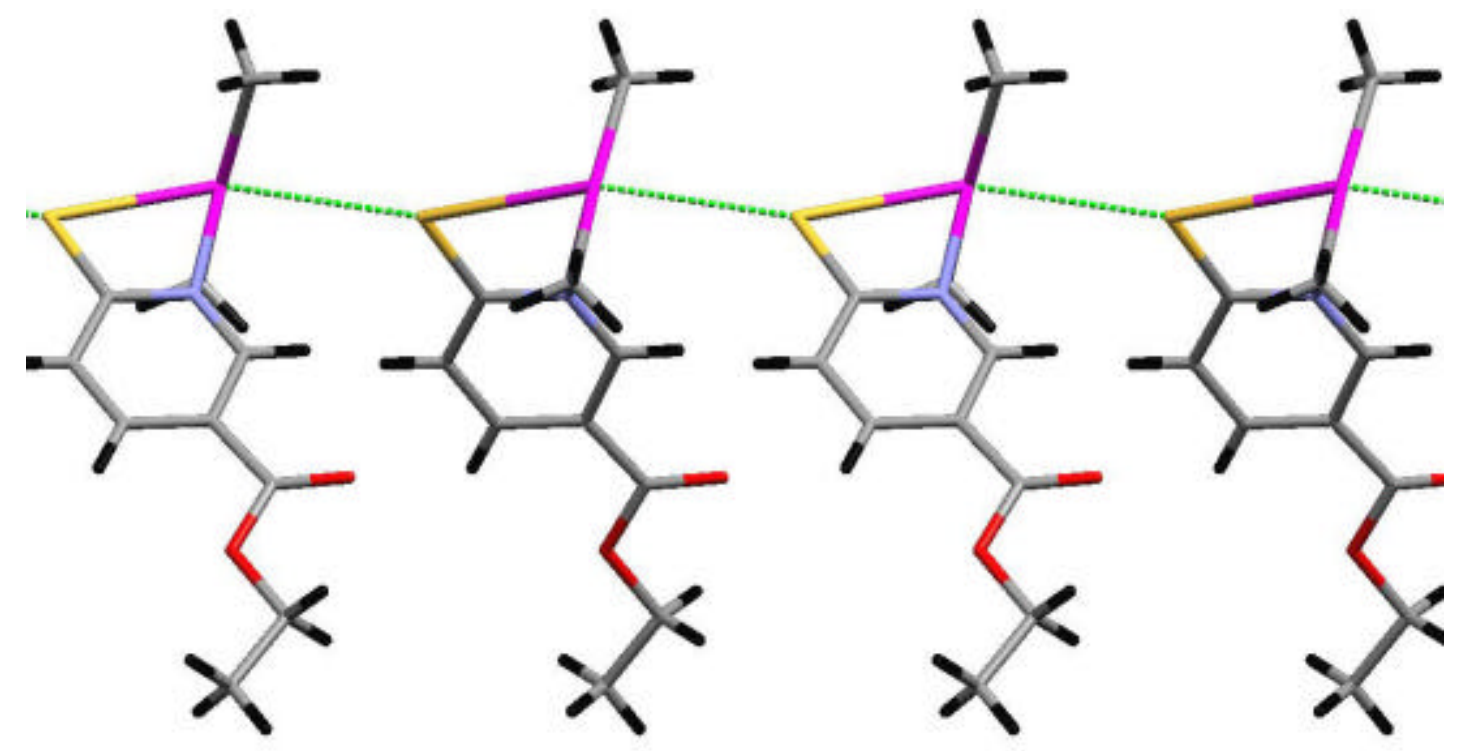

Figura 3.20: Arranjo na direção [001], formada pela interação $\mathrm{Tl}-\mathrm{S}^{i}$ (verde).

As interações $\mathrm{Tl}-\mathrm{S}$ são responsáveis por um arranjo paralelo ao longo das direções [010] e [001], gerado pela ação do eixo de roto-translação $2_{1}$ em $(0, y, 1 / 4)$ e pelo plano de deslizamento $c$ em $(\mathrm{x}, 1 / 4, \mathrm{z})$, respectivamente. $\mathrm{O}$ íon $\mathrm{Tl}$ interage com o átomo de $\mathrm{S}$ em $(\mathrm{x}, 1 / 2-\mathrm{y}, 1 / 2+\mathrm{z})$ e com outro átomo de $\mathrm{S}$ em $(-\mathrm{x}, 1 / 2+\mathrm{y}, 1 / 2-\mathrm{z})$. No entanto, o íon $\mathrm{Tl}$ da molécula em $(\mathrm{x}, 1 / 2-\mathrm{y}, 1 / 2+\mathrm{z})$ interage com o próximo átomo de $\mathrm{S}$ da molécula em $(\mathrm{x}, 1+\mathrm{y}, \mathrm{z})$, desta maneira, formando uma fita ao longo da direção [010], figura 3.21. Sucessivamente, o íon $\mathrm{Tl}$ da molécula em $(-\mathrm{x}, 1 / 2+\mathrm{y}, 1 / 2-\mathrm{z})$ interage com o próximo átomo de $S$ da molécula em $(x, y, z+1)$, formando uma fita ao longo da direção [001], figura 3.20. 


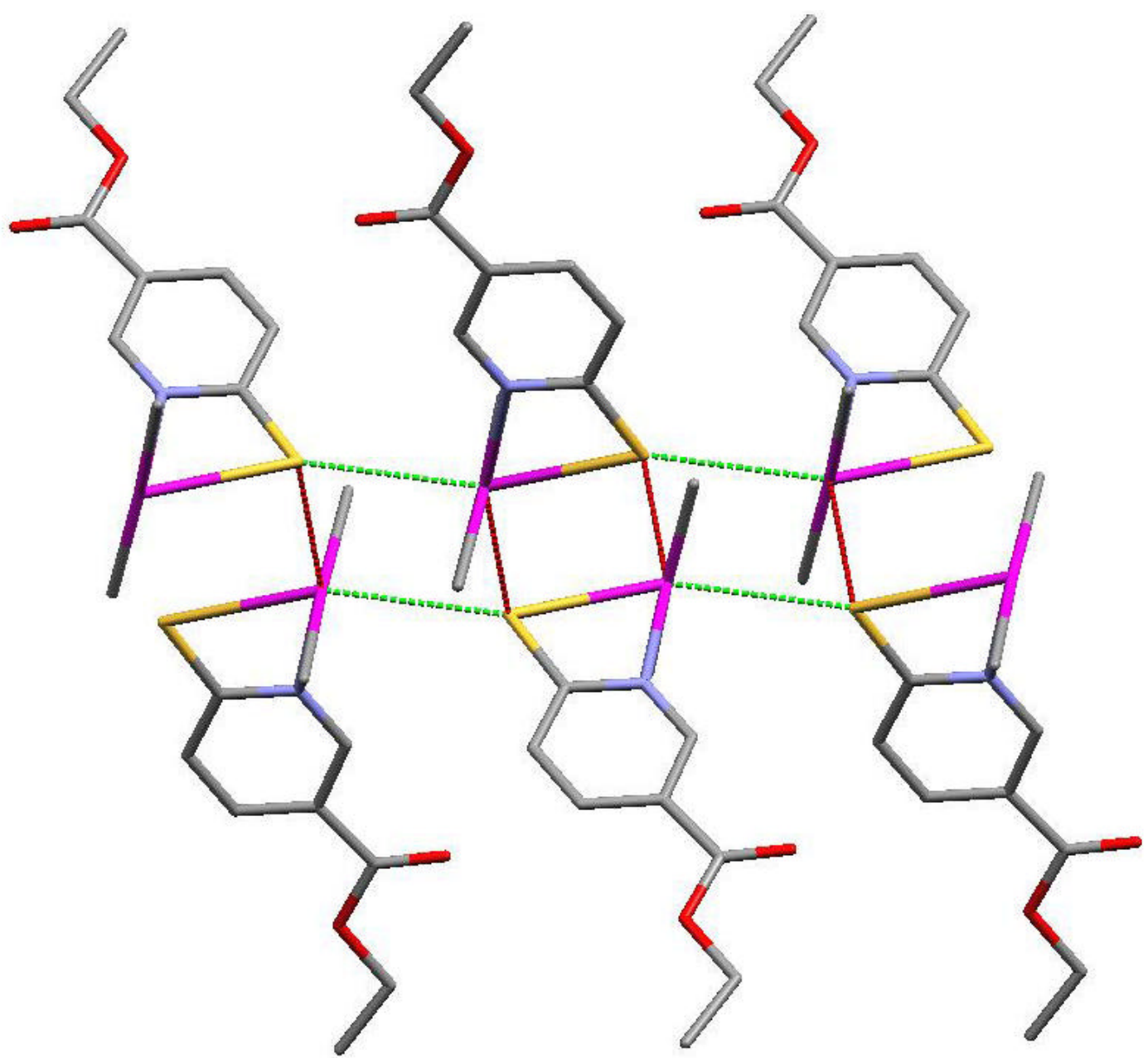

Figura 3.21: Arranjo na direção [010] com interações $\mathrm{Tl}-\mathrm{S}^{i}$ (verde) e $\mathrm{Tl}-\mathrm{S}^{i i}$ (vermelho).

No composto IV há quatro ligações de hidrogênio que ajudam a estabilizar o arranjo supramolecular. Estas ligações em conjunto com as interações secundárias orientam os arranjos nas direções [010] e [001]. As quatro ligações, são definidas como: ligações fracas (C8 - H8B ... O1, C8 - H8A ... O2 e C7 - H7A ... O1) e ligação forte (C3 - H3 ... O1) (Desiraju \& Steiner, 1999), tabela 3.9. O átomo C8 e C7 agem como doador da ligação de hidrogênio ao átomo $\mathrm{O} 1 \mathrm{em}(-\mathrm{x}, 1 / 2+\mathrm{y}, 1 / 2-\mathrm{z})$ colaborando com a estabilização do arranjo na direção [010], figuras 3.23 e 3.25, gerado pelo eixo de roto-translação $2_{l}$ em $(0, y, 1 / 4)$, por meio do átomo H8B e H7A, 
respectivamente. $\mathrm{O}$ átomo $\mathrm{C} 8$ age como doador ao átomo $\mathrm{O} 2 \mathrm{em}(-\mathrm{x},-\mathrm{y},-\mathrm{z})$ formando um arranjo de duas moléculas (figura 3.22), gerado pelo centro de inversão $\overline{1}$ em $(0,0,0)$ e o átomo $\mathrm{C} 3$ age como doador ao átomo $\mathrm{O} 1 \mathrm{em}(\mathrm{x}, 1 / 2-\mathrm{y}, 1 / 2+\mathrm{z})$, estabilizando o arranjo na direção [001] (figura 3.24), gerado pelo plano de deslizamento $c$ em $(\mathrm{x}, 1 / 4, \mathrm{z})$.

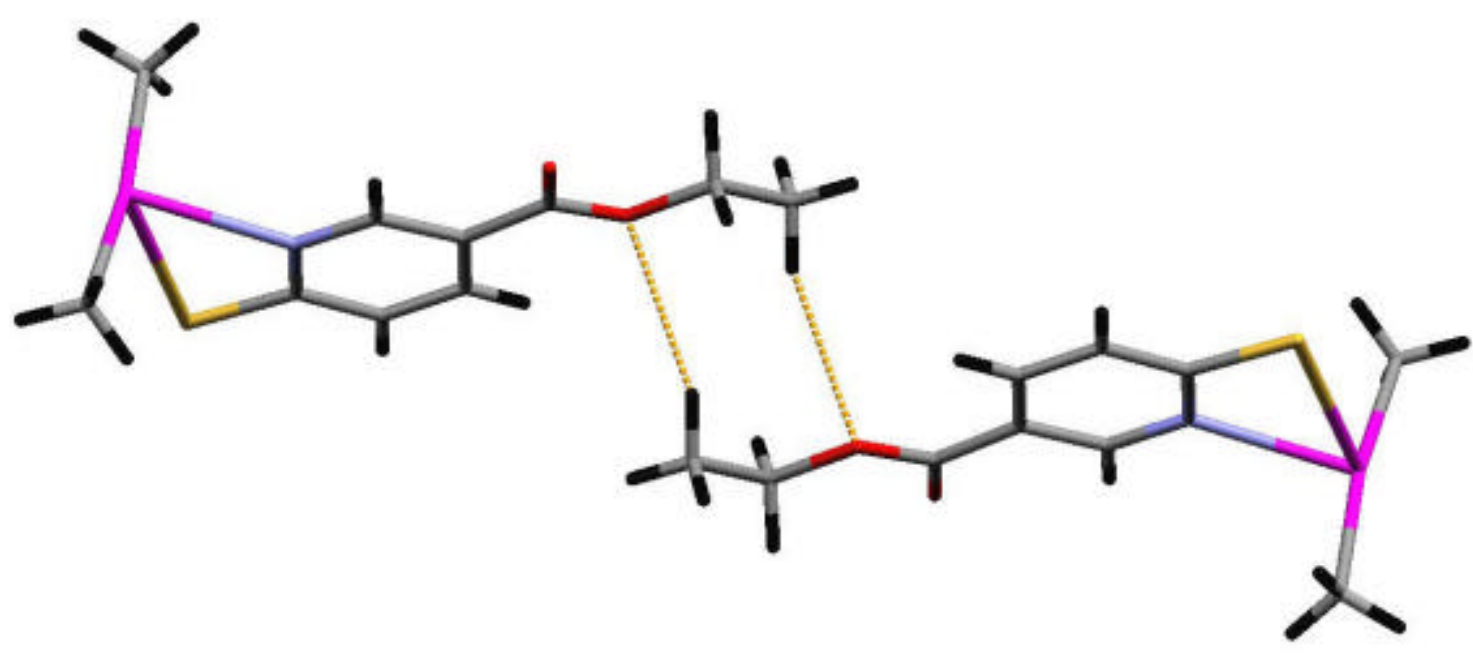

Figura 3.22: Arranjo com duas moléculas, gerado pela ligação de hidrogênio C8 - H8A ... O2 (amarelo). 


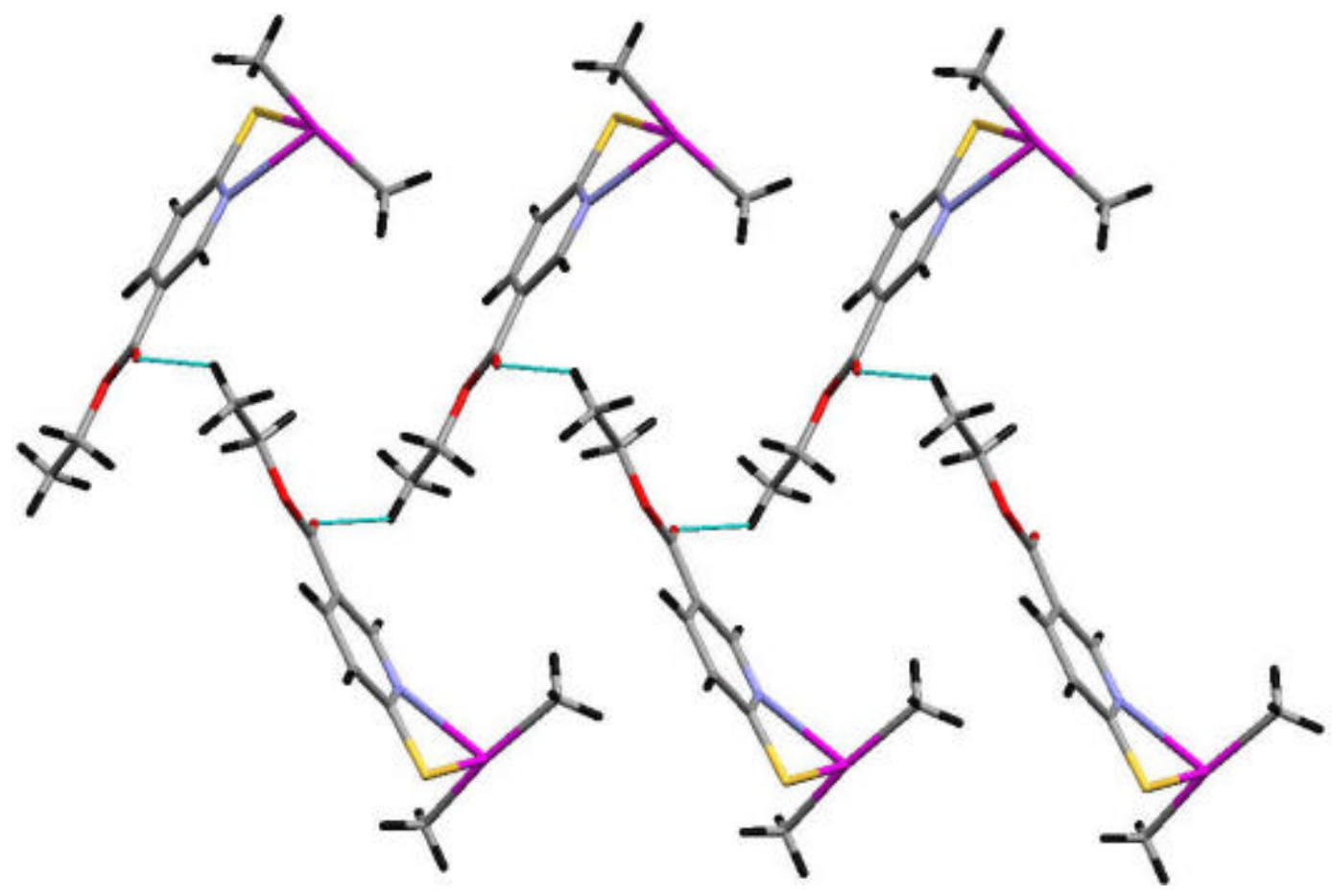

Figura 3.23: Arranjo na direção [010] com a presença da ligação de hidrogênio, C8 - H8B ... O1(azul).

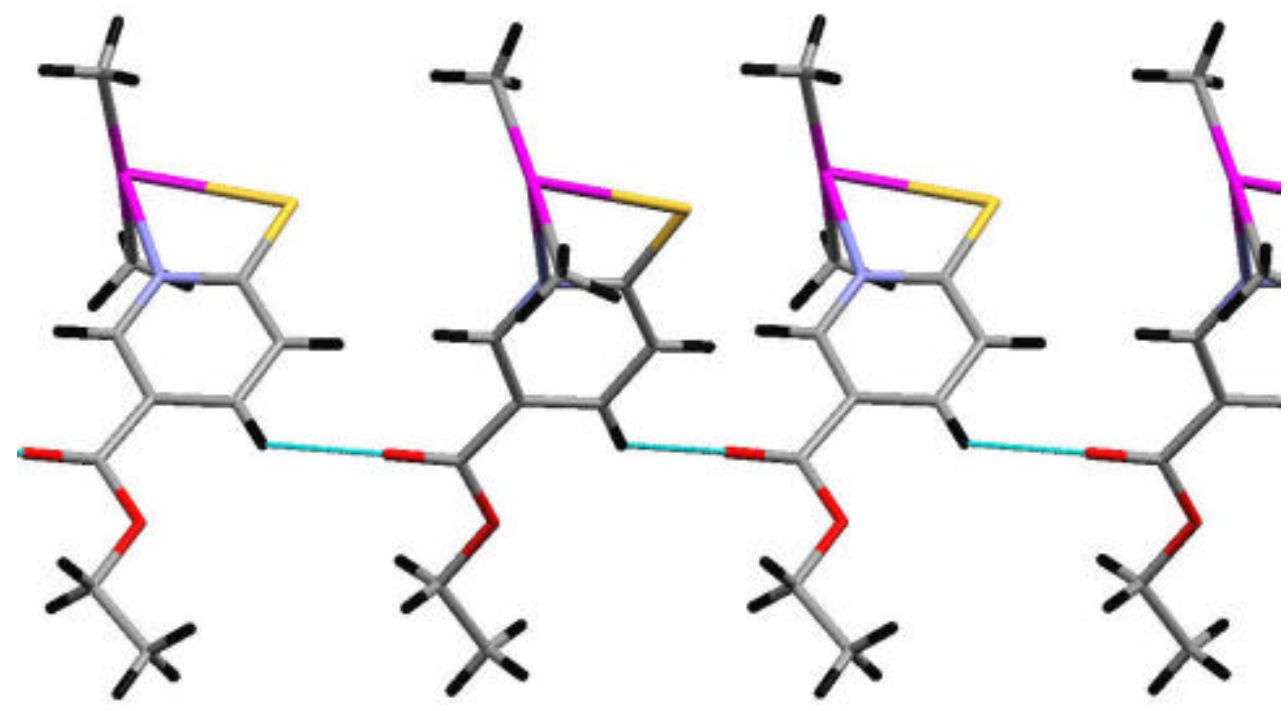

Figura 3.24: Arranjo na direção [001] gerado pela forte ligação de hidrogênio, C3 - H3 ... O1(azul). 


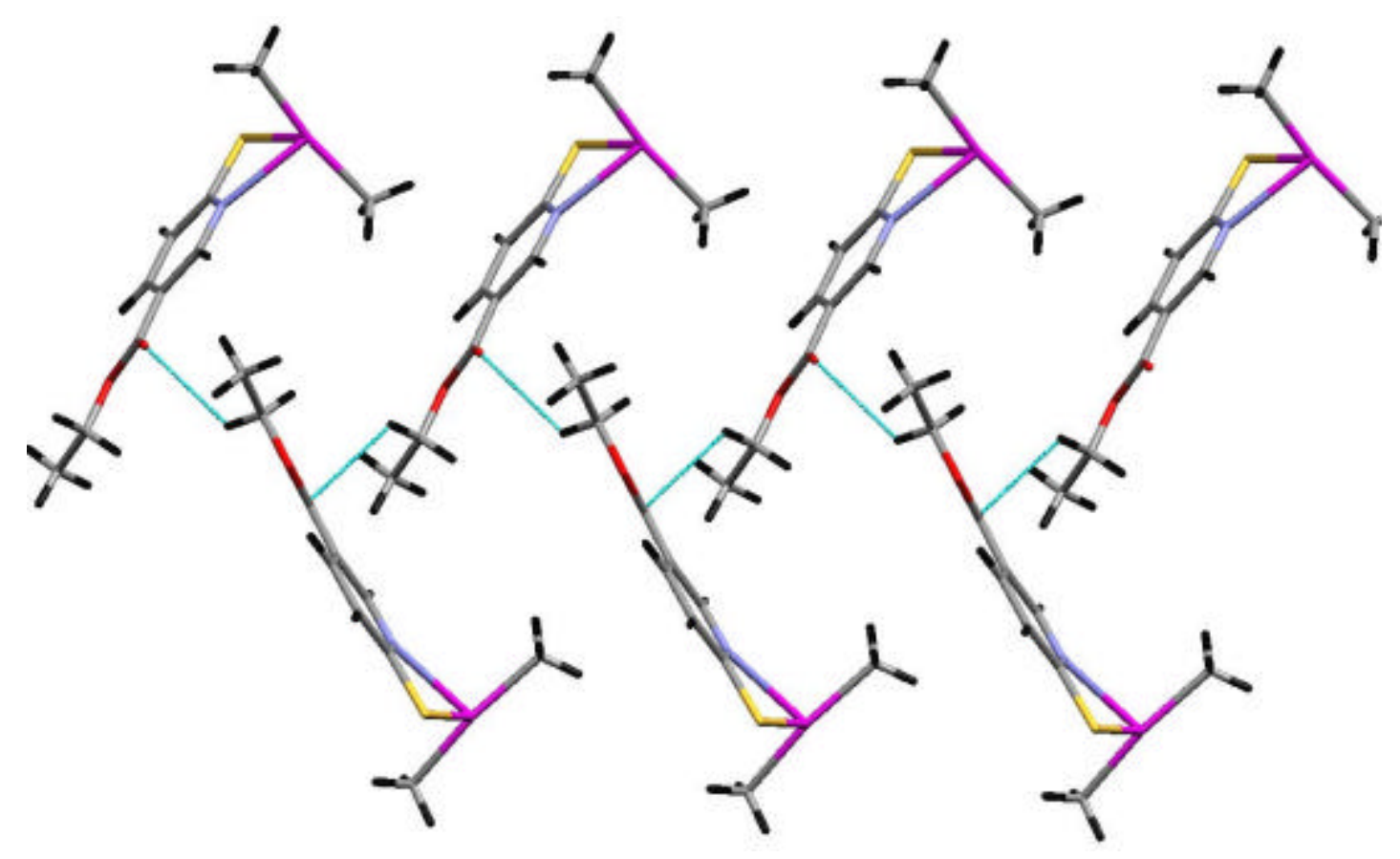

Figura 3.25: Arranjo na direção [010] gerado pela ligação de hidrogênio, C7 - H7A ... O1(azul).

Tabela 3.9: Distâncias e ângulos para as ligações de hidrogênio do composto IV.

\begin{tabular}{cccc}
\hline $\mathrm{D}-\mathrm{H} \ldots \mathrm{A}$ & $\mathrm{H} \ldots \mathrm{A}$ & $\mathrm{D} \ldots \mathrm{A}$ & $\mathrm{D}-\mathrm{H} \ldots \mathrm{A}$ \\
\hline $\mathrm{C} 3-\mathrm{H} 3 \ldots \mathrm{O} 1$ & $2,415(3) \AA$ & $3,153(4) \AA$ & $134,3^{\circ}$ \\
\hline $\mathrm{C} 8-\mathrm{H} 8 \mathrm{~B} \ldots \mathrm{O} 1$ & $2,556(4) \AA$ & $3,217(5) \AA$ & $124,8^{\mathrm{o}}$ \\
\hline $\mathrm{C} 7-\mathrm{H} 7 \mathrm{~A} \ldots \mathrm{O} 1$ & $2,708(4) \AA$ & $3,304(7) \AA$ & $119,1^{\circ}$ \\
\hline $\mathrm{C} 8-\mathrm{H} 8 \mathrm{~A} \ldots \mathrm{O} 2$ & $2,700(4) \AA$ & $3,614(6) \AA$ & $155,2^{\circ}$ \\
\hline
\end{tabular}

\subsubsection{DimetilTálio 2-mercapto-3-piridina -ethoxicarboxilato (V)}

A figura 3.26 mostra um diagrama tipo ORTEP do composto $\mathrm{V}$, com os nomes dos átomos. O composto é um monômero em que cada átomo metálico está 
coordenado com os carbonos dos dois grupos metil em trans, dois enxofres $[\mathrm{S}(\mathrm{x}, \mathrm{y}, \mathrm{z})$ e $\mathrm{S}(-1 / 2+\mathrm{x}, 1 / 2-\mathrm{y}, 1-\mathrm{z})]$ do grupo mercapto, um oxigênio [O1 $(1 / 2+\mathrm{x}, 1 / 2-\mathrm{y}, 1-\mathrm{z})]$ do ácido carboxílico e um nitrogênio $[\mathrm{N}(\mathrm{x}, \mathrm{y}, \mathrm{z})]$ da piridina. $\mathrm{O}$ íon tálio está com uma coordenação hexaédrica do tipo bipiramidal de base quadrada distorcida $\left[\mathrm{TlC}_{2} \mathrm{~S}_{2} \mathrm{ON}\right]$. Portanto, cada ligante age como uma ponte tridentada entre os dois átomos de tálio adjacentes do arranjo supramolecular.

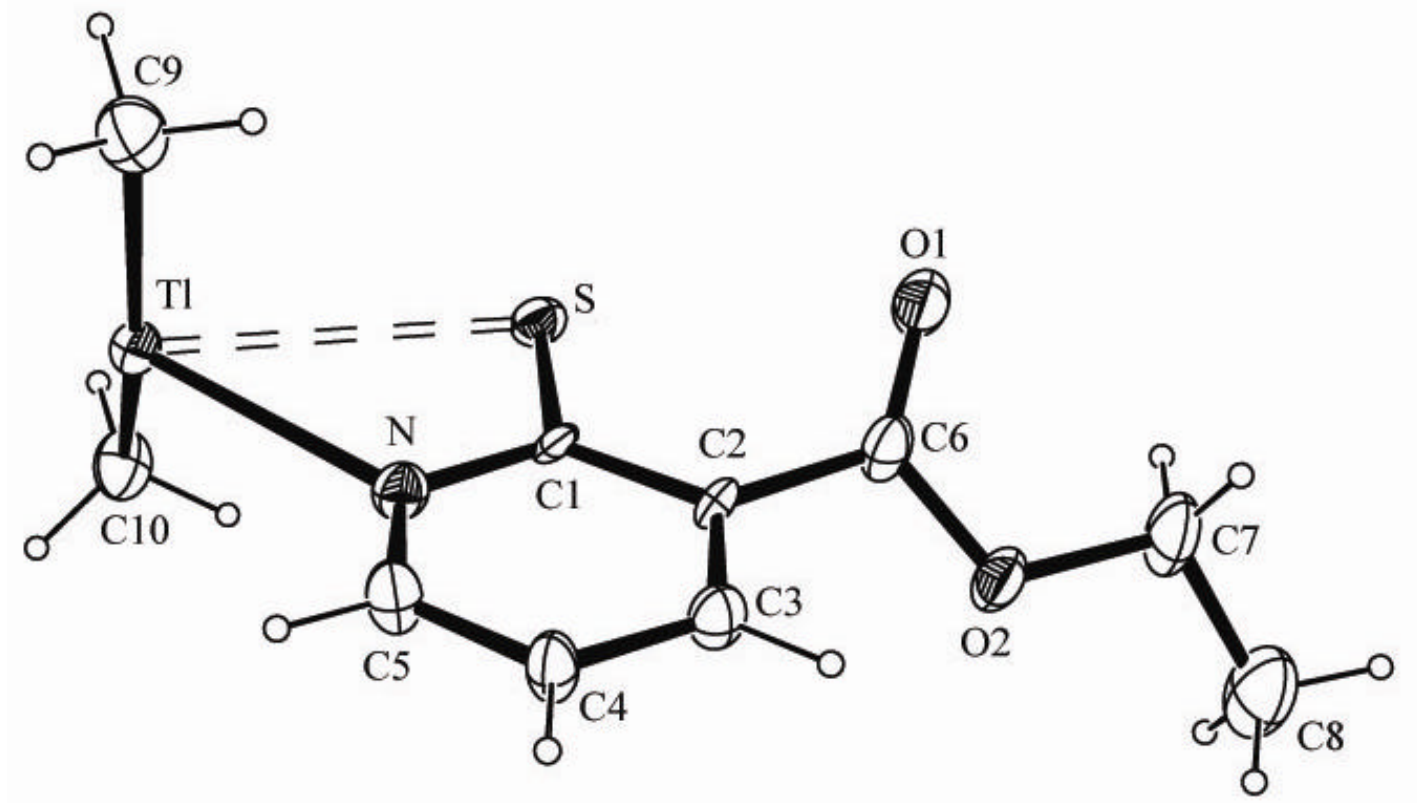

Figura 3.26: Diagrama tipo ORTEP da unidade assimétrica do composto $\mathrm{V}$, incluindo os nomes dos átomos.

As distâncias $\mathrm{Tl}-\mathrm{S}$ apresentam valores bem diferentes $[\mathrm{Tl}-\mathrm{S}=2,777(2) \AA$; $\left.\mathrm{Tl}-\mathrm{S}^{i}=3,288(7) \AA ̊ \AA\right]$ com uma ligação muito mais curta do que a outra. A mais curta adota um caráter covalente e a mais longa tem um caráter de ligação secundária, sendo que as duas estão dentro da distribuição estatística encontrada na base de dados $C S D$, figura 3.1. Já a distância $\mathrm{Tl}$ - O $\left[2,895(5) \AA^{i i}\right]$ é mais longa do que a 
média encontrada $C S D$, figura 3.2, o que gerou um encurtamento da ligação $\mathrm{O}=\mathrm{C}$ [1,209(7) Å], figura 3.5. Os comprimentos das ligações e ângulos de principal interesse estão na tabela 3.10.

O arranjo supramolecular de (V), figura 3.27, é dominado por interações moleculares, $\mathrm{Tl}-\mathrm{S}, \mathrm{Tl}-\mathrm{N}$ e $\mathrm{Tl}-\mathrm{O}$ que funcionam como o elo na formação das cadeias. $\mathrm{O}$ íon $\mathrm{Tl}$ da molécula liga covalentemente aos átomos de $\mathrm{N}$ e $\mathrm{S}$ na mesma molécula e ao átomo de $\mathrm{O}$ da molécula vizinha na posição $(1 / 2+\mathrm{x}, 1 / 2-\mathrm{y}, 1-\mathrm{z})$. Já o mesmo íon $\mathrm{Tl}$ faz uma interação secundária com o átomo de $\mathrm{S}$ da molécula na posição $(-1 / 2+\mathrm{x}, 1 / 2-\mathrm{y}, 1-\mathrm{z})$, tabela 3.10. Entretanto, o átomo de Tl das moléculas em $(1 / 2+\mathrm{x}, 1 / 2-\mathrm{y}, 1-\mathrm{z} ;-1 / 2+\mathrm{x}, 1 / 2-\mathrm{y}, 1-\mathrm{z})$ interagem com suas vizinhas da mesma maneira.

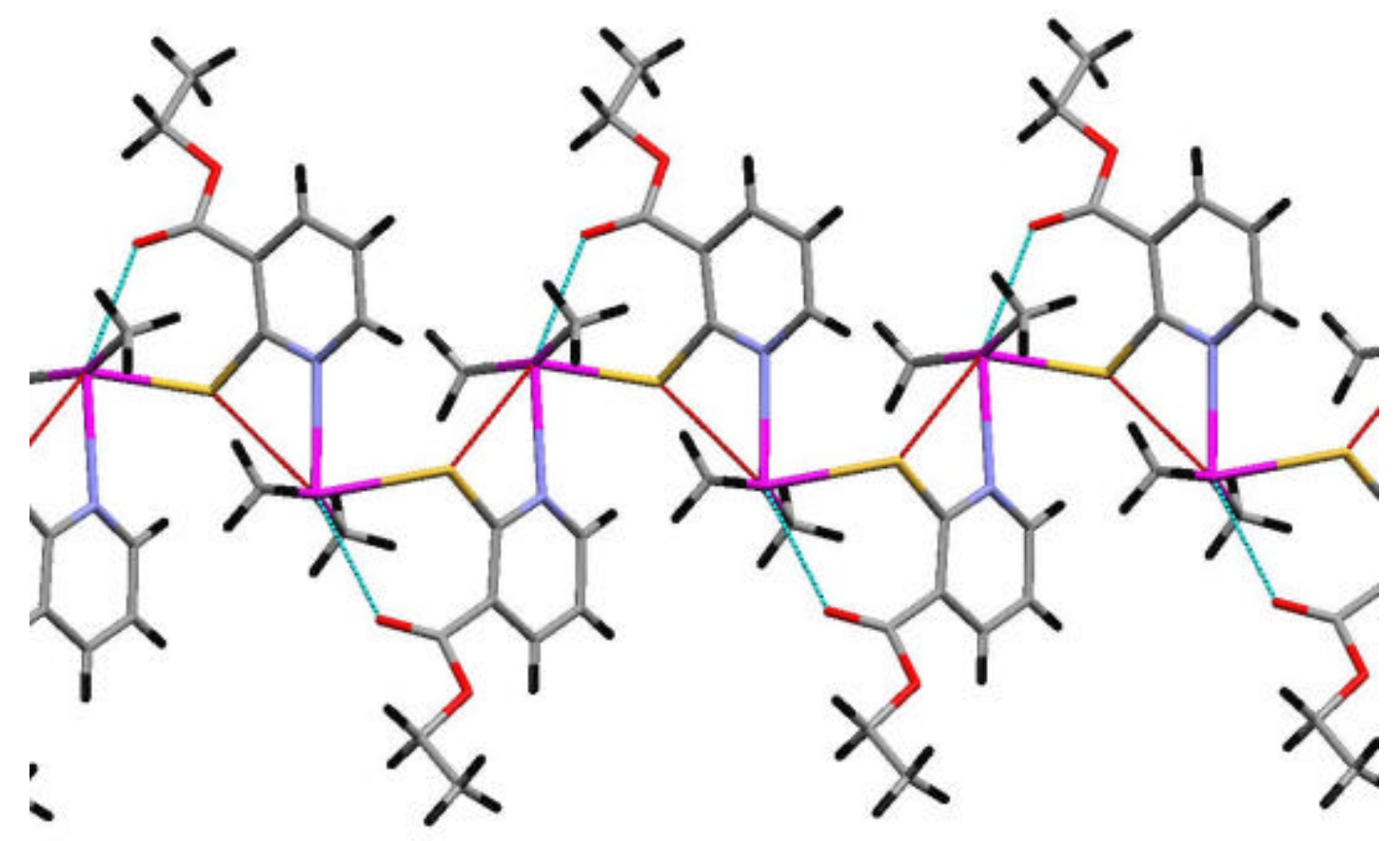

Figura 3.27: Arranjo unidimensional na direção [100], com as interações Tl - S (vermeho) e $\mathrm{Tl}-\mathrm{O}($ azul) 
As unidades assimétricas estão ligadas formando 'ribbons', em duas direções preferenciais [100] e [011], interconectadas formando uma estrutura bidimensional.

As ligações $\mathrm{Tl}-\mathrm{S}, \mathrm{Tl}-\mathrm{N}$ e $\mathrm{Tl}-\mathrm{O}$ são responsáveis pelo arranjo unidimensional, ao longo da direção [100], gerado pela ação do eixo de rototranslação $2_{1}$ em $(\mathrm{x}, 1 / 4,0)$. $\mathrm{O}$ átomo de $\mathrm{Tl}$ em $(\mathrm{x}, \mathrm{y}, \mathrm{z})$ liga-se ao átomo de $\mathrm{O}$ da próxima molécula $(1 / 2+\mathrm{x}, 1 / 2-\mathrm{y},-\mathrm{z}+1)$ e interage com o átomo de $\mathrm{S}$ da molécula precedente $(-1 / 2+\mathrm{x}, 1 / 2-\mathrm{y},-\mathrm{z}+1)$, deste modo construindo um 'ribbon' em torno da direção [100], figura 3.27.

Tabela 3.10: Distâncias e ângulos de ligação para o composto V.

\begin{tabular}{|c|c|c|c|c|}
\hline & Distâncias (Å) & Ângulos $\left(^{\circ}\right)$ & $\begin{array}{l}\text { Soma dos raios de } \\
\text { van der Waals } \\
(\AA) \text {, Bondi } 1964 \text { e } \\
\text { Batsanov 1999.. }\end{array}$ & $\begin{array}{l}\text { Soma dos raios } \\
\text { covalentes (̊), } \\
\text { Glidewell } 1976 .\end{array}$ \\
\hline $\mathrm{Tl}-\mathrm{S}$ & $2,777(2)$ & $129,29(5)\left(\mathrm{S}-\mathrm{Tl}-\mathrm{S}^{i}\right)$ & 4,15 & 2,47 \\
\hline $\mathrm{Tl}-\mathrm{S}^{i}$ & $3,288(7)$ & & 4,15 & 2,47 \\
\hline $\mathrm{Tl}-\mathrm{O}^{i i}$ & $2,895(5)$ & $68,32(22)(\mathrm{S}-\mathrm{Tl}-\mathrm{O} 1)$ & 3,87 & 2,195 \\
\hline $\mathrm{Tl}-\mathrm{N}$ & $2,589(4)$ & $80,58(10)(\mathrm{S}-\mathrm{Tl}-\mathrm{N})$ & 3,90 & 2,147 \\
\hline $\mathrm{S}-\mathrm{C} 1$ & $1,745(5)$ & $101,0(2)(\mathrm{Tl}-\mathrm{S}-\mathrm{C} 1)$ & 3,50 & 1,787 \\
\hline \multirow[t]{2}{*}{$\mathrm{N}-\mathrm{C} 1$} & $1,348(7)$ & $115,0(3)(\mathrm{C} 1-\mathrm{N}-\mathrm{Tl})$ & 3,25 & 1,493 \\
\hline & & $115,2(4)\left(S^{i}-\mathrm{C} 1-\mathrm{N}\right)$ & & \\
\hline $\mathrm{N}-\mathrm{C} 5$ & $1,346(7)$ & $124,5(3)(\mathrm{Tl}-\mathrm{N}-\mathrm{C} 5)$ & 3,25 & 1,493 \\
\hline $\mathrm{O} 1-\mathrm{C} 6$ & $1,209(7)$ & $127,0(5)(\mathrm{Tl}-\mathrm{O} 1-\mathrm{C} 6)$ & 3,22 & 1,512 \\
\hline
\end{tabular}

$\mathrm{O}$ composto $\mathrm{V}$ apresenta uma ligação não convencional C4 - H4 ... S, tabela 3.11. Esta ligação de hidrogênio é forte (Potrzebowski et al., 1998) formando um arranjo na direção [010]. O átomo C4 em (x, y, z) age como doador ao átomo S em $(-\mathrm{x}, 1 / 2+\mathrm{y}, 1 / 2-\mathrm{z})$, gerado pelo eixo de roto-translação $2_{1} \mathrm{em}(0, \mathrm{y}, 1 / 4)$, estabilizando o arranjo bidimensional, figura 3.28. 
Tabela 3.11: Distâncias e ângulos para a ligação de hidrogênio do composto V.

$\begin{array}{cccc}\mathrm{D}-\mathrm{H} \ldots \mathrm{A} & \mathrm{H} \ldots \mathrm{A} & \mathrm{D} \ldots \mathrm{A} & \mathrm{D}-\mathrm{H} \ldots \mathrm{A} \\ \mathrm{C} 4-\mathrm{H} 4 \ldots \mathrm{S} & 2,810(5) \AA & 3,576(8) \AA & 138,3^{\circ}\end{array}$

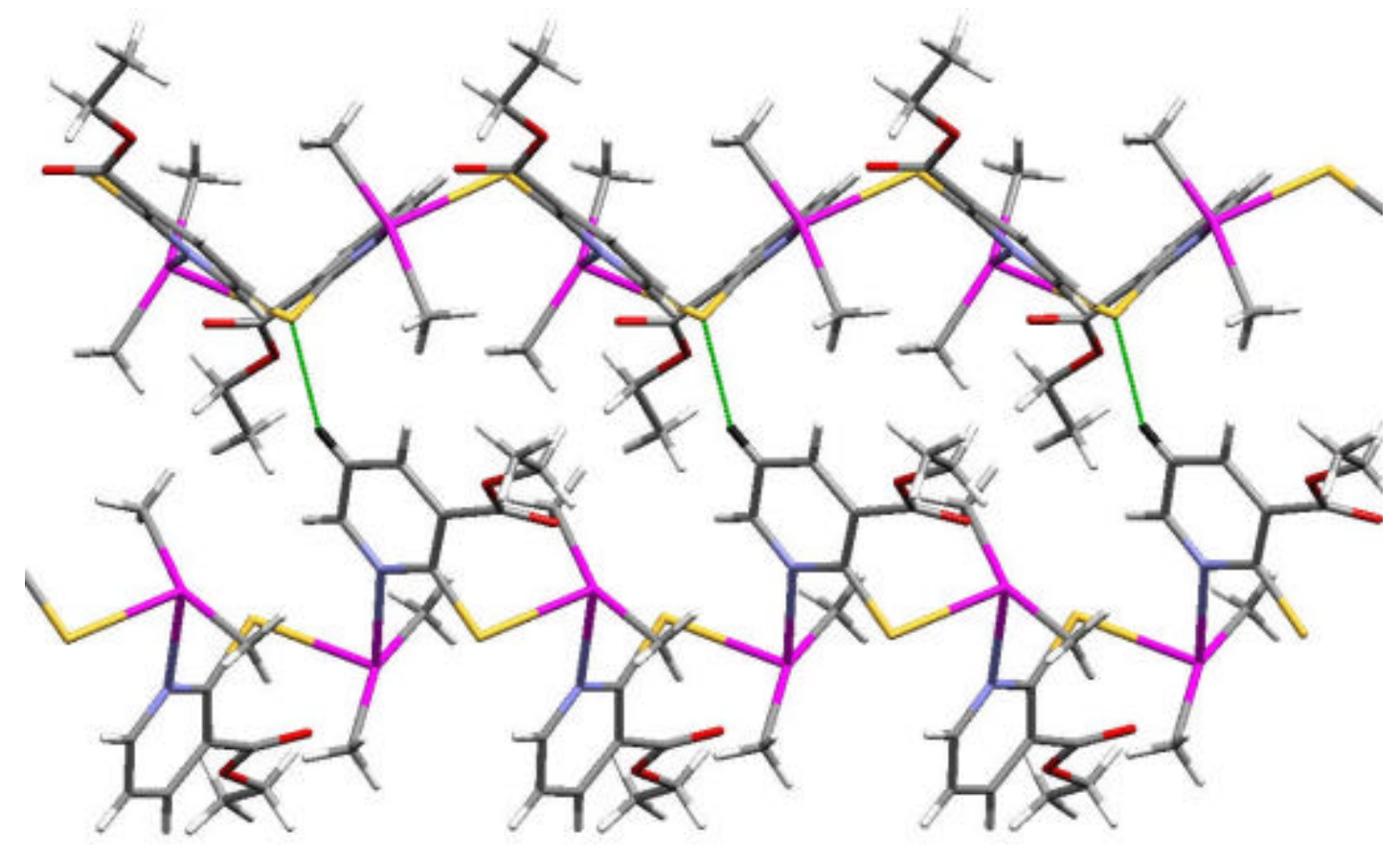

Figura 3.28: Arranjo bidimensional do composto $V$, onde a ligação de hidrogênio (C4 - H4 ... S) está em verde, com o hidrogênio da ligação em preto.

\subsection{Discussão dos Resultados}

Os compostos com $\left[\mathrm{TIMe}_{2}\right]^{+}$apresentaram uma grande propensão a formar agregados supramoleculares quando ligados as mercapto piridinas. Essa facilidade ou predisposição a formação de arranjos se deve, em parte, a uma versatilidade ocupacional dos grupos COOR para se ligarem ao íon metálico do $\left[\mathrm{TIMe}_{2}\right]^{+}$. Ao mesmo tempo, a alta eletronegatividade dos átomos de $\mathrm{O}, \mathrm{N}$ e $\mathrm{S}$ dos ligantes fazem 
com que haja uma importante redistribuição da carga eletrônica em torno do átomo de Tálio.

As distâncias das ligações Tl - S [2,777(2) - 3,087(2) Å] obtidas para estes compostos são consistentes com as interações $\mathrm{Tl}$ - $\mathrm{S}$ observadas e graficadas da base de dados CSD. Portanto, algumas distâncias Tl - S mais longas [3,193(2) - 3,379(2) Å] sugerem interações tálio-enxofre fracas. O amplo intervalo de valores obtidos se deve ao fato de coexistir mais de um tipo de interação $\mathrm{Tl}-\mathrm{S}$, sendo as mais curtas de um caráter mais covalente do que as mais longas.

Os comprimentos das ligações $\mathrm{Tl}$ - O [2,522(3) e 2,589(3) Å] podem ser consideradas de médio a forte quando comparadas à distribuição encontrada das interações $\mathrm{Tl}-\mathrm{O}$ com base na CSD. Já a interação $\mathrm{Tl}-\mathrm{O}=3,212(2) \AA ̊$ do composto III é mais curta que a soma dos raios de van der Waals ( $\mathrm{Tl}-\mathrm{O}=3,87 \AA$ ) (Batsanov, 1999) e é consistente com uma interação metaloxigênio muito fraca.

As distâncias das ligações $\mathrm{Tl}$ - $\mathrm{N}$ estão em um intervalo de 2,553(5) 2,620(6) Å. Estes valores são muito menores que a soma dos raios de van der Waals $(\mathrm{Tl}-\mathrm{N}=3,55 \AA$ A $)($ Batsanov, 1999) e encontra-se abaixo da média encontrada na base CSD, 2,590 Å. Há apenas uma ligação com uma distância levemente acima, 2,620(6) А.

As distâncias das ligações C -S [1,715(5) - 1,745(5) Å] são mais curtas que a distância de ligação simples $\mathrm{C}$ - S (1,79 ̊), mas maiores que a distância de uma ligação dupla $\mathrm{C}=\mathrm{S}(1,69 \AA ̊$ ), o que pode ser entendido como uma ligação de caráter intermediário. As distâncias das interações carbono-oxigênio para os compostos de II a V [1,209(7) - 1,269(5) Å] dos grupos COOR são consistentes com uma ligação dupla $\mathrm{C}=\mathrm{O}$, para o oxigênio interagindo com o metal pesado. 
A esfera de coordenação do dimetil - tálio foi preenchida por interações do tipo $\mathrm{Tl}-\mathrm{S}, \mathrm{Tl}-\mathrm{O}$ e $\mathrm{Tl}-\mathrm{N}$. Havendo diferentes conformações para os compostos. Em todos os compostos o íon metálico apresenta seis posições coordenadas, sendo duas axiais preenchidas pelos grupos metil e outras quatro equatoriais preenchidas pelos ligantes. As quatro coordenações equatoriais, apresentaram em geral, duas de caráter mais forte (comprimento de ligações menores que a média obtida pela CSD) e outras duas mais fracas. No composto I, há duas interações, $\mathrm{Tl}$ - $\mathrm{O}$, mais rígidas e duas $\mathrm{Tl}$ - $\mathrm{S}$ sendo uma mais fraca e outra de média intensidade. Já nos outros compostos prevaleceram as interações $\mathrm{Tl}-\mathrm{S}$ e $\mathrm{Tl}-\mathrm{N}$ que apresentaram maior rigidez e outras mais fracas sendo $\mathrm{Tl}-\mathrm{S}$ e $\mathrm{Tl}-\mathrm{O}$, excetuando o composto $\mathrm{IV}$ onde a interação $\mathrm{Tl}$ - O dá lugar a uma outra interação $\mathrm{Tl}$ - S. 


\section{Compostos Corrigidos por Absorção}

\subsection{Introdução}

Existem várias formas de correções dos dados de difração de raios $\mathrm{X}$ em monocristais. Durante o processamento das intensidades coletadas realizam-se várias correções, tais como: Lorentz, polarização, absorção e eventualmente correção por deterioração da amostra. No caso de coleta de dados feitas em difratômetros equipados com detector de área, esta última correção não é muito necessária, devido ao menor tempo na aquisição de dados.

A correção por absorção é fortemente recomendada para cristais que possuem fortes absorvedores em sua forma estrutural. Hoje existem recomendações precisas sobre o tolerável para o aceite em revistas publicadas pela IUCr (International Union of Crystallography). Nas instruções para autores da "Acta Crystallographica, Section C" é dito o seguinte: "correções analíticas e numéricas são fortemente recomendada se $\mu R$ exceder a 1,0 e obrigatória se $\mu R$ estiver acima de 3,0 . Com $\mu R$ abaixo de 0,1 as correções são usualmente desnecessárias, caso contrario métodos semi-empíricos ou empíricos são aceitáveis. Métodos de absorção por refinamento são desencorajados, exceto em circunstâncias especiais". Onde $\mu$ refere-se ao coeficiente 
de absorção e $R$ é a metade da maior dimensão do cristal, também conhecido como raio médio do cristal.

A linha de pesquisa da qual o presente trabalho faz parte, envolve o estudo de complexos de ligante orgânico com metais pesados. Daí surgiu-se o interesse em estudar os efeitos da absorção dos raios X em amostras cristalinas, assim como fazer uma comparação dos resultados obtidos ao aplicar os diferentes métodos de correções por absorção disponíveis. Os cristais foram escolhidos de maneira que abordasse um grande número de átomos pesados distintos, dentre os metais e metais de transição. Porém, fram escolhidos somente aqueles complexos para os quais a indexação das faces estivesse disponível.

Como as características atômicas da estrutura cristalográfica influenciam diretamente no fator de absorção do feixe de raios $\mathrm{X}$ difratado. Em um primeiro momento serão apresentados neste capítulo alguns dados cristalográficos das estruturas escolhidas.

Em um segundo momento serão discutidas as diferentes figuras de mérito, assim como o excesso e ausência de densidade de carga residuais (highest peak e deepest hole ) no mapa diferença de Fourrier para cada composto corrigido, pelos diferentes métodos de correção por absorção. Também serão analisadas as mudanças nos parâmetros de deslocamento anisotrópicos e por último serão apresentados e discutidos os comprimentos e ângulos de ligações em torno do átomo pesado. 


\subsection{Compostos Analisados}

Foram coletados os dados de 15 (quinze) compostos contendo diferentes tipos de átomo pesados e resolvidas suas respectivas estruturas cristalográficas. As coletas de dados foram feitas em 2 (dois) difratômetros distintos. Os compostos aqui estudados serão rotulados por algarismos romanos de I - XV. Os compostos de I VIII foram coletados em um difratômetro Nonius Kappa CCD a baixa temperatura, equipados com detectores de área, já os compostos e IX - XV foram coletados em um difratômetro Enraf-Nonius CAD4 a temperatura ambiente. Figuras e tabelas com os dados cristalográficos destes compostos estão mostrados no Anexo C.

Serão mostrados abaixo um esquema das estruturas cristalográficas e alguns parâmetros do cristal nas tabelas 4.1 e 4.2 .

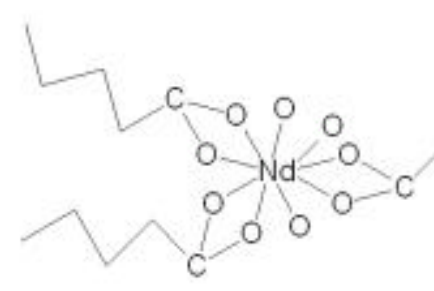

(l)<smiles>C[SH](C)(C)(O)[R]1(Cl)OC(N)NN1CC1CCC(N(O)O)O1</smiles>

(III)

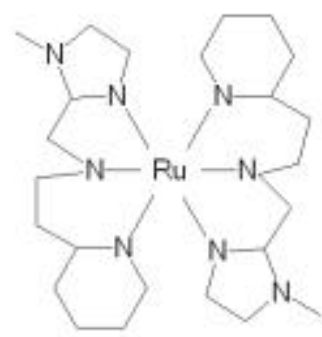

(II)

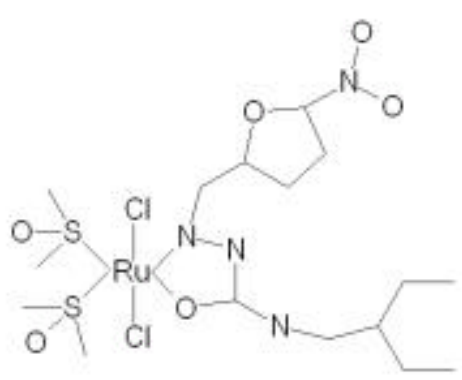

(IV) 


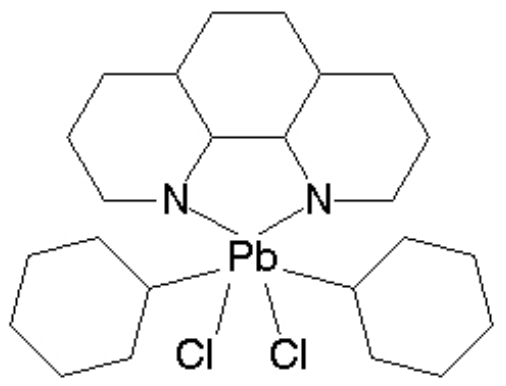

(v)

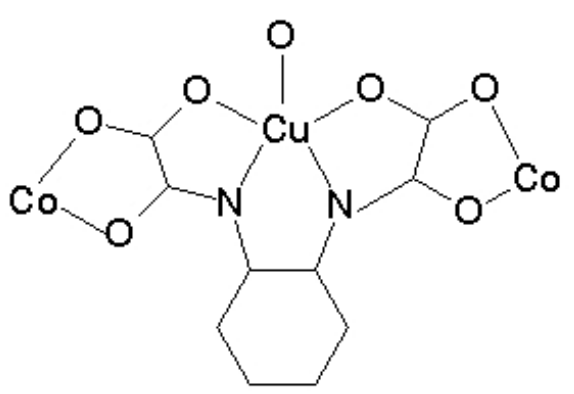

(VII)

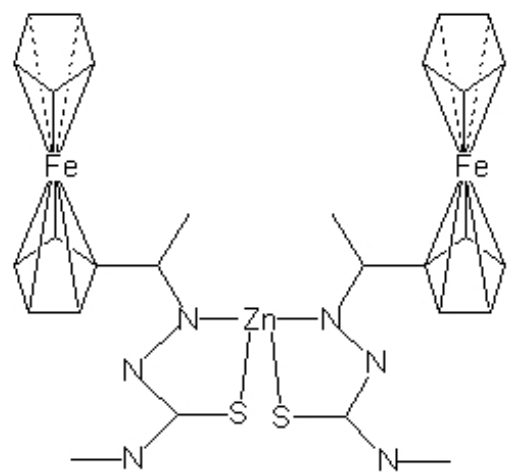

(IX)

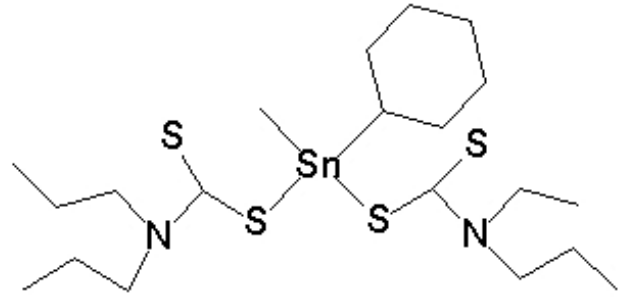

(VI)

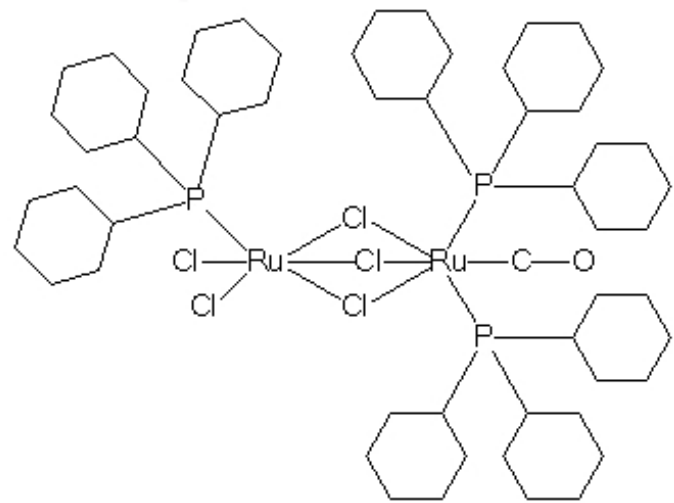

(VIII)

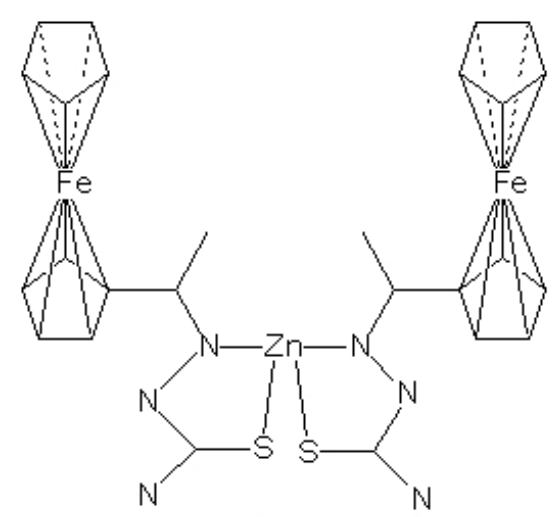

(X) 


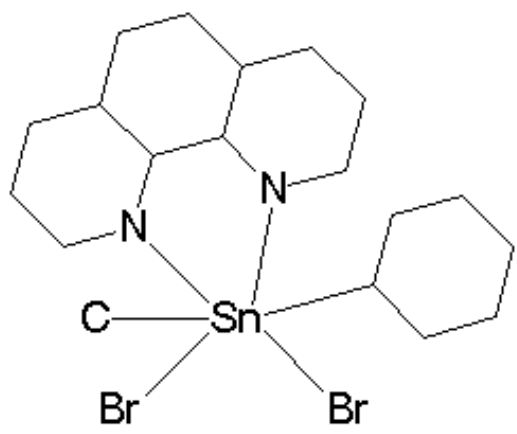

(XI)

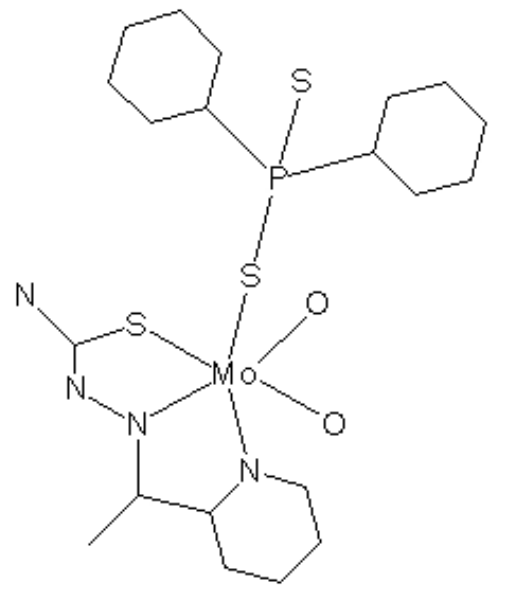

(XII)
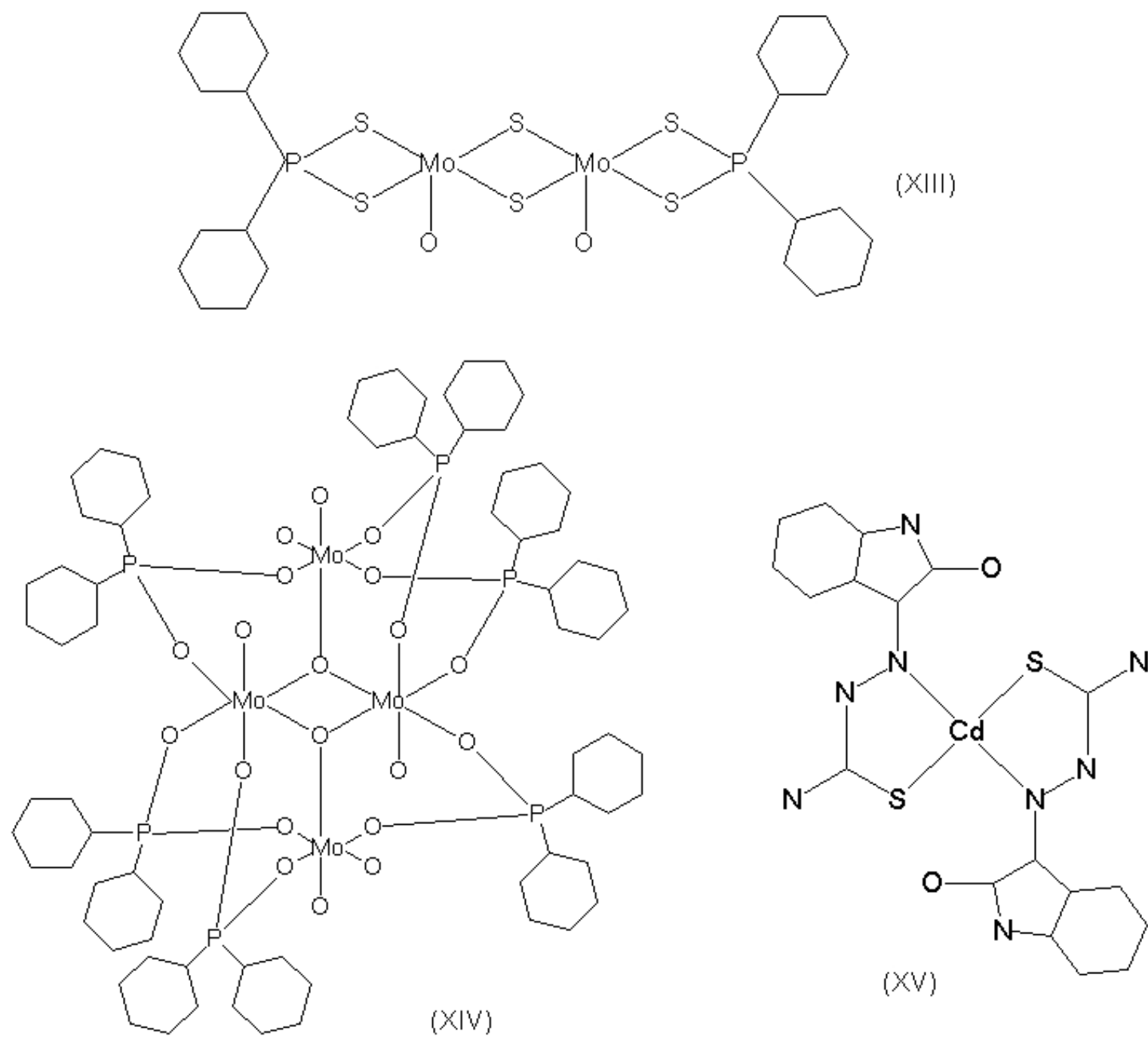

(XV) 
Tabela 4.2: Parâmetros cristalinos selecionados dos compostos analisados.

\begin{tabular}{|c|c|c|c|c|c|}
\hline Composto & $\rho\left(\mathrm{g} / \mathrm{cm}^{3}\right)$ & $\begin{array}{c}\text { Volume da } \\
\text { cela }\left(\AA^{3}\right)\end{array}$ & $\mu\left(\mathbf{m m}^{-1}\right)$ & $\mu \mathbf{R}$ & HM (Z) \\
\hline $\mathbf{I}$ & 2,057 & 2398,23 & 4,35 & 1,479 & $\mathrm{Nd}(60)$ \\
\hline II & 1,655 & 1434,02 & 0,79 & 0,190 & $\mathrm{Ru}(44)$ \\
\hline III & 1,890 & 3692,12 & 1,40 & 0,245 & $\mathrm{Ru}(44)$ \\
\hline IV & 1,622 & 1163,84 & 1,12 & 0,358 & $\mathrm{Ru}(44)$ \\
\hline $\mathbf{V}$ & 1,884 & 4319,84 & 8,07 & 1,614 & $\mathrm{~Pb}(82)$ \\
\hline VI & 1,340 & 2792,69 & 1,22 & 0,415 & Sn (50) \\
\hline VII & 1,685 & 2384,49 & 1,90 & 0,228 & $\mathrm{Co}(27)$ e $\mathrm{Cu}(29)$ \\
\hline VIII & 1,685 & 5241,59 & 1,04 & 0,270 & $\mathrm{Ru}(44)$ \\
\hline IX & 1,626 & 2834,42 & 10,70 & 2,012 & $\mathrm{Fe}(26)$ e $\mathrm{Zn}(30)$ \\
\hline $\mathbf{X}$ & 1,574 & 4600,09 & 9,91 & 1,506 & $\mathrm{Fe}(26)$ e $\mathrm{Zn}(30)$ \\
\hline $\mathbf{X I}$ & 1,760 & 1914,97 & 14,35 & 4,305 & Sn (50) \\
\hline XII & 1,511 & 10172,03 & 7,32 & 1,464 & Mo (42) \\
\hline XIII & 1,742 & 2960,07 & 11,69 & 2,806 & Mo (42) \\
\hline XIV & 1,546 & 1948,95 & 6,89 & 2,205 & Mo (42) \\
\hline$\overline{X V}$ & 1,503 & 2034,31 & 6,23 & 4,548 & $\mathrm{Cd}(48)$ \\
\hline
\end{tabular}

$\mathrm{R}$ - raio médio do cristal, $\mathrm{HM}$ - átomo pesado (heavy metal), $\mathrm{Z}$ - número atômico

\subsection{Figuras de Mérito ou Parâmetros de Concordância}

Aqui serão discutidas as mudanças ocorridas nas figuras de mérito (parâmetros de concordância) e picos de excesso e vales de densidade de carga no mapa residual de Fourrier dos compostos listados nas tabelas 4.3, 4.4, 4.5, 4.6 e 4.7, antes e após terem sido feitas as correções por absorção. As figuras de mérito são ferramentas indicativas de quanto o modelo proposto se aproxima do modelo observado. Uma descrição simplificada das figuras de mérito mencionadas e abordadas neste trabalho, encontra-se no Anexo B. 
Nos compostos III, IV, V, VI, IX e XII constatou-se uma pequena melhora nas figuras de mérito após a correção por absorção da forma analítica, como pode ser visto nas tabelas 4.3, 4.4, 4.5, 4.6 e 4.7. Os compostos IV e XII apresentaram uma pequena melhora na concordância dos modelos após a correção por absorção. Já os compostos V, VI e IX apresentaram bons resultados após o refinamento do modelo sem corrigir por absorção, portanto não houve uma margem muito grande para minimizar o R1, mas o método analítico ainda assim melhorou a concordância nos mapas calculados e observados.

O composto II apresentou um comportamento atípico depois de realizadas as diferentes correções por absorção. Foram feitas as correções analíticas, semiempíricas e empíricas, onde a correção empírica do tipo DFABS apresentou o melhor resultado, o que geralmente é esperado devido à metodologia usada para calcular a superfície de absorção. Há uma grande possibilidade do insucesso ser devido ao baixo $\mu R$ da amostra, o que determina uma maior viabilidade na utilização de métodos empíricos e semi-empíricos, como pode ser visto nas tabelas 4.3, 4.4, 4.5, 4.6 e 4.7 .

Um exemplo típico de erro na correção por absorção ocorreu para o composto XIII. Este composto apresentou um coeficiente de absorção altíssimo, 11,69 mm $\mathrm{mm}^{-1}$, mesmo aliado à escolha de um cristal de dimensões reduzidas, o seu $\mu R$ ainda continuou alto, 2,806. Após as correções por absorção, constatourse que a analítica apresentou os piores resultados, possivelmente esses resultados foram devido a uma má determinação da forma e tamanho do cristal, junto como uma indexação das faces errônea.

Já os compostos VII e VIII permaneceram com seus parâmetros praticamente iguais após as correções por absorção, novamente devido ao fato que o $\mu R$ dos 
cristais foram muito baixos o que não levaria a uma absorção relevante da radiação pelo cristal.

Com uma boa escolha do cristal, indexação das faces cristalinas e uma correta definição nos parâmetros para a coleta de dados, são possíveis minimizar drasticamente os erros e consequentemente, melhorar os parâmetros de concordância. Os cristais dos compostos I, X, XI, XIV e XV apresentavam boas características morfológicas antes da coleta de dados e posteriormente após uma coerente indexação das faces e medidas das dimensões cristalinas, foram aplicados os diferentes tipos de correções por absorção. A que apresentou os melhores resultados foi a correção por absorção analítica. 
Tabela 4.3: Valores das figuras de mérito e outros dados sem correção por absorção.

\begin{tabular}{|c|c|c|c|c|c|c|c|c|c|c|c|c|}
\hline \multirow[t]{2}{*}{ Composto } & \multicolumn{3}{|c|}{ HP } & \multicolumn{3}{|c|}{ DH } & \multirow[t]{2}{*}{$\mathbf{R} 1$} & \multirow[t]{2}{*}{$\mathbf{R} 1^{\$}$} & \multirow[t]{2}{*}{$\mathbf{R}($ Int $)$} & \multirow[t]{2}{*}{$\mathbf{R}(\sigma)$} & \multirow[t]{2}{*}{ Goof S } & \multirow[t]{2}{*}{ wR2 } \\
\hline & Altura & Distância & Átomo & Profundidade & Distância & Átomo & & & & & & \\
\hline I & 1,63 & 0,05 & $\mathrm{Nd} 1$ & 2,34 & 0,92 & $\mathrm{Nd1}$ & 0,0519 & 0,0560 & 0,1266 & 0,0669 & 1,381 & 0,1531 \\
\hline II & 0,78 & 0,99 & C9 & 0,61 & 0,97 & Ru1 & 0,0457 & 0,0457 & 0,0601 & 0,0369 & 1,060 & 0,1218 \\
\hline III & 1,65 & 1,10 & S21 & 1,60 & 1,19 & $\mathrm{Ru} 2$ & 0,0801 & 0,1273 & 0,2203 & 0,1145 & 1,183 & 0,2232 \\
\hline IV & 3,21 & 0,06 & $\mathrm{C} 3$ & 1,74 & 0,92 & Ru1 & 0,0538 & 0,0633 & 0,0590 & 0,0325 & 1,218 & 0,1715 \\
\hline $\mathbf{V}$ & 1,95 & 1,34 & Pb1c & 1,46 & 0,92 & Pb1c & 0,0342 & 0,0291 & 0,1483 & 0,0622 & 1,127 & 0,0926 \\
\hline VI & 1,09 & 0,01 & Sn1 & 0,46 & 0,92 & Sn1 & 0,0325 & 0,0333 & 0,0662 & 0,0248 & 0,538 & 0,1294 \\
\hline VII & 0,80 & 0,52 & $\mathrm{H} 21 \mathrm{E}$ & 0,99 & 0,80 & $\mathrm{Cu}$ & 0,0479 & 0,0637 & 0,0486 & 0,0327 & 1,522 & 0,1479 \\
\hline VIII & 0,86 & 1,26 & P1 & 1,25 & 0,92 & Ru1 & 0,0541 & 0,0696 & 0,1360 & 0,0650 & 1,202 & 0,1483 \\
\hline IX & 0,49 & 2,28 & H14A & 0,82 & 1,43 & $\mathrm{Zn} 1$ & 0,0443 & 0,0785 & 0,0541 & 0,0529 & 1,166 & 0,1138 \\
\hline $\mathbf{X}$ & 0,57 & 1,14 & $\mathrm{Fe}$ & 0,81 & 0,86 & $\mathrm{Zn}$ & 0,0589 & 0,1361 & 0,1128 & 0,1036 & 1,227 & 0,1227 \\
\hline XI & 2,72 & 1,29 & Sn1 & 2,46 & 0,97 & Sn1 & 0,0946 & 0,1546 & 0,0426 & 0,0502 & 1,839 & 0,2289 \\
\hline XII & 0,90 & 0,85 & $\mathrm{O} 2$ & 0,95 & 0,53 & S11 & 0,0499 & 0,0585 & 0,0746 & 0,0456 & 1,121 & 0,1406 \\
\hline XIII & 0,68 & 1,11 & S1 & 1,01 & 0,85 & Mo2 & 0,0388 & 0,0483 & 0,0286 & 0,0232 & 1,040 & 0,1104 \\
\hline XIV & 3,02 & 0,95 & Mo1 & 2,03 & 1,01 & Mo1 & 0,0656 & 0,0760 & 0,0368 & 0,0279 & 1,399 & 0,1701 \\
\hline $\mathbf{X V}$ & 3,28 & 1,06 & $\mathrm{Cd} 1$ & 3,44 & 0,86 & $\mathrm{Cd} 1$ & 0,0969 & 0,0991 & 0,0717 & 0,0202 & 1,364 & 0,2367 \\
\hline
\end{tabular}

\$ - R1 depois do merge por Fourrier; HP - Pico mais alto (Highest Peak); DP - Poço mais fundo (Deepest Hole) 
Tabela 4.4: Valores das figuras de mérito e outros dados com correção por absorção do tipo semi-empírico.

\begin{tabular}{|c|c|c|c|c|c|c|c|c|c|c|c|c|}
\hline \multirow[t]{2}{*}{ Composto } & \multicolumn{3}{|c|}{ HP } & \multicolumn{3}{|c|}{ DH } & \multirow[t]{2}{*}{ R1 } & \multirow[t]{2}{*}{ R1 ${ }^{\$}$} & \multirow[t]{2}{*}{$\mathbf{R}($ Int $)$} & \multirow[t]{2}{*}{$\mathbf{R}(\sigma)$} & \multirow[t]{2}{*}{ Goof $S$} & \multirow[t]{2}{*}{ wR2 } \\
\hline & Altura & Distânciz & Átomo & Profundidade & Distânci & Átomo & & & & & & \\
\hline $\mathbf{I}^{*}$ & 1,82 & 0,06 & $\mathrm{Nd} 1$ & 2,45 & 0,86 & $\mathrm{Nd} 1$ & 0,0560 & 0,0601 & 0,0000 & 0,0656 & 1,427 & 0,1570 \\
\hline II $^{*}$ & 0,82 & 0,99 & C9 & 0,60 & 0,82 & C11 & 0,0464 & 0,0464 & 0,0000 & 0,0407 & 1,055 & 0,1234 \\
\hline III $^{*}$ & 1,54 & 1,12 & S21 & 1,58 & 1,19 & $\mathrm{Ru} 2$ & 0,0781 & 0,1324 & 0,1761 & 0,1477 & 1,084 & 0,2209 \\
\hline IV $^{*}$ & 2,05 & 0,04 & Ru1 & 1,61 & 0,99 & Ru1 & 0,0528 & 0,0610 & 0,0000 & 0,0353 & 1,270 & 0,1720 \\
\hline $\mathbf{V}^{*}$ & 2,73 & 0,08 & Pb1b & 1,85 & 0,92 & Pb1c & 0,0399 & 0,0332 & 0,0000 & 0,0606 & 0,832 & 0,1090 \\
\hline $\mathbf{V I}^{*}$ & 1,24 & 0,01 & Sn1 & 0,63 & 0,95 & Sn1 & 0,0353 & 0,0359 & 0,0000 & 0,0268 & 1,403 & 0,1182 \\
\hline VII $^{*}$ & 0,84 & 0,44 & $\mathrm{H} 21 \mathrm{E}$ & 1,07 & 0,81 & $\mathrm{Cu}$ & 0,0488 & 0,0628 & 0,0000 & 0,0341 & 1,531 & 0,1464 \\
\hline VIII" $^{*}$ & 1,01 & 1,15 & $\mathrm{Ru} 2$ & 1,26 & 0,94 & Ru1 & 0,0557 & 0,0705 & 0,0000 & 0,0686 & 1,092 & 0,1476 \\
\hline $\mathbf{I X}^{\#}$ & 0,75 & 1,11 & Fe1 & 0,99 & 1,30 & $\mathrm{Zn} 1$ & 0,0507 & 0,0859 & 0,0657 & 0,0560 & 1,326 & 0,1277 \\
\hline $\mathbf{X}^{\#}$ & 0,42 & 1,17 & $\mathrm{Fe}$ & 0,70 & 0,83 & $\mathrm{Zn}$ & 0,0510 & 0,0859 & 0,0876 & 0,0928 & 1,138 & 0,1229 \\
\hline $\mathbf{X I}^{\#}$ & 2,04 & 1,03 & Sn1 & 1,65 & 1,03 & Sn1 & 0,0852 & 0,1233 & 0,0403 & 0,0446 & 1,663 & 0,2102 \\
\hline $\mathbf{X I I}^{\#}$ & 0,92 & 0,88 & Mo & 0,99 & 0,51 & S11 & 0,0506 & 0,0594 & 0,0551 & 0,0424 & 1,137 & 0,1421 \\
\hline XIII $^{\#}$ & 0,71 & 1,09 & S1 & 1,02 & 0,85 & Mo2 & 0,0391 & 0,0487 & 0,0286 & 0,0232 & 1,047 & 0,1112 \\
\hline $\mathbf{X I V}^{\#}$ & 1,83 & 1,09 & O11 & 2,11 & 0,95 & Mo2 & 0,0565 & 0,0670 & 0,0432 & 0,0282 & 1,275 & 0,1552 \\
\hline $\mathbf{X} \mathbf{V}^{\#}$ & 2,25 & 0,98 & $\mathrm{Cd} 1$ & 2,46 & 0,91 & $\mathrm{Cd} 1$ & 0,0784 & 0,0805 & 0,0633 & 0,0202 & 1,262 & 0,2188 \\
\hline
\end{tabular}

$\$$ - R1 depois do merge por Fourrier; HP - Pico mais alto (Highest Peak); DP - Poço mais fundo (Deepest Hole) 
Tabela 4.5: Valores das figuras de mérito e outros dados com correção por absorção do tipo analítica.

\begin{tabular}{|c|c|c|c|c|c|c|c|c|c|c|c|c|}
\hline \multirow[t]{2}{*}{ Composto } & \multicolumn{3}{|c|}{ HP } & \multicolumn{3}{|c|}{ DH } & \multirow[t]{2}{*}{ R1 } & \multirow[t]{2}{*}{$\mathbf{R 1}^{\mathrm{s}}$} & \multirow[t]{2}{*}{$\mathbf{R}($ Int $)$} & \multirow[t]{2}{*}{$\mathbf{R}(\sigma)$} & \multirow[t]{2}{*}{ Goof S } & \multirow[t]{2}{*}{ wR2 } \\
\hline & Altura & Distância & Átomo & Profundidade & Distância & Átomo & & & & & & \\
\hline I & 1,38 & 0,96 & $\mathrm{O} 1 \mathrm{~W}$ & 1,56 & 0,96 & $\mathrm{Nd1}$ & 0,0403 & 0,0444 & 0,0810 & 0,0476 & 1,258 & 0,1276 \\
\hline II & 0,79 & 1,00 & C9 & 0,80 & 0,96 & Ru1 & 0,0465 & 0,0464 & 0,0611 & 0,0372 & 1,071 & 0,1225 \\
\hline III & 1,52 & 1,10 & S21 & 1,67 & 1,19 & $\mathrm{Ru} 2$ & 0,0789 & 0,1259 & 0,2122 & 0,1110 & 1,177 & 0,2205 \\
\hline IV & 1,94 & 0,15 & $\mathrm{C} 3$ & 1,74 & 0,95 & Ru1 & 0,0509 & 0,0596 & 0,0627 & 0,0338 & 1,263 & 0,1650 \\
\hline $\mathbf{V}$ & 1,93 & 1,34 & Pb1c & 1,41 & 0,84 & Pb1a & 0,0330 & 0,0282 & 0,1342 & 0,0567 & 1,143 & 0,0884 \\
\hline VI & 0,88 & 0,02 & Sn1 & 0,62 & 0,89 & Sn1 & 0,0304 & 0,0309 & 0,0739 & 0,0266 & 1,361 & 0,1121 \\
\hline VII & 0,80 & 0,52 & $\mathrm{H} 21 \mathrm{E}$ & 0,99 & 0,80 & $\mathrm{Cu}$ & 0,0479 & 0,0637 & 0,0486 & 0,0327 & 1,522 & 0,1479 \\
\hline VIII & 0,85 & 1,08 & Ru1 & 1,33 & 0,91 & Ru1 & 0,0543 & 0,0698 & 0,1356 & 0,0649 & 1,154 & 0,1520 \\
\hline IX & 0,46 & 1,20 & Fe1 & 0,70 & 1,45 & $\mathrm{Zn} 1$ & 0,0434 & 0,0788 & 0,0453 & 0,0531 & 1,158 & 0,1115 \\
\hline $\mathbf{X}$ & 0,36 & 1,12 & $\mathrm{Fe}$ & 0,49 & 0,83 & $\mathrm{Zn}$ & 0,0471 & 0,1233 & 0,0901 & 0,0922 & 1,055 & 0,1167 \\
\hline XI & 1,13 & 0,90 & N1 & 0,72 & 1,03 & Sn1 & 0,0575 & 0,1145 & 0,0417 & 0,0447 & 1,224 & 0,1582 \\
\hline XII & 0,96 & 0,89 & $\mathrm{O} 2$ & 0,96 & 0,55 & S11 & 0,0477 & 0,0574 & 0,0554 & 0,0428 & 1,093 & 0,1367 \\
\hline XIII & 1,12 & 1,38 & Mo1 & 0,73 & 0,86 & Mo2 & 0,0415 & 0,0508 & 0,0523 & 0,0246 & 1,046 & 0,1125 \\
\hline XIV & 0,95 & 0,93 & Mo2 & 1,51 & 1,01 & Mo1 & 0,0430 & 0,0536 & 0,0393 & 0,0276 & 1,024 & 0,1257 \\
\hline $\mathbf{X V}$ & 1,54 & 1,14 & $\mathrm{Cd} 1$ & 1,38 & 0,88 & $\mathrm{Cd} 1$ & 0,0623 & 0,0645 & 0,0606 & 0,0189 & 1,024 & 0,1823 \\
\hline
\end{tabular}

\$ - R1 depois do merge por Fourrier; HP - Pico mais alto (Highest Peak); DP - Poço mais fundo (Deepest Hole) 
Tabela 4.6: Valores das figuras de mérito e outros dados com correção por absorção do tipo DFABS.

\begin{tabular}{|c|c|c|c|c|c|c|c|c|c|c|c|c|}
\hline \multirow[t]{2}{*}{ Composto } & \multicolumn{3}{|c|}{ HP } & \multicolumn{3}{|c|}{ DH } & \multirow[t]{2}{*}{ R1 } & \multirow[t]{2}{*}{$\mathrm{R1}^{\mathrm{s}}$} & \multirow[t]{2}{*}{ R(Int) } & \multirow[t]{2}{*}{$\mathbf{R}(\sigma)$} & \multirow[t]{2}{*}{ Goof $S$} & \multirow[t]{2}{*}{ wR2 } \\
\hline & Altura & Distânci: & Átomo & Profundidade & Distânciء & Átomo & & & & & & \\
\hline $\mathbf{I}$ & 1,36 & 0,97 & O1W & 1,40 & 0,95 & $\mathrm{Nd} 1$ & 0,0397 & 0,0440 & 0,0776 & 0,0458 & 1,263 & 0,1272 \\
\hline II & 0,79 & 1,00 & C9 & 0,46 & 0,31 & H7B & 0,0419 & 0,0417 & 0,0411 & 0,0328 & 1,005 & 0,1143 \\
\hline III & 0,86 & 0,43 & $\mathrm{H} 28 \mathrm{C}$ & 1,68 & 1,15 & $\mathrm{Ru} 2$ & 0,0716 & 0,1206 & 0,1920 & 0,1033 & 1,191 & 0,1916 \\
\hline IV & 1,80 & 0,32 & C3 & 1,49 & 1,57 & Ru1 & 0,0496 & 0,0590 & 0,0478 & 0,0299 & 1,227 & 0,1667 \\
\hline $\mathbf{V}$ & - & - & - & - & - & - & - & - & - & - & - & - \\
\hline VI & 0,50 & 2,28 & $\mathrm{H} 14 \mathrm{~A}$ & 0,43 & 1,56 & Sn1 & 0,0380 & 0,0659 & 0,0000 & 0,0526 & 0,991 & 0,0975 \\
\hline VII & 0,94 & 0,34 & $\mathrm{H} 21 \mathrm{~F}$ & 1,63 & 1,39 & $\mathrm{Cu}$ & 0,0903 & 0,1089 & 0,1181 & 0,0480 & 1,741 & 0,2351 \\
\hline VIII & 0,76 & 0,90 & Ru1 & 1,11 & 0,77 & Ru2 & 0,0503 & 0,0660 & 0,1062 & 0,0557 & 1,107 & 0,1399 \\
\hline IX & 0,50 & 2,28 & $\mathrm{H} 14 \mathrm{~A}$ & 0,43 & 1,56 & Zn1 & 0,0380 & 0,0659 & 0,0000 & 0,0526 & 0,991 & 0,0975 \\
\hline $\mathbf{X}$ & 0,34 & 0,42 & C31 & 0,27 & 0,15 & $\mathrm{Zn}$ & 0,0405 & 0,1053 & 0,0000 & 0,0874 & 0,943 & 0,1000 \\
\hline XI & 1,11 & 0,97 & Sn1 & 0,95 & 0,96 & Sn1 & 0,0576 & 0,1033 & 0,0000 & 0,0427 & 1,126 & 0,1473 \\
\hline XII & - & - & - & - & - & - & - & - & - & - & - & - \\
\hline XIII & 0,63 & 1,01 & S1 & 0,59 & 0,81 & Mo2 & 0,0345 & 0,0432 & 0,0000 & 0,0228 & 0,944 & 0,1003 \\
\hline XIV & - & - & - & - & - & - & - & - & - & - & - & - \\
\hline $\mathbf{X V}$ & 1,24 & 0,96 & $\overline{C d 1}$ & 1,03 & 0,80 & $\mathrm{Cd} 1$ & 0,0675 & 0,0698 & 0,0000 & 0,0201 & 1,096 & 0,1960 \\
\hline
\end{tabular}

$\$$ - R1 depois do merge por Fourrier; HP - Pico mais alto (Highest Peak); DP - Poço mais fundo (Deepest Hole) 
Tabela 4.7: Valores das figuras de mérito e outros dados com correção por absorção do tipo XABS2.

\begin{tabular}{|c|c|c|c|c|c|c|c|c|c|c|c|c|}
\hline \multirow[t]{2}{*}{ Composto } & \multicolumn{3}{|c|}{ HP } & \multicolumn{3}{|c|}{ DH } & \multirow[t]{2}{*}{ R1 } & \multirow[t]{2}{*}{$\mathbf{R} 1^{\$}$} & \multirow[t]{2}{*}{$\mathbf{R}($ Int $)$} & \multirow[t]{2}{*}{$\mathbf{R}(\sigma)$} & \multirow[t]{2}{*}{ Goof $S$} & \multirow[t]{2}{*}{ wR2 } \\
\hline & Altura & Distânciz & Átomo & Profundidade & Distância & Átomo & & & & & & \\
\hline $\mathbf{I}$ & 2,30 & 0,79 & $\mathrm{O} 1 \mathrm{~W}$ & 1,66 & 1,08 & $\mathrm{Nd} 1$ & 0,0475 & 0,0517 & 0,0782 & 0,0457 & 1,463 & 0,1485 \\
\hline II & 0,82 & 1,00 & C9 & 0,49 & 0,29 & H7B & 0,0454 & 0,0451 & 0,0425 & 0,0324 & 1,082 & 0,1121 \\
\hline III & 0,85 & 0,44 & $\mathrm{H} 28 \mathrm{C}$ & 1,49 & 1,10 & $\mathrm{Ru} 2$ & 0,0710 & 0,1195 & 0,1908 & 0,1010 & 1,201 & 0,1874 \\
\hline IV & 1,81 & 0,32 & $\mathrm{C} 3$ & 1,43 & 1,60 & S1 & 0,0492 & 0,0586 & 0,0468 & 0,0301 & 1,243 & 0,1621 \\
\hline $\mathbf{V}$ & 1,49 & 1,31 & $\mathrm{~Pb} 1 \mathrm{c}$ & 1,24 & 0,83 & Pb1a & 0,0273 & 0,0275 & 0,0845 & 0,0424 & 1,098 & 0,0608 \\
\hline VI & 0,81 & 0,03 & Sn1 & 0,72 & 0,95 & Sn1 & 0,0347 & 0,0350 & 0,0700 & 0,0255 & 0,611 & 0,1253 \\
\hline VII & - & - & - & - & - & - & - & - & - & - & - & - \\
\hline VIII & 0,78 & 1,49 & Ru1 & 1,16 & 0,89 & Ru1 & 0,0507 & 0,0663 & 0,0930 & 0,0527 & 1,117 & 0,1397 \\
\hline IX & 0,57 & 2,28 & H14A & 0,56 & 1,50 & $\mathrm{Zn} 1$ & 0,0378 & 0,0726 & 0,0382 & 0,0521 & 1,043 & 0,1018 \\
\hline $\mathbf{X}$ & 0,33 & 0,41 & C31 & 0,34 & 0,11 & $\mathrm{Zn}$ & 0,0426 & 0,1210 & 0,0829 & 0,0900 & 1,013 & 0,1075 \\
\hline XI & 1,14 & 0,89 & N1 & 0,73 & 1,03 & Sn1 & 0,0574 & 0,1145 & 0,0417 & 0,0447 & 1,223 & 0,1581 \\
\hline XII & - & - & - & - & - & - & - & - & - & - & - & - \\
\hline XIII & 0,71 & 0,99 & $\mathrm{~S} 1$ & 0,47 & 0,79 & Mo2 & 0,0323 & 0,0400 & 0,0239 & 0,0214 & 0,933 & 0,0949 \\
\hline XIV & - & - & - & - & - & - & - & - & - & - & - & - \\
\hline $\mathbf{X V}$ & 1,01 & 1,63 & C26 & 1,84 & 0,87 & $\mathrm{Cd} 1$ & 0,0619 & 0,0646 & 0,0852 & 0,0211 & 0,999 & 0,1771 \\
\hline
\end{tabular}

$\$$ - R1 depois do merge por Fourrier; HP - Pico mais alto (Highest Peak); DP - Poço mais fundo (Deepest Hole) 


\subsection{Resultados}

Serão apresentados aqui os resultados obtidos para alguns compostos depois de efetuada todos os tipos de correção por absorção. Foram escolhidos os compostos que apresentaram os melhores resultados após a correção por absorção na forma analítica, levando a uma fácil visualização dos resultados.

\subsubsection{Composto I}

Este composto apresentou bons resultados após a correção por absorção analítica. Antes de executar qualquer tipo de correção, o maior pico de excesso de densidade de carga remanescente do mapa diferença de Fourrier era de 1,63 e/ $\AA^{3}$ a $0,05 \AA$ do átomo de Neodímio e o vale de densidade de carga era de $-2,34$ e/ $\AA^{3}$ a 0,92 Å do mesmo átomo. Após a correção de absorção analítica o pico de densidade de carga caiu para 1,38 e/ $\AA^{3}$ a $0,96 \AA$ do átomo de Oxigênio da água (O1w) e o vale de densidade de carga foi para $-1,56$ e/ $\AA^{3}$ a $0,96 \AA$ do átomo de Neodímio. A figura 4.1 mostra o mapa de densidade de carga remanescente do mapa diferença de Fourrier, $\mathrm{F}_{\mathrm{obs}}-\mathrm{F}_{\text {calc }}$, com os picos e vales de densidade de carga residual antes e depois da correção por absorção. A escala de cores variando do branco ao preto à direita de cada figura é indicativa da altura de cada pico. Esta mudança na posição do pico de excesso de densidade de carga para próximo do átomo de oxigênio da molécula de água do composto, pode ser uma desordem da molécula de água na estrutura cristalina ou um átomo de hidrogênio em uma posição distinta da que foi colocada. 


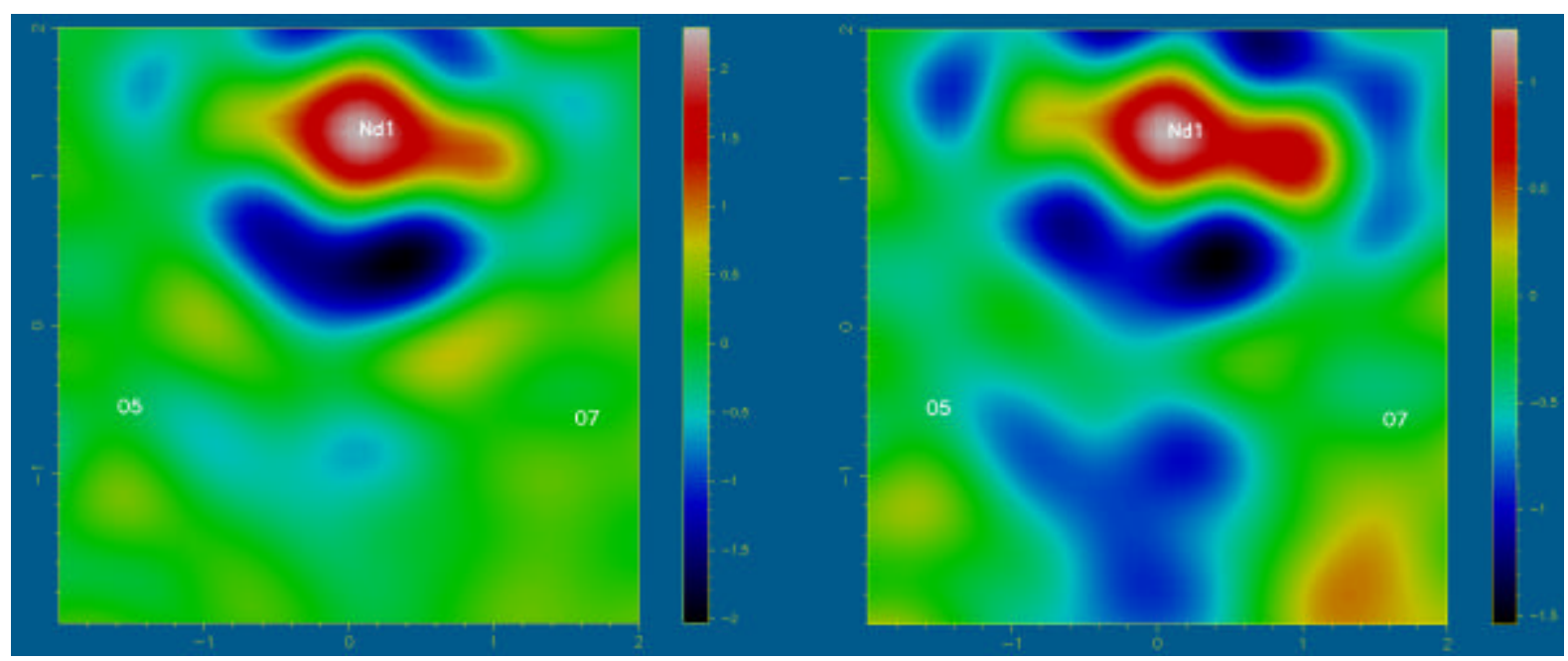

(a)

(b)

Figura 4.1: Mapas residuais de densidade carga, $\mathrm{F}_{\mathrm{obs}}-\mathrm{F}_{\text {calc }}$ para o composto $\mathrm{I}$, em azul é o maior vale de densidade de carga residual, os rótulos representam as posições atômicas no mapa: (a) antes da correção por absorção; (b) depois da correção por absorção analítica.

Depois de efetuada a correção por absorção analítica todos os outros parâmetros estatísticos tiveram reduções bastante significativas, tabelas 4.3 e 4.5, o $\mathrm{R} 1$ diminuiu de 0,0519, para 0,0403. Da mesma maneira o R(Int) diminuiu de 0,1266 para 0,0810 e o goof(S) ficou mais próximo de 1, após a correção. Houve também uma redistribuição no volume do elipsóide térmico do átomo de Neodímio e um redimensionamento do volume dos elipsóides dos oxigênios ligados ao átomo pesado, tabela D.1.

Nas distâncias e ângulos de ligações dos átomos em torno do átomo pesado aconteceram pequenas variações. A maior parte das distâncias diminuiu $(\mathrm{Nd}-\mathrm{O} 1$, $\mathrm{Nd}-\mathrm{O} 2, \mathrm{Nd}-\mathrm{O} 3, \mathrm{Nd}-\mathrm{O} 5$ e $\mathrm{Nd}-\mathrm{O} 6$ ) aproximando os átomos de oxigênio, como pode ser visto na tabela D.16. No restante das distâncias e ângulos de ligações não houve mudanças sensíveis. 


\subsubsection{Composto $X$}

A estrutura cristalográfica deste composto possui dois átomos pesados diferentes, ferro e zinco. O produto do coeficiente de absorção, $\mu$, pela espessura média, $R$, estava alto, $\mu R=1,506$. Daí a necessidade de corrigir as reflexões pelo método analítico. A correção analítica aumentou a concordância entre os modelos calculado e observado, tabela 4.5. O parâmetro goof(S) diminuiu de 1,227 para 1,055. Os picos relativos ao excesso de densidade de carga residuais e os vales de densidade de carga residuais diminuíram consideravelmente $\left(0,57 \mathrm{e} / \AA^{3}\right.$ a $1,14 \AA$ do átomo de Ferro para 0,36 e/ $\AA^{3}$ a $1,12 \AA$ do mesmo átomo, figura $4.2 ;-0,81$ e/ $\AA^{3}$ a 0,86 $\AA$ do átomo de Zinco para $-0,49$ e/ $\AA^{3}$ a $0,83 \AA$ do mesmo átomo, figura 4.3) após a correção por absorção analítica.

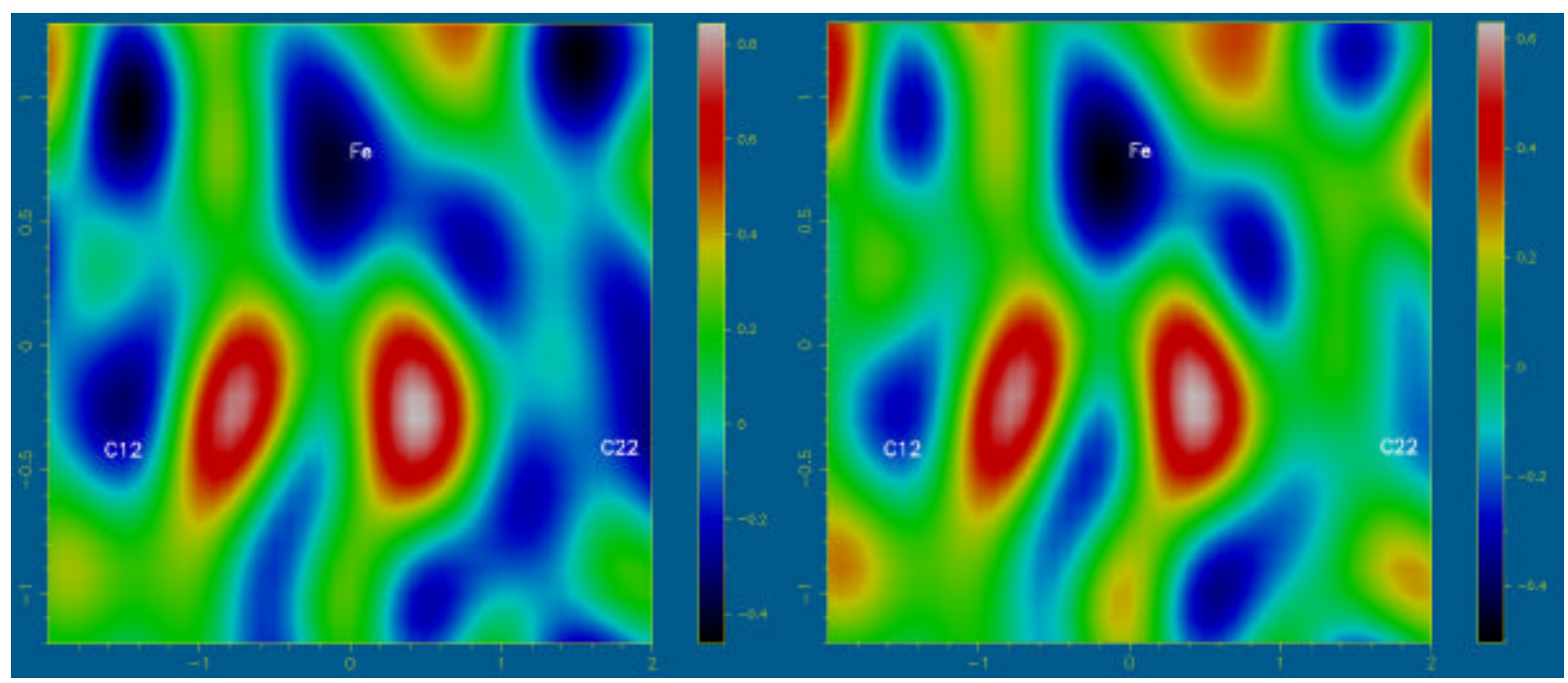

(a)

Figura 4.2: Mapas residuais de densidade carga, $F_{\text {obs }}-F_{\text {calc }}$ para o composto $X$, em vermelho é o maior pico de densidade de carga residual, os rótulos representam as posições atômicas no mapa: (a) antes da correção por absorção; (b) depois da correção por absorção analítica. 
Os parâmetros de deslocamentos anisotrópicos sofreram poucas alterações. As mudanças mais significantes ocorreram nos carbonos do ferroceno, havendo um ajuste no volume em seus elipsóides térmicos e mudanças nas direções de seus eixos principais. As distâncias e ângulos das ligações também sofreram pequenas variações.

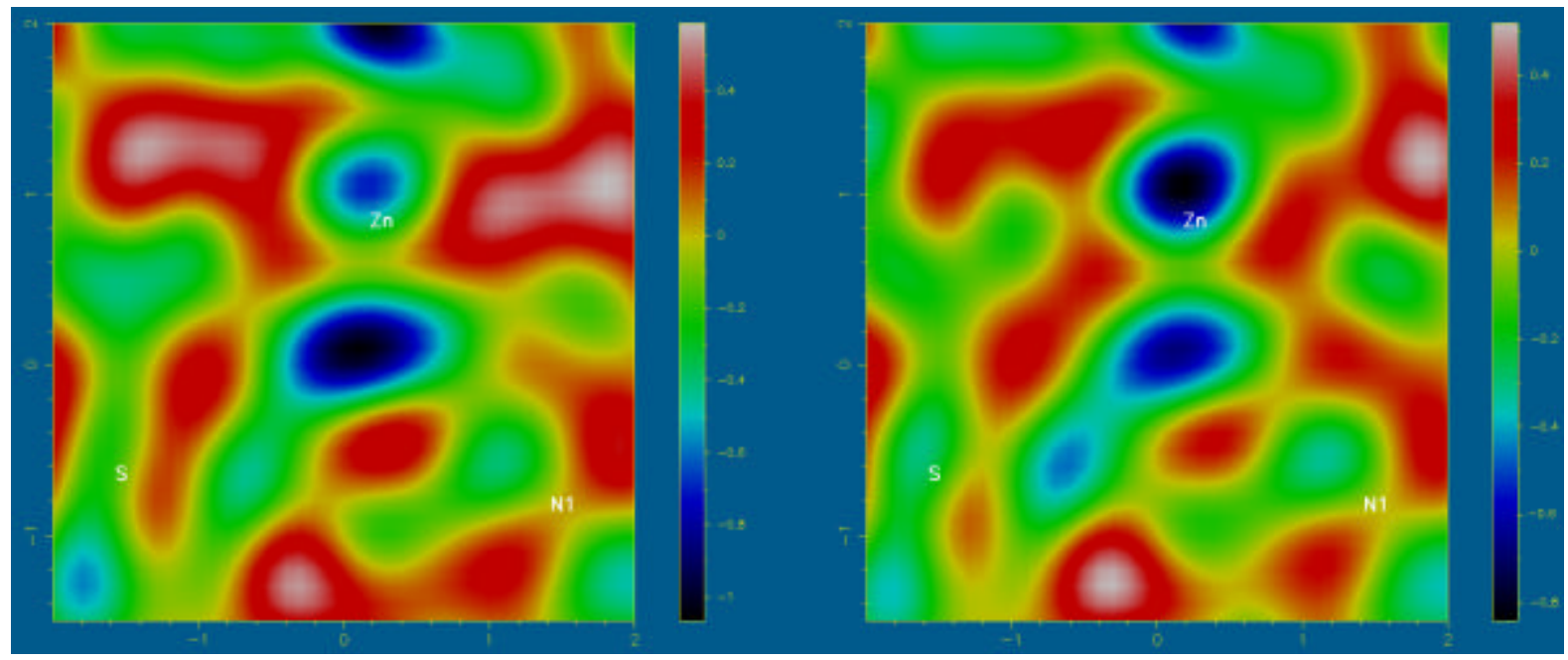

(a)

(b)

Figura 4.3: Mapas residuais de densidade carga, $F_{\text {obs }}-F_{\text {calc }}$ para o composto $X$, em azul é o maior vale de densidade de carga residual, os rótulos representam as posições atômicas no mapa: (a) antes da correção por absorção; (b) depois da correção por absorção analítica.

\subsubsection{Composto XIV}

Este composto possui dois átomos de Molibdênio em sua unidade assimétrica, portanto o seu coeficiente de absorção é de $6,89 \mathrm{~mm}^{-1}$, com $\mu R$ igual a 2,205. Daí a necessidade dos dados de difração de raios X serem corrigidos por correção por absorção analítica.

Os parâmetros de concordância tiveram um ajuste muito superior depois de aplicada a correção do tipo analítica do que quando aplicada a correção semi- 
empírica (PSI-Scan) ou a correção empírica (DFABS). O parâmetro goof(S) antes da correção por absorção analítica estava em 1,399 e após a correção por absorção na forma analítica caiu para 1,024. O R1 caiu de 0,0656 para 0,0430 após a correção. Os picos de excesso e vales de densidade de carga residual tiveram uma diminuição extraordinária, o pico que antes estava em 3,02 e/ $\AA^{3}$ a $0,95 \AA$ do átomo de Molibdênio (Mo1) foi para $0,95 \mathrm{e} / \AA^{3}$ a $0,93 \AA$ do átomo de Molibdênio (Mo2), figura 4.5, e o vale que antes estava em -2,03 e/ $\AA^{3}$ a 1,01 $\AA$ do átomo de Molibdênio (Mo1) foi para -1,51 e/Å a 1,01 Å do átomo de Molibdênio (Mo1), figura 4.6. Houve também um ótimo ajuste dos parâmetros de concordância.

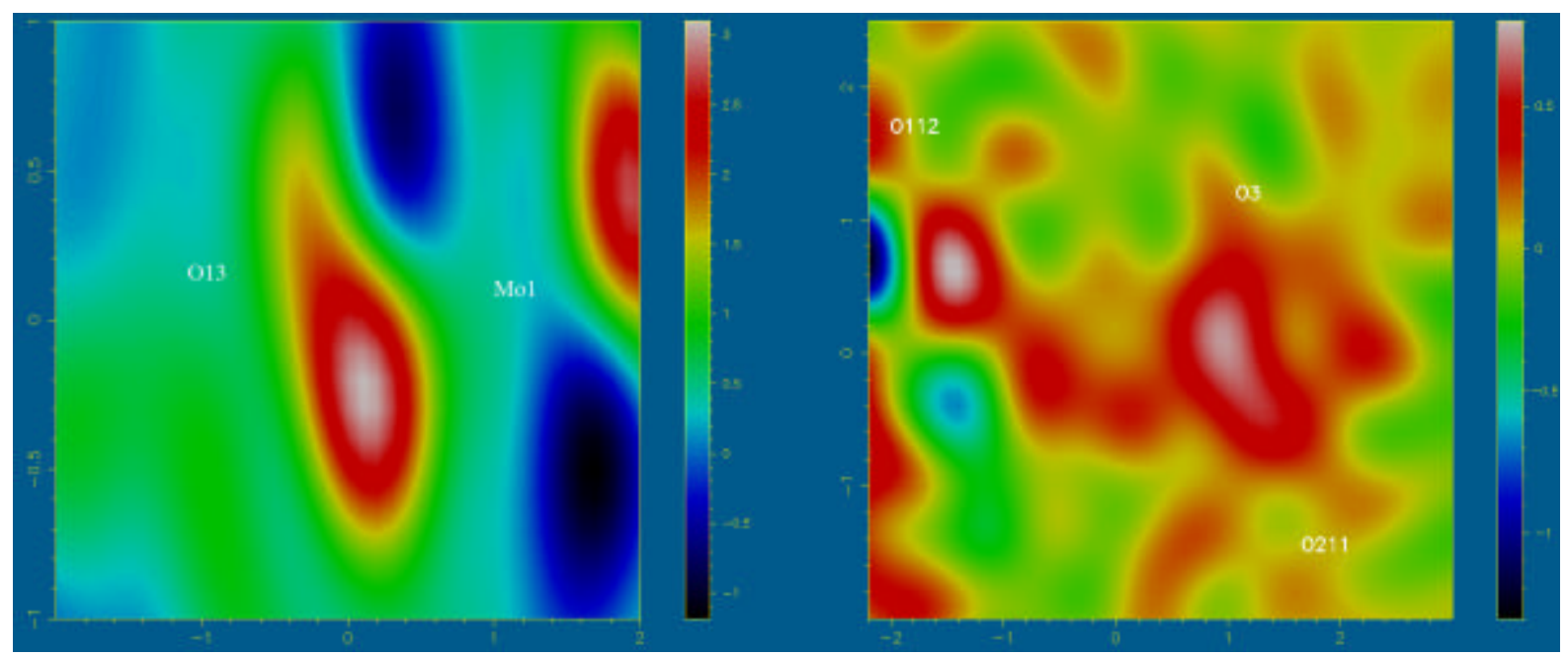

(a)

(b)

Figura 4.5: Mapas residuais de densidade carga, $\mathrm{F}_{\mathrm{obs}}-\mathrm{F}_{\text {calc }}$ para o composto XIV, em vermelho é o maior pico de densidade de carga residual, os rótulos representam as posições atômicas no mapa: (a) antes da correção por absorção; (b) depois da correção por absorção analítica. 


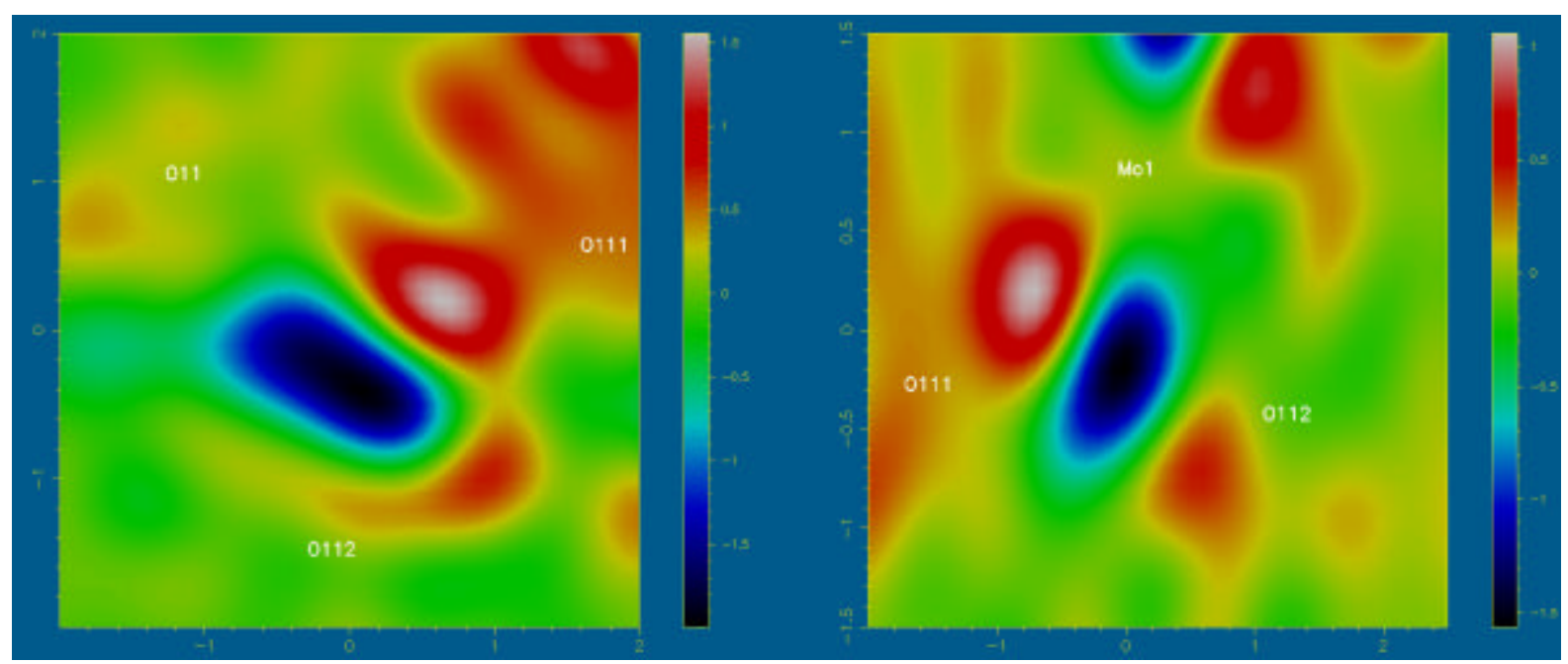

(a)

(b)

Figura 4.6: Mapas residuais de densidade carga, $\mathrm{F}_{\text {obs }}-\mathrm{F}_{\text {calc }}$ para o composto XIV, em azul é o maior vale de densidade de carga residual, os rótulos representam as posições atômicas no mapa: (a) antes da correção por absorção; (b) depois da correção por absorção analítica.

Os parâmetros de deslocamentos anisotrópicos variaram após a correção por absorção analítica, aumentando o volume dos elipsóides térmicos dos átomos de molibdênio e dos átomos coordenados ao molibdênio, os átomos de oxigênio. Houve também pequenas variações nas distâncias e ângulos de ligações.

\subsubsection{Composto XV}

Este foi o composto que apresentou o maior produto do coeficiente de absorção, $\mu$, pela dimensão média, $R$, com um valor de 4,548. Daí a obrigatoriedade da correção por absorção na forma analítica.

Os parâmetros de concordâncias melhoraram de uma forma substancial, caindo de valores não aceitos em revistas dentificas para publicação até valores aceitáveis. O parâmetro R1, por exemplo, estava em 0,0969 antes da correção, após a correção por absorção analítica caiu para 0,0623. O parâmetro goof(S) também 
obteve uma grande melhora caiu de 1,364 para 1,024 após a correção por absorção analítica. Os picos de excesso de densidade de carga e os vales de densidade de carga residuais resultante do mapa diferença de Fourrier, também sofreram uma enorme diminuição. O mais alto pico de excesso de densidade de carga que antes da correção estava em 3,28 e/ $\AA^{3}$ a $1,06 \AA$ do átomo de Cádmio caiu para 1,54 e/ $\AA^{3}$ a $0,86 \AA$ do mesmo átomo. Já o vale de densidade de carga que estava em - 3,44 e/ $\AA^{3}$ a $0,86 \AA$ do átomo de Cádmio diminuiu para $-1,38$ e/ $\AA^{3}$ a $0,88 \AA$ do mesmo átomo, figura 4.7, o que é extremamente significante quando se observa que isto é resultante do melhor ajuste entre os modelos calculado e observado.

Os parâmetros de deslocamentos anisotrópicos variaram, havendo um aumento do volume dos elipsóides térmicos do átomo pesado (cádmio) e de seus primeiros vizinhos (enxofres, nitrogênios e oxigênios). Já as distâncias e ângulos de ligações não apresentaram variações significativas.

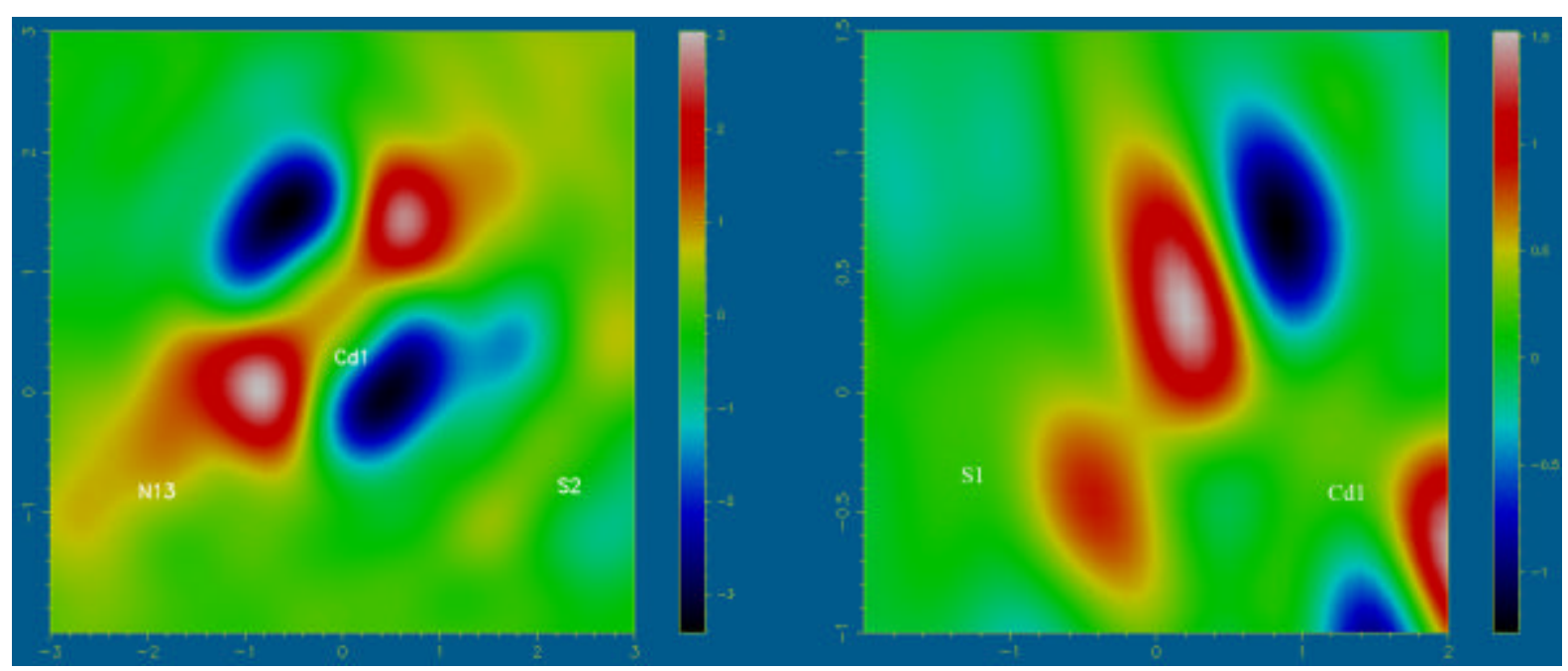

(a)

(b)

Figura 4.7: Mapas residuais de densidade carga, $F_{\text {obs }}-F_{\text {calc }}$ para o composto I, em vermelho é o maior pico de densidade de carga e em azul é o maior vale de densidade de carga residual, os rótulos representam as posições atômicas no mapa: (a) antes da correção por absorção; (b) depois da correção por absorção analítica. 


\subsection{Discussões dos Resultados}

Foram executadas correções por absorção da forma analítica, semi-empírica e empírica nas amostras. Foi possível observar vários comportamentos distintos para as diferentes correções por absorção. O comportamento das figuras de mérito resultantes das várias correções por absorção sofreu variações altíssimas, o mesmo ocorrendo para os parâmetros de deslocamentos anisotrópicos.

Como era esperada, a correção por absorção na forma analítica apresentou em geral os melhores resultados. No caso em que a correção analítica não levou a melhores resultados acredita-se que tenha havido uma má indexação das faces do cristal e/ou um dimensionamento incorreto, estes problemas foram uma fonte de erro gravíssimo no momento de execução da correção por absorção analítica. Pequenas diferenças nas dimensões do cristal (em torno de $0,01 \mathrm{~mm}$ ) podem levar a grande erro na correção por absorção analítica. Existem programas que ajustam as dimensões do cristal com o objetivo de minimizar as figuras de merito.

Por outro lado, no caso de cristais de baixo $\mu R$, pequenos erros nas correções por absorção podem gerar parâmetros de concordância piores do que antes de um refinamento sem correção por absorção.

Assim, quando o produto do coeficiente de absorção, $\mu$, pelo raio médio, $R$, estiver próximo de 0,1 ou ligeiramente maior, correções por absorção do tipo semiempíricas ou empíricas podem apresentar resultados superiores ou extremamente melhores.

Os cristais dos compostos II, III, IV, VI, VII e VIII apresentaram o coeficiente $\mu R$ muito baixo, sendo que qualquer uma das correções por absorção 
poderiam ser executadas sem prejuízo na qualidade do modelo final. Os cristais II, III, VII e VIII apresentaram resultados muito melhores com correções por absorção do tipo empírica. Enquanto os cristais IV e VI tiveram resultados muito próximos após as correções empírica e analítica.

O composto XIII, que possuía um cristal com $\mu R=2,806$, levou a resultados piores após a correção analítica, sendo que os melhores resultados foi alcançado com uma correção empírica. Provavelmente, isto foi devido ao fato de ter havido falhas no momento da indexação das faces cristalinas e dimensionamento do cristal. Este processo requer uma perfeita harmonia em um grande conjunto de fatores, tais como:

- Cristal com faces bem definidas;

- Cristal bem colado à fibra de vidro;

- Bom ajuste do conjunto ótico;

- Boa iluminação do cristal;

- Outros.

Lembrando que esta indexação foi feita em difratômetro Enraf-Nonius CAD-4, neste tipo de equipamento vários destes fatores não são muito adequados.

Os compostos que apresentaram uma expressiva melhora em seus parâmetros de concordância após a correção por absorção analítica, foram os dos cristais; I, X, XI, XIV e XV. Estes compostos reduziram sensivelmente os picos residuais de densidade de carga do mapa diferença de Fourrier e ajustaram as figuras de mérito. Em vários casos a correção por absorção na forma empírica apresentou resultados tão bons quanto os obtidos através das correções por absorção analítica.

Uma comparação da geometria molecular dos vários refinamentos feitos a partir das diferentes correções por absorção, mostra que houve uma pequena 
diferença após as correções. Pequenas mudanças acontecem na vizinhança do átomo pesado, com os átomos de sua esfera de coordenação.

Os parâmetros de deslocamentos anisotrópicos sofreram leves mudanças após as correções por absorção. As mudanças mais significantes foram observadas após a correção por absorção da forma empírica, os parâmetros de deslocamento anisotrópicos aumentam levando o elipsóide térmico a ocupar um maior volume. Já na grande maioria dos casos onde a correção analítica alcançou sucesso os átomos pesados (metais) e os átomos coordenados a ele apresentaram uma leve diminuição no volume dos elipsóides térmicos, assim como uma reorientação dos eixos principais dos elipsóides térmicos. Os picos residuais geralmente estavam localizados nas proximidades do átomo pesado. Estes picos tendem a se localizar nas direções das ligações dos átomos coordenados ao átomo pesado. 


\section{CONCLUSÕES}

Uma significante conclusão a respeito dos arranjos supramoleculares de complexos de $\left[\mathrm{TlMe}_{2}\right]^{+}$com mercapto piridinas deste estudo, é que as interações intermoleculares, ligações de hidrogênio e interações secundárias $\mathrm{Tl}-\mathrm{S}, \mathrm{Tl}-\mathrm{O}$ e Tl - N, estão controlando os arranjos supramoleculares.

Complexos de dimetal-tálio com estes quelantes oferecem uma grande variabilidade na coordenação do metal e consequentemente no empacotamento cristalino que levam à arranjos supramoleculares de complexos de $\left[\mathrm{TlMe}_{2}\right]^{+}$ unidimensionais, bidimensionais e/ou tridimensionais.

Interações intermoleculares do tipo $\mathrm{Tl}-\mathrm{S}, \mathrm{Tl}-\mathrm{O}$ e $\mathrm{Tl}-\mathrm{N}$ são bastante proeminentes no arranjo supramolecular dos complexos moleculares $\left[\mathrm{TlMe}_{2}\right]^{+}$com ligantes quelante. Existe uma correlação entre o comprimento das ligações $\mathrm{Tl}-\mathrm{S}$, $\mathrm{Tl}-\mathrm{N}$ e $\mathrm{Tl}$ - O com o surgimento e fortalecimento das ligações de hidrogênio, o que proporciona arranjos supramoleculares mais estáveis. Assim foi observado que para os menores comprimentos das ligações $\mathrm{Tl}-\mathrm{S}$, $\mathrm{Tl}-\mathrm{N}$ e $\mathrm{Tl}-\mathrm{O}$ nos arranjos supramoleculares, houve um aumento significativo na quantidade e intensidade das ligações de hidrogênio.

A esfera de coordenação do íon dimetil - tálio foi preenchida de formas diferentes, mas sempre respeitando um padrão com duas interações mais curtas e outras duas mais longas, sendo que as quatros coordenações do ligante estão na posição equatorial. Havendo também uma preferência do dimetil - tálio se coordenar mais rigidamente com os átomos de $\mathrm{S}$ e $\mathrm{N}$ da mercapto - piridina. 
Este estudo mostrou que para minimizar os efeitos da absorção de raios X por complexos fortemente absorvedores, a maneira mais fácil é escolher um cristal de dimensões reduzidas e com boa morfologia para facilitar a indexação das faces no caso de um difratômetro Enraf-Nonius KappaCCD. No caso de um difratômetro Nonius CAD4, sugere-se escolher um cristal com dimensões maiores e com faces bem definidas para facilitar a visualização e consequentemente, a indexação e dimensionamento do cristal.

Apesar de terem sido estudados cristais que são fortes absorvedores, as diferenças encontradas antes e depois da correção por absorção nas diferentes figuras de mérito escolhidas, em geral, foram pequenas. Devido ao fato da maioria das medidas terem sido feitas com cristais muito pequenos, os efeitos absorção da radiação pela amostra foram minimizados.

Correções por absorção na forma analítica, quando bem executadas, minimizam drasticamente os picos de excesso de densidade carga e os vales de densidade de carga do mapa Fourrier diferença, $F_{o b s}-F_{c a l c}$. A concordância entre os mapas calculado e observado também aumentam sensivelmente, como pode ser constatado pela minimização das figuras de mérito. No entanto, o êxito da correção por absorção analítica depende drasticamente da medida das dimensões do cristal.

No caso de cristais que apresentam um valor de $\mu R$ muito baixo, $\mu R$ aproximadamente igual a 0,2, mesmo contendo átomos pesados, recomenda-se executar correções semi-empíricas ou empíricas. Estes cristais apresentam dimensões reduzidas, diminuindo muito o $\mu R$ da amostra cristalina. Para cristais com valores de menores que 0,1 , as correções por absorção em geral são desnecessárias, já que podem introduzir erros no refinamento da estrutura, levando a um pior resultado final. 
Após serem feitas as correções por absorção, constataram-se que os parâmetros de deslocamentos anisotrópicos sofreram pequenas mudanças, levando a um redimensionamento e reposicionamento dos elipsóides térmicos. Observourse também, que os métodos empíricos geraram um melhor ajuste dos mapas calculado e observado, em detrimento dos parâmetros de deslocamentos anisotrópicos aumentando o volume dos elipsóides térmicos.

Apesar de ser bastante discutido na literatura, não foram observadas mudanças substanciais nas distâncias e ângulos de ligações nas estruturas cristalográficas após executadas as diferentes correções por absorção. 


\section{ANEXO A}

Neste anexo estão mostrados as tabelas com os dados cristalográficos e figuras da estrutura cristalográfica dos compostos utilizados para o estudo dos arranjos supramoleculares. 


\section{A.1 COMPOSTO I}

Tabela A.1: Dados do cristal e da estrutura e refinamento para o Composto I.

Fórmula empírica

Peso da fórmula

Temperatura

Comprimento de onda

Sistema cristalino

Grupo espacial

Parâmetros da cela unitária

Volume

Z

Densidade (calculada)

Coeficiente de absorção

$\mathrm{F}(000)$

Dimensões do cristal

Intervalo de teta para a coleta de dados

Intervalo dos índices

Reflexões coletadas

Reflexões independentes

Completeza em teta $=25.00^{\circ}$

Correção por absorção

Método de refinamento

Dados / parâmetros

Goodness-of-fit em $\mathrm{F}^{2}$

$\mathrm{R}$ final $[\mathrm{I}>2 \sigma(\mathrm{I})]$

$\mathrm{R}$ (todos dados)

Coeficiente de extinção

Maiores picos e vales de densidade residual
$\mathrm{C}_{8} \mathrm{H}_{12} \mathrm{NO}_{3} \mathrm{STl}$

406.62

120(2) K

$0.71070 \AA$

Ortorrômbico

Pbna

$a=7.5400(1) \AA$

$b=15.9570(3) \AA$

$c=18.4190(4) \AA$

$2216.10(7) \AA^{3}$

8

$2.437 \mathrm{Mg} / \mathrm{m}^{3}$

$14.746 \mathrm{~mm}^{-1}$

1504

$0.60 \times 0.20 \times 0.16 \mathrm{~mm}^{3}$

2.55 to $25.00^{\circ}$.

$0 \leq \mathrm{h} \leq 8,0 \leq \mathrm{k} \leq 18,0 \leq 1 \leq 21$

3596

$1943[\mathrm{R}($ int $)=0.0150]$

$99.8 \%$

Analítica

Métodos mínimos quadrados em $\mathrm{F}^{2}$

1943 / 130

1.091

$\mathrm{R} 1=0.0234, \mathrm{wR} 2=0.0648$

$\mathrm{R} 1=0.0274, \mathrm{wR} 2=0.0680$

$0.0028(1)$

1.420 e -1.663 e. $\AA^{-3}$

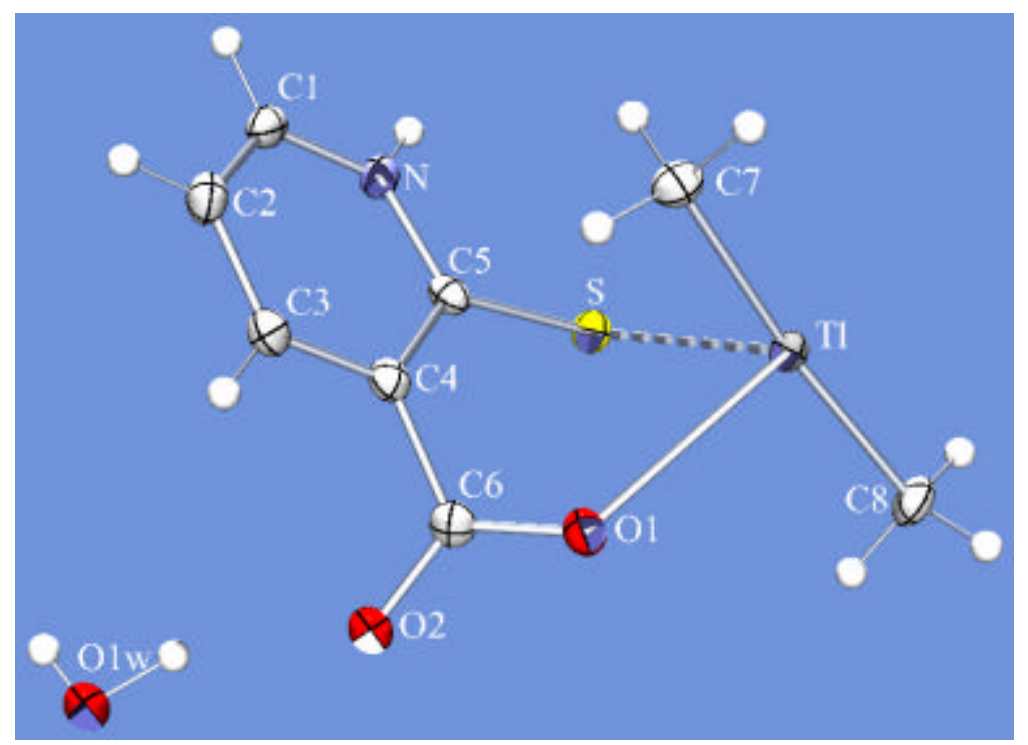

Figura A.1: Estrutura molecular do composto I. 


\section{A.2 COMPOSTO II}

Tabela A.2: Dados do cristal e da estrutura e refinamento para o Composto II.

Fórmula empírica

Peso da fórmula

Temperatura

Comprimento de onda

Sistema cristalino

Grupo espacial

Parâmetros da cela unitária

Volume

$\mathrm{Z}$

Densidade (calculada)

Coeficiente de absorção

$\mathrm{F}(000)$

Dimensões do cristal

Intervalo de teta para a coleta de dados

Intervalo dos índices

Reflexões coletadas

Reflexões independentes

Completeza em teta $=25.00^{\circ}$

Correção por absorção

Método de refinamento

Dados / parâmetros

Goodness-of-fit em $\mathrm{F}^{2}$

$R$ final $[\mathrm{I}>2 \sigma(\mathrm{I})]$

$\mathrm{R}$ (todos dados)

Maiores picos e vales de densidade residual
$\mathrm{C}_{9} \mathrm{H}_{12} \mathrm{NO}_{2} \mathrm{STl}$

402.63

120(2) K

$0.71070 \AA$

Monoclínica

C $2 / \mathrm{c}$

$a=13.3430(3) \AA$

$b=8.2230(2) \AA$

$c=21.2220(4) \AA$

$\beta=101.712(1)^{\circ}$.

2279.99(9) $\AA^{3}$

8

$2.346 \mathrm{Mg} / \mathrm{m}^{3}$

$14.326 \mathrm{~mm}^{-1}$

1488

$0.18 \times 0.10 \times 0.08 \mathrm{~mm}^{3}$

1.96 to $25.00^{\circ}$.

$0 \leq \mathrm{h} \leq 15,0 \leq \mathrm{k} \leq 9,-25 \leq 1 \leq 24$

3874

$2018[\mathrm{R}($ int $)=0.0228]$

$100.0 \%$

Analítica

Métodos mínimos quadrados em $\mathrm{F}^{2}$

2018 / 130

1.242

$\mathrm{R} 1=0.0362, \mathrm{wR} 2=0.0960$

$\mathrm{R} 1=0.0410, \mathrm{wR} 2=0.1238$

1.289 e -3.465 e. $\AA^{-3}$

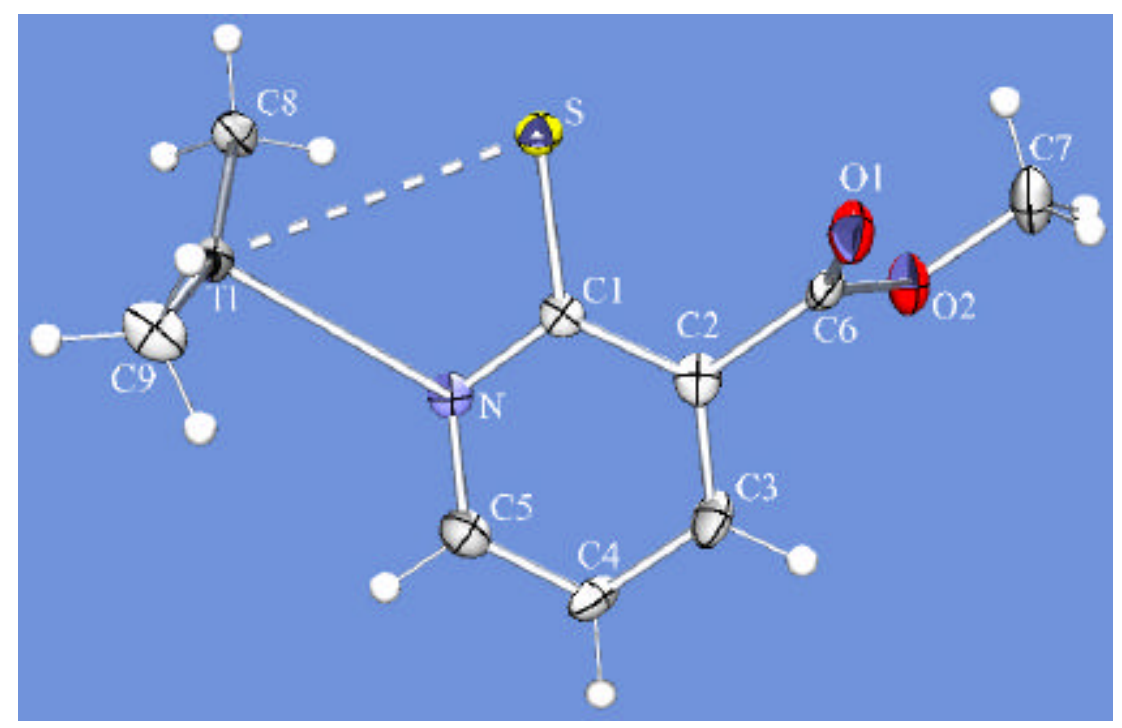

Figura A.2: Estrutura molecular do composto II. 


\section{A.3 COMPOSTO III}

Tabela A.3: Dados do cristal e da estrutura e refinamento para o Composto III.

Fórmula empírica

Peso da fórmula

Temperatura

Comprimento de onda

Sistema cristalino

Grupo espacial

Parâmetros da cela unitária

Volume

$\mathrm{Z}$

Densidade (calculada)

Coeficiente de absorção

$\mathrm{F}(000)$

Dimensões do cristal

Intervalo de teta para a coleta de dados

Intervalo dos índices

Reflexões coletadas

Reflexões independentes

Completeza em teta $=25.00^{\circ}$

Correção por absorção

Método de refinamento

Dados / parâmetros

Goodness-of-fit em $\mathrm{F}^{2}$

$\mathrm{R}$ final $[\mathrm{I}>2 \sigma(\mathrm{I})]$

$\mathrm{R}$ (todos dados)

Coeficiente de extinção

Maiores picos e vales de densidade residual

\section{$\mathrm{C}_{9} \mathrm{H}_{12} \mathrm{NO}_{2} \mathrm{STl}$}

402.63

100(2) K

$0.71070 \AA$

Tetragonal

I $4 / 1 / a$

$a=20.0750(5) \AA$

$b=20.0750(5) \AA$

$c=11.2770(4) \AA$

4544.7(2) $\AA^{3}$

16

$2.354 \mathrm{Mg} / \mathrm{m}^{3}$

$14.374 \mathrm{~mm}^{-1}$

2976

$0.22 \times 0.15 \times 0.03 \mathrm{~mm}^{3}$

2.03 to $25.00^{\circ}$.

$-23 \leq \mathrm{h} \leq 23,-23 \leq \mathrm{k} \leq 17,-13 \leq 1 \leq 9$

5951

$1995[\mathrm{R}($ int $)=0.0580]$

$99.7 \%$

Analítica

Métodos mínimos quadrados em $\mathrm{F}^{2}$

1995 / 131

1.032

$\mathrm{R} 1=0.0264, \mathrm{wR} 2=0.0643$

$\mathrm{R} 1=0.0328, \mathrm{wR} 2=0.0676$

$0.00024(3)$

0.803 e -1.021 e. $\AA^{-3}$

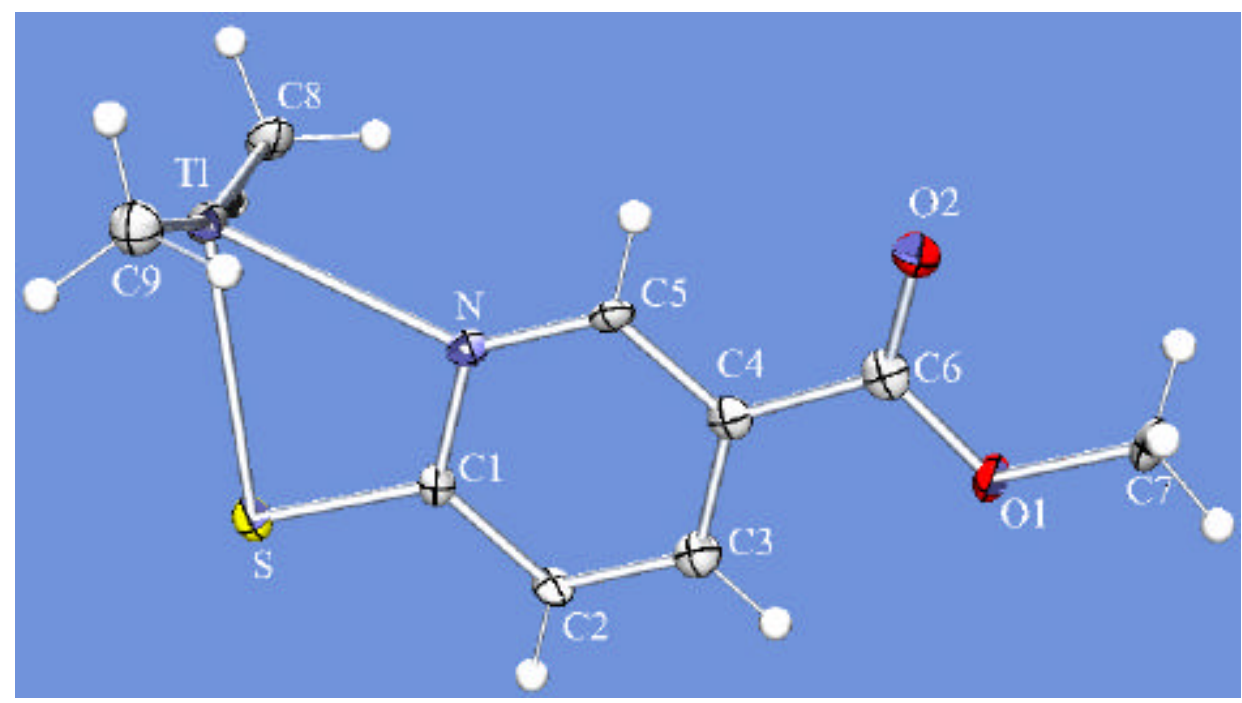

Figura A.3: Estrutura molecular do composto III. 


\section{A.4 COMPOSTO IV}

Tabela A.4: Dados do cristal e da estrutura e refinamento para o Composto IV.

Fórmula empírica

Peso da fórmula

Temperatura

Comprimento de onda

Sistema cristalino

Grupo espacial

Parâmetros da cela unitária

Volume

$\mathrm{Z}$

Densidade (calculada)

Coeficiente de absorção

$\mathrm{F}(000)$

Dimensões do cristal

Intervalo de teta para a coleta de dados

Intervalo dos índices

Reflexões coletadas

Reflexões independentes

Completeza em teta $=25.00^{\circ}$

Correção por absorção

Método de refinamento

Dados / parâmetros

Goodness-of-fit em $\mathrm{F}^{2}$

$R$ final $[\mathrm{I}>2 \sigma(\mathrm{I})]$

$\mathrm{R}$ (todos dados)

Maiores picos e vales de densidade residual
$\mathrm{C}_{10} \mathrm{H}_{14} \mathrm{NO}_{2} \mathrm{STl}$

416.65

120(2) K

$0.71070 \AA$

Monoclínico

$\mathrm{P} 2 / \mathrm{c}$

$a=14.7450(2) \AA$

$b=7.65000(10) \AA \quad \beta=105.8090(10)^{\circ}$.

$c=11.6710(3) \AA$

1266.68(4) $\AA^{3}$

4

$2.185 \mathrm{Mg} / \mathrm{m}^{3}$

$12.897 \mathrm{~mm}^{-1}$

776

$0.30 \times 0.18 \times 0.08 \mathrm{~mm}^{3}$

1.44 to $25.00^{\circ}$.

$0 \leq \mathrm{h} \leq 17,-9 \leq \mathrm{k} \leq 9,-13 \leq 1 \leq 13$

4141

$2229[\mathrm{R}($ int $)=0.0206]$

$100.0 \%$

Analítica

Métodos mínimos quadrados em $\mathrm{F}^{2}$

2229 / 139

1.345

$\mathrm{R} 1=0.0215, \mathrm{wR} 2=0.0738$

$\mathrm{R} 1=0.0234, \mathrm{wR} 2=0.0862$

0.634 e -1.739 e. $\AA^{-3}$

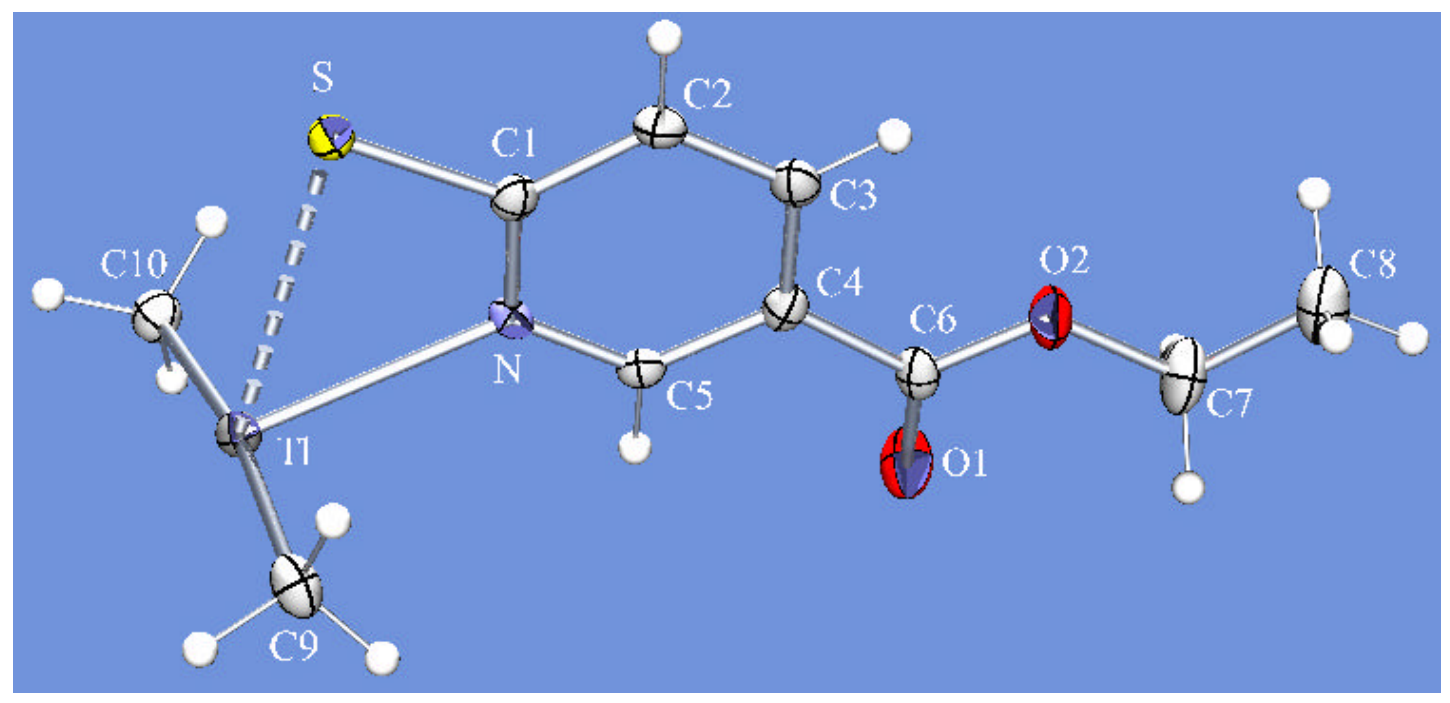

Figura A.4: Estrutura molecular do composto IV. 


\section{A.5 COMPOSTO V}

Tabela A.5: Dados do cristal e da estrutura e refinamento para o Composto V.

Fórmula empírica

Peso da fórmula

Temperatura

Comprimento de onda

Sistema cristalino

Grupo espacial

Parâmetros da cela unitária

Volume

Z

Densidade (calculada)

Coeficiente de absorção

$\mathrm{F}(000)$

Dimensões do cristal

Intervalo de teta para a coleta de dados

Intervalo dos índices

Reflexões coletadas

Reflexões independentes

Completeza em teta $=25.00^{\circ}$

Correção por absorção

Método de refinamento

Dados / parâmetros

Goodness-of-fit em $\mathrm{F}^{2}$

$\mathrm{R}$ final $[\mathrm{I}>2 \sigma(\mathrm{I})]$

$\mathrm{R}$ (todos dados)

Absolute structure parameter

Maiores picos e vales de densidade residual
$\mathrm{C}_{10} \mathrm{H}_{14} \mathrm{NO}_{2} \mathrm{STl}$

416.65

120(2) K

$0.71070 \AA$

Ortorrômbico

$\mathrm{P} 22_{1} 2_{1}$

$a=8.6860(3) \AA$

$b=10.8480(3) \AA$

$c=13.3660(5) \AA$

$1259.42(7) \AA^{3}$

4

$2.197 \mathrm{Mg} / \mathrm{m}^{3}$

$12.971 \mathrm{~mm}^{-1}$

776

$0.21 \times 0.09 \times 0.08 \mathrm{~mm}^{3}$

2.42 to $25.0^{\circ}$.

$-10 \leq \mathrm{h} \leq 10,-12 \leq \mathrm{k} \leq 12,-15 \leq 1 \leq 15$

10661

$2195[\mathrm{R}($ int $)=0.0600]$

$99.8 \%$

Multiscan

Métodos mínimos quadrados em $\mathrm{F}^{2}$

$2195 / 138$

1.155

$\mathrm{R} 1=0.0214, \mathrm{wR} 2=0.0502$

$\mathrm{R} 1=0.0218, \mathrm{wR} 2=0.0504$

$0.009(10)$

0.790 e -1.491 e. $\AA^{-3}$

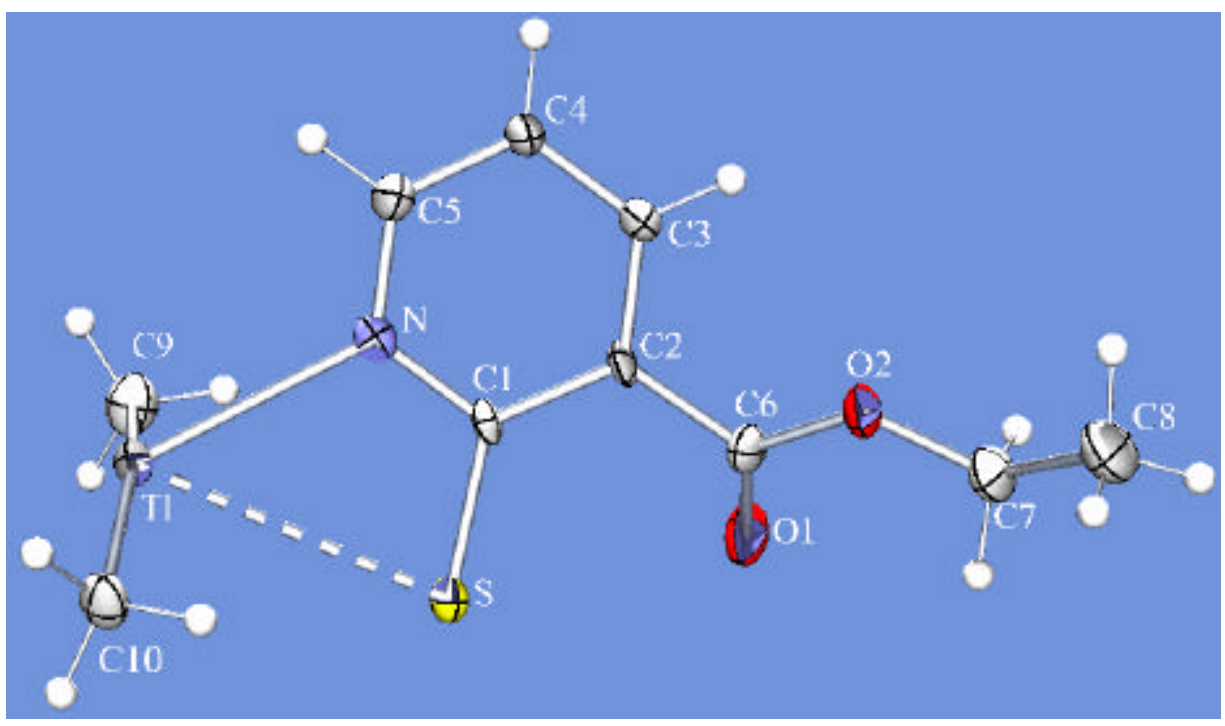

Figura A.5: Estrutura molecular do composto V. 


\begin{abstract}
ANEXO B

\section{Fatores de Discrepância ou Figuras de Mérito}

Estes fatores oferecem uma maneira rápida de avaliar a concordância entre os modelos calculados e observados. Para refinamentos baseados em $\mathrm{F}^{2}$, os fatores de discrepância são rotineiramente calculados pelos programas usualmente utilizados nos refinamentos de estruturas de monocristais.

Depois de completar um ciclo de refinamento por mínimos quadrados é possível calcular vários parâmetros que levam a interpretação da concordância dos dados coletados com o modelo proposto.
\end{abstract}

\title{
B.1 Goodness-of-Fit (S)
}

Um destes parâmetros é o de goodness-of-fit (goof) e é definido como:

$$
\operatorname{goof}(S)=\sqrt{\sum^{m} w\left[\left|F_{o}(h)\right|-\left|F_{c}(h)\right|\right]^{2} /(m-n)},
$$


onde $w$ é uma função peso baseada nos desvios padrão estimados das reflexões

observadas, $\left|F_{o}(h)\right|$ é o módulo do fator de estrutura observado, $\left|F_{c}(h)\right|$ é o módulo do fator de estrutura calculado, $m$ é o número de fatores de estruturas observados usado no refinamento de mínimos quadrados e $n$ é o número total de parâmetros independentes (fator de escala, posições atômicas e parâmetros de deslocamento anisotrópicos e de ocupação).

Se a função peso está correta, $w$, e o modelo matemático é bom, o valor de $S$ estará próximo de 1,0. De fato, o problema quase sempre não é devido a erros durante as medidas das intensidades, mas no modelo matemático usado.

\section{B.2 R (Int)}

Também chamado de "R interno", leva a uma indicação da qualidade dos dados. É definido como:

$$
R(\text { Int })=\frac{\sum\left|F_{o}^{2}-\bar{F}_{o}^{2}\right|}{\sum F_{o}^{2}},
$$

onde $F_{o}$ é o fator de estrutura observado. Ambas somatórias envolvem todas as reflexões, inclusive as análogas por simetria. 


\section{B.3 R( $(\sigma)$}

A figura de mérito $R(\sigma)$ também é usada para conferir a qualidade dos dados que sofreram "merge" e é definida por:

$$
R(\sigma)=\frac{\sum \sigma\left(F_{o}^{2}\right)}{\sum F_{o}^{2}},
$$

sobre todas as reflexões na lista das "merge".

\section{B.4 wR2}

$$
w R 2=\sqrt{\frac{\sum w\left(F_{o}^{2}-F_{c}^{2}\right)^{2}}{\sum w\left(F_{o}^{2}\right)^{2}}}
$$

O wR2 é uma função peso de R1 calculada sobre todos os dados, mostrando o progresso do refinamento, sendo este em $F^{2}$.

\section{B.5 R1}

$$
R 1=\frac{\sum\left|F_{o}\right|-\left|F_{c}\right|}{\sum\left|F_{o}\right|}
$$


B.6 R1(merge)

$$
R 1(\text { merge })=\frac{\sum\left|F_{o}\right|-\left|F_{c}\right|}{\sum\left|F_{o}\right|}
$$

Este fator de discrepância é calculado da mesma forma que o anterior, mas leva em consideração as reflexões que foram fundidas (merged) por Fourrier. 


\section{ANEXO C}

Neste anexo estão mostrados as tabelas com os dados cristalográficos e figuras da estrutura cristalográfica dos compostos utilizados para o estudo comparativo dos métodos de correção por absorção. 


\section{C.1 COMPOSTO I}

Tabela C.1: Dados do cristal e da estrutura e refinamento para o Composto I.

Fórmula empírica

Peso da fórmula

Temperatura

Comprimento de onda

Sistema cristalino

Grupo espacial

Parâmetros da cela unitária

Volume

Z

Densidade (calculada)

Coeficiente de absorção

$\mathrm{F}(000)$

Dimensões do cristal

Intervalo de teta para a coleta de dados

Intervalo dos índices

Reflexões coletadas

Reflexões independentes

Completeza em teta $=25.00^{\circ}$

Correção por absorção

Método de refinamento

Dados / parâmetros

Goodness-of-fit em $\mathrm{F}^{2}$

$\mathrm{R}$ final $[\mathrm{I}>2 \sigma(\mathrm{I})]$

$\mathrm{R}$ (todos dados)

Coeficiente de extinção

Maiores picos e vales de densidade residual
$\mathrm{C}_{15} \mathrm{H}_{18} \mathrm{Nd}_{2} \mathrm{O}_{16}$

742.78

120(2) K

$0.71070 \AA$

monoclínico

$\mathrm{C} 2 / \mathrm{c}$

$a=8.0712(2) \AA$

$b=15.0745(6) \AA$

$c=19.7536(5) \AA$

$\beta=93.760(2)^{\circ}$

2398.23(13) $\AA^{3}$

4

$2.057 \mathrm{Mg} / \mathrm{m}^{3}$

$4.354 \mathrm{~mm}^{-1}$

1424

$0.68 \times 0.29 \times 0.10 \mathrm{~mm}^{3}$

2.07 a $25.00^{\circ}$

$-9 \leq \mathrm{h} \leq 9,-17 \leq \mathrm{k} \leq 17,-23 \leq 1 \leq 23$

10454

$2072[\mathrm{R}(\mathrm{Int})=0.0810]$

$98.1 \%$

Analítica

Métodos mínimos quadrados em $\mathrm{F}^{2}$

2072 / 164

1.258

$\mathrm{R} 1=0.0403, \mathrm{wR} 2=0.1173$

$\mathrm{R} 1=0.0444, \mathrm{wR} 2=0.1276$

0.0129(8)

1.377 e -1.563 e. $\AA^{-3}$

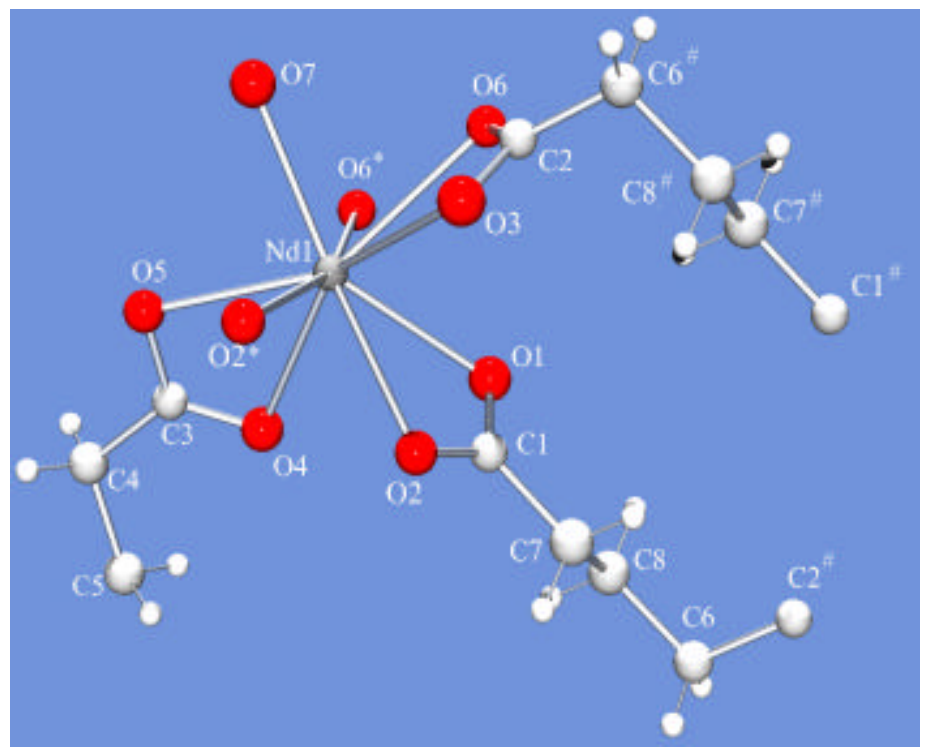

Figura C.1: Estrutura molecular do composto I. *($\mathrm{x},-\mathrm{y},-\mathrm{z})$ \#(1/2-x, 1/2-y, -z) 


\section{C.2 COMPOSTO II}

Tabela C.2: Dados do cristal e da estrutura e refinamento para o Composto II.

Fórmula empírica

Peso da fórmula

Temperatura

Comprimento de onda

Sistema cristalino

Grupo espacial

Parâmetros da cela unitária

\section{Volume}

$\mathrm{Z}$

Densidade (calculada)

Coeficiente de absorção

$\mathrm{F}(000)$

Dimensões do cristal

Intervalo de teta para a coleta de dados

Intervalo dos índices

Reflexões coletadas

Reflexões independentes

Completeza em teta $=25.00^{\circ}$

Correção por absorção

Método de refinamento

Dados / parâmetros

Goodness-of-fit em $\mathrm{F}^{2}$

$\mathrm{R}$ final $[\mathrm{I}>2 \sigma(\mathrm{I})]$

$\mathrm{R}$ (todos dados)

Coeficiente de extinção

Maiores picos e vales de densidade residual
$\mathrm{C}_{24} \mathrm{H}_{30} \mathrm{ClN}_{8} \mathrm{O}_{4} \mathrm{Ru}$

$631.08+$

120(2) K

$0.71070 \AA$

monoclínico

$\mathrm{P} 2 / \mathrm{c}$

$a=9.6507(4) \AA$

$b=13.7395(6) \AA$

$c=11.1112(4) \AA$

$\beta=103.260(2)^{\circ}$.

1434.02(10) $\AA^{3}$

2

$1.655 \mathrm{Mg} / \mathrm{m}^{3}$

$0.796 \mathrm{~mm}^{-1}$

744

$0.48 \times 0.24 \times 0.06 \mathrm{~mm}^{3}$

2.93 a $25.00^{\circ}$

$-11 \leq \mathrm{h} \leq 11,-14 \leq \mathrm{k} \leq 16,-13 \leq 1 \leq 13$

12465

$2519[\mathrm{R}(\mathrm{Int})=0.0411]$

$99.8 \%$

DFABS

Métodos mínimos quadrados em $\mathrm{F}^{2}$

2519 / 216

1.005

$\mathrm{R} 1=0.0419, \mathrm{wR} 2=0.1009$

$\mathrm{R} 1=0.0503, \mathrm{wR} 2=0.1143$

$0.0000(10)$

0.790 e -0.460 e. $\AA^{-3}$

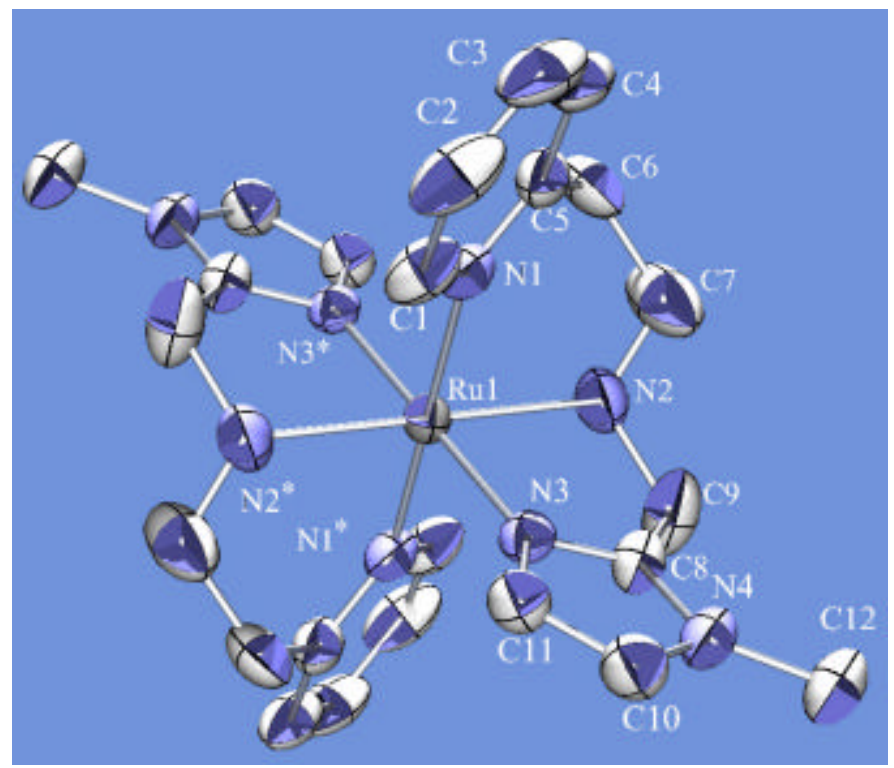

Figura C.2: Estrutura molecular do composto II.

$*(-\mathrm{x},-\mathrm{y},-\mathrm{z})$ 


\section{C.3 COMPOSTO III}

Tabela C.3: Dados do cristal e da estrutura e refinamento para o Composto III.

Fórmula empírica

Peso da fórmula

Temperatura

Comprimento de onda

Sistema cristalino

Grupo espacial

Parâmetros da cela unitária

Volume

Z

Densidade (calculada)

Coeficiente de absorção

$\mathrm{F}(000)$

Dimensões do cristal

Intervalo de teta para a coleta de dados

Intervalo dos índices

Reflexões coletadas

Reflexões independentes

Completeza em teta $=25.00^{\circ}$

Correção por absorção

Método de refinamento

Dados / parâmetros

Goodness-of-fit em $\mathrm{F}^{2}$

$\mathrm{R}$ final $[\mathrm{I}>2 \sigma(\mathrm{I})]$

$\mathrm{R}$ (todos dados)

Coeficiente de extinção

Maiores picos e vales de densidade residual
$\mathrm{C}_{10} \mathrm{H}_{17} \mathrm{Cl}_{2} \mathrm{~N}_{4} \mathrm{O}_{6} \mathrm{RuS}_{2}$

525.36

120(2) K

$0.71070 \AA$

monoclínico

$\mathrm{P} 21 / \mathrm{c}$

$a=8.2569(3) \AA$

$b=31.9814(11) \AA$

$c=13.9862(6) \AA$

$\beta=91.4490(10)^{\circ}$.
3692.1(2) $\AA^{3}$

8

$1.890 \mathrm{Mg} / \mathrm{m}^{3}$

$1.400 \mathrm{~mm}^{-1}$

2104

$0.28 \times 0.13 \times 0.13 \mathrm{~mm}^{3}$

1.27 a $25.00^{\circ}$

$-7 \leq \mathrm{h} \leq 7,-30 \leq \mathrm{k} \leq 30,-13 \leq 1 \leq 13$

18716

$3444[\mathrm{R}(\mathrm{Int})=0.1920]$

$99.0 \%$

DFABS

Métodos mínimos quadrados em $\mathrm{F}^{2}$ 3444 / 430

1.191

$\mathrm{R} 1=0.0716, \mathrm{wR} 2=0.1642$

$\mathrm{R} 1=0.1214, \mathrm{wR} 2=0.1916$

$0.0005(2)$

0.865 e -1.684 e. $\AA^{-3}$

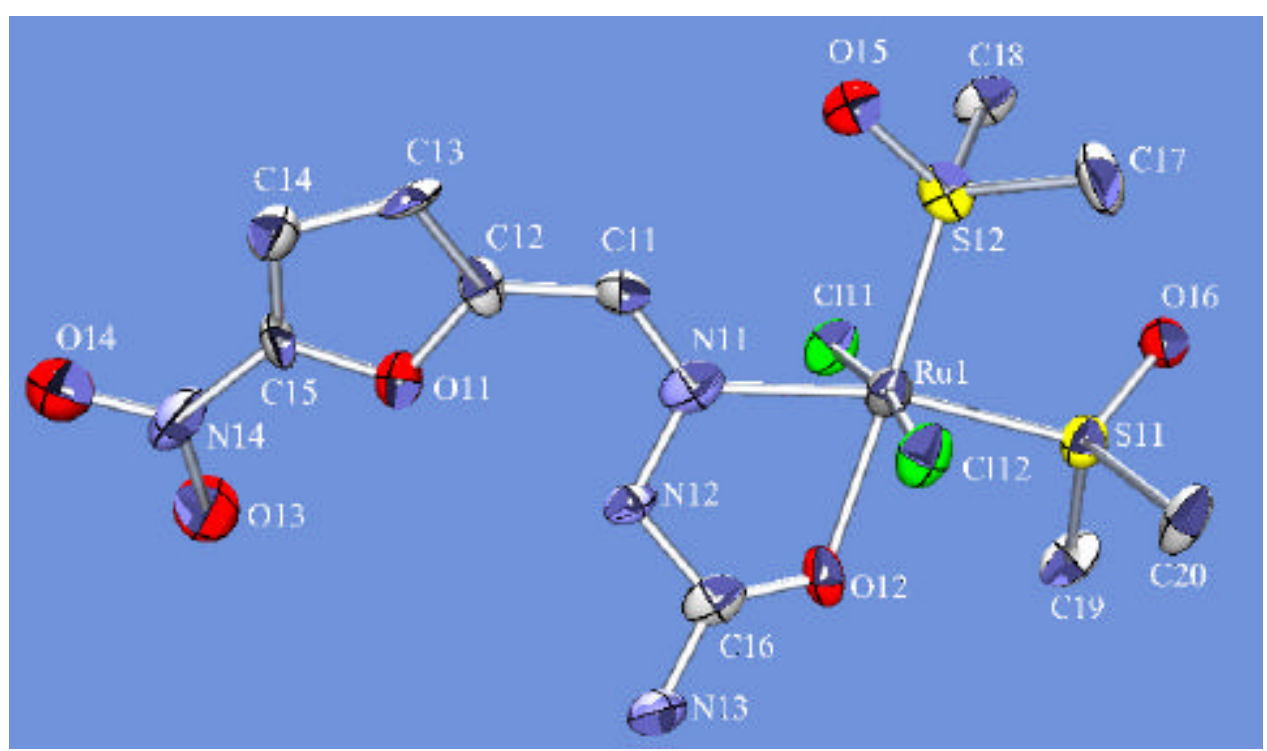

Figura C.3: Estrutura molecular do composto III. 


\section{C.4 COMPOSTO IV}

Tabela C.4: Dados do cristal e da estrutura e refinamento para o Composto IV.

Fórmula empírica

Peso da fórmula

Temperatura

Comprimento de onda

Sistema cristalino

Grupo espacial

Parâmetros da cela unitária

\section{Volume}

Z

Densidade (calculada)

Coeficiente de absorção

$\mathrm{F}(000)$

Dimensões do cristal

Intervalo de teta para a coleta de dados

Intervalo dos índices

Reflexões coletadas

Reflexões independentes

Completeza em teta $=25.00^{\circ}$

Correção por absorção

Método de refinamento

Dados / parâmetros

Goodness-of-fit em $\mathrm{F}^{2}$

$\mathrm{R}$ final $[\mathrm{I}>2 \sigma(\mathrm{I})]$

$\mathrm{R}$ (todos dados)

Coeficiente de extinção

Maiores picos e vales de densidade residual
$\mathrm{C}_{14} \mathrm{H}_{26} \mathrm{Cl}_{2} \mathrm{~N}_{4} \mathrm{O}_{6} \mathrm{RuS}_{2}$

582.48

120(2) K

$0.71070 \AA$

triclínico

P-1

$a=8.43180(10) \AA$

$b=12.5874(2) \AA$

$c=12.7582(2) \AA$

$1163.84(3) \AA^{3}$

2

$1.622 \mathrm{Mg} / \mathrm{m}^{3}$

$1.119 \mathrm{~mm}^{-1}$

592

$0.64 \times 0.13 \times 0.12 \mathrm{~mm}^{3}$

1.81 a $25.00^{\circ}$

$-9 \leq \mathrm{h} \leq 10,-14 \leq \mathrm{k} \leq 14,-15 \leq 1 \leq 15$

22498

$4092[\mathrm{R}(\mathrm{Int})=0.0627]$

$99.9 \%$

Analítica

Métodos mínimos quadrados em $\mathrm{F}^{2}$

4092 / 284

1.263

$\mathrm{R} 1=0.0509, \mathrm{wR} 2=0.1394$

$\mathrm{R} 1=0.0599, \mathrm{wR} 2=0.1650$

$0.077(5)$

1.940 e -1.744 e. $\AA^{-3}$

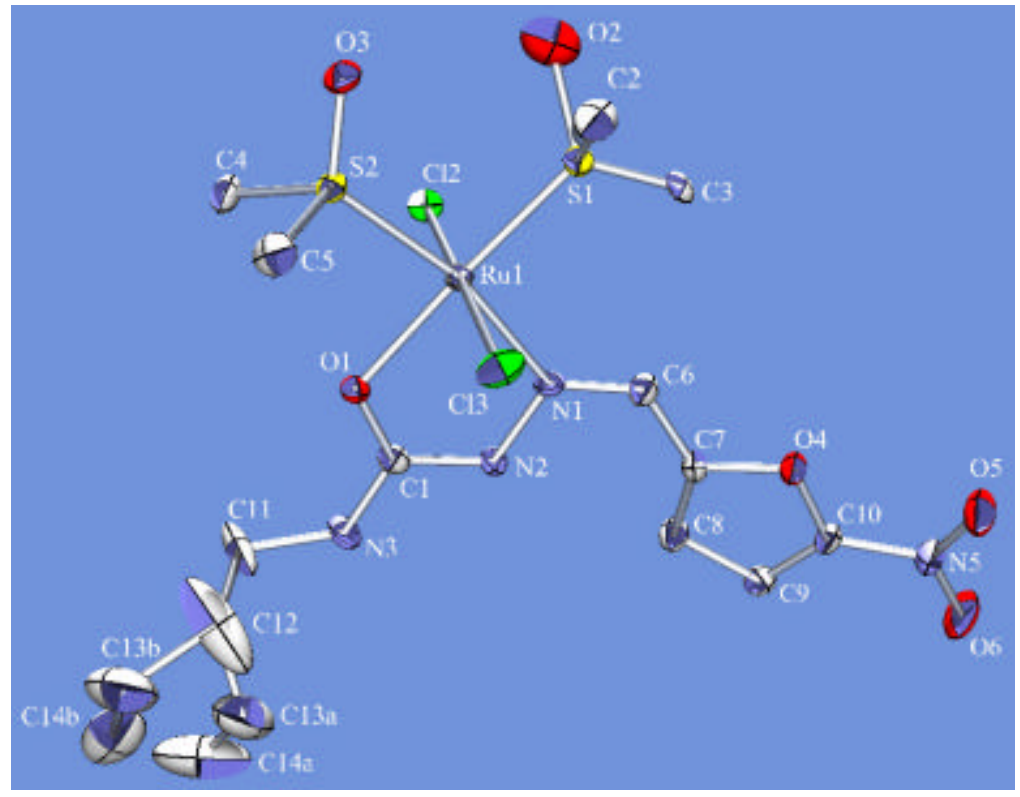

Figura C.4: Estrutura molecular do composto IV. 


\section{C.5 COMPOSTO V}

Tabela C.5: Dados do cristal e da estrutura e refinamento para o Composto V.

Fórmula empírica

Peso da fórmula

Temperatura

Comprimento de onda

Sistema cristalino

Grupo espacial

Parâmetros da cela unitária

\section{Volume}

Z

Densidade (calculada)

Coeficiente de absorção

$\mathrm{F}(000)$

Dimensões do cristal

Intervalo de teta para a coleta de dados

Intervalo dos índices

Reflexões coletadas

Reflexões independentes

Completeza em teta $=25.00^{\circ}$

Correção por absorção

Método de refinamento

Dados / restrições / parâmetros

Goodness-of-fit em $\mathrm{F}^{2}$

$\mathrm{R}$ final $[\mathrm{I}>2 \sigma(\mathrm{I})]$

$\mathrm{R}$ (todos dados)

Parâmetro de estrutura absoluta

Coeficiente de extinção

Maiores picos e vales de densidade residual
$\mathrm{C}_{24} \mathrm{H}_{18} \mathrm{Cl}_{2} \mathrm{~N}_{2} \mathrm{~Pb}$

612.50

120(2) K

$0.71070 \AA$

monoclínico

$\mathrm{P} 21$

$a=17.3343(2) \AA$

$b=13.49460(10) \AA$

$c=18.4810(2) \AA$

$\beta=92.212(9)^{\circ}$.

4319.84(8) $\AA^{3}$

8

$1.884 \mathrm{Mg} / \mathrm{m}^{3}$

$8.071 \mathrm{~mm}^{-1}$

2336

$0.32 \times 0.12 \times 0.10 \mathrm{~mm}^{3}$

1.10 a $25.00^{\circ}$

$-19 \leq \mathrm{h} \leq 20,-16 \leq \mathrm{k} \leq 16,-21 \leq 1 \leq 21$

122402

$15211[\mathrm{R}(\mathrm{Int})=0.1342]$

$100.0 \%$

Analítica

Métodos mínimos quadrados em $\mathrm{F}^{2}$

15211 / 1 / 1044

1.143

$\mathrm{R} 1=0.0330, \mathrm{wR} 2=0.0741$

$\mathrm{R} 1=0.0393, \mathrm{wR} 2=0.0884$

$0.497(5)$

$0.00052(4)$

1.934 e -1.411 e. $\AA^{-3}$

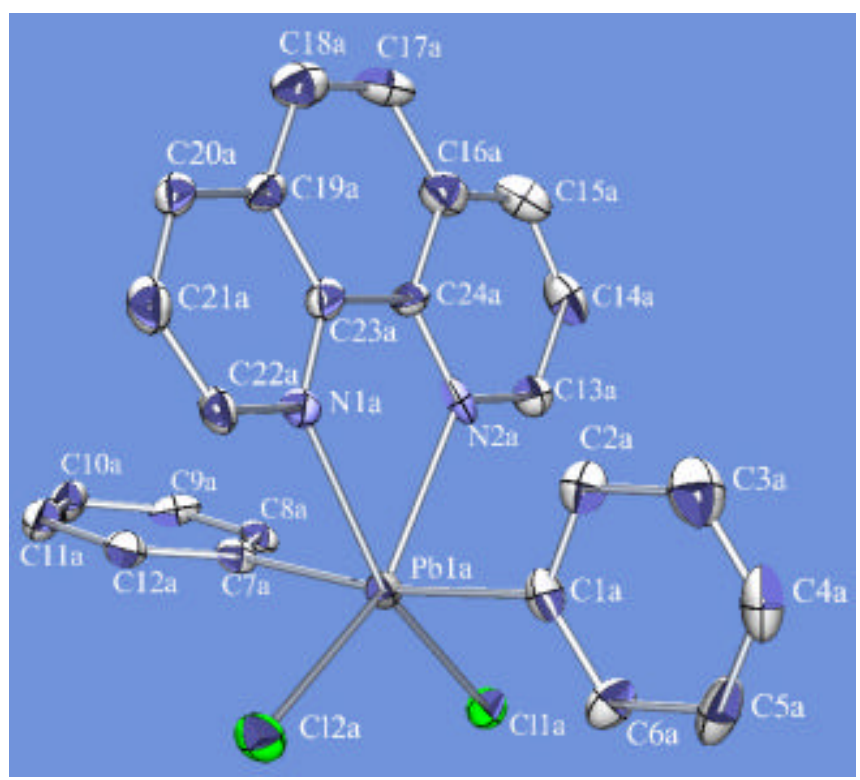

Figura C.5: Estrutura

molecular do composto $\mathrm{V}$. 


\section{C.6 COMPOSTO VI}

Tabela C.6: Dados do cristal e da estrutura e refinamento para o Composto VI.

Fórmula empírica

Peso da fórmula

Temperatura

Comprimento de onda

Sistema cristalino

Grupo espacial

Parâmetros da cela unitária

Volume

Z

Densidade (calculada)

Coeficiente de absorção

$\mathrm{F}(000)$

Dimensões do cristal

Intervalo de teta para a coleta de dados

Intervalo dos índices

Reflexões coletadas

Reflexões independentes

Completeza em teta $=25.00^{\circ}$

Correção por absorção

Método de refinamento

Dados / parâmetros

Goodness-of-fit em $\mathrm{F}^{2}$

$\mathrm{R}$ final $[\mathrm{I}>2 \sigma(\mathrm{I})]$

$\mathrm{R}$ (todos dados)

Coeficiente de extinção

Maiores picos e vales de densidade residual
$\mathrm{C}_{21} \mathrm{H}_{36} \mathrm{~N}_{2} \mathrm{~S}_{4} \mathrm{Sn}$

563.51

120(2) K

$0.71070 \AA$

monoclínico

$\mathrm{P} 21 / \mathrm{n}$

$a=16.5009(3) \AA$

$b=9.9075(1) \AA$

$c=17.1947(2) \AA$

2792.69(7) $\AA^{3}$

4

$1.340 \mathrm{Mg} / \mathrm{m}^{3}$

$1.224 \mathrm{~mm}^{-1}$

1160

$0.68 \times 0.30 \times 0.23 \mathrm{~mm}^{3}$

1.62 a $25.00^{\circ}$

$-19 \leq \mathrm{h} \leq 19,-11 \leq \mathrm{k} \leq 10,-20 \leq 1 \leq 20$

68801

$4916[\mathrm{R}(\mathrm{Int})=0.0739]$

$100 \%$

Analítica

Métodos mínimos quadrados em $\mathrm{F}^{2}$

$4916 / 259$

1.361

$\mathrm{R} 1=0.0304, \mathrm{wR} 2=0.0827$

$\mathrm{R} 1=0.0423, \mathrm{wR} 2=0.1121$

0.004889

0.884 e -0.621 e. $\AA^{-3}$ $\beta=96.549(1)^{\circ}$.

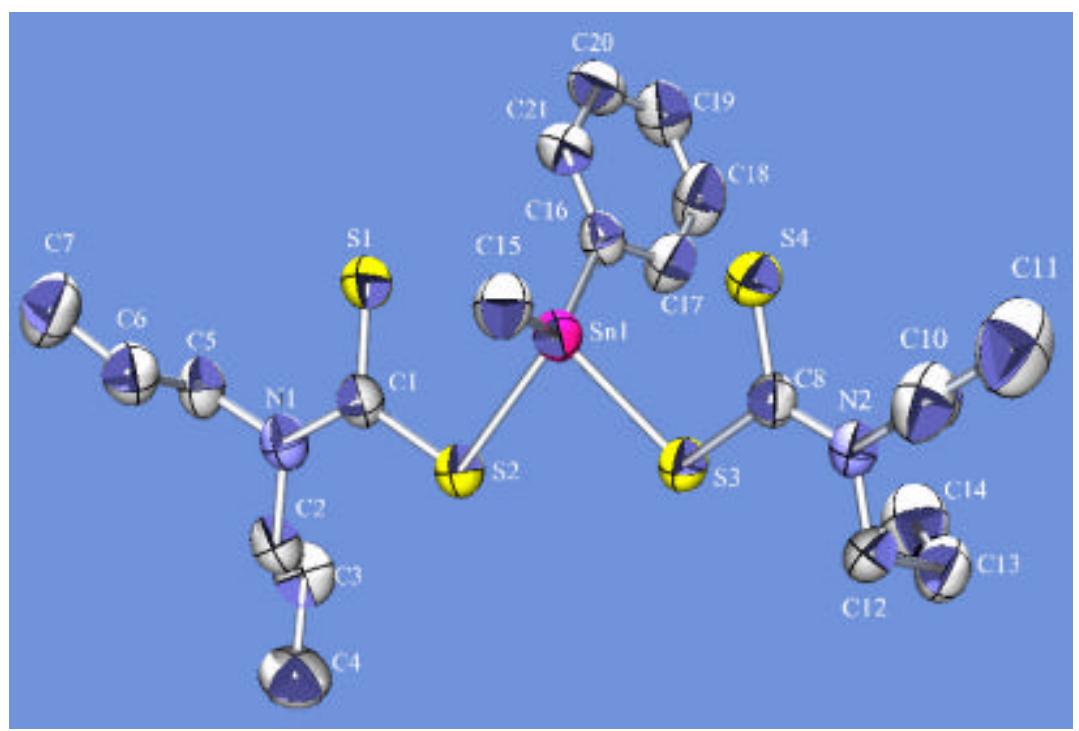

Figura C.6: Estrutura molecular do composto VI. 


\section{C.7 COMPOSTO VII}

Tabela C.7: Dados do cristal e da estrutura e refinamento para o Composto VII.

Fórmula empírica

Peso da fórmula

Temperatura

Comprimento de onda

Sistema cristalino

Grupo espacial

Parâmetros da cela unitária

Volume

Z

Densidade (calculada)

Coeficiente de absorção

$\mathrm{F}(000)$

Dimensões do cristal

Intervalo de teta para a coleta de dados

Intervalo dos índices

Reflexões coletadas

Reflexões independentes

Completeza em teta $=25.00^{\circ}$

Correção por absorção

Método de refinamento

Dados / parâmetros

Goodness-of-fit em $\mathrm{F}^{2}$

$R$ final $[\mathrm{I}>2 \sigma(\mathrm{I})]$

$\mathrm{R}$ (todos dados)

Maiores picos e vales de densidade residual
$\mathrm{C}_{17} \mathrm{H}_{15} \mathrm{~N}_{2} \mathrm{SO}_{13} \mathrm{Co}_{2} \mathrm{Cu}$

668.79

120(2) K

$0.71070 \AA$

ortorrômbico

Pnma

$a=7.6710(2) \AA$

$b=21.0030(3) \AA$

$c=14.8000(5) \AA$

2384.49(12) $\AA^{3}$

4

$1.685 \mathrm{Mg} / \mathrm{m}^{3}$

$1.902 \mathrm{~mm}^{-1}$

1232

$0.24 \times 0.10 \times 0.08 \mathrm{~mm}^{3}$

1.00 a $27.48^{\circ}$

$-9 \leq \mathrm{h} \leq 9,-19 \leq \mathrm{k} \leq 17,-27 \leq 1 \leq 27$

22475

$1812[\mathrm{R}(\mathrm{Int})=0.0486]$

$99.6 \%$

Analítico

Métodos mínimos quadrados em $\mathrm{F}^{2}$

1812 / 211

1.522

$\mathrm{R} 1=0.0479, \mathrm{wR} 2=0.1148$

$\mathrm{R} 1=0.0652, \mathrm{wR} 2=0.1479$

0.804 e -0.992 e. $\AA^{-3}$

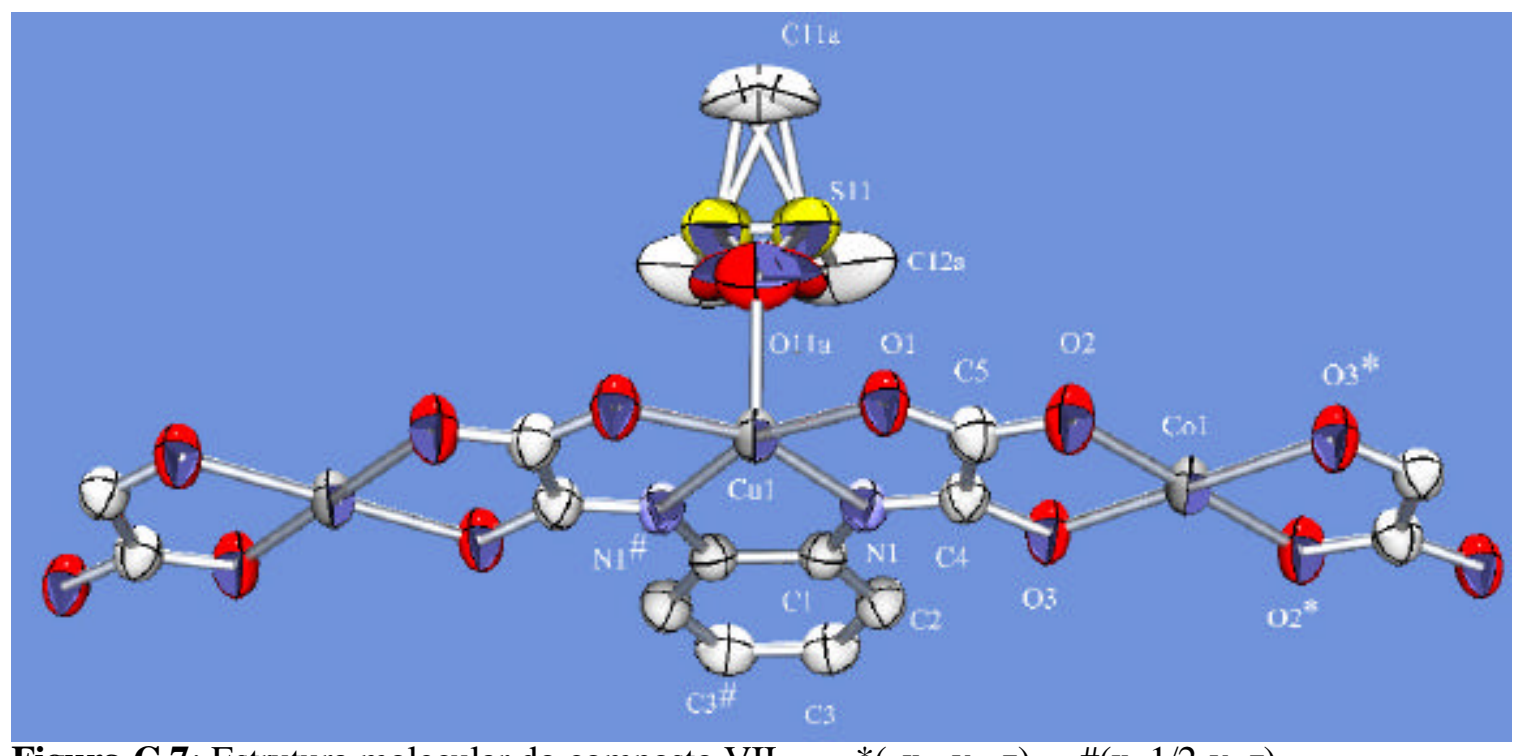

Figura C.7: Estrutura molecular do composto VII. $*(-\mathrm{x},-\mathrm{y},-\mathrm{z}) \quad \#(\mathrm{x}, 1 / 2-\mathrm{y}, \mathrm{z})$ 


\section{C.8 COMPOSTO VIII}

Tabela C.8: Dados do cristal e da estrutura e refinamento para o composto VIII.

Fórmula empírica

Peso da fórmula

Temperatura

Comprimento de onda

Sistema cristalino

Grupo espacial

Parâmetros da cela unitária

Volume

Z

Densidade (calculada)

Coeficiente de absorção

$\mathrm{F}(000)$

Dimensões do cristal

Intervalo de teta para a coleta de dados

Intervalo dos índices

Reflexões coletadas

Reflexões independentes

Completeza em teta $=25.00^{\circ}$

Correção por absorção

Método de refinamento

Dados / parâmetros

Goodness-of-fit em $\mathrm{F}^{2}$

$\mathrm{R}$ final $[\mathrm{I}>2 \sigma(\mathrm{I})]$

$\mathrm{R}$ (todos dados)

Maiores picos e vales de densidade residual
$\mathrm{C}_{54} \mathrm{H}_{45} \mathrm{Cl}_{5} \mathrm{OP}_{3} \mathrm{Ru}_{2}$

693.79

100(2) K

$0.71070 \AA$

monoclínico

$\mathrm{P} 21 / \mathrm{c}$

$a=14.5190(3) \AA$.

$b=18.0400(4) \AA$

$c=20.2990(4) \AA$

$\beta=99.6470(10)^{\circ}$.

5241.59(19) $\AA^{3}$

4

$1.626 \mathrm{Mg} / \mathrm{m}^{3}$

$1.039 \mathrm{~mm}^{-1}$

2530

$0.52 \times 0.08 \times 0.02 \mathrm{~mm}^{3}$

2.33 a $25.00^{\circ}$

$-17 \leq \mathrm{h} \leq 17,-21 \leq \mathrm{k} \leq 21,-23 \leq 1 \leq 24$

59594

$9231[\mathrm{R}(\mathrm{Int})=0.1062]$

$99.9 \%$

DFABS

Métodos mínimos quadrados em $\mathrm{F}^{2}$ $9231 / 622$

1.107

$\mathrm{R} 1=0.0503, \mathrm{wR} 2=0.1272$

$\mathrm{R} 1=0.0666, \mathrm{wR} 2=0.1399$

0.764 e -1.114 e. $\AA^{-3}$

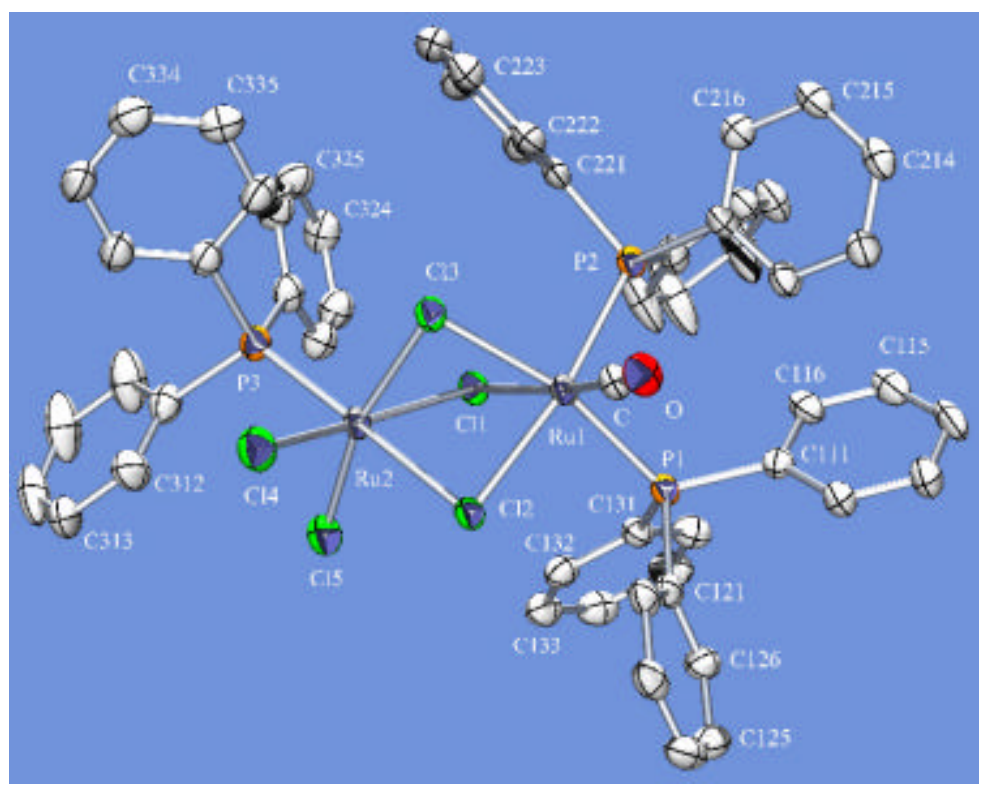

Figura C.8: Estrutura molecular do composto VIII. 


\section{C.9 COMPOSTO IX}

Tabela C.9: Dados do cristal e da estrutura e refinamento para o composto IX.

Fórmula empírica

Peso da fórmula

Temperatura

Comprimento de onda

Sistema cristalino

Grupo espacial

Parâmetros da cela unitária

Volume

Z

Densidade (calculada)

Coeficiente de absorção

$\mathrm{F}(000)$

Dimensões do cristal

Intervalo de teta para a coleta de dados

Intervalo dos índices

Reflexões coletadas

Reflexões independentes

Completeza em teta $=69.88^{\circ}$

Correção por absorção

Método de refinamento

Dados / parâmetros

Goodness-of-fit em $\mathrm{F}^{2}$

$\mathrm{R}$ final $[\mathrm{I}>2 \sigma(\mathrm{I})]$

$\mathrm{R}$ (todos dados)

Maiores picos e vales de densidade residual
$\mathrm{C}_{28} \mathrm{H}_{32} \mathrm{Fe}_{2} \mathrm{~N}_{6} \mathrm{~S}_{2} \mathrm{Zn}$

693.79

293(2) K

$1.54184 \AA$

Monoclínico

$\mathrm{C} 2 / \mathrm{c}$

$a=16.358(2) \AA$

$b=13.898(2) \AA$

$c=14.0518(15) \AA$.

$\beta=117.466(10)^{\circ}$.

2834.4(6) $\AA^{3}$

4

$1.626 \mathrm{Mg} / \mathrm{m}^{3}$

$10.698 \mathrm{~mm}^{-1}$

1424

$0.38 \times 0.06 \times 0.05 \mathrm{~mm}^{3}$

4.40 a $69.88^{\circ}$

$-19 \leq \mathrm{h} \leq 17,0 \leq \mathrm{k} \leq 16,0 \leq 1 \leq 17$

2750

$2634[\mathrm{R}(\mathrm{Int})=0.0453]$

$98.5 \%$

Analítica

Métodos mínimos quadrados em $\mathrm{F}^{2}$

2634 / 187

1.158

$\mathrm{R} 1=0.0434, \mathrm{wR} 2=0.0986$

$\mathrm{R} 1=0.0863, \mathrm{wR} 2=0.1115$

0.463 e -0.704 e. $\AA^{-3}$

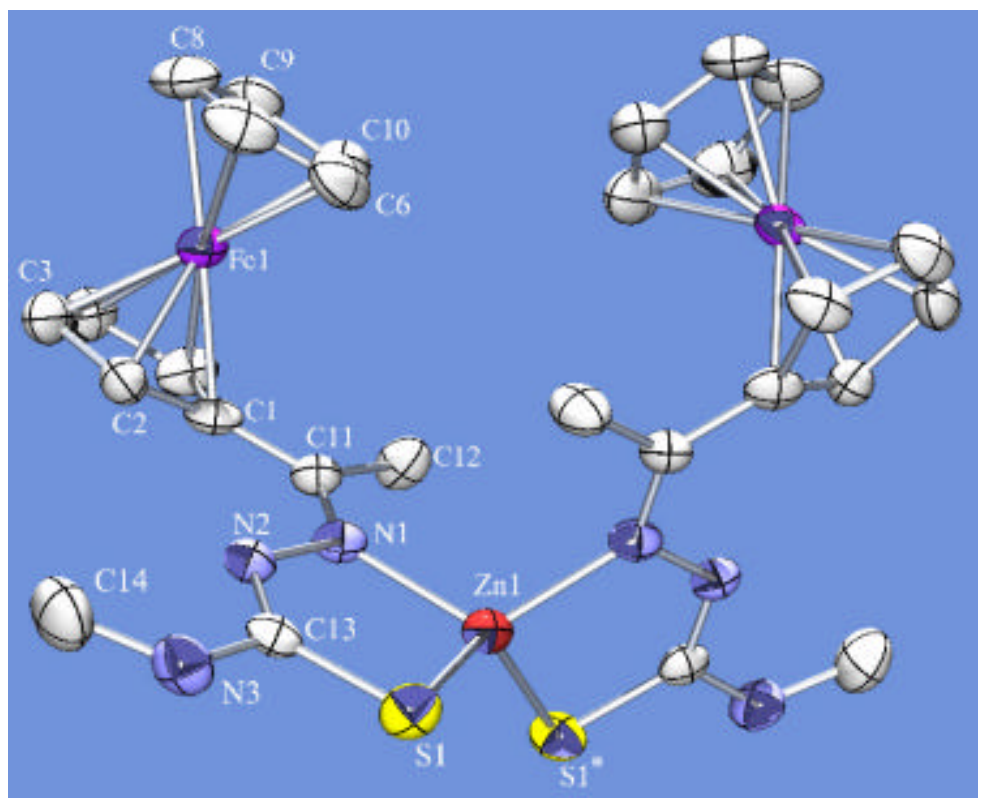

Figura C.9: Estrutura molecular do composto IX.

$*(-\mathrm{x}, \mathrm{y}, 1 / 2-\mathrm{z})$ 


\section{C.10 COMPOSTO X}

Tabela C.10: Dados do cristal e da estrutura e refinamento para o composto X.

Fórmula empírica

Peso da fórmula

Temperatura

Comprimento de onda

Sistema cristalino

Grupo espacial

Parâmetros da cela unitária

\section{Volume}

$\mathrm{Z}$

Densidade (calculada)

Coeficiente de absorção

$\mathrm{F}(000)$

Dimensões do cristal

Intervalo de teta para a coleta de dados

Intervalo dos índices

Reflexões coletadas

Reflexões independentes

Completeza em teta $=70.02^{\circ}$

Correção por absorção

Método de refinamento

Dados / parâmetros

Goodness-of-fit em $\mathrm{F}^{2}$

$\mathrm{R}$ final $[\mathrm{I}>2 \sigma(\mathrm{I})]$

$\mathrm{R}$ (todos dados)

Coeficiente de extinção

Maiores picos e vales de densidade residual
$\mathrm{C}_{26} \mathrm{H}_{28} \mathrm{Fe}_{2} \mathrm{~N}_{6} \mathrm{~S}_{2} \mathrm{Zn}$

726.68

293(2) K

$1.54184 \AA$

romboédrico

$\mathrm{R}-3 \mathrm{c}$

$a=17.651(3) \AA$

$\alpha=106.83(2)^{\circ}$.

$b=17.651(3) \AA$

$\beta=106.83(3)^{\circ}$.

$c=17.651(7) \AA$

$\gamma=106.83(2)^{\circ}$.

4600(2) $\AA^{3}$

6

$1.574 \mathrm{Mg} / \mathrm{m}^{3}$

$9.914 \mathrm{~mm}^{-1}$

2249

$0.36 \times 0.07 \times 0.07 \mathrm{~mm}^{3}$

3.12 a $70.02^{\circ}$

$-21 \leq \mathrm{h} \leq 18,0 \leq \mathrm{k} \leq 20,0 \leq 1 \leq 20$

7511

$2924[\mathrm{R}(\mathrm{Int})=0.0901]$

$99.8 \%$

Analítica

Métodos mínimos quadrados em $\mathrm{F}^{2}$ 2924 / 198

1.055

$\mathrm{R} 1=0.0471, \mathrm{wR} 2=0.0959$

$\mathrm{R} 1=0.1338, \mathrm{wR} 2=0.1167$

$0.00007(3)$

0.359 e -0.494 e. $\AA^{-3}$

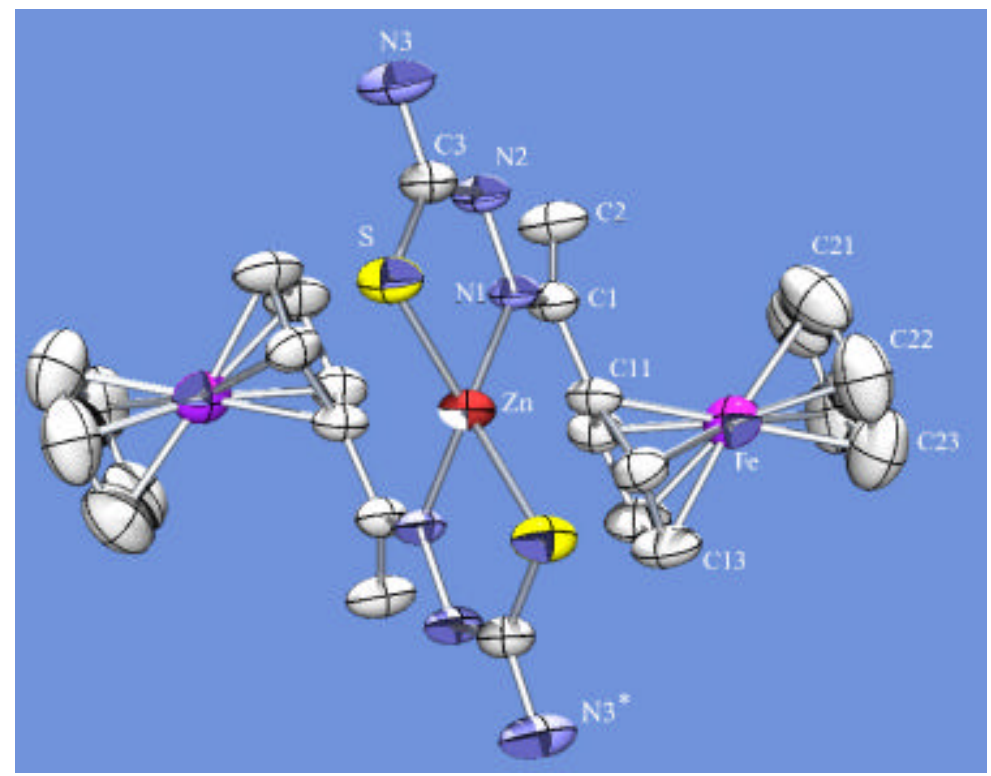

Figura C.10: Estrutura molecular do composto $\mathrm{X}$. $*(1 / 2-\mathrm{y}, 1 / 2-\mathrm{x}, 1 / 2-\mathrm{z})$ 


\section{C.11 COMPOSTO XI}

Tabela C.11: Dados do cristal e da estrutura e refinamento para o composto XI.

Fórmula empírica

Peso da fórmula

Temperatura

Comprimento de onda

Sistema cristalino

Grupo espacial

Parâmetros da cela unitária

Volume

Z

Densidade (calculada)

Coeficiente de absorção

$\mathrm{F}(000)$

Dimensões do cristal

Intervalo de teta para a coleta de dados

Intervalo dos índices

Reflexões coletadas

Reflexões independentes

Completeza em teta $=69.92^{\circ}$

Correção por absorção

Método de refinamento

Dados / parâmetros

Goodness-of-fit em $\mathrm{F}^{2}$

$\mathrm{R}$ final $[\mathrm{I}>2 \sigma(\mathrm{I})]$

$\mathrm{R}$ (todos dados)

Maiores picos e vales de densidade residual
$\mathrm{C}_{19} \mathrm{H}_{16} \mathrm{BrClN}_{2} \mathrm{Sn}$

506.39

293(2) K

$1.54184 \AA$

monoclínico

$\mathrm{P} 21 / \mathrm{n}$

$a=9.1620(10) \AA$

$b=11.2100(10) \AA$

$c=18.682(3) \AA$

$\beta=93.600(10)^{\circ}$.

1915.0(4) $\AA^{3}$

4

$1.760 \mathrm{Mg} / \mathrm{m}^{3}$

$14.351 \mathrm{~mm}^{-1}$

984

$0.60 \times 0.08 \times 0.03 \mathrm{~mm}^{3}$

4.60 a $69.92^{\circ}$

$0 \leq \mathrm{h} \leq 11,0 \leq \mathrm{k} \leq 13,-22 \leq 1 \leq 22$

3870

$3633[\mathrm{R}(\mathrm{Int})=0.0417]$

$100.0 \%$

Analítica

Métodos mínimos quadrados em $\mathrm{F}^{2}$

3633 / 238

1.224

$\mathrm{R} 1=0.0575, \mathrm{wR} 2=0.1259$

$\mathrm{R} 1=0.1192, \mathrm{wR} 2=0.1582$

1.130 e -0.724 e. $\AA^{-3}$

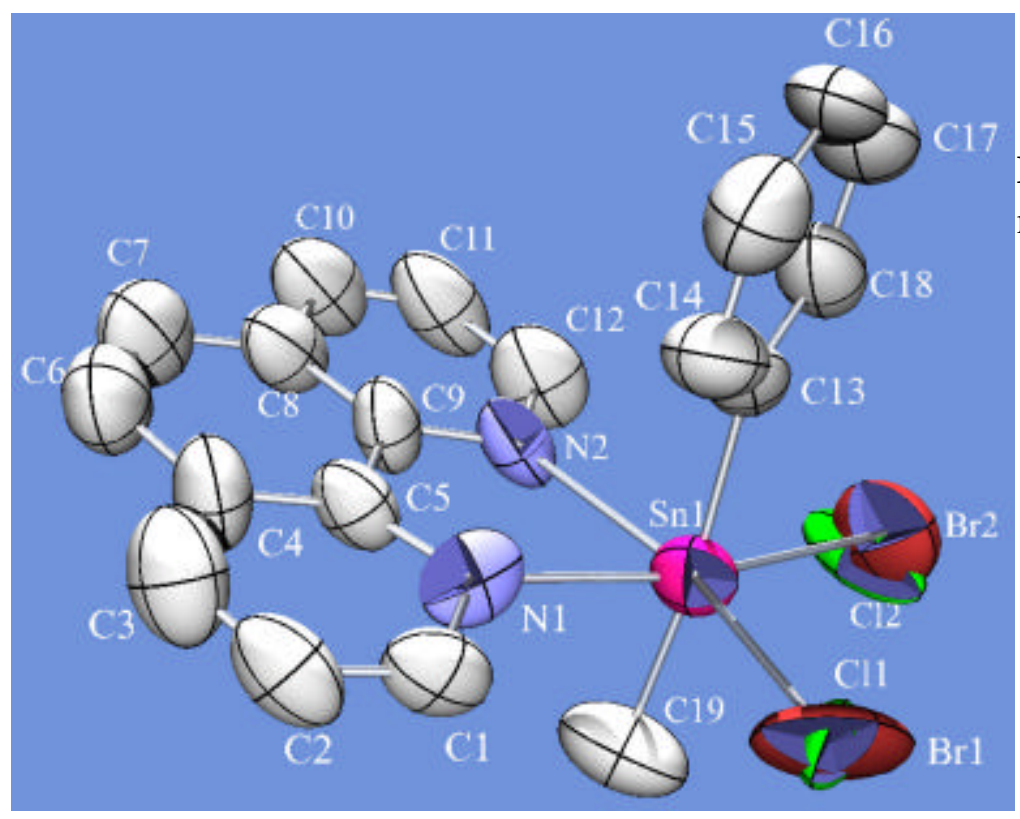

Figura C.11: Estrutura

molecular do composto XI. 


\section{C.12 COMPOSTO XII}

Tabela C.12: Dados do cristal e da estrutura e refinamento para o Composto XII.

Fórmula empírica

Peso da fórmula

Temperatura

Comprimento de onda

Sistema cristalino

Grupo espacial

Parâmetros da cela unitária

Volume

$\mathrm{Z}$

Densidade (calculada)

Coeficiente de absorção

$\mathrm{F}(000)$

Dimensões do cristal

Intervalo de teta para a coleta de dados

Intervalo dos índices

Reflexões coletadas

Reflexões independentes

Completeza em teta $=62.5^{\circ}$

Correção por absorção

Método de refinamento

Dados / parâmetros

Goodness-of-fit em $\mathrm{F}^{2}$

$R$ final $[\mathrm{I}>2 \sigma(\mathrm{I})]$

$\mathrm{R}$ (todos dados)

Coeficiente de extinção

Maiores picos e vales de densidade residual
$\mathrm{C}_{41} \mathrm{P}_{2} \mathrm{O}_{4} \mathrm{~S}_{6} \mathrm{H}_{42} \mathrm{Mo}_{2} \mathrm{~N}_{8}$

1157

298(2) K

$1.54184 \AA$

tetragonal

I-42d

$a=20.314(8) \AA$

$b=20.314(8) \AA$

$c=24.650(4) \AA$

10172(6) $\AA^{3}$

8

$1.511 \mathrm{Mg} / \mathrm{m}^{3}$

$7.322 \mathrm{~mm}^{-1}$

4688

$0.40 \times 0.09 \times 0.09 \mathrm{~mm}^{3}$

2.82 a $66.9^{\circ}$

$-1 \leq \mathrm{h} \leq 24,0 \leq \mathrm{k} \leq 24,0 \leq 1 \leq 29$

3174

$2725[\mathrm{R}(\mathrm{Int})=0.0554]$

$100 \%$

Analítica

Métodos mínimos quadrados em $\mathrm{F}^{2}$

2725 / 268

1.093

$\mathrm{R} 1=0.0477, \mathrm{wR} 2=0.1148$

$\mathrm{R} 1=0.0587, \mathrm{wR} 2=0.1367$

0.000113

0.960 e -0.963 e. $\AA^{-3}$

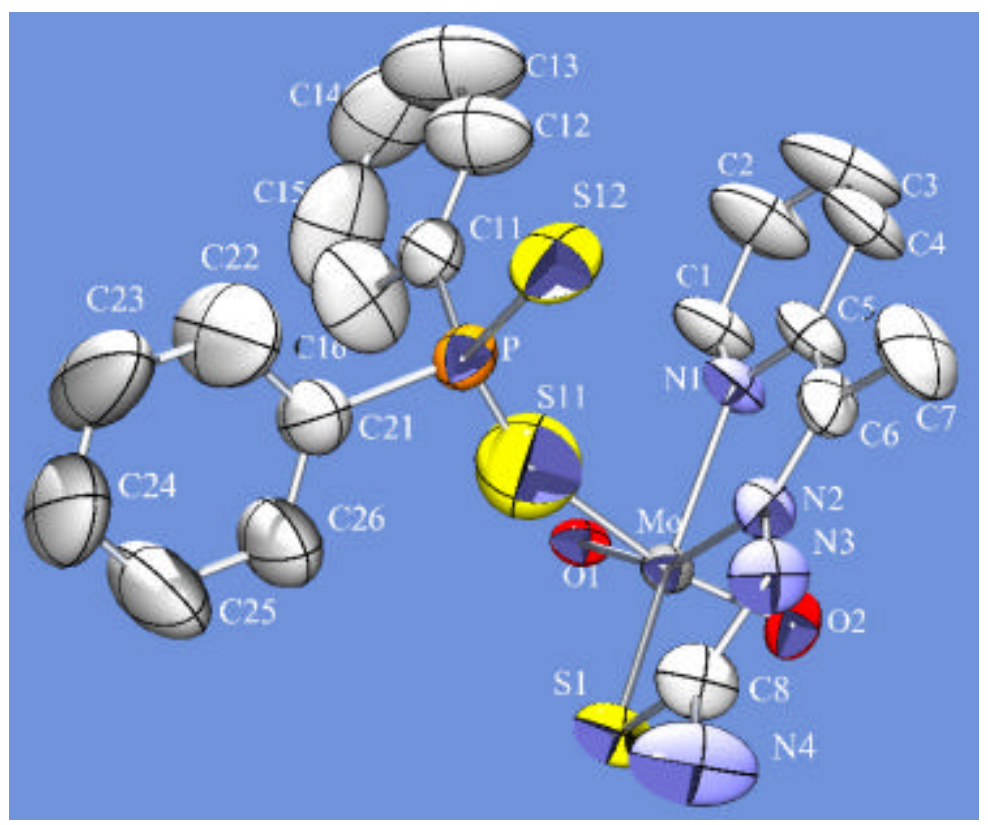

Figura C.12: Estrutura

molecular do composto XII. 


\section{C.13 COMPOSTO XIII}

Tabela C.13: Dados do cris tal e da estrutura e refinamento para o composto XIII.

Fórmula empírica

Peso da fórmula

Temperatura

Comprimento de onda

Sistema cristalino

Grupo espacial

Parâmetros da cela unitária

Volume

Z

Densidade (calculada)

Coeficiente de absorção

$\mathrm{F}(000)$

Dimensões do cristal

Intervalo de teta para a coleta de dados

Intervalo dos índices

Reflexões coletadas

Reflexões independentes

Completeza em teta $=66.93^{\circ}$

Correção por absorção

Método de refinamento

Dados / parâmetros

Goodness-of-fit em $\mathrm{F}^{2}$

$\mathrm{R}$ final $[\mathrm{I}>2 \sigma(\mathrm{I})]$

$\mathrm{R}$ (todos dados)

Coeficiente de extinção

Maiores picos e vales de densidade residual
$\mathrm{C}_{24} \mathrm{H}_{20} \mathrm{Mo}_{2} \mathrm{O} 2.65 \mathrm{P} 2 \mathrm{~S} 5.35$

776.10

293(2) K

$1.54184 \AA$

monoclínico

$\mathrm{P} 21 / \mathrm{c}$

$a=12.346(3) \AA$

$b=13.6695(18) \AA \quad \beta=96.82(2)^{\circ}$.

$c=17.665(5) \AA$

2960.1(12) $\AA^{3}$

4

$1.742 \mathrm{Mg} / \mathrm{m}^{3}$

$11.691 \mathrm{~mm}^{-1}$

1539

$0.48 \times 0.13 \times 0.12 \mathrm{~mm}^{3}$

3.61 a $66.93^{\circ}$

$0 \leq \mathrm{h} \leq 14,0 \leq \mathrm{k} \leq 16,-21 \leq 1 \leq 20$

5524

$5264[\mathrm{R}(\mathrm{Int})=0.0286]$

$100.0 \%$

Nenhum

Métodos mínimos quadrados em $\mathrm{F}^{2}$

5264 / 335

1.040

$\mathrm{R} 1=0.0388, \mathrm{wR} 2=0.1043$

$\mathrm{R} 1=0.0495, \mathrm{wR} 2=0.1104$

$0.00019(3)$

0.683 e -1.011 e. $\AA^{-3}$

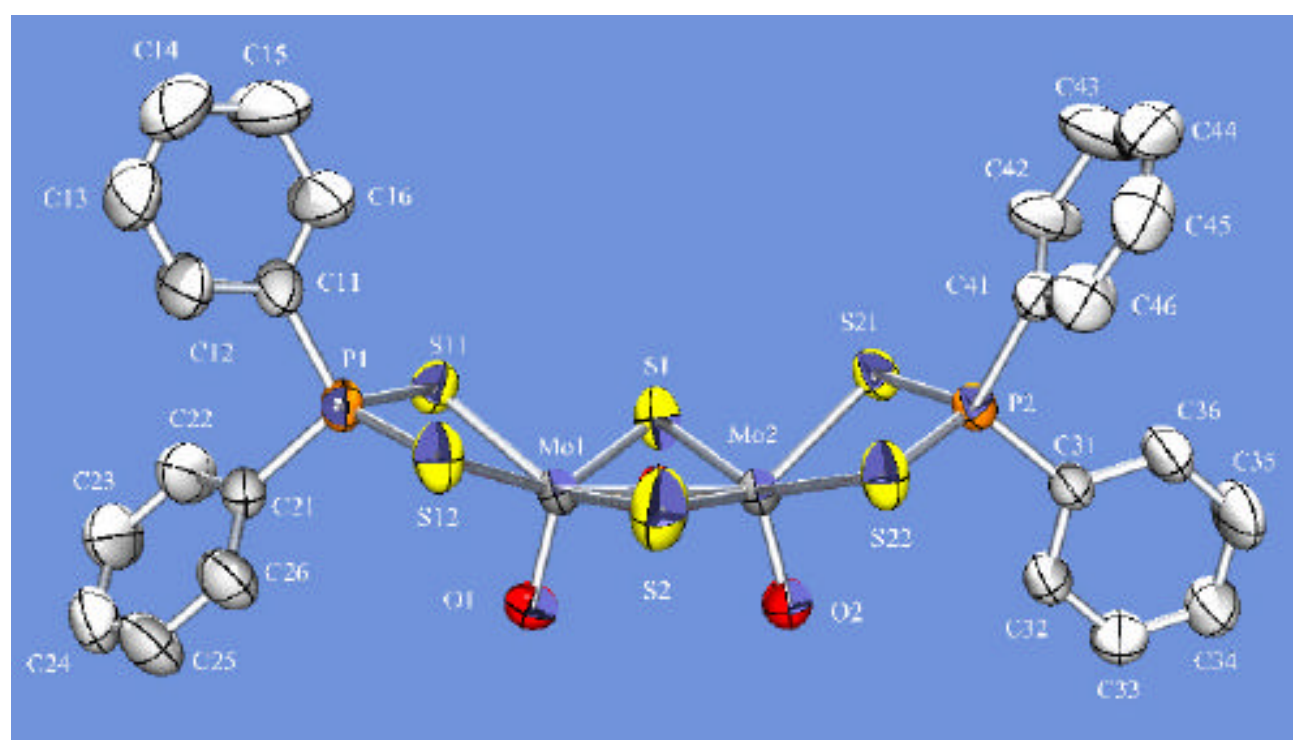

Figura C.13: Estrutura molecular do composto XIII. 


\section{C.14 COMPOSTO XIV}

Tabela C.14: Dados do cristal e da estrutura e refinamento para o composto XIV.

Fórmula empírica

Peso da fórmula

Temperatura

Comprimento de onda

Sistema cristalino

Grupo espacial

Parâmetros da cela unitária

\section{Volume}

Z

Densidade (calculada)

Coeficiente de absorção

$\mathrm{F}(000)$

Dimensões do cristal

Intervalo de teta para a coleta de dados

Intervalo dos índices

Reflexões coletadas

Reflexões independentes

Completeza em teta $=66.92^{\circ}$

Correção por absorção

Método de refinamento

Dados / parâmetros

Goodness-of-fit em $\mathrm{F}^{2}$

$\mathrm{R}$ final $[\mathrm{I}>2 \sigma(\mathrm{I})]$

$\mathrm{R}$ (todos dados)

Coeficiente de extinção

Maiores picos e vales de densidade residual
$\mathrm{C}_{72} \mathrm{H}_{60} \mathrm{Mo}_{4} \mathrm{O}_{20} \mathrm{P}_{6}$

1814.78

293(2) K

$1.54184 \AA$

triclín ico

P-1

$a=11.884(3) \AA$

$b=13.545(2) \AA$

$\alpha=91.865(14)^{\circ}$.

$c=14.471(2) \AA$

1949.0(7) $\AA^{3}$

1

$1.546 \mathrm{Mg} / \mathrm{m}^{3}$

$6.889 \mathrm{~mm}^{-1}$

910

$0.60 \times 0.16 \times 0.07 \mathrm{~mm}^{3}$

3.30 a $66.92^{\circ}$

$-14 \leq \mathrm{h} \leq 12,0 \leq \mathrm{k} \leq 16,-17 \leq 1 \leq 17$

7260

$6941[\mathrm{R}(\mathrm{Int})=0.0393]$

$100.0 \%$

Analítica

Métodos mínimos quadrados em $\mathrm{F}^{2}$

6941 / 461

1.024

$\mathrm{R} 1=0.0430, \mathrm{wR} 2=0.1163$

$\mathrm{R} 1=0.0546, \mathrm{wR} 2=0.1257$

$0.00027(8)$

0.951 e -1.515 e. $\AA^{-3}$

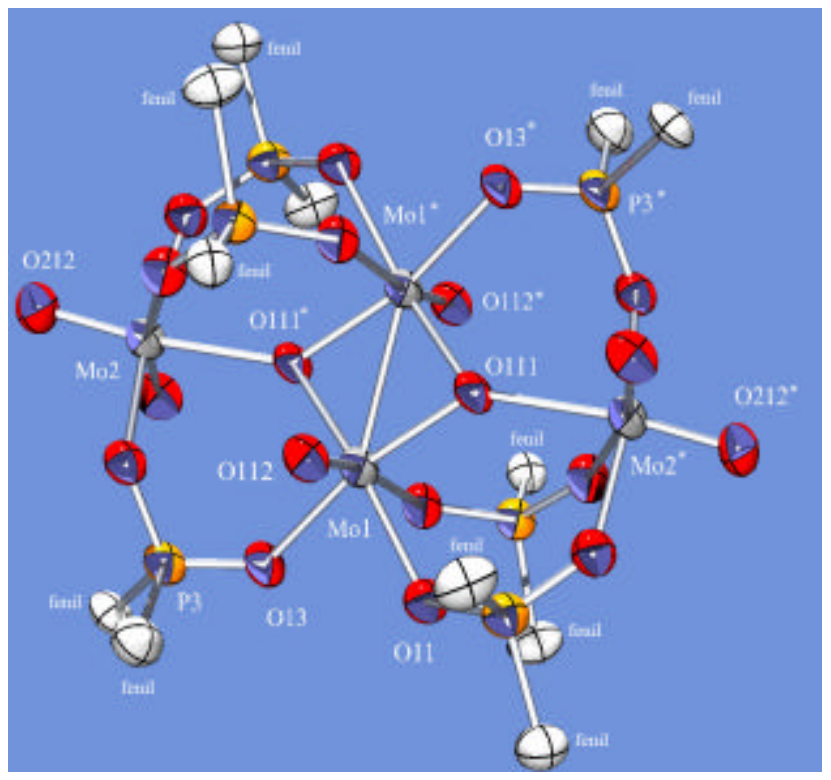

Figura C.14: Estrutura

molecular do composto XIV.

$*(-\mathrm{x},-\mathrm{y},-\mathrm{z})$ 


\section{C.15 COMPOSTO XV}

Tabela C.15: Dados do cristal e da estrutura e refinamento para o composto XV.

Fórmula empírica

Peso da fórmula

Temperatura

Comprimento de onda

Sistema cristalino

Grupo espacial

Parâmetros da cela unitária

\section{Volume}

$\mathrm{Z}$

Densidade (calculada)

Coeficiente de absorção

$\mathrm{F}(000)$

Dimensões do cristal

Intervalo de teta para a coleta de dados

Intervalo dos índices

Reflexões coletadas

Reflexões independentes

Completeza em teta $=66.93^{\circ}$

Correção por absorção

Método de refinamento

Dados / parâmetros

Goodness-of-fit em $\mathrm{F}^{2}$

$\mathrm{R}$ final $[\mathrm{I}>2 \sigma(\mathrm{I})]$

$\mathrm{R}$ (todos dados)

Coeficiente de extinção

Maiores picos e vales de densidade residual
$\mathrm{C}_{33} \mathrm{H}_{39} \mathrm{CdN}_{14} \mathrm{O}_{5} \mathrm{~S}_{3}$

920.36

293(2) K

$1.54184 \AA$

triclín ico

P-1

$a=10.814(8) \AA$

$\alpha=69.51(3)^{\circ}$.

$b=14.180(5) \AA$

$\beta=76.23(5)^{\circ}$.

$c=15.265(7) \AA$

2034.3(19) $\AA^{3}$

$\gamma=69.36(4)^{\circ}$.

$1.503 \mathrm{Mg} / \mathrm{m}^{3}$

$6.228 \mathrm{~mm}^{-1}$

942

$0.84 \times 0.56 \times 0.40 \mathrm{~mm}^{3}$

3.12 a $66.93^{\circ}$

$0 \leq \mathrm{h} \leq 12,-15 \leq \mathrm{k} \leq 16,-17 \leq 1 \leq 18$

7643

$7225[\mathrm{R}(\mathrm{Int})=0.0606]$

$99.8 \%$

Analítica

Métodos mínimos quadrados em $\mathrm{F}^{2}$

7225 / 538

1.024

$\mathrm{R} 1=0.0623, \mathrm{wR} 2=0.1775$

$\mathrm{R} 1=0.0657, \mathrm{wR} 2=0.1823$

$0.0015(3)$

1.541 e -1.381 e. $\AA^{-3}$

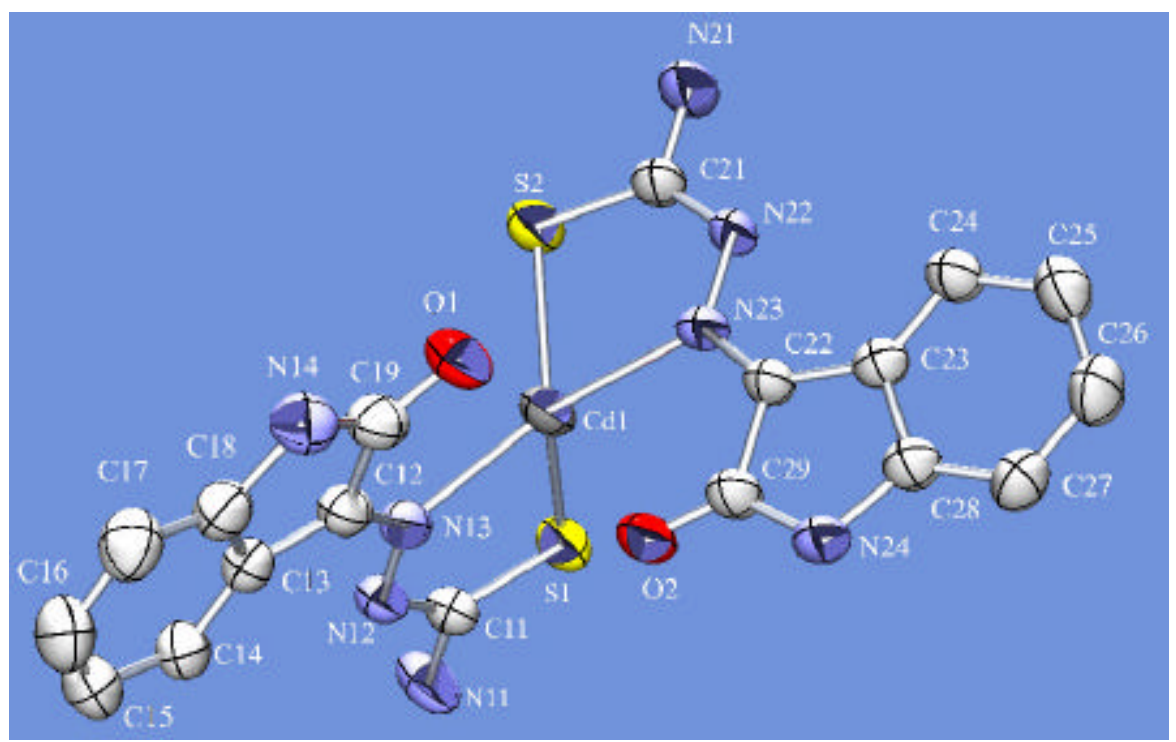

Figura C.15: Estrutura molecular do composto XV. 


\begin{abstract}
ANEXO D
Neste anexo serão apresentadas tabelas de parâmetros de deslocamentos anisotrópicos do átomo pesado e de sua esfera de coordenação, para alguns dos compostos usados no estudo comparativo das diferentes correções por absorção. Também serão mostradas tabelas com distâncias e ângulos de ligações para os átomos coordenados com o metal pesado.
\end{abstract}


Tabela D.1: Valores para os parâmetros de deslocamentos anisotrópicos para os diferentes métodos de correção por absorção aplicados, composto I

\begin{tabular}{|c|c|c|c|c|c|c|c|c|c|c|c|c|}
\hline \multirow[t]{2}{*}{ Átomo } & \multicolumn{3}{|c|}{ Sem correção } & \multicolumn{3}{|c|}{ Semi-empírico } & \multicolumn{3}{|c|}{ Analítico } & \multicolumn{3}{|c|}{ DFABS } \\
\hline & $\mathrm{U}_{11}$ & $\mathrm{U}_{22}$ & $\mathrm{U}_{33}$ & $\mathrm{U}_{11}$ & $\mathrm{U}_{22}$ & $\mathrm{U}_{33}$ & $\mathrm{U}_{11}$ & $\mathrm{U}_{22}$ & $\mathrm{U}_{33}$ & $\mathrm{U}_{11}$ & $\mathrm{U}_{22}$ & $\mathrm{U}_{33}$ \\
\hline $\mathrm{Nd}$ & 0,02021 & 0,01259 & 0,02478 & 0,02084 & 0,01284 & 0,02509 & 0,01839 & 0,01571 & 0,02492 & 0,02048 & 0,02127 & 02474 \\
\hline O1 & 0,02214 & 0,02018 & 0,05430 & 0,02342 & 0,02063 & 0,05267 & 0,02043 & 0,02372 & 0,05222 & 0,02229 & 0,02972 & 0,05103 \\
\hline $\mathrm{O} 2$ & 0,02668 & 0,01660 & 0,03811 & 0,02805 & 0,01792 & 0,03797 & 0,02504 & 0,01932 & 0,03867 & 0,02732 & 0,02421 & 0,03844 \\
\hline $\mathrm{O} 3$ & 0,02559 & 0,03975 & 0,03935 & 804 & 0,04040 & 0,03997 & 2458 & 0,04468 & 0,03943 & 0,02720 & 0,05128 & 0,03875 \\
\hline $\mathrm{O} 4$ & 0,04740 & 0,01455 & 0,03435 & 0,04610 & 0,01627 & 0,03330 & 0,04530 & 0,01898 & 0,03360 & 0,04696 & 0,02486 & 0,03420 \\
\hline $\mathrm{O5}$ & 0,04294 & 0,01679 & 0,02501 & 0,04423 & 0,01591 & 0,02499 & 0,04136 & 0,01956 & 0,02471 & 0,04291 & 0,02646 & 0,02421 \\
\hline O6 & 0,02627 & 0,02435 & 0,02872 & 0,02872 & 0,02306 & 0,02979 & 0,02485 & 0,02751 & 0,02996 & 0,02721 & 0,03437 & 0,02919 \\
\hline $\mathrm{O} 7$ & 0,04097 & 0,01676 & 0,04288 & 0,03987 & 0,01777 & 0,04360 & 0,03752 & 0,02090 & 0,04403 & 0,03965 & 0,02675 & 0,04432 \\
\hline
\end{tabular}

Tabela D.2: Valores para os parâmetros de deslocamentos anisotrópicos para os diferentes métodos de correção por absorção aplicados, composto II

\begin{tabular}{|c|c|c|c|c|c|c|c|c|c|c|c|c|c|c|c|}
\hline \multirow[t]{2}{*}{ Átomo } & \multicolumn{3}{|c|}{ Sem correção } & \multicolumn{3}{|c|}{ Semi-empírico } & \multicolumn{3}{|c|}{ Analítico } & \multicolumn{3}{|c|}{ DFABS } & \multicolumn{3}{|c|}{ XABS2 } \\
\hline & $\mathrm{U}_{11}$ & $\mathrm{U}_{22}$ & $\mathrm{U}_{33}$ & $\mathrm{U}_{11}$ & $\mathrm{U}_{22}$ & $\mathrm{U}_{33}$ & $\mathrm{U}_{11}$ & $\mathrm{U}_{22}$ & $\mathrm{U}_{33}$ & $\mathrm{U}_{11}$ & $\mathrm{U}_{22}$ & $\mathrm{U}_{33}$ & $\mathrm{U}_{11}$ & $\mathrm{U}_{22}$ & $\mathrm{U}_{33}$ \\
\hline $\mathrm{Ru}$ & 0,03050 & 0,03363 & 0,03681 & 0,03070 & 0,03375 & 0,03710 & 0,02953 & 0,03447 & 0,03700 & 0,03134 & 0,03337 & 0,03702 & 0,03075 & 0,03241 & 0,03555 \\
\hline N1 & 0,03491 & 0,04725 & 0,04078 & 0,03486 & 0,04785 & 0,04098 & 0,03459 & 0,04743 & 0,04104 & 0,03612 & 0,04559 & 0,04155 & 0,03570 & 0,04678 & 0,03909 \\
\hline $\mathrm{N} 2$ & 0,06743 & 0,04845 & 0,04848 & 0,06793 & 0,04847 & 0,04856 & 0,06619 & 0,04973 & 0,04849 & 0,06677 & 0,04973 & 0,04920 & 0,06724 & 0,04902 & 0,04716 \\
\hline N3 & 0,03187 & 0,03835 & 0,04219 & 0,03201 & 0,03884 & 0,04234 & 0,03120 & 0,03922 & 0,04200 & 0,03254 & 0,03951 & 0,04004 & 0,03189 & 0,03770 & 0,04012 \\
\hline
\end{tabular}


Tabela D.3: Valores para os parâmetros de deslocamentos anisotrópicos para os diferentes métodos de correção por absorção aplicados, composto III

\begin{tabular}{|c|c|c|c|c|c|c|c|c|c|c|c|c|c|c|c|}
\hline \multirow[t]{2}{*}{ Átomo } & \multirow{2}{*}{\multicolumn{3}{|c|}{ Sem correção }} & \multicolumn{3}{|c|}{ Semi -empírico } & \multicolumn{3}{|c|}{ Analítico } & \multicolumn{3}{|c|}{ DFABS } & \multicolumn{3}{|c|}{ XABS2 } \\
\hline & & & & $\mathrm{U}_{11}$ & $\mathrm{U}_{22}$ & $\mathrm{U}_{33}$ & $\mathrm{U}_{11}$ & $\mathrm{U}_{22}$ & $\mathrm{U}_{33}$ & $\mathrm{U}_{11}$ & $\mathrm{U}_{22}$ & $\mathrm{U}_{33}$ & $\mathrm{U}_{11}$ & $\mathrm{U}_{22}$ & $\mathrm{U}_{33}$ \\
\hline Ru1 & 0,02086 & 0,01622 & 0,04238 & 0,02215 & 0,01633 & 0,04186 & 0,02225 & 0,01637 & 0,04090 & 0,02501 & 0,02240 & 0,02994 & 0,02729 & 0,02363 & 0,03251 \\
\hline Cl11 & 0,02571 & 0,02080 & 0,05863 & 0,02674 & 0,02118 & 0,05851 & 0,02702 & 0,02086 & 0,05672 & 0,02868 & 0,02753 & 0,04532 & 0,03160 & 0,02858 & 0,04791 \\
\hline $\mathrm{Cl12}$ & 0,02483 & 0,02209 & 0,05878 & 0,02548 & 0,02057 & 0,06042 & 0,02628 & 0,02186 & 0,05707 & 0,02768 & 0,02773 & 0,04778 & 0,03007 & 0,02774 & 0,05085 \\
\hline S11 & 0,03168 & 0,01537 & 0,04432 & 0,03392 & 0,01523 & 0,04352 & 0,03250 & 0,01628 & 0,04287 & 0,03273 & 0,02298 & 0,03349 & 0,03437 & 0,02493 & 0,03543 \\
\hline S12 & 0,01851 & 0,03188 & 0,04557 & 0,01945 & 0,03174 & 0,04482 & 0,01966 & 0,03188 & 0,04438 & 0,02307 & 0,03774 & 0,03293 & 0,02558 & 0,03870 & 0,03585 \\
\hline N11 & 0,01933 & 0,01977 & 0,06768 & 0,02249 & 0,02026 & 0,05581 & 0,02135 & 0,02309 & 0,05442 & 0,02579 & 0,02771 & 0,04249 & 0,02670 & 0,02795 & 0,04496 \\
\hline O12 & 0,00934 & 0,02372 & 0,06199 & 0,01140 & 0,02415 & 0,05848 & 0,01118 & 0,02405 & 0,05676 & 0,02191 & 0,02896 & 0,03276 & 0,02452 & 0,02864 & 0,03780 \\
\hline $\mathrm{Ru} 2$ & 58 & 02 & & & & & & & & & & & & & \\
\hline $\mathrm{Cl} 21$ & 0,02989 & 0,02698 & 0,05044 & 0,03035 & 0,02675 & 0,04932 & 0,03117 & 0,02722 & 0,04874 & 0,03419 & 0,03245 & 0,03838 & 0,03640 & 0,03337 & 0,04077 \\
\hline $\mathrm{Cl} 22$ & 0,02588 & 0,02241 & 0,05902 & 0,02772 & 0,02287 & 0,05771 & 0,02696 & 0,02249 & 0,05780 & 0,02868 & 0,02750 & 0,04738 & 0,03165 & 0,02783 & 0,05008 \\
\hline S21 & 0,02097 & 0,02320 & 0,04807 & 0,02133 & 0,02209 & 0,04724 & 0,02217 & 0,02346 & 0,04625 & 0,02525 & 0,02943 & 0,03397 & 0,02715 & 0,03088 & 0,03551 \\
\hline S22 & 0,02856 & 0,01563 & 0,05095 & 0,02856 & 0,01589 & 0,05078 & 0,02964 & 0,01599 & 0,04910 & 0,03333 & 0,02186 & 0,03767 & 0,03474 & 0,02272 & 0,04078 \\
\hline $\mathrm{N} 21$ & 0,03260 & 0,01495 & 0,04376 & 0,02654 & 0,01297 & 0,05279 & 0,03164 & 0,01421 & 0,04588 & 0,03890 & 0,01896 & 0,03481 & 0,03790 & 0,01871 & 0,03770 \\
\hline $\mathrm{O} 22$ & 0,00985 & 0,02351 & 0,06500 & 0,01041 & 0,02523 & 0,06161 & 0,00960 & 0,02645 & 0,06280 & 0,01284 & 0,03384 & 0,03978 & 0,01421 & 0,03674 & 0,04248 \\
\hline
\end{tabular}

Tabela D.4: Valores para os parâmetros de deslocamentos anisotrópicos para os diferentes métodos de correção por absorção aplicados, composto IV

\begin{tabular}{|c|c|c|c|c|c|c|c|c|c|c|c|c|c|c|c|}
\hline \multirow[t]{2}{*}{ Átomo } & \multicolumn{3}{|c|}{ Sem correção } & \multicolumn{3}{|c|}{ Semi-empírico } & \multicolumn{3}{|c|}{ Analítico } & \multicolumn{3}{|c|}{ DFABS } & \multicolumn{3}{|c|}{ XABS2 } \\
\hline & $\mathrm{U}_{11}$ & $\mathrm{U}_{22}$ & $\mathrm{U}_{33}$ & $\mathrm{U}_{11}$ & $\mathrm{U}_{22}$ & $\mathrm{U}_{33}$ & $\mathrm{U}_{11}$ & $\mathrm{U}_{22}$ & $\mathrm{U}_{33}$ & $\mathrm{U}_{11}$ & $\mathrm{U}_{22}$ & $\mathrm{U}_{33}$ & $\mathrm{U}_{11}$ & $\mathrm{U}_{22}$ & $\mathrm{U}_{33}$ \\
\hline $\mathrm{Ru} 1$ & 0,01608 & 0,01135 & 0,01695 & 0,01578 & 0,01099 & 0,01693 & 0,01588 & 0,01003 & 0,01643 & 0,01555 & 0,01077 & 0,01636 & 0,01571 & 0,01346 & 0,01641 \\
\hline $\mathrm{Cl} 2$ & 0,01858 & 0,01954 & 0,02538 & 0,01836 & 0,01930 & 0,02593 & 0,01846 & 0,01827 & 0,02558 & 0,01797 & 0,01895 & 0,02492 & 0,01826 & 0,02168 & 0,02492 \\
\hline $\mathrm{Cl} 3$ & 0,02252 & 0,02838 & 0,04760 & 0,02248 & 0,02815 & 0,04788 & 0,02241 & 0,02723 & 0,04744 & 0,02193 & 0,02784 & 0,04697 & 0,02225 & 0,03045 & 0,04694 \\
\hline N1 & 0,01911 & 0,01218 & 0,02087 & 0,01876 & 0,01066 & 0,02050 & 0,01952 & 0,01042 & 0,01957 & 0,01891 & 0,01091 & 0,01954 & 0,01969 & 0,01273 & 0,02020 \\
\hline $\mathrm{O} 1$ & 0,02733 & 0,01224 & 0,01729 & 0,02659 & 0,01106 & 0,01746 & 0,02708 & 0,01071 & 0,01708 & 0,02693 & 0,01164 & 0,01650 & 0,02679 & 0,01421 & 0,01666 \\
\hline S1 & 0,02689 & 0,01290 & 0,02003 & 0,02700 & 0,01262 & 0,01989 & 0,02721 & 0,01173 & 0,01939 & 0,02684 & 0,01248 & 0,01891 & 0,02679 & 0,01524 & 0,01906 \\
\hline S2 & 0,01922 & 0,01480 & 0,02127 & 0,01874 & 0,01400 & 0,02157 & 0,01916 & 0,01332 & 0,02116 & 0,01875 & 0,01410 & 0,02082 & 0,01886 & 0,01668 & 0,02095 \\
\hline
\end{tabular}


Tabela D.5: Valores para os parâmetros de deslocamentos anisotrópicos para os diferentes métodos de correção por absorção aplicados, composto V

\begin{tabular}{|c|c|c|c|c|c|c|c|c|c|c|c|c|}
\hline \multirow[t]{2}{*}{ Átomo } & \multicolumn{3}{|c|}{ Sem correção } & \multicolumn{3}{|c|}{ Semi-empírico } & \multicolumn{3}{|c|}{ Analítico } & \multicolumn{3}{|c|}{ XABS2 } \\
\hline & $\mathrm{U}_{11}$ & $\mathrm{U}_{22}$ & $\mathrm{U}_{33}$ & $\mathrm{U}_{11}$ & $\mathrm{U}_{22}$ & $\mathrm{U}_{33}$ & $\mathrm{U}_{11}$ & $\mathrm{U}_{22}$ & $\mathrm{U}_{33}$ & $\mathrm{U}_{11}$ & $\mathrm{U}_{22}$ & $\mathrm{U}_{33}$ \\
\hline $\mathrm{Pb} 1 \mathrm{~A}$ & 02041 & 0,01630 & 02114 & 02168 & 01777 & 0,02257 & 02063 & 0,01625 & 02129 & 02073 & 0,01807 & \\
\hline $\mathrm{C} 1 \mathrm{~A}$ & & & & & & & & 0,01349 & & & 0,01476 & \\
\hline C7A & 484 & 2669 & 1024 & 2652 & & & 02494 &, 02587 & & 02267 &, 02443 & 1275 \\
\hline $\mathrm{Cl1A}$ & & & & & & & &, 02345 & & &, 02519 & \\
\hline $\mathrm{Cl} 2 \mathrm{~A}$ & & & & & & & & 834 & & & 0,02020 & \\
\hline $\mathrm{N} 1 \mathrm{~A}$ & 96 & & & & & & 662 & 0,02175 & & & 0,03030 & \\
\hline & & & & & & & & & & & 646 & \\
\hline 1B & & & & & & & & 0,01443 & & & 0,01576 & \\
\hline $1 \mathrm{~B}$ & & & & & & & & & & & 2469 & \\
\hline B & & & & & & & & & & & 2204 & \\
\hline $11 \mathrm{~B}$ & & & & & & & & & & & 0,03094 & \\
\hline 2 & & & & & & & & & & & 3616 & \\
\hline $1 \mathrm{~B}$ & & & & & & & & & & & 1453 & \\
\hline $2 \mathrm{~B}$ & & & & & & & & & & & 0,01649 & \\
\hline 4 & & & & & & & & & & & & \\
\hline $1 \mathrm{C}$ & & & & & & & & 52 & & & 0,02579 & \\
\hline $\mathrm{C} 7 \mathrm{C}$ & & & & & & & & 545 & & & 2582 & \\
\hline $11 \mathrm{C}$ & & & & & & & & 3096 & & & & \\
\hline $\mathrm{Cl} 2 \mathrm{C}$ & & & & & & & & & & & 0,02383 & \\
\hline & & & & & & & & 6688 & & & 0,01550 & \\
\hline $\mathrm{N} 2 \mathrm{C}$ & & & & & & & & 674 & & 83 & 0,02107 & \\
\hline $\mathrm{Pb} 1 \mathrm{D}$ & & & & & & & & 0,01687 & & & 0,01851 & 995 \\
\hline & & & & & & & & 2199 & & & 0,02348 & \\
\hline C7D & & & & & & & 479 & 0,01560 & 164 & 399 & 0,01838 & 239 \\
\hline Cl1D & & & & & & & 753 & 2707 & & 774 & 0,02882 & 675 \\
\hline $\mathrm{Cl} 2 \mathrm{D}$ & & & & & & & & & & & 0,02178 & \\
\hline N1D & & & & & & & & 0,01467 & & & 0,01579 & 0,02415 \\
\hline $\mathrm{N} 2 \mathrm{D}$ & 0,02175 & 0,01717 & 0,02117 & 01950 & 0,02157 & 0,02368 & 0,02171 & 0,01716 & 0,02057 & 0,01722 & 0,02358 & 0,01781 \\
\hline
\end{tabular}


Tabela D.6: Valores para os parâmetros de deslocamentos anisotrópicos para os diferentes métodos de correção por absorção aplicados, composto VI

\begin{tabular}{|c|c|c|c|c|c|c|c|c|c|c|c|c|c|c|c|}
\hline \multirow[t]{2}{*}{ Átomo } & \multicolumn{3}{|c|}{ Sem correção } & \multicolumn{3}{|c|}{ Semi-empírico } & \multicolumn{3}{|c|}{ Analítico } & \multicolumn{3}{|c|}{ DFABS } & \multicolumn{3}{|c|}{ XABS2 } \\
\hline & $\mathrm{U}_{11}$ & $\mathrm{U}_{22}$ & $\mathrm{U}_{33}$ & $\mathrm{U}_{11}$ & $\mathrm{U}_{22}$ & $\mathrm{U}_{33}$ & $\mathrm{U}_{11}$ & $\mathrm{U}_{22}$ & $\mathrm{U}_{33}$ & $\mathrm{U}_{11}$ & $\mathrm{U}_{22}$ & $\mathrm{U}_{33}$ & $\mathrm{U}_{11}$ & $\mathrm{U}_{22}$ & $\mathrm{U}_{33}$ \\
\hline Sn1 & 0,06392 & 0,04330 & 0,04720 & 0,06469 & 0,04369 & 0,04769 & 0,06199 & 0,04353 & 0,04748 & 0,06381 & 0,04862 & 0,05097 & 0,06243 & 0,05018 & 0,05173 \\
\hline $\mathrm{S} 2$ & 0,07516 & 0,06524 & 0,05158 & 0,07561 & 0,06576 & 0,05240 & 0,07286 & 0,06554 & 0,05221 & 0,07483 & 0,07070 & 0,05569 & 0,07322 & 0,07215 & 0,05662 \\
\hline S3 & 0,06626 & 0,06990 & 0,04716 & 0,06692 & 0,07039 & 0,04773 & 0,06453 & 0,07033 & 0,04756 & 0,06648 & 0,07518 & 0,05100 & 0,06504 & 0,07713 & 0,05171 \\
\hline $\mathrm{C} 15$ & 0,07366 & 0,06518 & 0,07850 & 0,07356 & 0,06533 & 0,07878 & 0,07109 & 0,06580 & 0,07857 & 0,07282 & 0,06923 & 0,08399 & 0,07241 & 0,07135 & 0,08337 \\
\hline C16 & 0,06689 & 0,04620 & 0,04493 & 0,06697 & 0,04668 & 0,04548 & 0,06487 & 0,04681 & 0,04447 & 0,06734 & 0,05013 & 0,04618 & 0,06544 & 0,05270 & 0,04686 \\
\hline
\end{tabular}

Tabela D.7: Valores para os parâmetros de deslocamentos anisotrópicos para os diferentes métodos de correção por absorção aplicados, composto VII

\begin{tabular}{|c|c|c|c|c|c|c|c|c|c|c|c|c|}
\hline \multirow[t]{2}{*}{ Átomo } & \multirow{2}{*}{\multicolumn{3}{|c|}{ Sem correção }} & \multicolumn{3}{|c|}{ Semi-empírico } & \multicolumn{3}{|c|}{ Analítico } & \multicolumn{3}{|c|}{ DFABS } \\
\hline & & & & $\mathrm{U}_{11}$ & $\mathrm{U}_{22}$ & $\mathrm{U}_{33}$ & $\mathrm{U}_{11}$ & $\mathrm{U}_{22}$ & $\mathrm{U}_{33}$ & $\mathrm{U}_{11}$ & $\mathrm{U}_{22}$ & $\mathrm{U}_{33}$ \\
\hline O11A & 0,02592 & 0,23685 & 0,06896 & 0,02210 & 0,24139 & 0,07319 & 0,02592 & 0,23685 & 0,06896 & 0,05476 & 0,13214 & 0,09635 \\
\hline $\mathrm{O} 1$ & 0,07225 & 0,03591 & 0,04113 & 0,07253 & 0,03575 & 0,04203 & 0,07225 & 0,03591 & 0,04113 & 0,07304 & 0,03702 & 0,04154 \\
\hline $\mathrm{N}$ & 0,05340 & 0,03802 & 0,03452 & 0,05366 & 0,03853 & 0,03530 & 0,05340 & 0,03802 & 0,03452 & 0,05708 & 0,04115 & 0,03336 \\
\hline $\mathrm{O} 3$ & 0,07630 & 0,03167 & 0,04562 & 0,07720 & 0,03176 & 0,04617 & 0,07630 & 0,03167 & 0,04562 & 0,07881 & 0,03397 & 0,04741 \\
\hline
\end{tabular}


Tabela D.8: Valores para os parâmetros de deslocamentos anisotrópicos para os diferentes métodos de correção por absorção aplicados, composto VIII

\begin{tabular}{|l|c|c|c|c|c|c|c|c|c|}
\hline \multicolumn{1}{|c|}{ Átomo } & \multicolumn{3}{|c|}{ Sem correção } & \multicolumn{3}{c|}{ DFABS } & \multicolumn{3}{c|}{ XABS2 } \\
\cline { 1 - 6 } & $\mathrm{U}_{11}$ & $\mathrm{U}_{22}$ & $\mathrm{U}_{33}$ & $\mathrm{U}_{11}$ & $\mathrm{U}_{22}$ & $\mathrm{U}_{33}$ & $\mathrm{U}_{11}$ & $\mathrm{U}_{22}$ & $\mathrm{U}_{33}$ \\
\hline Zn1 & 0,03523 & 0,02846 & 0,03794 & 0,03751 & 0,03438 & 0,03394 & 0,03724 & 0,03444 & 0,03395 \\
\hline Fe1 & 0,03044 & 0,02938 & 0,04190 & 0,03272 & 0,03531 & 0,03749 & 0,03261 & 0,03547 & 0,03754 \\
\hline S1 & 0,04446 & 0,04066 & 0,04362 & 0,04641 & 0,04666 & 0,03939 & 0,04649 & 0,04646 & 0,03947 \\
\hline N1 & 0,03285 & 0,02752 & 0,03381 & 0,03816 & 0,03408 & 0,02940 & 0,03601 & 0,03312 & 0,03003 \\
\hline C1 & 0,04064 & 0,02263 & 0,04019 & 0,03667 & 0,03386 & 0,03280 & 0,03692 & 0,03289 & 0,03421 \\
\hline C2 & 0,03959 & 0,03525 & 0,04825 & 0,04047 & 0,03866 & 0,04389 & 0,04027 & 0,04001 & 0,04359 \\
\hline C3 & 0,04017 & 0,04394 & 0,06694 & 0,04160 & 0,05226 & 0,06362 & 0,04015 & 0,05203 & 0,06332 \\
\hline C4 & 0,03635 & 0,04882 & 0,06950 & 0,03836 & 0,05505 & 0,06379 & 0,03871 & 0,05512 & 0,06555 \\
\hline C5 & 0,03335 & 0,04173 & 0,04789 & 0,03666 & 0,04906 & 0,04087 & 0,03668 & 0,04796 & 0,04063 \\
\hline C6 & 0,04229 & 0,04745 & 0,09595 & 0,04201 & 0,05545 & 0,09169 & 0,04278 & 0,05429 & 0,09207 \\
\hline C7 & 0,04640 & 0,04833 & 0,06454 & 0,05136 & 0,05428 & 0,06111 & 0,05154 & 0,05481 & 0,05747 \\
\hline C8 & 0,07670 & 0,03488 & 0,06781 & 0,07456 & 0,04466 & 0,06483 & 0,07247 & 0,04325 & 0,06621 \\
\hline C9 & 0,07696 & 0,03646 & 0,07365 & 0,06936 & 0,04431 & 0,06699 & 0,07040 & 0,04263 & 0,06858 \\
\hline C10 & 0,06795 & 0,03951 & 0,07123 & 0,07030 & 0,04863 & 0,06654 & 0,07144 & 0,04771 & 0,06582 \\
\hline
\end{tabular}


Tabela D.9: Valores para os parâmetros de deslocamentos anisotrópicos para os diferentes métodos de correção por absorção aplicados, composto IX

\begin{tabular}{|c|c|c|c|c|c|c|c|c|c|c|c|c|c|c|c|}
\hline \multirow[t]{2}{*}{ Átomo } & \multicolumn{3}{|c|}{ Sem correção } & \multicolumn{3}{|c|}{ Semi-empírico } & \multicolumn{3}{|c|}{ Analítico } & \multicolumn{3}{|c|}{ DFABS } & \multicolumn{3}{|c|}{ XABS2 } \\
\hline & $\mathrm{U}_{11}$ & $\mathrm{U}_{22}$ & $\mathrm{U}_{33}$ & $\mathrm{U}_{11}$ & $\mathrm{U}_{22}$ & $\mathrm{U}_{33}$ & $\mathrm{U}_{11}$ & $\mathrm{U}_{22}$ & $\mathrm{U}_{33}$ & $\mathrm{U}_{11}$ & $\mathrm{U}_{22}$ & $\mathrm{U}_{33}$ & $\mathrm{U}_{11}$ & $\mathrm{U}_{22}$ & $\mathrm{U}_{33}$ \\
\hline $\mathrm{Ru} 1$ & 0,02028 & 0,02799 & 0,02643 & 0,02112 & 0,02869 & 0,02736 & 0,01970 & 0,02841 & 0,02643 & 0,02177 & 0,02736 & 0,02518 & 0,02087 & 0,02912 & 0,02614 \\
\hline $\mathrm{C}$ & 0,03178 & 0,03316 & 0,03066 & 0,03268 & 0,03471 & 0,03111 & 0,03070 & 0,03385 & 0,03090 & 0,03116 & 0,04124 & 0,04197 & 0,03401 & 0,03311 & 0,02880 \\
\hline $\mathrm{P} 1$ & 0,02504 & 0,02872 & 0,02724 & 0,02569 & 0,02948 & 0,02800 & 0,02455 & 0,02910 & 0,02725 & 0,02649 & 0,02832 & 0,02590 & 0,02566 & 0,02982 & 0,02679 \\
\hline $\mathrm{P} 2$ & 0,02305 & 0,03374 & 0,02643 & 0,02376 & 0,03432 & 0,02739 & 0,02249 & 0,03414 & 0,02639 & 0,02426 & 0,03348 & 0,02557 & 0,02376 & 0,03516 & 0,02585 \\
\hline $\mathrm{Cl1}$ & 0,02397 & 0,03112 & 0,03233 & 0,02460 & 0,03155 & 0,03337 & 0,02339 & 0,03156 & 0,03231 & 0,02563 & 0,03091 & 0,03117 & 0,02467 & 0,03243 & 0,03203 \\
\hline $\mathrm{Cl} 2$ & 0,02409 & 0,03601 & 0,02783 & 0,02474 & 0,03707 & 0,02859 & 0,02346 & 0,03648 & 0,02784 & 0,02544 & 0,03585 & 0,02701 & 0,02446 & 0,03747 & 0,02772 \\
\hline $\mathrm{Cl} 3$ & 0,02775 & 0,03068 & 0,03418 & 0,02848 & 0,03146 & 0,03477 & 0,02721 & 0,03112 & 0,03416 & 0,02888 & 0,03009 & 0,03325 & 0,02797 & 0,03186 & 0,03403 \\
\hline $\mathrm{Ru} 2$ & 0,02172 & 0,02988 & 0,02910 & 0,02269 & 0,03056 & 0,03000 & 0,02115 & 0,03032 & 0,02907 & 0,02320 & 0,02931 & 0,02783 & 0,02231 & 0,03103 & 0,02887 \\
\hline P3 & 0,02395 & 0,03215 & 0,03599 & 0,02486 & 0,03322 & 0,03626 & 0,02330 & 0,03252 & 0,03602 & 0,02538 & 0,03157 & 0,03481 & 0,02431 & 0,03349 & 0,03573 \\
\hline $\mathrm{Cl1}$ & 0,02397 & 0,03112 & & 0,02460 & 0,03 & 0,03337 & & & 0,03 & & 091 & & 0,02467 & 0,03243 & 0,03203 \\
\hline $\mathrm{Cl} 2$ & 0,02409 & 0,03601 & 0,02783 & 0,02474 & 0,03707 & 0,02859 & 0,02346 & 0,03648 & 0,02784 & 0,02544 & 0,03585 & 0,02701 & 0,02446 & 0,03747 & 0,02772 \\
\hline $\mathrm{Cl} 3$ & 0,02775 & 0,03068 & 0,03418 & 0,02848 & 0,03146 & 0,03477 & 0,02721 & 0,03112 & 0,03416 & 0,02888 & 0,03009 & 0,03325 & 0,02797 & 0,03186 & 0,03403 \\
\hline $\mathrm{Cl} 4$ & 0,03699 & 0,05060 & 0,04940 & 0,03806 & 0,05109 & 0,04984 & 0,03635 & 0,05102 & 0,04932 & 0,03885 & 0,04990 & 0,04850 & 0,03809 & 0,05142 & 0,04958 \\
\hline $\mathrm{Cl} 5$ & 0,03560 & 0,04919 & 0,04467 & 0,03652 & 0,05004 & 0,04553 & 0,03491 & 0,04967 & 0,04457 & 0,03745 & 0,04855 & 0,04388 & 0,03651 & 0,05012 & 0,04452 \\
\hline
\end{tabular}


Tabela D.10: Valores para os parâmetros de deslocamentos anisotrópicos para os diferentes métodos de correção por absorção aplicados, composto X

\begin{tabular}{|c|c|c|c|c|c|c|c|c|c|c|c|c|c|c|c|}
\hline \multirow[t]{2}{*}{ Átomo } & \multirow{2}{*}{\multicolumn{3}{|c|}{ Sem correção }} & \multicolumn{3}{|c|}{ Semi-empírico } & \multicolumn{3}{|c|}{ Analítico } & \multicolumn{3}{|c|}{ DFABS } & \multicolumn{3}{|c|}{ XABS2 } \\
\hline & & & & $\mathrm{U}_{11}$ & $\mathrm{U}_{22}$ & $\mathrm{U}_{33}$ & $\mathrm{U}_{11}$ & $\mathrm{U}_{22}$ & $\mathrm{U}_{33}$ & $\mathrm{U}_{11}$ & $\mathrm{U}_{22}$ & $\mathrm{U}_{33}$ & $\mathrm{U}_{11}$ & $\mathrm{U}_{22}$ & $\mathrm{U}_{33}$ \\
\hline $\mathrm{Zn}$ & 0,03315 & 0,03315 & 0,03894 & 0,03378 & 0,03378 & 0,03934 & 0,03371 & 0,03371 & 0,03924 & 0,03478 & 0,03478 & 0,03948 & 0,03432 & 0,03432 & 0,03934 \\
\hline $\mathrm{S}$ & 0,04567 & 0,03959 & 0,04892 & 0,04583 & 0,04013 & 0,04914 & 0,04563 & 0,03972 & 0,04862 & 0,04597 & 0,04135 & 0,04919 & 0,04561 & 0,04091 & 0,04879 \\
\hline N1 & 0,02895 & 0,03855 & 0,02639 & 0,02922 & 0,03778 & 0,02712 & 0,02946 & 0,03651 & 0,02705 & 0,03126 & 0,03657 & 0,03096 & 0,03127 & 0,03674 & \\
\hline $\mathrm{Fe}$ & 0,05718 & 0,05246 & 0,05357 & 0,05777 & 0,05344 & 0,05445 & 0,05756 & 0,05375 & 0,05464 & 0,05932 & 0,05537 & 0,05587 & 0,05886 & 0,05449 & 0,05561 \\
\hline $\mathrm{C} 11$ & 0,03645 & 0,02771 & 0,04176 & 0,03715 & 0,02915 & 0,04252 & 0,03818 & 0,02914 & 0,04121 & 0,04011 & 0,03141 & 0,04470 & 0,03985 & 0,03064 & 0,04383 \\
\hline $\mathrm{C} 12$ & 0,05925 & 0,04480 & 0,04054 & 0,05799 & 0,04528 & 0,04091 & 0,05687 & 0,04302 & 0,04154 & 0,05650 & 0,04427 & 0,04004 & 0,05590 & 0,04460 & 0,04009 \\
\hline $\mathrm{C} 13$ & 0,05707 & 0,05848 & 0,04568 & 0,05780 & 0,06036 & 0,04559 & 0,05859 & 0,05814 & 0,04496 & 0,05913 & 0,05559 & 0,05028 & 0,05829 & 0,05592 & 0,04881 \\
\hline C14 & 0,04687 & 0,06269 & 0,05292 & 0,04704 & 527 & 0,05392 & 0,04563 & 0,06325 & 0,05307 & 0,04687 & 0,06490 & 0,05489 & 0,04654 & 0,06319 & 0,05446 \\
\hline $\mathrm{C} 15$ & 0,04577 & 0,04061 & 0,04584 & 0,04443 & 0,04221 & 0,04753 & 0,04298 & 0,04560 & 0,04937 & 0,04603 & 0,04543 & 0,05430 & 0,04637 & 0,04455 & 0,05316 \\
\hline $\mathrm{C} 21$ & 0,06763 & 0,10306 & 0,14915 & 0,06931 & 0,09158 & 0,13842 & 0,06921 & 0,08708 & 0,14092 & 0,07290 & 0,08269 & 0,13349 & 0,07341 & 0,08220 & 0,13344 \\
\hline $\mathrm{C} 22$ & 0,11296 & 0,09331 & 0,12900 & 0,11389 & 0,09807 & 0,13540 & 0,11592 & 0,09809 & 0,14179 & 0,11558 & 0,10272 & 0,13944 & 0,11529 & 0,10146 & 0,13522 \\
\hline $\mathrm{C} 23$ & 0,13549 & 0,09627 & 0,09566 & 0,13730 & 0,10120 & 0,09302 & 0,14563 & 0,10889 & 0,09559 & 0,14584 & 0,11263 & 0,09584 & 0,14685 & 0,11153 & 0,09597 \\
\hline $\mathrm{C} 24$ & 0,09660 & 0,10362 & 0,10121 & 0,10510 & 0,11170 & 0,10579 & 0,11048 & 0,11600 & 0,10484 & 0,11396 & 0,11877 & 0,11222 & 0,11383 & 0,11937 & 0,11074 \\
\hline $\mathrm{C} 25$ & 0,10152 & 0,06730 & 0,12961 & 0,10023 & 0,06556 & 0,12603 & 0,10364 & 0,06584 & 0,11718 & 0,09962 & 0,06487 & 0,12551 & 0,10031 & 0,06428 & 0,12613 \\
\hline
\end{tabular}

Tabela D.11: Valores para os parâmetros de deslocamentos anisotrópicos para os diferentes métodos de correção por absorção aplicados, composto XI

\begin{tabular}{|c|c|c|c|c|c|c|c|c|c|c|c|c|c|c|c|}
\hline \multirow[t]{2}{*}{ Átomo } & \multirow{2}{*}{\multicolumn{3}{|c|}{ Sem correção }} & \multicolumn{3}{|c|}{ Semi-empírico } & \multicolumn{3}{|c|}{ Analítico } & \multicolumn{3}{|c|}{ DFABS } & \multicolumn{3}{|c|}{ XABS2 } \\
\hline & & & & $\mathrm{U}_{11}$ & $\mathrm{U}_{22}$ & $\mathrm{U}_{33}$ & $\mathrm{U}_{11}$ & $\mathrm{U}_{22}$ & $\mathrm{U}_{33}$ & $\mathrm{U}_{11}$ & $\mathrm{U}_{22}$ & $\mathrm{U}_{33}$ & $\mathrm{U}_{11}$ & $\mathrm{U}_{22}$ & $\mathrm{U}_{33}$ \\
\hline Sn1 & 0,06145 & 0,07763 & 0,07418 & 0,05984 & 0,07910 & 0,08038 & 0,07421 & 0,07444 & 0,07203 & 0,07575 & 0,07720 & 0,07456 & 0,07420 & 0,07443 & 0,07203 \\
\hline Br1 & 0,06288 & 0,28465 & 0,11493 & 0,07405 & 0,19541 & 0,16979 & 0,08268 & 0,16863 & 0,08105 & 0,08660 & 0,15849 & 0,10691 & 0,08837 & 0,16476 & 0,07230 \\
\hline $\mathrm{Br} 2$ & 0,10922 & 0,08769 & 0,18705 & 0,10780 & 0,09343 & 0,25039 & 0,13806 & 0,08835 & 0,18445 & 0,13749 & 0,09299 & 0,17922 & 0,13673 & 0,08795 & 0,18500 \\
\hline N1 & 0,09181 & 0,10911 & 0,02042 & 0,08052 & 0,08193 & 0,03317 & 0,06930 & 0,07694 & 0,05071 & 0,07572 & 0,07307 & 0,05965 & 0,06895 & 0,07668 & 0,05105 \\
\hline $\mathrm{N} 2$ & 0,06812 & 0,09706 & 0,04251 & 0,06737 & 0,08435 & 0,05988 & 0,07890 & 0,07867 & 0,06897 & 0,09412 & 0,09197 & 0,05514 & 0,10315 & 0,08111 & 0,05540 \\
\hline $\mathrm{C} 13$ & 0,05001 & 0,08776 & 0,08069 & 0,05094 & 0,08652 & 0,08446 & 0,10530 & 0,12490 & 0,09864 & 0,07361 & 0,08541 & 0,08291 & 0,08116 & 0,07824 & 0,06822 \\
\hline C19 & 0,07102 & 0,15389 & 0,12630 & 0,07168 & 0,13507 & 0,12830 & 0,08151 & 0,09124 & 0,09459 & 0,10880 & 0,12264 & 0,11936 & 0,10515 & 0,12482 & 0,09860 \\
\hline $\mathrm{Cl1}$ & 0,07367 & 0,05254 & 0,05567 & 0,05602 & 0,09414 & 0,03545 & 0,07389 & 0,06580 & 0,16906 & 0,07247 & 0,10416 & 0,07003 & 0,07219 & 0,09223 & 0,11373 \\
\hline $\mathrm{Cl} 2$ & 0,06213 & 0,07094 & 0,22267 & 0,05953 & 0,06368 & 0,14322 & 0,07421 & 0,07444 & 0,07203 & 0,08178 & 0,07042 & 0,17639 & 0,07481 & 0,06506 & 0,17061 \\
\hline
\end{tabular}


Tabela D.12: Valores para os parâmetros de deslocamentos anisotrópicos para os diferentes métodos de correção por absorção aplicados, composto XII.

\begin{tabular}{|c|c|c|c|c|c|c|c|c|c|}
\hline \multirow[t]{2}{*}{ Átomo } & \multirow{2}{*}{\multicolumn{3}{|c|}{ Sem correção }} & \multicolumn{3}{|c|}{ Semi-empírico } & \multicolumn{3}{|c|}{ Analítico } \\
\hline & & & & $\mathrm{U}_{11}$ & $\mathrm{U}_{22}$ & $\mathrm{U}_{33}$ & $\mathrm{U}_{11}$ & $\mathrm{U}_{22}$ & $\mathrm{U}_{33}$ \\
\hline Mo & 0,03532 & 0,02674 & 0,03968 & 0,03522 & 0,02671 & 0,04012 & 0,03672 & 0,02818 & 0,03615 \\
\hline S1 & 0,04364 & 0,03297 & 0,08353 & 0,04364 & 0,03317 & 0,08306 & 0,04466 & 0,03454 & 0,07986 \\
\hline S11 & 0,15966 & 0,12997 & 0,14514 & 0,15726 & 0,13281 & 0,14715 & 0,15970 & 0,12959 & 0,13938 \\
\hline O1 & 0,03298 & 0,03046 & 0,05491 & 0,03427 & 0,03143 & 0,05240 & 0,03587 & 0,03219 & 0,04662 \\
\hline $\mathrm{O} 2$ & 0,06369 & 0,04540 & 0,04734 & 0,06270 & 0,04571 & 0,04814 & 0,06486 & 0,04518 & 0,04429 \\
\hline $\mathrm{N} 1$ & 0,04272 & 0,04995 & 0,05640 & 0,04216 & 0,05021 & 0,05834 & 0,04549 & 0,04944 & 0,05301 \\
\hline $\mathrm{N} 2$ & 0,05661 & 0,02487 & 0,05370 & 0,05526 & 0,02579 & 0,05275 & 0,05968 & 0,02610 & 0,04804 \\
\hline
\end{tabular}

Tabela D.13: Valores para os parâmetros de deslocamentos anisotrópicos para os diferentes métodos de correção por absorção aplicados, composto XIII

\begin{tabular}{|c|c|c|c|c|c|c|c|c|c|c|c|c|c|c|c|}
\hline \multirow[t]{2}{*}{ Átomo } & \multicolumn{3}{|c|}{ Sem correção } & \multicolumn{3}{|c|}{ Semi-empírico } & \multicolumn{3}{|c|}{ Analítico } & \multicolumn{3}{|c|}{ DFABS } & \multicolumn{3}{|c|}{ XABS2 } \\
\hline & $\mathrm{U}_{11}$ & $\mathrm{U}_{22}$ & $\mathrm{U}_{33}$ & $\mathrm{U}_{11}$ & $\mathrm{U}_{22}$ & $\mathrm{U}_{33}$ & $\mathrm{U}_{11}$ & $\mathrm{U}_{22}$ & $\mathrm{U}_{33}$ & $\mathrm{U}_{11}$ & $\mathrm{U}_{22}$ & $\mathrm{U}_{33}$ & $\mathrm{U}_{11}$ & $\mathrm{U}_{22}$ & $\mathrm{U}_{33}$ \\
\hline Mo1 & 0,04871 & 0,03466 & 0,04722 & 0,04768 & 0,03477 & 0,04815 & 0,05232 & 0,03821 & 0,04583 & 0,04814 & 0,03436 & 0,04835 & 0,04750 & 0,03454 & 0,04776 \\
\hline $\mathrm{O} 1$ & 0,07929 & 0,04417 & 0,08263 & 0,07735 & 0,04685 & 0,08058 & 0,08400 & 0,04895 & 0,07870 & 0,07932 & 0,04560 & 0,08320 & 0,07680 & 0,04699 & 0,08191 \\
\hline S1 & 0,07275 & 0,04734 & 0,05621 & 0,07092 & 0,04828 & 0,05688 & 0,07557 & 0,05096 & 0,05504 & 0,07117 & 0,04797 & 0,05786 & 0,07181 & 0,04803 & 0,05662 \\
\hline $\mathrm{S} 2$ & 0,05809 & 0,09649 & 0,13359 & 0,10270 & 0,04975 & 0,14538 & 0,10815 & 0,05710 & 0,12894 & 0,08957 & 0,08986 & 0,11324 & 0,06998 & 0,09305 & 0,12918 \\
\hline S11 & 0,04943 & 0,06136 & 0,04680 & 0,04795 & 0,06331 & 0,04739 & 0,05228 & 0,06601 & 0,04550 & 0,04864 & 0,06288 & 0,04729 & 0,04775 & 0,06305 & 0,04739 \\
\hline $\mathrm{S} 12$ & 0,07092 & 0,05962 & 0,06253 & 0,06996 & 0,06063 & 0,06421 & 0,07447 & 0,06375 & 0,06107 & 0,07067 & 0,06025 & 0,06464 & 0,06927 & 0,06058 & 0,06369 \\
\hline Mo2 & 0,05133 & 0,03595 & 0,04493 & 0,05058 & 0,03595 & 0,04612 & 0,05507 & 0,03946 & 0,04353 & 0,05096 & 0,03558 & 0,04621 & 0,05042 & 0,03566 & 0,04555 \\
\hline $\mathrm{O} 2$ & 0,08453 & 0,05117 & 0,06270 & 0,08198 & 0,05178 & 0,06819 & 0,08716 & 0,05430 & 0,06347 & 0,08356 & 0,05156 & 0,06732 & 0,08182 & 0,05150 & 0,06761 \\
\hline S1 & 0,07275 & 0,04734 & 0,05621 & 0,07092 & 0,04828 & 0,05688 & 0,07557 & 0,05096 & 0,05504 & 0,07117 & 0,04797 & 0,05786 & 0,07181 & 0,04803 & 0,05662 \\
\hline $\mathrm{S} 2$ & 0,05809 & 0,09649 & 0,13359 & 0,10270 & 0,04975 & 0,14538 & 0,10815 & 0,05710 & 0,12894 & 0,08957 & 0,08986 & 0,11324 & 0,06998 & 0,09305 & 0,12918 \\
\hline S21 & 0,05157 & 0,03780 & 0,06176 & 0,05068 & 0,03711 & 0,06326 & 0,05480 & 0,04134 & 0,06026 & 0,05082 & 0,03698 & 0,06348 & 0,05032 & 0,03700 & 0,06276 \\
\hline $\mathrm{S} 22$ & 0,06656 & 0,05632 & 0,06600 & 0,06462 & 0,05643 & 0,06510 & 0,06857 & 0,05990 & 0,06458 & 0,06408 & 0,05588 & 0,06643 & 0,06447 & 0,05603 & 0,06618 \\
\hline
\end{tabular}


Tabela D.14: Valores para os parâmetros de deslocamentos anisotrópicos para os diferentes métodos de correção por absorção aplicados, composto XIV

\begin{tabular}{|c|c|c|c|c|c|c|c|c|c|}
\hline \multirow[t]{2}{*}{ Átomo } & \multicolumn{3}{|c|}{ Sem correção } & \multicolumn{3}{|c|}{ Semi-empírico } & \multicolumn{3}{|c|}{ Analítico } \\
\hline & $\mathrm{U}_{11}$ & $\mathrm{U}_{22}$ & $\mathrm{U}_{33}$ & $\mathrm{U}_{11}$ & $\mathrm{U}_{22}$ & $\mathrm{U}_{33}$ & $\mathrm{U}_{11}$ & $\mathrm{U}_{22}$ & $\mathrm{U}_{33}$ \\
\hline Mo1 & 0,03786 & 0,01856 & 0,04163 & 0,03174 & 0,00001 & 0,03886 & 0,04170 & 0,03027 & 0,04328 \\
\hline O11 & 0,04272 & 0,03000 & 0,04411 & 0,04696 & 0,05658 & 0,03851 & 0,04997 & 0,04123 & 0,04517 \\
\hline $\mathrm{O} 12$ & 0,04123 & 0,02114 & 0,05356 & 0,03377 & 0,00001 & 0,05783 & 0,04474 & 0,03388 & 0,05561 \\
\hline O13 & 0,04838 & 0,02391 & 0,05850 & 0,02710 & 0,00001 & 0,07069 & 0,05021 & 0,03620 & 0,06046 \\
\hline O111 & 0,04082 & 0,01936 & 0,04607 & 0,03723 & 0,03097 & 0,04618 & 0,04498 & 0,03013 & 0,04659 \\
\hline $\mathrm{O} 112$ & 0,04730 & 0,03077 & 0,04531 & 0,04740 & 0,00001 & 0,04233 & 0,05050 & 0,04249 & 0,04796 \\
\hline Mo2 & 0,04229 & 0,01994 & 0,04423 & 0,03567 & 0,00616 & 0,04138 & 0,04614 & 0,03172 & 0,04577 \\
\hline O1 & 0,05202 & 0,04236 & 0,04546 & 0,05155 & 0,00001 & 0,04482 & 0,05707 & 0,05429 & 0,04502 \\
\hline $\mathrm{O} 2$ & 0,04243 & 0,02325 & 0,06093 & 0,01926 & 0,10241 & 0,09974 & 0,04408 & 0,03606 & 0,06443 \\
\hline $\mathrm{O} 3$ & 0,04201 & 0,03031 & 0,04949 & 0,04204 & 0,00001 & 0,04867 & 0,04844 & 0,04212 & 0,04907 \\
\hline $\mathrm{O} 111$ & 0,04082 & 0,01936 & 0,04607 & 0,03723 & 0,03097 & 0,04618 & 0,04498 & 0,03013 & 0,04659 \\
\hline O211 & 0,06279 & 0,02399 & 0,06228 & 0,04423 & 0,00001 & 0,06720 & 0,06886 & 0,03637 & 0,06158 \\
\hline $\mathrm{O} 212$ & 0,05731 & 0,04658 & 0,06014 & 0,04151 & 0,11142 & 0,05140 & 0,05773 & 0,05730 & 0,06549 \\
\hline
\end{tabular}

Tabela D.15: Valores para os parâmetros de deslocamentos anisotrópicos para os diferentes métodos de correção por absorção aplicados, composto XV.

\begin{tabular}{|c|c|c|c|c|c|c|c|c|c|c|c|c|c|c|c|}
\hline \multirow{2}{*}{ Átomo } & \multicolumn{3}{|c|}{ Sem correção } & \multicolumn{3}{|c|}{ Semi-empírico } & \multicolumn{3}{|c|}{ Analítico } & \multicolumn{3}{|c|}{ DFABS } & \multicolumn{3}{|c|}{ XABS2 } \\
\hline & $\mathrm{U}_{11}$ & $\mathrm{U}_{22}$ & $\mathrm{U}_{33}$ & $\mathrm{U}_{11}$ & $\mathrm{U}_{22}$ & $\mathrm{U}_{33}$ & $\mathrm{U}_{11}$ & $\mathrm{U}_{22}$ & $\mathrm{U}_{33}$ & $\mathrm{U}_{11}$ & $\mathrm{U}_{22}$ & $\mathrm{U}_{33}$ & $\mathrm{U}_{11}$ & $\mathrm{U}_{22}$ & $\mathrm{U}_{33}$ \\
\hline $\mathrm{Cd} 1$ & 0,08532 & 0,04356 & 0,02846 & 0,08368 & 0,04261 & 0,02736 & 0,07951 & 0,05144 & 0,03892 & 0,06103 & 0,05500 & 0,05188 & 0,05726 & 0,05210 & 0,05038 \\
\hline S1 & 0,07391 & 0,04673 & 0,04645 & 0,07158 & 0,04549 & 0,04540 & 0,06815 & 0,05463 & 0,05659 & 0,04945 & 0,05816 & 0,06924 & 0,04676 & 0,05435 & 0,06732 \\
\hline S2 & 0,12130 & 0,06474 & 0,03700 & 0,11979 & 0,06426 & 0,03675 & 0,11448 & 0,07211 & 0,04770 & 0,09561 & 0,07626 & 0,06092 & 0,09194 & 0,07351 & 0,05950 \\
\hline N13 & 0,06389 & 0,04222 & 0,03065 & 0,07105 & 0,03753 & 0,02804 & 0,05863 & 0,04876 & 0,04137 & 0,04533 & 0,05354 & 0,05381 & 0,04043 & 0,04434 & 0,05015 \\
\hline $\mathrm{N} 23$ & 0,07354 & 0,03579 & 0,03386 & 0,07121 & 0,03548 & 0,02583 & 0,05895 & 0,04400 & 0,04441 & 0,04931 & 0,04864 & 0,05646 & 0,04252 & 0,04703 & 0,05289 \\
\hline $\mathrm{O} 1$ & 0.08623 & 0.05963 & 0.03835 & 0.08145 & 0.05765 & 0.03626 & 0.07882 & 0.06552 & 0.04799 & 0.05725 & 0.06729 & 0.06125 & 0.05580 & 0.06703 & 0.06074 \\
\hline $\mathrm{O} 2$ & 0.10838 & 0.05178 & 0.03482 & 0.10752 & 0.04895 & 0.03647 & 0.09991 & 0.05738 & 0.04605 & 0.08296 & 0.06300 & 0.05802 & 0.07812 & 0.05836 & 0.05826 \\
\hline
\end{tabular}


Tabela D.16: Valores para distâncias e ângulos de ligação para a esfera de coordenação do átomo pesado para o composto I.

\begin{tabular}{|c|c|c|c|c|c|c|c|c|c|c|c|c|c|}
\hline & \multicolumn{7}{|c|}{ DISTÂNCIAS } & \multicolumn{6}{|c|}{ ÂNGULOS } \\
\hline & $\mathrm{Nd}-\mathrm{O} 1$ & $\mathrm{Nd}-\mathrm{O} 2$ & $\mathrm{Nd}-\mathrm{O} 3$ & $\mathrm{Nd}-\mathrm{O} 4$ & $\mathrm{Nd}-\mathrm{O} 5$ & $\mathrm{Nd}-\mathrm{O} 6$ & $\mathrm{Nd}-\mathrm{O} 7$ & $\mathrm{O} 2-\mathrm{Nd} 1-\mathrm{O} 1$ & O3-Nd1-O6 & $\mathrm{O} 4-\mathrm{Nd} 1-\mathrm{O} 5$ & $\mathrm{O} 2-\mathrm{C} 1-\mathrm{O} 1$ & $\mathrm{O} 3-\mathrm{C} 2-\mathrm{O} 6$ & $\mathrm{O} 4-\mathrm{C} 3-\mathrm{O} 5$ \\
\hline Sem correção & $2,513(5)$ & $2,433(5)$ & $2,491(6)$ & $2,484(6)$ & $2,503(5)$ & $2,439(6)$ & $2,443(5)$ & $50.79(17)$ & $50.36(18)$ & $52.11(18)$ & $120.29(68)$ & $119.30(72)$ & $119.75(74)$ \\
\hline Semi-empirico & $2,513(5)$ & $2,437(5)$ & $2,492(6)$ & $2,484(6)$ & $2,505(6)$ & $2,441(6)$ & $2,442(6)$ & $50.72(17)$ & $50.29(19)$ & $52.26(19)$ & $120.07(71)$ & $119.36(74)$ & $119.96(77)$ \\
\hline & & & & & & & & & & & & & (63) \\
\hline & 2,5 & $2,432(4)$ & 2,4 & 2,48 & $2(5)$ & (5) & 2,4 & 4) & & (15) & 57) & (61) & (62) \\
\hline SHELXA & $2,513(5)$ & $2,436(5)$ & $2,486(6)$ & $2,489(6)$ & $2,508(5)$ & $2,437(6)$ & $2,445(6)$ & $50.84(17)$ & $50.41(19)$ & $52.07(18)$ & $120.48(64)$ & $118.75(67)$ & $119.52(67$ \\
\hline
\end{tabular}

Tabela D.17: Valores para distâncias e ângulos de ligação para a esfera de coordenação do átomo pesado para o composto II.

\begin{tabular}{|c|c|c|c|c|c|c|c|c|c|}
\hline & \multicolumn{3}{|c|}{ DISTÂNCIAS } & \multicolumn{6}{|c|}{ ÂNGULOS } \\
\hline & $\mathrm{Ru}-\mathrm{N} 1$ & $\mathrm{Ru}-\mathrm{N} 2$ & $\mathrm{Ru}-\mathrm{N} 3$ & $\mathrm{~N} 1-\mathrm{Ru}-\mathrm{N} 2$ & N1-Ru-N3 & $\mathrm{N} 2-\mathrm{Ru}-\mathrm{N} 3$ & $\mathrm{~N} 1-\mathrm{Ru}-\mathrm{N} 2^{\&}$ & $\mathrm{~N} 1-\mathrm{Ru}-\mathrm{N} 3^{\mathrm{\alpha}}$ & $\mathrm{N} 2-\mathrm{Ru}-\mathrm{N} 3^{8}$ \\
\hline Sem correção & $2.096(4)$ & $2.095(4)$ & $2.089(4)$ & $86.89(17)$ & $87.95(13)$ & $77.32(15)$ & 93.11(17) & $92.05(13)$ & $102.68(15)$ \\
\hline Semi-empirico & $2.096(4)$ & $2.095(4)$ & $2.089(4)$ & $86.87(13)$ & $87.97(14)$ & $77.30(15)$ & $93.13(18)$ & $92.03(14)$ & $102.70(15)$ \\
\hline Analítico & $2.095(4)$ & $2.096(4)$ & $2.089(4)$ & $86.91(17)$ & $87.97(14)$ & $77.37(15)$ & $93.09(17)$ & $92.03(14)$ & $102.63(15)$ \\
\hline DFABS & $2.095(3)$ & $2.095(4)$ & $2.089(3)$ & $86.93(16)$ & $87.95(13)$ & $77.23(14)$ & $93.07(16)$ & $92.05(13)$ & $102.77(14)$ \\
\hline SHELXA & $2.096(4)$ & $2.096(4)$ & $2.090(3)$ & $86.94(17)$ & $87.92(13)$ & $77.22(14)$ & $93.06(17)$ & $92.08(13)$ & $102.78(14)$ \\
\hline
\end{tabular}

Tabela D.18: Valores para distâncias e ângulos de ligação para a esfera de coordenação do átomo pesado para o composto IV.

\begin{tabular}{|c|c|c|c|c|c|c|c|c|c|c|c|}
\hline & \multicolumn{9}{|c}{ DISTÂNCIAS } & \multicolumn{5}{c|}{ ANGULOS } \\
& $\mathrm{Ru}-\mathrm{Cl} 2$ & $\mathrm{Ru}-\mathrm{Cl} 3$ & $\mathrm{Ru}-\mathrm{N} 1$ & $\mathrm{Ru}-\mathrm{O} 1$ & $\mathrm{Ru}-\mathrm{S} 1$ & $\mathrm{Ru}-\mathrm{S} 2$ & $\mathrm{~S} 1-\mathrm{Ru}-\mathrm{N} 1$ & \multicolumn{1}{c|}{ S1-Ru-S2 } & \multicolumn{1}{c|}{ S2-Ru-O1 } & N1-Ru-O1 \\
\hline Sem correção & $2.410(1)$ & $2.393(1)$ & $2.117(4)$ & $2.121(3)$ & $2.231(1)$ & $2.245(1)$ & $98.53(12)$ & $94.70(5)$ & $88.95(10)$ & $77.85(14)$ \\
\hline Semi-empirico & $2.411(1)$ & $2.393(1)$ & $2.112(4)$ & $2.121(3)$ & $2.230(1)$ & $2.245(1)$ & $98.53(12)$ & $94.70(5)$ & $88.97(10)$ & $77.84(15)$ \\
\hline Analítico & $2.410(1)$ & $2.393(1)$ & $2.115(4)$ & $2.120(3)$ & $2.230(1)$ & $2.245(1)$ & $98.59(12)$ & $94.68(5)$ & $88.98(10)$ & $77.80(15)$ \\
\hline DFABS & $2.411(1)$ & $2.393(1)$ & $2.110(4)$ & $2.120(3)$ & $2.230(1)$ & $2.245(1)$ & $98.57(11)$ & $94.70(4)$ & $88.96(9)$ & $77.82(14)$ \\
\hline SHELXA & $2.410(1)$ & $2.393(1)$ & $2.112(4)$ & $2.121(3)$ & $2.230(1)$ & $2.245(1)$ & $98.58(11)$ & $94.66(4)$ & $88.98(9)$ & $77.82(14)$ \\
\hline
\end{tabular}


Tabela D.19: Valores para distâncias e ângulos de ligação para a esfera de coordenação do átomo pesado para o composto VI.

\begin{tabular}{|c|c|c|c|c|c|c|c|c|c|c|}
\hline & \multicolumn{4}{|c|}{ DISTÂNCIAS } & \multicolumn{6}{|c|}{ ÂNGULOS } \\
\hline & $\mathrm{Sn}-\mathrm{S} 2$ & $\mathrm{Sn}-\mathrm{S} 3$ & Sn-C15 & Sn-C16 & $\mathrm{S} 2-\mathrm{Sn}-\mathrm{S} 3$ & S2-Sn-C15 & S2-Sn-C16 & S3-Sn-C15 & S3-Sn-C16 & C15-Sn-C16 \\
\hline Sem correção & $2.516(1)$ & $2.498(1)$ & $2.113(4)$ & $2.136(3)$ & $81.62(3)$ & $105.29(12)$ & 114.71(9) & $109.95(11)$ & $106.47(9)$ & $128.76(14)$ \\
\hline Semi-empirico & $2.516(1)$ & $2.498(1)$ & $2.114(4)$ & $2.135(3)$ & $81.63(3)$ & $105.32(12)$ & 114.68(9) & $109.90(11)$ & 106.49(9) & $128.77(15)$ \\
\hline Analítico & $2.516(1)$ & $2.498(1)$ & $2.114(3)$ & $2.134(3)$ & $81.61(2)$ & $105.28(10)$ & $114.68(7)$ & 109.98(9) & $106.49(8)$ & $128.76(12)$ \\
\hline DFABS & $2.516(1)$ & $2.498(1)$ & $2.115(4)$ & $2.135(3)$ & $81.61(3)$ & $105.37(12)$ & $114.65(9)$ & $109.96(11)$ & $106.45(9)$ & $128.75(14)$ \\
\hline SHELXA & $2.516(1)$ & $2.498(1)$ & $2.115(4)$ & $2.133(4)$ & $81.60(3)$ & $105.34(12)$ & $114.67(9)$ & $109.92(12)$ & $106.45(10)$ & $128.79(15)$ \\
\hline
\end{tabular}

Tabela D.20: Valores para distâncias e ângulos de ligação para a esfera de coordenação dos átomos pesados para o composto IX.

\begin{tabular}{|c|c|c|c|c|c|c|c|c|c|c|c|c|}
\hline & \multicolumn{6}{|c|}{ DISTÂNCIAS } & \multicolumn{6}{|c|}{ ÂNGULOS } \\
\hline & $\mathrm{Ru} 1-\mathrm{Cl} 1$ & $\mathrm{Ru} 1-\mathrm{Cl} 2$ & $\mathrm{Ru} 1-\mathrm{Cl} 3$ & Ru1 - P1 & Ru1-P2 & $\mathrm{Ru} 1-\mathrm{C}$ & $\mathrm{Cl} 1-\mathrm{Ru} 1-\mathrm{Cl} 2$ & $\mathrm{Cl1}-\mathrm{Ru} 1-\mathrm{Cl} 3$ & $\mathrm{Cl} 2-\mathrm{Ru} 1-\mathrm{Cl} 3$ & C-Ru 1-P1 & C-Ru 1-P2 & P1-Ru 1-P2 \\
\hline & $2.478(1)$ & $2.454(1)$ & $2.485(1)$ & $2.361(1)$ & $2.345(1)$ & $1.839(6)$ & $81.27(4)$ & $77.29(4)$ & $78.53(4)$ & 93.12(18) & $89.15(17)$ & $100.74(5)$ \\
\hline Semi-empirico & $2.477(1)$ & $2.454(1)$ & $2.484(1)$ & $2.361(1)$ & $2.344(1)$ & $1.837(6)$ & $81.28(1)$ & $77.28(1)$ & $78.53(1)$ & $93.05(18)$ & $89.16(17)$ & $100.77(2)$ \\
\hline Analítico & $2.478(1)$ & $2.454(1)$ & $2.485(1)$ & $2.361(1)$ & $2.345(1)$ & $1.839(6)$ & $81.26(4)$ & $77.28(5)$ & $78.53(5)$ & $93.09(18)$ & (18) & $4(5)$ \\
\hline DFABS & $2.479(1)$ & $2.455(1)$ & $2.485(1)$ & $2.361(1)$ & $2.344(1)$ & $1.842(5)$ & $81.28(4)$ & $77.27(4)$ & $78.51(4)$ & $93.24(17)$ & $89.04(17)$ & $100.75(5)$ \\
\hline SHELXA & $2.478(1)$ & $2.455(1)$ & $2.485(1)$ & $2.361(1)$ & $2.345(1)$ & $1.836(6)$ & $81.27(4)$ & $77.28(4)$ & $78.53(4)$ & $93.18(17)$ & $89.12(17)$ & $100.75(5)$ \\
\hline & & & & & & & & & & & & \\
\hline & Ru2-Cl1 & $\mathrm{Ru} 2-\mathrm{Cl} 2$ & $\mathrm{Ru} 2-\mathrm{Cl} 3$ & Ru2-Cl4 & Ru2-Cl5 & $\begin{array}{l}\mathrm{Ru} 2-\mathrm{P} 3 \\
\end{array}$ & $\mathrm{Cl1}-\mathrm{Ru} 2-\mathrm{Cl} 2$ & Cl1-Ru2-Cl3 & $\mathrm{Cl} 2-\mathrm{Ru} 2-\mathrm{Cl} 3$ & Cl4-Ru2-Cl5 & Cl4-Ru2-P3 & Cl5-Ru2-P3 \\
\hline Sen & $2.419(1)$ & $2.476(1)$ & $2.421(1)$ & 2.32 & 2.3 & $2.297(1)$ & & 79. & $79.35(5)$ & $98.81(6)$ & $53(6)$ & $90.35(6)$ \\
\hline Semi & $2.419(4)$ & & $2.421(4)$ & 232 & & & & & $79.32(4)$ & $2(6)$ & (6) & $6(6)$ \\
\hline Analítico & $2.419(1)$ & $2.476(1)$ & $2.421(1)$ & $2.326(2)$ & $2.319(2)$ & $2.297(1)$ & $2.02(5)$ & $79.63(5)$ & $79.35(5)$ & $98.81(6)$ & $87.53(6)$ & $90.35(6)$ \\
\hline DFABS & $2.419(1)$ & $2.476(1)$ & $2.420(1)$ & $2.325(2)$ & $2.318(2)$ & $2.296(1)$ & $82.04(4)$ & 79.64(4) & $79.34(4)$ & $98.83(6)$ & $87.52(5)$ & $90.34(5)$ \\
\hline SHELXA & $2.419(1)$ & $2.476(1)$ & $2.421(1)$ & $2.326(2)$ & $2.318(2)$ & $2.297(1)$ & $82.03(4)$ & $79.62(4)$ & $79.36(4)$ & $98.82(6)$ & $87.53(5)$ & $90.35(5)$ \\
\hline
\end{tabular}


Tabela D.21: Valores para distâncias e ângulos de ligação para a esfera de coordenação dos átomos pesados para o composto X.

\begin{tabular}{|c|c|c|c|c|c|c|c|c|c|c|}
\hline & \multicolumn{6}{|c|}{ DISTÂANCIAS } & \multicolumn{4}{|c|}{ ÂNGULOS } \\
\hline & $\mathrm{Fe}-\mathrm{C} 11$ & $\mathrm{Fe}-\mathrm{C} 12$ & $\mathrm{Fe}-\mathrm{C} 13$ & $\mathrm{Fe}-\mathrm{C} 14$ & $\mathrm{Fe}-\mathrm{C} 15$ & $\mathrm{Fe}-\mathrm{C} 21$ & $\mathrm{C} 11-\mathrm{Fe}-\mathrm{C} 21$ & $\mathrm{C} 12-\mathrm{Fe}-\mathrm{C} 22$ & $\mathrm{C} 13-\mathrm{Fe}-\mathrm{C} 23$ & $\mathrm{C} 14-\mathrm{Fe}-\mathrm{C} 24$ \\
\hline Sem correção & $2.028(6)$ & $2.020(6)$ & $2.031(7)$ & $2.046(7)$ & $2.025(7)$ & $2.054(9)$ & $110.39(32)$ & $107.46(33)$ & $108.73(36)$ & $106.73(33)$ \\
\hline Semi-empirico & $2.028(5)$ & $2.023(5)$ & $2.026(6)$ & $2.040(6)$ & $2.025(6)$ & $2.052(7)$ & $109.98(27)$ & $107.78(29)$ & $108.46(31)$ & $106.92(29)$ \\
\hline Analítico & $2.028(5)$ & $2.025(5)$ & $2.027(5)$ & $2.040(6)$ & $2.027(6)$ & $2.050(7)$ & $109.96(26)$ & $107.90(27)$ & $108.09(29)$ & $107.04(28)$ \\
\hline DFABS & $2.032(4)$ & $2.023(4)$ & $2.025(5)$ & $2.038(5)$ & $2.020(5)$ & $2.051(6)$ & $109.83(23)$ & $108.22(23)$ & $107.65(26)$ & $106.92(24)$ \\
\hline SHELXA & $2.029(5)$ & $2.024(5)$ & $2.027(5)$ & $2.041(5)$ & $2.020(5)$ & $2.052(6)$ & $109.85(24)$ & $108.18(25)$ & $107.88(28)$ & $106.99(26)$ \\
\hline & $\mathrm{Fe}-\mathrm{C} 22$ & $\mathrm{Fe}-\mathrm{C} 23$ & $\mathrm{Fe}-\mathrm{C} 24$ & $\mathrm{Fe}-\mathrm{C} 25$ & $\mathrm{Zn}-\mathrm{N} 1$ & $\mathrm{Zn}-\mathrm{S}$ & C15-Fe-C25 & S-Zn-N1 & N1-Zn-N1 ${ }^{\#}$ & S-Zn-S \\
\hline Sem correção & $2.054(10)$ & $2.030(9)$ & $2.017(8)$ & $2.035(8)$ & $2.073(4)$ & $2.297(2)$ & $108.29(32)$ & $86.42(13)$ & $107.60(24)$ & $109.82(10)$ \\
\hline Semi-empirico & $2.049(8)$ & $2.033(8)$ & $2.019(7)$ & $2.031(7)$ & $2.075(4)$ & $2.296(2)$ & $108.21(28)$ & $86.42(12)$ & $107.46(22)$ & $109.79(9)$ \\
\hline Analítico & $2.045(8)$ & $2.041(8)$ & $2.020(6)$ & $2.030(6)$ & \begin{tabular}{|l|}
$2.074(4)$ \\
\end{tabular} & $2.296(2)$ & $108.14(26)$ & $86.43(11)$ & $107.58(21)$ & 109.81(9) \\
\hline DFABS & $2.044(7)$ & $2.040(7)$ & $2.017(5)$ & $2.035(5)$ & $2.071(3)$ & $2.296(2)$ & $107.98(23)$ & $86.29(10)$ & $107.88(18)$ & $109.79(8)$ \\
\hline SHELXA & $2.043(7)$ & $2.042(7)$ & $2.020(6)$ & $2.034(6)$ & \begin{tabular}{|l|}
$2.074(3)$ \\
\end{tabular} & $2.296(2)$ & $108.15(25)$ & $86.39(11)$ & $107.72(19)$ & $109.81(8)$ \\
\hline
\end{tabular}

Tabela D.22: Valores para distâncias e ângulos de ligação para a esfera de coordenação do átomo pesado para o compos to XI.

\begin{tabular}{|c|c|c|c|c|c|c|c|c|c|c|c|}
\hline & \multicolumn{6}{|c|}{ DISTÂNCIAS } & \multicolumn{5}{|c|}{ ÂNGULOS } \\
\hline & Sn-N1 & $\mathrm{Sn}-\mathrm{N} 2$ & $\mathrm{Sn}-\mathrm{Br} 1$ & $\mathrm{Sn}-\mathrm{Br} 2$ & $\mathrm{Sn}-\mathrm{C} 13$ & $\mathrm{Sn}-\mathrm{C} 19$ & N1-Sn-N2 & $\mathrm{C} 13-\mathrm{Sn}-\mathrm{C} 19$ & $\mathrm{Br} 1-\mathrm{Sn}-\mathrm{Br} 2$ & $\mathrm{C} 13-\mathrm{Sn}-\mathrm{Br} 1$ & C19-Sn-N1 \\
\hline Sem correção & $2.336(15)$ & $2.386(12)$ & $2.567(10)$ & $2.615(14)$ & $2.124(17)$ & $2.104(17)$ & $69.05(40)$ & $174.26(75)$ & $102.15(45)$ & $91.82(47)$ & $89.99(67)$ \\
\hline Sem & 2.37 & & & & & & & & $(50)$ & & \\
\hline & 2.390 & $2.392(8)$ & $2.550(9)$ & 2.592 & & 2.1 & 69.9 & 47) & $102.42(53)$ & & (41) \\
\hline DFABS & $2.399(8)$ & $2.399(8)$ & $2.527(19)$ & $2.602(11)$ & $2.128(11)$ & $2.114(11)$ & $69.87(27)$ & $173.26(47)$ & $102.40(61)$ & $91.62(58)$ & $87.33(38)$ \\
\hline SHELXA & $2.390(8)$ & $2.392(8)$ & $2.550(8)$ & $2.592(14)$ & $2.128(12)$ & $2.114(11)$ & $69.89(27)$ & $173.52(47)$ & $102.63(56)$ & $91.82(41)$ & $87.55(41)$ \\
\hline
\end{tabular}


Tabela D.23: Valores para distâncias e ângulos de ligação para a esfera de coordenação dos átomos pesados para o composto XIV.

\begin{tabular}{|c|c|c|c|c|c|c|c|c|c|c|c|c|c|}
\hline & \multicolumn{6}{|c|}{ DISTÂNCIAS } & \multicolumn{7}{|c|}{ ÂNGULOS } \\
\hline & Mo1-O11 & Mo1-O12 & \multirow{2}{*}{$\frac{\text { Mol-O13 }}{2.097(4)}$} & Mo1-O11 & Mo1-O111* & Mo1-O112 & \multicolumn{2}{|c|}{ O11-Mo1-O12 } & \multicolumn{2}{|c|}{ O11-Mo1-O13 } & \multicolumn{2}{|c|}{ O11-Mo1-O111 } & \multirow{2}{*}{$\begin{array}{c}\text { O12-Mo1-O13 } \\
79.54(15)\end{array}$} \\
\hline Sem correção & $2.125(4)$ & $2.132(4)$ & & $1.998(3)$ & $1.978(4)$ & $1.673(4)$ & \multicolumn{2}{|c|}{$80.14(16)$} & \multicolumn{2}{|c|}{$82.63(16)$} & & $169.09(14)$ & \\
\hline Semi-empirico & $2.130(11)$ & $2.130(15)$ & $2.169(1.03)$ & $2.027(29)$ & $1.979(12)$ & $1.735(53)$ & \multicolumn{2}{|c|}{$\begin{array}{l}79.91(50) \\
\end{array}$} & \multicolumn{2}{|c|}{$81.38(1.36)$} & & $167.26(1.27)$ & $79.06(1.07)$ \\
\hline \multirow[t]{3}{*}{ Analítico } & $2.126(3)$ & $2.129(3)$ & $2.099(3)$ & $1.987(3)$ & $1.978(3)$ & $1.667(3$ & $80.18(1$ & & 82.6 & $4(12)$ & & $169.07(11)$ & $79.33(11)$ \\
\hline & \multicolumn{6}{|c|}{ DISTÂNCIAS } & \multicolumn{7}{|c|}{ ÂNGULOS } \\
\hline & Mo2-O1* & Mo2-O2* & Mo2-O3 & Mo2-O111* & Mo2-O211 & Mo2-O212 & $\mathrm{O} 1-\mathrm{Mo} 2-\mathrm{O} 2$ & O1-N & Io2-O3 & $\mathrm{O} 2-\mathrm{Mo} 2$ & & O1-Mo2-O111 & O211-Mo2-O212 \\
\hline Sem correção & $2.026(4)$ & $2.131(4)$ & $2.024(4)$ & $2.246(4)$ & $1.683(4)$ & $1.678(4)$ & $85.66(17)$ & 167. & $13(16)$ & 84.24( & & $84.15(15)$ & $103.30(23)$ \\
\hline Semi-empirico & $2.048(15)$ & $2.066(1.36)$ & $2.010(10)$ & $2.218(20)$ & $1.669(28)$ & $1.683(20)$ & $84.33(1.33)$ & 163.5 & $8(1.73)$ & $82.71(1$ & & $83.87(63)$ & $103.55(1.37)$ \\
\hline Analítico & $2.028(3)$ & $2.124(3)$ & $2.022(3)$ & $2.248(3)$ & $1.684(3)$ & $1.685(3)$ & $85.65(13)$ & & $14(12)$ & 84.31( & & $84.41(11)$ & $103.20(17)$ \\
\hline
\end{tabular}

Tabela D.24: Valores para distâncias e ângulos de ligação para a esfera de coordenação dos átomos pesados para o composto XV.

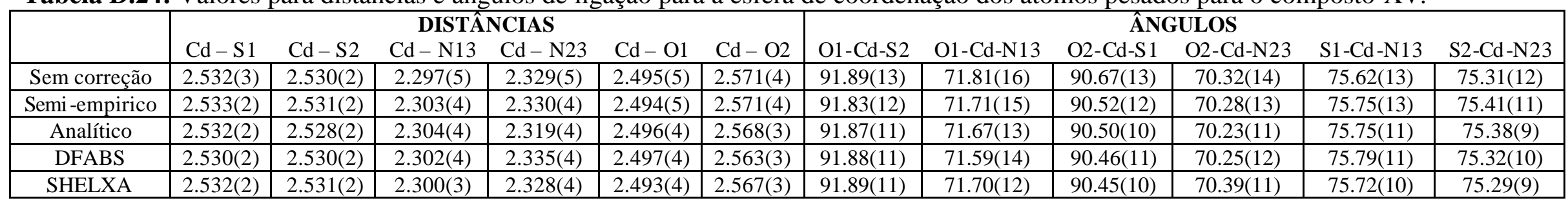




\section{Referências Bibliográficas}

Albrecht, G. (1939). Rev. Sci. Instrum., 10, 221.

Alcock, N. W. (1972). Adv. Inorg. Chem. Radiochem., 15, 1.

Alcock, N. W. \& Countryman, R. M. (1977). J. Chem. Soc. Dalton Trans., 217.

Alcock, N. W. \& Sawyer, J. F., (1977). J. Chem. Soc. Dalton Trans., 1090.

Allen F.H., Davies J.E., Galloy J.J., Johnson O., Kenard O., Macrae C.F., Mitchell E.M., Mitchell G.F., Smith J.M. \& Watson D.G. (1991) J. Chem. Inf. Comput. Sci. 31, 187.

Allinger, N. L. (1976). Adv. Phys. Org. Chem., 13, 1.

Amabilino, D. \& Stoddart, J. F., (1994). New Scientist, 25.

Animalu, A. O. E. (1977). Intermediate Quantum Theory of Crystalline Solids, Englewood Cliffs/New Jersey: Prentice-Hall, Inc.

Aslanov, L. A., Fetisov, G. V. \& Howard, J. A. K. (1998). Crystallographic Instrumentation, New York: Oxford University Press.

Batsanov, S. S. (1999). J. Mol. Struct., 468, 151.

Bilton, C., Allen, F. H., Shields, G. P. \& Howard, J. A. K. (2000). Acta Cryst. B56, 849 .

Bondi, A. (1964). J. Phys. Chem. 68, 441.

Bosch, B.E., Eisenhawer, M., Kersting, B., Kirschbaum, K., Krebs, B. \& Giolando D.M. (1996). Inorg. Chem. 15, 6599.

Braga, D., Grepione, F., Biradha, K., Pedireddi, V. R. \& Desiraju, G. R. (1995). J. Am. Chem. Soc. 117, 3156.

Busing, W. R. \& Levy, H. A. (1957). Acta Cryst., 10, 180.

Casas, J. S., Castaño, M. V., Cifuentes, M. C., Sanchez, A. \& Sordo, J. (2002). Polyedron 21, 1651. 
Casas, J. S., Castellano, E. E., Ellena, J., Haiduc, I., Sanchez, A., Semeniuc, R. F. \& Sordo, J. (2002). Inorg. Chim. Acta 329, 71.

Casas, J. S., Castellano, E. E., Ellena, J., Haiduc, I., Sanchez, A. \& Sordo, J. (1999). J. Chem.Cryst. 29, 831.

Casas, J. S., Castellano, E. E., Garcia-Tasende, M. S., Sanchez, A. \& Sordo, J. (2000). Inorg. Chim. Acta 304, 283.

Casas, J. S., Castellano, E. E., Garcia-Tasende, M. S., Sanchez, A., Sordo, J. \& Vidarte, M. J. (1998). Polyhedron 17, 2249.

Casas, J. S., Castineiras A., Haiduc, I., Sanchez, A., Sordo, J. \& VazquezLopez, E. M. (1994). Polyhedron 13, 1805.

Coppens, P. Edited by; Ahmed, F. R. (1970). Crystallographic Computing, Copenhagen: Munksgaard International Booksellers and Publishers LTD.

Coppens, P., Leiserowitz, L. \& Rabinovich, D. (1965). Acta Cryst., 18, 1035.

Dance, I. (2003) New J. Chem., 27, 22.

Desiraju, G. R. (2001) Nature, 412, 397.

Desiraju, G. R. \& Steiner, T. (1999). The Weak Hydrogen Bond, Oxford: Oxford University Press.

Dunitz, J. D. (1979). X-ray Analysis and the Structure of Organic Molecules, London: Cornell University Press.

Evans, H. T. \& Ekstein, M. G. (1952). Acta Cryst., 5, 540.

Farrugia, L. J. (1997). J. Appl. Cryst. 30, 565.

Ferrari, A., Braibanti, A. \& Tiripicchio, A. (1961). Acta Cryst., 14, 1089.

Flack, H. D. (1983). Acta Cryst. A39, 871.

Flack, H. D. (1984). J. Appl. Cryst., 17, 361.

Glidewell, C. (1976). Inorg. Chim. Acta. 20, 113.

Haiduc, I. (1997). Coord. Chem. Reviews, 158, 325.

Haiduc, I. \& Edelmann, F. T. (1999). Supramolecular Organometallic Chemistry, Weinheim/New York: Wiley-VCH.

Haiduc, I.; Sowerby, D. B. \& Lu, S. F. (1995). Polyhedron 14, 3389.

Howells, R. G. (1950). Acta Cryst., 3, 366.

Huber, R. \& Kopfmann, G. (1969). Acta Cryst., A25, 143.

Kenard, O. \& Allen F.H. (1993a) Chem. Desing Autom. News 8, 1.

Kenard, O. \& Allen F.H. (1993b) Chem. Desing Autom. News 8, 31.

Kimblin, C., Bridgewater, B.M., Hascall, T. \& Parkin, G. (2000). J. Chem. Soc., Dalton Trans., 891.

Kimblin, C., Bridgewater, B.M., Hascall, T. \& Parkin, G. (2000). J. Chem. Soc., Dalton Trans., 1267.

Kopfmann, G. \& Huber, R. (1968). Acta Cryst., A24, 348. 
Landrum, G. A. \& Hoffmann, R. (1998). Angew. Chem. Int. Ed., 37, 1887.

Meulenaer, J. \& Tompa, H. (1965). Acta Cryst., 19, 1014.

Nonius (1997-2002). COLLECT. Nonius BV, Delft, The Netherlands.

North, A. C. T., Phillips, D. C. \& Scott Mathews, F. (1968). Acta Cryst., A24, 351.

Otwinowski, Z. \& Minor, W. (1997). Methods in Enzymology, Vol. 276, Macromolecular Crystallography, Part. A, edited by C. W. Carter Jr and R. M. Sweet, pp. 307-326. New York: Academic Press.

Parkin, S., Moezzi, B. \& Hope, H. (1995). J. Appl. Cryst., 28, 53.

Phillips, J. C. (1970). Phisics Today, 23, 23.

Potrzebowski, M. J., Michalska, M., Koziol, A. E., Kazmierski, S., Lis, T., Pluskowski, J. \& Ciesielski, W. (1998). J. Org. Chem., 63, 4209.

Rehkamper, M. \& Nielsen, S. G. (2004). Marine Chemistry, 85, 125.

Schedlbauer, O. F. \& Heumann, K. G. (2000). Appl. Organomet. Chem. 14, 330.

Sheldrick, G. M. (1997). SHELXS97 \& SHELXL97. University of Göttingen, Germany.

Starbuck, J., Norman N. C. \& Orpen A. G. (1999). New J. Chem., 23, 969.

Walker, N. \& Stuart, D. (1983). Acta Cryst., A39, 158.

Zalkin, A. \& Sands, D. E. (1958). Acta Cryst., 11, 615. 


\section{TRABALHOS PRODUZIDOS DURANTE O DOUTORADO}

SANTOS, S., SANCHEZ A., CASTELLANO E.E., ELLENA J., CASAS J.S, SORDO J., GARCIATASENDE M.S, TOMA M.

Supramolecular Associations via Intermolecular Secondary Interactions in DimethylThallium Complexes. Acta Crystallographica A., v.A58, p.c314, 2002.

SANTOS S., GUILARDI S., RESENDE J.A.L.C., RUBINGER M.M.M., OLIVEIRA M.R.L., ELLENAJ.

Redetermination of nickel bis(dithiocarbamate) at $100 \mathrm{~K}$.. Acta Crystallographica Section E-Crystal Structure Communications., v.E59, n.2, p.m77, 2003.

RESENDE J.A.L.C., SANTOS S., ELLENA J., GUILARDI S.

2-Cyano-N-(2-hydroxyphenyl)acetamide. Acta Crystallographica Section E-Crystal Structure Communications. , v.E59, n.5, p.o723, 2003.

FRANCA E.F., MACHADO A.E.H., OLIVEIRACAMPOS A.M.F., SANTOS S., ELLENA J., GUILARDI S.

3-(Benzoxazol-2-yl)-7-hydroxychromen-2-one methanol solvate. Acta Crystallographica Section E-Crystal Structure Communications. , v.E59, n.6, p.o820, 2003.

LIMA RJC, SASAKI JM, AYALA AP, FREIRE PTC, MENDES J, MELO FEA, ELLENA J, SANTOS S

New crystals in the lithium sulfate family

Acta Crystallographica Section C-Crystal Structure Communications. 59: I67 Part 7 JUL 2003

SANTIAGO MO, BATISTA AA, DE ARAÚJO MP, DONNICI CL, MOREIRA IS, CASTELLANO EE, ELLENA J, SANTOS S, QUEIROZ S.

${ }^{631} \mathrm{P}\{1 \mathrm{H}\}-$ N.M.R. as a Tool for Identification of Ruthenium Isomers Containing $\mathrm{PPh}_{3}$ or 1,4-Bis(Diphenylphosphino)Butane Ligands. X-Ray Structures of the cis$\left\{\mathrm{RuCl}_{2}\left(\mathrm{PPh}_{3}\right)_{2}[4,4[\right.$ prime]-(-X)2-2,2[prime]-bipy] $\}$ Complexes $[\mathrm{X}=-\mathrm{H},-\mathrm{Me},-\mathrm{SMe}$ and (-Cl, -Me)]".

Transition Metal Chemistry, (2004) no prelo. 